\title{
Effect of temperature variations on premature cracking of dowel jointed concrete pavements
}

Gergis W. William

West Virginia University

Follow this and additional works at: https://researchrepository.wvu.edu/etd

\section{Recommended Citation}

William, Gergis W., "Effect of temperature variations on premature cracking of dowel jointed concrete pavements" (2003). Graduate Theses, Dissertations, and Problem Reports. 2523.

https://researchrepository.wvu.edu/etd/2523

This Dissertation is protected by copyright and/or related rights. It has been brought to you by the The Research Repository @ WVU with permission from the rights-holder(s). You are free to use this Dissertation in any way that is permitted by the copyright and related rights legislation that applies to your use. For other uses you must obtain permission from the rights-holder(s) directly, unless additional rights are indicated by a Creative Commons license in the record and/ or on the work itself. This Dissertation has been accepted for inclusion in WVU Graduate Theses, Dissertations, and Problem Reports collection by an authorized administrator of The Research Repository @ WVU.

For more information, please contact researchrepository@mail.wvu.edu. 


\title{
EFFECT OF TEMPERATURE VARIATIONS ON PREMATURE CRACKING OF DOWEL JOINTED CONCRETE PAVEMENTS
}

\author{
Gergis W. William
}

\author{
Dissertation submitted to the \\ College of Engineering and Mineral Resources \\ at West Virginia University \\ in partial fulfillment of the requirements \\ for the degree of
}
Doctor of Philosophy
In
Civil Engineering

\author{
Samir N. Shoukry, Ph.D., Chair \\ David R. Martinelli, Ph.D. \\ Julio F. Davalos, Ph.D. \\ Darrell Dean, Ph.D. \\ Kenneth H. Means, Ph.D.
}

Department of Civil and Environmental Engineering

Morgantown, West Virginia

2003

Keywords: Rigid Pavements, Temperature Effects, Instrumentation, 3D Finite Element Analysis, Pavement Instrumentation. 


\title{
ABSTRACT \\ EFFECT OF TEMPERATURE VARIATIONS ON PREMATURE CRACKING OF DOWEL JOINTED CONCRETE PAVEMENTS
}

\author{
Gergis W. William
}

Dowel jointed concrete pavements exhibit premature top-down transverse cracking at mid slab leading to a dramatic decrease in pavement service life. In the past, such cracks were attributed to combined stresses caused by the temperature differential through the slab thickness and heavy vehicle joint loading. This reasoning failed to explain transverse cracking of Palmdale, California slabs (developed before opening the pavement to traffic) as well as the transverse cracks on I-80 in Pennsylvania, USA that appeared after one to two years of construction. In this study nonlinear 3D Finite Element (3DFE) analysis that includes detailed consideration of slab constraints by dowel bars is used to analyze the problem of premature transverse cracking in jointed concrete pavements. The 3DFE model response to ambient temperature variations is validated versus field-measured data obtained from WVU instrumented jointed concrete pavement section along Route 33 near Elkins, West Virginia. Both Field measured data as well as 3DFE modeling results indicate that dowel bar bending due to slab curling causes significant edge restraints to slab contraction or expansion. Under such constraints, high tensile stresses develop in the concrete slab as its mean temperature decreases. Such stresses are not accounted for in the current design procedures of concrete pavements and shown in this study to be the primary reason for premature mid-slab transverse cracks. The slab length is shown to be a critical parameter that governs the magnitude of thermal stress induced at mid-slab. It is shown in this study that $4.5 \mathrm{~m}$ long slabs are most resistant to mid-slab cracking, a conclusion that agrees with field observations and the data records from Long Term Pavement Performance (LTPP) program. 


\section{ACKNOWLEDGMENTS}

I would like to express my gratitude to my research and academic advisor Dr. Samir N. Shoukry for providing the focus and direction for completion of this work. His unlimited help, advice, guidance, encouragement, and support have been indispensable in the completion of this work. Thank you Dr. Shoukry for the long time you spent evaluating, correcting, and improving this work.

Sincere appreciation must also be expressed to Professors David R. Martinelli, Darrell R. Dean, Julio F. Davalos, and Kenneth Means for serving on my examining committee. I would also like to thank Mrs. Marlene Iskander for the linguistic and editorial review of this dissertation.

I would like to thank my parents and my grandfather for their love, encouragement, understanding and for being there when times were rough. Special thanks are extended to my beloved sister Maria for her unlimited support during the preparation of this dissertation. Thanks are also extended to my friends for their encouragement and help.

The author gratefully acknowledges the financial support for his research from West Virginia Division of Highways. 


\section{TABLE OF CONTENTS}

ABSTRACT

ACKNOWLEDMENTS

ii

TABLE OF CONTENTS

iii

LIST OF TABLES

iv

LIST OF FIGURES

vi

$\mathrm{V}$

CHAPTER ONE INTRODUCTION

1.1 Background

1.2 Problem Statement

1.3 Research Objectives

1.4 Research Hypotheses

1.5 Dissertation's Outline

CHAPTER TWO IITERATURE REVIEW 10

2.1 Classical Response Models $\quad 10$

$\begin{array}{ll}2.1 .1 & \text { Limitations of Westergaard Theory } \\ 2.12\end{array}$

2.1.2 Subsequent Advances in Curling Analysis 13

2.2 Classical Models of Dowel Bars 14

2.3 Two-Dimensional Finite Element Analysis 16

2.4 Three-Dimensional Finite Element Analysis 19

$\begin{array}{lll}2.5 & \text { Summary } & 23\end{array}$

CHAPTER THREE FINITE ELEMENT MODEL 26

$\begin{array}{lll}3.1 & \text { Introduction } & 26\end{array}$

3.2 Pavement Structural Model 26

$\begin{array}{lll}3.3 & \text { Contact Interfaces } & 28\end{array}$

$\begin{array}{lll}3.4 & \text { Material Models } & 30\end{array}$

3.4.1 Concrete and Dowels $\quad 30$

3.4.2 Base and Subgrade Materials $\quad 33$

$\begin{array}{lll}3.5 & \text { Model Loading } & 34\end{array}$

$\begin{array}{ll}\text { 3.5.1 Thermal Loading } & 34\end{array}$

3.5.2 Traffic Loading 36

3.6 Model Results 38

$\begin{array}{lll}3.7 & \text { Conclusions } & 42\end{array}$

CHAPTER FOUR EXPERIMENTAL VALIDATION OF 3DFE MODEL RESPONSE TO TEMPERATURE VARIATIONS 43

$\begin{array}{lll}4.1 & \text { Introduction } & 43\end{array}$

4.2 Pavement Test Section 43

$\begin{array}{ll}4.3 & \text { Coordinate System } \\ 4.45\end{array}$

4.4 Instrumentation 46

4.5 Joint Opening 49 
4.6 Measured Slab Strains $\quad 52$

4.7 Material Testing 55

4.8 3DFE Model Validation $\quad 57$

4.9 3DFE Model Validation Procedures 58

$\begin{array}{lll}4.10 & \text { Conclusions } & 68\end{array}$

CHAPTER FIVE TEMPERATURE-INDUCED STRESSES IN DOWEL JOINTED CONCRETE PAVEMENTS 71

$\begin{array}{lll}5.1 & \text { Introduction } & 71\end{array}$

$\begin{array}{lll}5.2 & \text { Terminology } & 71\end{array}$

$\begin{array}{lll}5.3 & \text { Curling Deflection } & 72\end{array}$

$\begin{array}{lll}5.4 & \text { Curling Stresses } & 77\end{array}$

$\begin{array}{lll}5.5 & \text { Discussion } & 82\end{array}$

5.6 Effect of Uniform Temperature Change 83

$\begin{array}{lll}5.7 & \text { Summary } & 87\end{array}$

CHAPTER SIX NONLINEAR TEMPERATURE GRADIENT EFFECTS IN DOWEL JOINTED CONCRETE SLABS 88

$\begin{array}{lll}6.1 & \text { Introduction } & 88\end{array}$

6.2 Gradient Nonlinearity Characterization 88

6.3 Effect of TGP Nonlinearity on Slab Strain 90

6.4 Effect of TGP Nonlinearity on Slab stress 94

6.5 Uniform Temperature Changes 97

$\begin{array}{ll}6.6 \text { Conclusions } & 100\end{array}$

CHAPTER SEVEN EFFECT OF DESIGN PARAMETERS ON THE 3D FINITE ELEMENT PREDICTED THERMAL STRESSES 102

$\begin{array}{lll}7.1 & \text { Introduction } & 102\end{array}$

$\begin{array}{ll}7.2 & \text { Effect of Concrete Slab Length } \\ 7.3 & 102\end{array}$

$\begin{array}{lll}7.3 & \text { Effect of Traffic Loading } & 104\end{array}$

$\begin{array}{lll}\text { 7.3.1 Effect of Negative Temperature Gradient } & 104\end{array}$

$\begin{array}{ll}\text { 7.3.2 Effect of Uniform Temperature Drop } & 105\end{array}$

$\begin{array}{lll}7.4 & \text { Effect of Slab Thickness } & 109\end{array}$

$\begin{array}{ll}7.5 & 112\end{array}$

$\begin{array}{ll}7.6 \text { Effect of Concrete-Dowel interface } & 115\end{array}$

$\begin{array}{lll}7.7 & \text { Conclusions } & 118\end{array}$

$\begin{array}{ll}\text { CHAPTER EIGHT CONCLUSIONS } & 119\end{array}$

$\begin{array}{lll}8.1 \text { Conclusions } & 119\end{array}$

$\begin{array}{ll}8.2 & \text { Future Work } \\ & 122\end{array}$

$\begin{array}{ll}\text { REFERENCES } & 123\end{array}$ 


\section{LIST OF TABLES}

Table 2.1 Features of 2D FE Models of Rigid Pavements 16

Table 3.1 Material Properties $\quad 33$

Table 4.1 Material Properties of Pavement layers $\quad 56$

Table 4.2 Measured Temperatures, Joint Openings, and Strains. 70

Table 5.1 Maximum Transverse Stress at Mid Slab for $-10^{\circ} \mathrm{C}$ Gradient $\quad 79$

Table 5.2 Maximum Longitudinal Stress at Mid Slab for $-10^{\circ} \mathrm{C}$ Gradient $\quad 79$

Table 5.1 Material Properties of Pavement Layers 72 


\section{LIST OF FIGURES}

Figure 1.1 Recorded History of Mean Slab Temperature and Dowel Axial Force 5

$\begin{array}{lll}\text { Figure 3.1 } & \text { Finite Element Mesh } & 27\end{array}$

Figure 3.2 Finite Element Mesh for Concrete Slab and Dowel Bars 28

Figure 3.3 Displacement-Time Histories for Different Damping Ratios 35

Figure 3.4 Time History of the FWD Applied Load 36

Figure 3.5 Maximum Principal Stress at slab Bottom along Joint Edge 37

Figure 3.6 Shearing Force Distribution among Dowel Bars 37

Figure 3.7 Fringes of Longitudinal Stresses Due to Temperature

Gradient $-0.02^{\circ} \mathrm{C} / \mathrm{mm}$

Figure 3.8 Fringes of Vertical Stresses around Dowel Hole Due to Temperature

Gradient $-0.02{ }^{\circ} \mathrm{C} / \mathrm{mm} \quad 40$

Figure 3.9 Distribution of Maximum Principal Stress around Dowel Bar Hole 41

Figure 4.1 Layout of West Virginia Instrumented Pavement Site 44

Figure 4.2 Typical Slab Instrumentation Prior to Concrete Placement 45

Figure 4.3 Sensors in a Typical Instrumented Slab on Corridor H 46

Figure 4.4 Transverse Joint Opening along Instrumented Pavement Section 48

$\begin{array}{ll}\text { Figure 4.5 } & \text { Recorded Means Slab Temperature, Joint Opening, and Dowel Axial } \\ & \text { Force }\end{array}$

Figure 4.6 Recorded Temperature Differential and Dowel Bending Moment 51

Figure 4.7 Recorded Temperature Profiles and Strain Histories 54

Figure 4.8 Compressive and Tensile Strength of Concrete 56

Figure 4.9 Finite Element Model of the WV Instrumented Concrete Pavement 57

Figure 4.10 3DFE-Computed and Measured Strains on Day 88 (December 3, 2001) 60

Figure 4.11 3DFE-Computed and Measured Strains on Day 49 (October 21, 2001) 61

Figure 4.12 3DFE-Computed and Measured Strains on Day 100 (December 15, 2001) 62

Figure 4.13 3DFE-Computed and Measured Strains on Day 160 (February 3, 2002) 63

Figure 4.14 3DFE-Computed and Measured Strains on Day 200 (March 25, 2002) 64

Figure 4.15 3DFE-Computed and Measured Strains on Day 250 (May 14, 2002) 65

Figure 4.16 3DFE-Computed Versus Measured Bending Moment in Shoulder Side $\begin{array}{ll}\text { Dowel } & 68\end{array}$

$\begin{array}{lll}\text { Figure 5.1 Deformed Slab mesh } & 73\end{array}$

$\begin{array}{lll}\text { Figure 5.2 Slab Deflection along Longitudinal Centerline } & 74\end{array}$

$\begin{array}{lll}\text { Figure 5.3 Deflection at Mid-slab along Transverse Centerline } & 75\end{array}$

Figure 5.4 Deflection Profile along Joint Edge 75

Figure 5.5 Measured Versus 3DFE-Computed Slab Profiles 76

Figure 5.6 Transverse Stresses Due to Positive Gradient of $+10{ }^{\circ} \mathrm{C} \quad 78$

$\begin{array}{ll}\text { Figure 5.7 Comparison of 3DFE-Computed Longitudinal Stress } \sigma_{\mathrm{x}} \text { with } & \\ & \text { Westergaard's Solution }\end{array}$

Figure 5.8 Effect of Magnitude of Temperature Gradient on Longitudinal Stress $\quad 81$

Figure 5.9 Cross-Section through the Center Dowel of a Curled Slab 84

Figure 5.10 Deformation of Dowel Bars Along a Transverse Joint 85

$\begin{array}{lll}\text { Figure } 5.11 & \text { Stresses Due to }-10^{\circ} \mathrm{C} \text { Linear Gradient Combined with } \\ & -16.67^{\circ} \mathrm{C} \text { Uniform Drop }\end{array}$ 
Figure 6.1 Assessment of Nonlinearity in TGP 89

$\begin{array}{lll}\text { Figure 6.2 Through-Thickness Strain Profile } & 90\end{array}$

Figure 6.3 Effect of TGP Nonlinearity on Strain at Mid Slab 91

Figure 6.4 Effect of TGP Nonlinearity on Longitudinal Slab Profile 92

Figure 6.5 Effect of TGP Nonlinearity on Slab thickness 94

Figure 6.6 Effect of TGP Nonlinearity on Longitudinal stress 96

Figure 6.7 Effect of TGP Nonlinearity on the maximum Longitudinal Stress 97

Figure 6.8 Effect of $-16.7^{\circ} \mathrm{C}$ Uniform Temperature Drop 98

Figure 6.9 Effect of $-33.3{ }^{\circ} \mathrm{C}$ Uniform Temperature Drop 99

Figure 7.1 Effect of Slab Length 103

Figure 7.2 Deformed Slabs Due to Negative Gradient and Joint Loads 104

Figure 7.3 Longitudinal Stress Distribution on Slab Top Due to Temperature Gradient

Figure 7.4 Longitudinal Stress Distribution Due to Temperature Gradient and Axle Loading

Figure 7.5 Effect of Uniform Temperature Drop and Axle Loading on Longitudinal Stresses

Figure 7.6 Effect of Slab Length and Uniform Temperature Drop on MidSlab Stress

Figure 7.7 Effect of Slab Thickness on Longitudinal Stress Profile along Slab Centerline (Temperature Gradient $-0.02{ }^{\circ} \mathrm{C} / \mathrm{mm}$ )

Figure 7.8 Effect of Slab Thickness on Longitudinal Stress Profile along Slab Centerline (Temperature Gradient $-0.02{ }^{\circ} \mathrm{C} / \mathrm{mm}$ Combined with Uniform Temperature Drop of $-33.3^{\circ} \mathrm{C}$ )

Figure 7.9 Effect of Slab Thickness on Maximum Tensile Stress 112

Figure 7.10 Effect of Dowel bar Diameter on Longitudinal Stresses 113

Figure 7.11 Effect of Dowel bar Diameter on Dowel-Concrete Contact Stress 114

Figure 7.12 Effect of Concrete-Dowel Interface on longitudinal Stress in the Slab (Temperature Gradient $-10^{\circ} \mathrm{C}$ )

Figure 7.13 Effect of Concrete-Dowel Interface on longitudinal Stress in the Slab (Temperature Gradient $-10^{\circ} \mathrm{C}$ Combined with $-33.3^{\circ} \mathrm{C}$ Uniform Drop) 


\section{CHAPTER ONE}

\section{INTRODUCTION}

\subsection{Background}

Portland Cement Concrete (PCC) pavements have been used in highway pavements and airport runways for the past eight decades. Concrete pavements are dynamic systems subjected to movements resulting from traffic loads, changes in moisture, and temperature variations. To control the natural cracking associated with temperature variations, concrete pavements are constructed with transverse and longitudinal joints. Such joints are supposed to alleviate concrete slab movements during contraction or expansion and relieve stresses due to temperature variations. To reduce the deflection and bending stresses along the slab edges, dowel bars are installed across transverse joints to transfer the edge wheel load between adjacent slabs (Westergaard, 1929; NCHRP, 1973). However, the slab discontinuity within transverse joints constitutes the theoretical region that can initiate pavement distress (Snyder, 1989; Dutt, 1992).

The average expected service life of a rigid pavement is about 30 years. Although this life is shorter than 50 years service life expected for other concrete structures (Farrel and Patrick, 1953; Bontz et al., 2002), concrete pavements usually deteriorate rapidly and don't survive their expected service life. Rigid pavements suffer several types of distress as a consequence of dynamic loading and variations in environmental conditions. Most of the observed concrete pavement failures are of structural nature and cannot be attributed to weakness or disintegration of the concrete itself (Friberg, 1955). This is confirmed through the high compressive and tensile strengths of the concrete measured after each concrete placement. Concrete pavement deteriorations usually occur at the slab center in the form of transverse cracks or at the region of transverse joints. Joint distresses include faulting, pumping, spalling, and premature cracking (Darter et al. 1985, Ioannides et al. 1990). Such distresses result in poor riding quality and lessen the expected lifetime of the concrete pavements. A great number of concrete pavement 
sections are resurfaced each year to halt deterioration and enhance the ride quality. Attempts to overcome the cracking problem by increasing the concrete slab thickness did not reduce the premature distress of concrete pavements. As a result, the economic burden for repairing and maintaining existing highway pavements is rapidly increasing and becoming a significant portion of the annual construction budget.

\subsection{Problem Statement}

Most concrete pavements exhibit premature transverse cracks at mid slab, in some cases prior to the passage of any traffic loadings. Such cracks usually initiate from the slab top and propagate toward the bottom. Considering the fact that concrete pavements are massive concrete structures, thermal stresses developed in concrete pavements from the time of concrete placement are very critical and could be responsible for initiating premature cracking. Although transverse joints are provided in concrete pavements to relieve such stresses and allow for edge movements due to slab expansion or contraction (Huang, 1993; McGhee, 1995), their role in achieving such function has not been evaluated theoretically or experimentally in the rigid pavement literature yet.

The effect of temperature differential between the slab top and bottom has been examined over the past eight decades and the formulae to calculate the slab bending moments and stresses were developed (Westegaard, 1927). Although Westergaard recommended algebraic addition of thermally induced stresses to those calculated due to traffic loading when designing the concrete slab thickness, the effect of such stresses has not been accounted for in the mechanistic design procedures of rigid pavements (AASHTO Pavement Design Guides 1986, 1993). In such design specifications, concrete slab thickness was based on empirical formulae based on the AASHO Road Test conducted in the late 1950s and early 1960s (HRB, 1962). Such formulae correlate slab thickness required to sustain a certain number of equivalent single axle loads during its service life with the concrete modulus of rupture and the modulus of subgrade reaction. Ignorance of thermally induced stresses in designing concrete slab pavements was justified by arguments such as: 
a) Joints are provided to compensate for thermal stresses, which also are relieved when the concrete cracks.

b) The number of stress reversals due to curling is quite limited compared with that due to traffic load repetitions during the design period. So, it was considered impractical to combine such stresses with those due to traffic loading in pavement design.

c) If the design is governed by the edge stress, curling stress should be added to loading stress during the day but subtracted from loading stresses at night. Since a large number of heavy trucks travel over the pavement at night, it may not be critical if curling stresses are ignored (Rollings and Pittman, 1992; Huang, 1993).

Field observations from Long Term Pavement Performance (LTPP) program showed the occurrence of premature cracking of concrete slabs (Smith et al., 1998). It was also reported that the concrete slab becomes more susceptible to such cracking as its length increases. Increasing the slab thickness did not eliminate the occurrence of such cracks (Yu et al., 1998). The FHWA technical advisory (FHWA, 1990) recommended transverse joint spacing of $4.6 \mathrm{~m}(15 \mathrm{ft})$ to eliminate the occurrence of transverse cracking. A survey on the current design practices of state highway agencies demonstrated that the slab lengths across the nation range from 4 to $6 \mathrm{~m}$ (13 to $20 \mathrm{ft}$ ). However, adopting such slab lengths did not eliminate the problem of transverse cracking. Premature transverse cracking in concrete pavements were reported in several states across the country. The following are just a few examples of the most recent cases:

1. Premature transverse cracking of $6.1 \mathrm{~m}$ long slabs on Interstate I-80 in Pennsylvania after less than two years from construction (ERES, 2000).

2. Premature top-down transverse cracking of $4.6 \mathrm{~m}$ long slab in Michigan (Hansen and Jensen, 2001).

3. Top-down transverse cracking of $6.1 \mathrm{~m}$ long slab in Palmdale, California (Heath and Roeseller, 2000).

4. Premature transverse cracking observed in Iowa on Highways I-80, US 20, Iowa 175, I35, and US 218 (Stutzman, 1999). 
Premature transverse cracking brought the attention to the effect of temperature variations on rigid pavements. In recent years, there has been a movement toward mechanistic design procedures for concrete pavements (Hall, 2000). The recent advances in the computational technologies helped recognize the significant effect of temperature changes on concrete pavements (Faraggi et al., 1987; Thompson et al., 1987). The AASHTO Supplement for concrete pavement design (1998) incorporated the induced flexural stresses due to temperature differential through the slab thickness in the mechanistic design procedures of concrete slab thickness. The AASHTO Guide recommended considering the maximum expected operating temperature differential through the slab thickness as well as an additional temperature gradient equivalent to moisture and construction curling in designing the concrete slab thickness. Additionally, the AASHTO Supplement (1998) recommended ranges for design values of the temperature gradients that should be considered in designing concrete pavements according to the geographic location. Although, this is a positive step towards considering an important stress component that has been ignored for over seven decades, it still relies on a hypothesis that axial movements of the slabs due to variations in the mean slab temperature are unrestrained.

Constructing a transverse joint was postulated to allow free contraction or expansion of the slab due the variations in the mean slab temperature, and relieve stresses due to the variations in the mean slab temperature. To achieve this assumption in practice, dowel bars used across transverse joints are specified to be lubricated so that the concrete slab could slide freely along the dowel surface as the slab contracted or expanded. Therefore, friction between the concrete slab and the underlying base layer has been considered the only external restraint to the slab movement due to the variation in its mean temperature. Effect of friction was found to be minimal and can be neglected (Yodar and Witczak, 1975; Huang, 1993). Results from West Virginia instrumented pavement section showed that even lubricated dowel bars in the field violate such assumption (Shoukry, 2002). Figure 1.1 illustrates the change in the measured mean slab temperature and the corresponding change in the dowel axial force measured at the corner dowel bar. Magnitudes of such forces agree with the results from dowel pullout tests reported by Van-Breeman, 1955; Crovetti, 1999; and ERES, 2000. Such forces in dowel bars produce a significant resistance to the slab movement during contraction or expansion. In view of the fact that such restraints cause severe cracks, their control is eminent. This requires a deep 
understanding of the behavior of a dowel jointed concrete slab under temperature variations, and determining the conditions that lead to the development of thermal stresses responsible for premature distress are mandated.
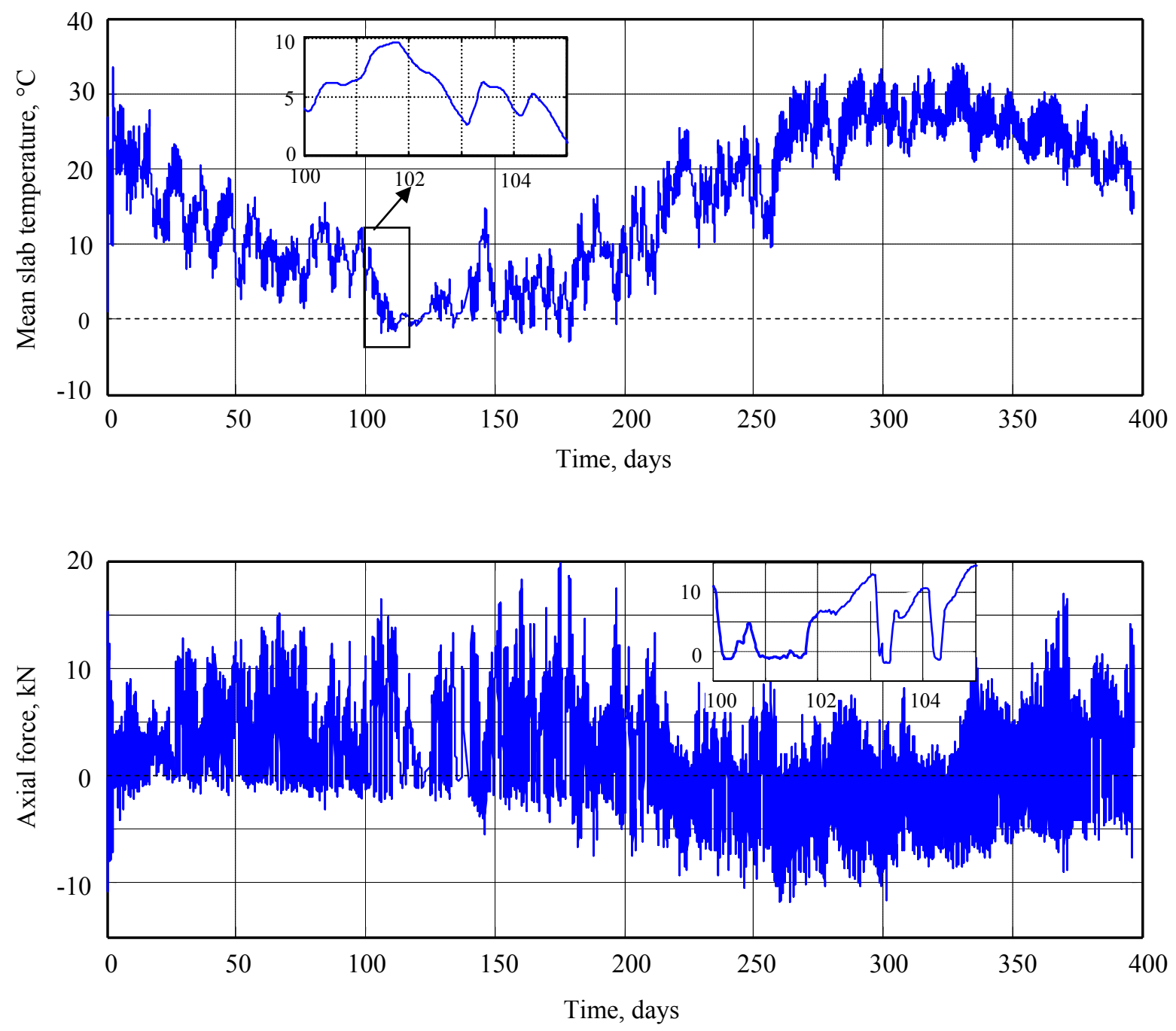

Figure 1.1 Recorded History of Mean Slab Temperature and Dowel Axial Force.

\subsection{Research Objectives}

The main objective of this study is to identify the contribution of temperature changes on premature distress that takes place in doweled jointed concrete pavements under the restraining action of the dowel bars installed at transverse joints, then select the most optimized dimensions 
of the concrete slab to minimize the chance of premature pavement distress and to enhance its expected service life. In order to achieve this overall objective, supportive objectives have been identified as:

1. Developing a detailed 3D finite element model that overcomes certain deficiencies in the current state-of-the-art of concrete pavement modeling in order to investigate the performance of a dowel jointed concrete slab under the effect of temperature variations. The major features required in the new model are:

- Detailed modeling of the dowel bars and their interfaces with the surrounding concrete. This approach enables identifying the causes of slab movement restraints. Additionally, the fine mesh of the concrete surrounding the dowels help reveal the triaxial state of contact stress that develops at the concrete-dowel interface which is responsible for transverse joint distress.

- Development of a new approach for validating the model response to temperature variations. This is achieved by comparing the 3DFE-calculated strains with experimentally measured ones obtained from West Virginia instrumented pavement section (Shoukry, 2002).

2. Using the model results to evaluate the current design procedures of concrete slab thickness assuming the main cause of thermal stress is a linear temperature differential through the slab thickness.

3. Examining the effect of the variations in mean slab temperature on the state of stress induced in the concrete slab when occurred simultaneously with a temperature gradient.

4. Investigating the effect of the nonlinearity in the temperature gradient profile on the state of stress and deformation induced in the concrete slab.

5. Examining the effect of the slab length, slab thickness, dowel bar diameter, and characteristics of concrete-dowel interface on the state of stress at mid-slab slab. 


\section{$1.4 \quad$ Research Hypotheses}

The problem of thermal effects on concrete pavements involves a coupling of heat transfer problem and thermoelasticity. In such a coupled system, the variations in strains within the concrete slab are generally accompanied by variations in temperature and consequently a flow of heat as it can be seen from the energy equation 1.1 .

$$
k T_{, m m}=\rho C \dot{T}+(3 \lambda+2 \mu) \alpha T_{o} \dot{\varepsilon}_{k k}
$$

where $\mathrm{k}$ is the thermal conductivity of the concrete slab,

$\mathrm{C}$ is the specific heat of concrete slab,

$\rho$ is the density,

$\lambda$ and $\mu$ are Lame constants,

$T_{o}$ is the reference temperature,

$\varepsilon$ is the strain induced in the concrete slab.

For solid mechanics' applications, strains induced in a solid body due to mechanical loading and/or temperature change were reported not to introduce a significant change in the temperature distribution within that body (Kavalenko, 1969; Boley and Weiner, 1985). Therefore, it is customary to omit the coupling term in the Equation 1.1. This assumption was also adopted in other studies on concrete pavements and bridges (Imbsen et al., 1985; Liang and Niu, 1998, McCullough and Rasmussen, $1999 a, b)$. This forms the main hypothesis of this study: temperature can be determined independently of the deformation of the concrete slab, which subsequently means that deformations are very small. It was also assumed that temperature varies only through the slab thickness but is constant at all points of equal depth.

\subsection{Dissertation's Outline}

The research methodology followed in this study is described through work done in each chapter in the remainder of this dissertation as follows: 
Chapter Two presents a literature survey on the classical models of concrete pavement analysis with emphasis on computation of thermal stresses in concrete slabs. The Chapter will also include a review on the finite element modeling of concrete pavement slabs. This serves to identify the current state-of-the-art and the required enhancements in the modeling techniques.

Chapter Three describes the development of 3D finite element model of a concrete pavement. A brief description of the interfaces between the dowel bars and the surrounding concrete is presented. The boundary conditions, material models for different pavement layers, and applied loads are also discussed. Some results are presented to illustrate the quality of the results obtained from the model.

Chapter Four presents an experimental validation of 3DFE model response to temperature variations using data recorded from West Virginia Smart Road (Shoukry 2002). A validation technique is developed in order to reduce the impact of nonlinear contributors: construction curling, shrinkage, and moisture that affect the value of the built in strain developed in the concrete slab throughout its age and cannot be accounted for in 3DFE models.

In Chapter Four, the effect of linear temperature gradient through the slab thickness on the state of stress and deflection in the concrete slab has been investigated. The 3DFE-calculated stresses and deflections were compared with those obtained with the closed form solution of Westergaard (1927). The remarkable agreement, observed between both solutions, provides a theoretical validation of the finite element response. Results indicated that the temperature differential between the slab top and bottom cannot be responsible for mid-slab cracking observed in the field.

Chapter Six the effect of the nonlinearity in the temperature gradient profile on strain, slab profile, and stress that develops in a dowel jointed concrete slab is examined using nonlinear 3D Finite Element (3DFE) modeling. Temperature gradient profiles with the same differential through the slab thickness and different magnitudes of nonlinearity will be applied to the 3DFE models. Results indicate that the nonlinearity in temperature gradient profile has its maximum 
effect on the longitudinal stress near the end of the embedded parts of dowel bars, i.e. at transverse joints.

In Chapter Seven, a parametric study is conducted to investigate the effect of design parameters as: slab length, traffic loading, slab thickness, dowel bar diameter, and characteristics of concrete-dowel interface on mid-slab longitudinal stresses.

Chapter Eight summarizes the conclusions of the research work presented in this dissertation. 


\section{CHAPTER TWO}

\section{LITERATURE REVIEW}

\subsection{Classical Response Model}

The structural design of a concrete pavement is based on estimating the stresses occurring under given circumstances. In the early 1920s, Westergaard published two papers dealing with the computation of stresses in concrete pavements. The first dealt with stresses and deflections due to wheel loads (Westergaard, 1926), the second with stresses and deflections due to temperature variations (Westergaard, 1927). In deriving the governing equations, Westergaard made the following assumptions:

1. The wheel loads are assumed static, that is the inertia effect of the pavement and subgrade was not considered.

2. The concrete slab acts as a homogeneous, isotropic, elastic thin plate.

3. The slabs are infinitely extended in the horizontal direction, i.e. effect of discontinuities such as joints or cracks was not considered.

4. All pavement layers underneath the slab are modeled as a dense liquid (Winkler) foundation that must be represented by a single parameter, the modulus of subgrade reaction, $\mathrm{k}$.

5. The slab remains in full contact with the foundations as it curls due to thermal gradient.

6. The material behavior is linearly elastic, thus the principle of superposition could be used to add the curling stresses to the load induced stresses.

The analysis was performed based on linear elasticity and medium plate theory (Timoshinko and Eoinowsky-Krieger, 1959), which imposes an additional limitation of no compressibility within the thickness of the slab. Westergaard introduced the term of radius of relative stiffness $\ell$. This 
term quantifies the stiffness of the slab relative to that of the subgrade. For a concrete slab of thickness h, modulus of elasticity E, and Poisson's ratio $v$, the radius of relative stiffness is:

$$
\ell=\sqrt[4]{\frac{E h^{3}}{12\left(1-v^{2}\right) k}}
$$

The first paper (Westergaard, 1926) contains formulae and tables for the stresses induced in a concrete slab of uniform thickness due to a single wheel for the following three cases:

a. Wheel load close to the corner of a semi-infinite slab.

b. Wheel load is acting at the interior of an infinite slab.

c. Wheel load at the edge of a semi-infinite slab.

Diagrams of deflections and bending moments' distributions were also given in the paper. Using these diagrams, the combined effect due to multiple wheel loads can be determined by the principle of superposition.

Pickett and Ray (1951) developed a graphical solution of the Westergaard theory in the form of influence charts. These charts greatly simplified determining the deflections and bending moments caused by wheel loads on slabs for three different loading cases: interior, edge, and near the center of a concrete slab resting on three different types of foundations spring, elastic solid, and elastic layer subgrade. Those charts were adopted by the Portland Cement Association (PCA), Federal Aviation Administration (FAA), and U.S. Army to compute the maximum tensile stress for edge loading (Hutchinson, 1966).

In the second paper, Westergaard (1927) divided the total thermal stress into two components. The first arises from the slow seasonal changes of temperature and the second from the quick changes of temperature occurring, for example, between a cool night to a hot day and vice versa. He went on to classify the change of temperature through the concrete slab thickness into two components. The first was a uniform temperature change throughout the thickness of the slab resulting in stress that was analyzed under the subtitle "Uniform Decrease of Temperature". The second takes the form of a thermal gradient in which the slab temperature remains constant at the middle plane of the slab with a definite temperature gradient through the thickness i.e. the 
temperature of the slab top is different from that of its bottom. The gradient component leads to slab deformation out of plane giving rise to curling stresses. The stresses calculated for the two temperature components must be algebraically added to obtain the overall stress in the slab due to temperature change. For an infinitely long slab resting on subgrade, Westergaard demonstrated (using the principles of thermoelasticity) that a uniform component of temperature drop of $50^{\circ} \mathrm{C}$ would give rise to tensile stress that exceeds the modulus of rupture of concrete. This stress should be relieved by transverse cracking or the construction of a transverse joint. For slabs constructed with transverse joints, the stress induced by a uniform temperature drop was postulated to arise only from slab-base friction, which is small, according to the subgrade drag theory (Yoder and Witczack, 1975). For example, the tensile stress component in a $9.14 \mathrm{~m}$ long slab subjected to a uniform temperature drop would be $0.162 \mathrm{MPa}$ (23.44 psi), assuming a coefficient of friction of 1.5 and $25.4 \mathrm{~cm}$ (10 in.) slab thickness. This stress magnitude would only arise when the temperature drop is sufficient to cause gross slab sliding and remains constant as the magnitude of the temperature drop increases. Thus, it became customary among pavement designers and researchers to neglect the stress component due to uniform temperature change since it is very small in comparison with the much larger curling stress due to temperature gradient.

\subsubsection{Limitations of Westergaard Theory}

For nearly 80 years, Westergaard's theory has been used to calculate the response of rigid pavements to wheel loads and temperature variations. The theory is widely accepted as accurate (Hammons, 1997); however there are several limitations as follows:

1. All pavement layers below the slab must be represented by a single parameter, which is the modulus of subgrade reaction. Generally, a pavement may contain several layers including subbases and base coarse. Each overlying layer has an increase in quality and stiffness. When applying Westergaard's theory on such a system, these layers are modeled by an increased modulus of subgrade reaction intended to produce an equivalent response. This clearly decreases the accuracy of the analysis. 
2. The foundation must always respond linear-elastically. Some subgrade and subbase materials exhibit nonlinear behavior.

3. Westergaard assumed the slab is in full contact with the subgrade. Therefore, boundary conditions are violated if a void is formed under the slab due to pumping, or if the slab is separated from the subgrade due to curling.

4. Westergaard assumed infinitely extended slabs; however concrete slabs have discontinuities due to transverse and longitudinal joints.

5. Load transfer across transverse joints cannot be directly modeled.

6. Slab thickness must be uniform.

\subsubsection{Subsequent Advances in Curling Analysis}

Based on Westergaard's solution, Bradbury (1938) developed a simple chart to evaluate curling stresses in finite slabs with all edges free. Tang et al. (1993) extended Westergaard's solution for a slab subjected to negative thermal gradient to take into account that a gap can be formed between the slab edge and the subgrade. However, this solution is not applicable in the case of the positive thermal gradient where the slab is only supported on its corners and a gap is formed under the middle of the slab. Additionally, the finite slab dimensions were not accounted for in Tang's solution. Representing the subgrade using Pasternak foundations that take into account the effect of shear stresses within the subgrade (unlike Winkler foundations that represent the subgrade with a spring), Shi et al. (1993) analyzed the curling stresses in a concrete slab due to a linear thermal gradient though the slab thickness. Their results showed that ignoring the shear stress of foundations in Westergaard and Bradbury's solutions led to overestimated curling stresses. However, the accuracy of this solution depends on the accuracy of determining the shear parameters required for the model.

One of the main objections raised to Westergaard's work was the fact that measured temperature gradients profiles through concrete slab thickness are nonlinear (Teller and Sutherland, 1935). Thomlinson (1940) was the first to develop a rational approach to account for the effect of the nonlinearity by adding a new stress component to those suggested by Westergaard (1927). Due 
to such nonlinearity in the temperature gradient, various fibers of the slab cross-section tend to expand (or contract) with different amounts. However, the main assumption in the elastic plate theory is that the cross-section of a plate remains plane after bending. To satisfy the aforementioned assumptions, the different fibers of the slab cross-section must exert a restraining action on each other, which produces additional stresses in the slab. Such stresses were assumed to be due to self-equilibrating dummy external forces, which mean the total force on any slab cross section is zero, so that it causes neither axial deformation nor curling in the concrete slab but contributes to the maximum tensile or compressive stress acting on the top or bottom of the slab.

\subsection{Classical Models of Dowel Bars}

Westergaard (1929) developed the first rational method of designing joints in concrete pavements under joint loading by developing a theoretical means for computing the shearing force in each active dowel bar along the transverse joint, as well as the critical stresses that occur in the slab under edge loading. Based on the assumption that the edge deflections of two joined slabs are equal (a case that never exists in practice), he concluded that only the first two dowel bars located at each side of a point load applied at the joint edge are active in transferring the load to the adjacent slab. Friberg (1938) postulated that only the dowels that fall at a distance (from the wheel load) greater than 1.8 times the radius of the relative stiffness $\ell$ would not transfer any load to the adjacent slab.

Assuming that an effective dowel may be modeled as an elastic beam encased in an elastic media (Timoshenko and Lessels, 1925), and that the shear stress in each dowel decays linearly with its distance from the load, Friberg concluded that the bearing compressive pressure $\sigma_{\mathrm{b}}$ in the concrete supporting the dowel is:

$$
\sigma_{b}=\frac{K e^{-\beta x}}{2 \beta^{3} E I}\left[P_{t} \cos \beta x-\beta M_{o}(\cos \beta x-\sin \beta x)\right]
$$


Where: $\quad P_{t}=$ the load transmitted by the dowel to the adjacent slab.

$M_{o}=-0.5 w P_{t}=$ moment applied by the dowel for a joint opening $w$.

$K=$ Modulus of dowel support.

$x=$ The distance along the dowel measured from the joint face.

$\beta=$ Relative stiffness of an elastic bar embedded in an elastic media, given by

$$
\beta=\sqrt[4]{\frac{K b}{4 E I}}
$$

$d, E$, and $I$, are the diameter, modulus of elasticity, and moment of inertia of the dowel bar.

Although the compressive stress predicted from Equation 2.2 was introduced by Friberg as the stress that ultimately leads to the failure of the doweled connection, he reported that the first sign of joint distress was the development of a "very small horizontal crack", which took place long before full failure. Since the doweled joint took considerably large loads after the horizontal crack was observed, this crack was ignored in later studies of stresses in doweled joints. To date, the compressive bearing stress is the only stress in use to ensure that the dowel joint will withstand fatigue due to traffic loading repetitions (AASHTO 1998). The accuracy of the bearing pressure computed using Equation 2.1 depends on the value of the modulus of dowel support K. Over the years, values of $\mathrm{K}$ ranging from $8 \times 10^{10}$ to $8 \times 10^{11} \mathrm{~N} / \mathrm{m}^{3}(300,000$ to $3,000,000$ pci) were reported and/or measured. $\mathrm{K}=4 \times 10^{11} \mathrm{~N} / \mathrm{m}^{3}(1,500,000 \mathrm{pci})$ is a typical value often used in design (Yoder and Witczak, 1975; Huang, 1993). The modulus of dowel support, K, changes with the modulus of elasticity of concrete, diameter of the dowel bar, method of measurement, and strength of the dowel concrete bond. The lack of standardized experimental or theoretical procedures for determining both the modulus of dowel bar support $\mathrm{K}$, and the magnitude of the load transferred by each dowel placed doubts on the stress calculations using equation 2.2. Kushing and Fremont (1940) reported that the range of distribution of load transfer hardly extended over more than $\pi l$ on each side of the load. However, Sutherland (1940) reported experimental results that supported Westergaard's assumption that only the two dowels near the load are effective in load transfer. Based on Two Dimensional Finite Element (2DFE) analysis, 
Tabatabaie and Barenberg (1978) supported Friberg's assumption that the dowel shearing forces decrease linearly with the dowel distance from the loading point; however, he found that the effective dowels in load transfer were those that fall within a distance equal to the radius of relative stiffness. The reduced load distribution length was also supported by the results of Heinrichs et al. (1989).

\subsection{Two-Dimensional Finite Element Analysis}

Introduction of finite element methods in the seventies draws the attention to curling stresses in concrete slabs. Several finite element programs have been revised to incorporate the capability of calculating curling stresses including: ILLI-SLAB (Tabatbaie and Barenberg, 1978; Krovosis, 1990), JSLAB (Tayabji and Colley, 1986), KENSLABS (Huang and Wang, 1974), WESLIQUID (Chou, 1981), WESLAYER (Chou, 1981), KENLAYER (Huang, 1993), FEACONS IV (Tia et al., 1987; Wu and Larsen, 1993), and ISLAB2000 (Khazanovich et al., 2000, Beckemeyer et al., 2002). It is worth mentioning here that all these programs simulated the traffic loads as a static load. Table 2.1 presents an overview of the features of such $2 \mathrm{D}$ finite element programs.

Table 2.1 Features of 2D FE Models of Rigid Pavements.

\begin{tabular}{|l|l|l|l|}
\hline Program & Slab Model & Dowel Bar & Foundation Material \\
\hline $\begin{array}{l}\text { ILLI_SLAB } \\
\text { (Tabatabaie 1978) }\end{array}$ & $\begin{array}{l}\text { Medium- } \\
\text { thick plate. }\end{array}$ & Beam elements & $\begin{array}{l}\text { Dense liquid, Boussinesq, } \\
\text { nonlinear resilient. }\end{array}$ \\
\hline $\begin{array}{l}\text { JSLAB (Tayabji and } \\
\text { Colley, 1986) }\end{array}$ & $\begin{array}{l}\text { Medium- } \\
\text { thick plate. }\end{array}$ & Beam elements & Dense liquid. \\
\hline $\begin{array}{l}\text { WESLIQUID (Chou } \\
\text { 1981) and KENSLABS } \\
\text { (Huang 1993). }\end{array}$ & $\begin{array}{l}\text { Medium- } \\
\text { thick plate. }\end{array}$ & Linear Springs & Dense liquid. \\
\hline $\begin{array}{l}\text { WESLAYER (Chou 1981) } \\
\text { and KENLAYER (Huang } \\
\text { and Wang, 1974). }\end{array}$ & $\begin{array}{l}\text { Medium- } \\
\text { thick plate. }\end{array}$ & Linear Springs & Layered elastic. \\
\hline $\begin{array}{l}\text { FEACONS IV (Wu and } \\
\text { Larsen., 1993) }\end{array}$ & $\begin{array}{l}\text { Medium- } \\
\text { thick plate. }\end{array}$ & $\begin{array}{l}\text { Linear and } \\
\text { torsion Springs }\end{array}$ & $\begin{array}{l}\text { Dense liquid (linear or } \\
\text { nonlinear springs). }\end{array}$ \\
\hline $\begin{array}{l}\text { ISLAB2000 (Khazanovich } \\
\text { et al., 2000) }\end{array}$ & $\begin{array}{l}\text { Medium- } \\
\text { thick plate. }\end{array}$ & Beam elements & $\begin{array}{l}\text { Winkler, Pasternak, or Kerr } \\
\text { Models. }\end{array}$ \\
\hline
\end{tabular}


Table 2.1 reveals that all of the 2D FE programs use 2D medium-thick plate element to model the concrete slab. A detailed description of the formulation of such element could be found in a number of Finite Element references such as: Zienkiewicz and Cheung (1967), Cook et al., (1989), and Bathe (1996). This four-node plate-bending element is located in the $\mathrm{x}-\mathrm{y}$ plane. Each node has three degrees of freedom: a displacement $\delta_{z}$ in the vertical direction (z-direction), a rotation $\theta_{\mathrm{x}}$ about the $\mathrm{x}$-axis, and a rotation $\theta_{\mathrm{y}}$ about the $\mathrm{y}$-axis. Additionally, the following assumptions are made for this element:

a) The plate material is isotropic, elastic, and homogeneous.

b) Vertical loads are carried only by flexure rather than by in-plane forces (thin plates and shells) or by transverse shear (thick plate).

c) Plane cross sections remain planes after bending.

d) The middle surface remains normal to the plate cross-section, and unstretched.

e) Each lamina parallel to the middle surface is in a state of plane stress; axial or in-plane shear stress develops due to loading.

Based on the assumption inherit in the formulation of medium-thick plate bending element, the major drawbacks in this representation can be summarized as:

a) The inability of the plate elements to model the stress distribution across the depth and ignoring the vertical normal stresses that are important particularly around the dowel bars (Channakeshava et al., 1993; Shoukry and William, 1998).

b) The most common form of doweled transverse joint failure is a concrete chunk that splits leaving the embedded part of the dowel bar uncovered (SHRP Distress Manual, 1993). This type of damage indicates that slab stresses near a transverse joint are triaxial, therefore representing the slab with a plate element may not be valid at the vicinity of a transverse joint.

c) Additionally, ignoring the change in the slab thickness as well as restraining the horizontal displacement to the vertical direction only makes it impossible to study the 
effect of volumetric changes due to any form of temperature variation other than linear temperature gradient.

d) A nonlinear temperature gradient through the slab thickness that represents either slab warping or curling cannot be considered.

The other feature in the 2DFE programs is representing the dowel bars using beam elements or spring elements. In such a representation, it is assumed that the displacements at the ends of the beam or spring element are equal to those slab elements. Nishizawa et al. (1989) rejected this assumption and suggested modeling dowels using a combination of linear and torsional springs that simulated both the dowel bar and the aggregate interlock. Guo (1995) integrated the modulus of dowel support in a two-dimensional finite element formulation in order to simplify dowel bar simulation in 2DFE models of rigid pavements and to account for dowel looseness. The 2DFE-calculated shear force in the dowel bar is substituted into Equation 2.1 to calculate the bearing stress in the concrete surrounding that dowel. However, the triaxial state of stress that takes place around the dowel could not be viewed. Further, the horizontal friction force between the dowel bars and the surrounding concrete cannot be modeled.

In an attempt to account for the nonlinearity of the temperature gradient profile through the slab thickness, total thermal stress was calculated by superposition of two stress components: one due to linear thermal gradient which is calculated by the 2DFE program; the other is due to a nonlinear component based on Thomlinson's approach. (Choubane and Tia, 1992, 1995; Khazanovich 1994; Harik et al., 1994; Ioannides and Khazanovich, 1998; Khazanovich et al. 2000). The objection to this approach is that the principle of superposition is not applicable to rigid pavement structures that display mostly nonlinear behavior. Apart from material nonlinearity, concrete pavements exhibit geometrical nonlinearity due to dowel bar friction, slabbase friction, and non-uniform slab support due to curling and warping. Such an approach cannot be applied to calculate the thermal stress near slab edges since the assumption of plane cross sections inherit in the plate theory will not be valid at the free edge in absence of external edge constraints. Therefore, the calculated stress at the free edge in this case will not satisfy the equilibrium conditions. 


\subsection{Three-Dimensional Finite Element Analysis}

The rapid advances in computer time and memory, and the necessity for enhancing a better understanding of the reasons for some modes of pavement failure are among the factors that led many pavement researchers to adopt the 3D-FEM approach. Due to the ignorance of thermal stresses in concrete pavement design, the early 3DFE models were mainly developed to examine the pavement performance due to traffic loading. Ioannides and Donnelly (1988) examined the effect of subgrade support conditions on rigid pavements. The 3DFE program GEOSYS was used to model a single concrete slab on a subgrade. The study examined the effect of mesh refinement, vertical and lateral extent of the subgrade, and boundary conditions on pavement response. Zaghloul (1994) used the 3DFE code ABAQUS to examine the effect of the overload trucks on rigid pavements simulated by an $80 \mathrm{KN}$ (18-kips) single axle load. Results indicated that the edge loading results in tensile stresses 40 percent larger than those due to interior loading. Hammons studied the effect of changing the static coefficient of friction $(\mu)$ from 0.1 to 100 at the slab/base interface. The results indicated that the largest separation occurs for the lowest value of $\mu$ due to the largest differential movement between the slab and base. Uddin et al. (1994) examined the effect of discontinuities at transverse joints on the slab deflection to Falling Weight Deflectometer (FWD) impact. Shoukry (2000) examined the effect of nonlinear thermal gradient on the deflection basin due to FWD impact. Shoukry's results indicated that the values obtained for pavement layers moduli using backcalculation programs seem to be reliable as long as the thermal gradient through pavement layers is negative.

Channakeshava et al. (1993) developed a nonlinear static 3D-FE model to study the combined effect of a linear thermal gradient and a static wheel load. Dowel bars were simulated as beam elements mounted on elastic springs of constants equal to the modulus of dowel support $\mathrm{K}$. Effect of different extents of loss of subgrade support and different dowel-concrete interface characteristics were considered. The study concluded that nighttime curling is a critical loading case since truck traffic is heaviest during the night; in addition, it causes loss of support under the

joints. They also reported a large concentration of tensile stresses in the elements below the 
dowel bars. A finding that does not explain the small horizontal cracks observed in Friberg's (1938) experiments.

Darter et al. (1995) developed a 3D-FE model using the general code ABAQUS to investigate the effect of loss of support under concrete slabs. The effect of widened base on the stress level in the concrete slab was examined under the effect of an $80 \mathrm{KN}$ single axle load and linear temperature gradient. Results indicated that bonding concrete slab to base coarse did not reduce slab stresses for a curled slab situation.

Zamman and Alvappillai (1995) examined the dynamic response of rigid airport pavement to a moving aircraft axle and temperature gradient. The slabs were modeled using 4-node rectangular thin plate element resting on viscoelastic Winkler foundations. In an attempt to consider contact nonlinearity, dowel bars at transverse joints were modeled as a grid with a possibility of debonding and gap formation. The constraint conditions at the concrete dowel-interface were: a) no penetration of nodal points; b) no tensional contact forces; and c) Coulomb friction is assumed between the dowel and the surrounding concrete in the longitudinal direction. Model results indicated that increasing the temperature gradient of the slab increases both tensile stress and deflection of the pavement. It was also shown that dowel bars reduce the discontinuities in the displacement at transverse joint.

Beegle and Sargand (1995) developed a 3D finite element program to model rigid pavement under static truck loading and thermal gradient. Concrete slabs, base, and subgrade were modeled using 20-node solid brick elements, while dowel bars and tie bars are modeled using beam elements. Interface elements were used at the pavement-soil interface and in the joints between adjacent slabs. The model was used to investigate the effect of varying the material properties on pavement response. Model results indicated that when slabs are subjected to thermal gradient, increasing the concrete modulus results in higher deflection. It was also shown that decreasing the subgrade modulus results in an increased contact area between the curled slab and base layer. Experimental results from Ohio Road test (Sargand et al., 1997) were used to validate the 3DFE model response. Limited agreement was found between predicted and measured values for displacement and stress due to temperature changes. This was attributed to 
the fact that the initial conditions of the slab were unknown due to the change of the slab profile during curing. However, the calculated stresses based on the measured strain indicate that the effect of the change of mean slab temperature was omitted in the finite element model. A good agreement between the measured and predicted pavement response to a moving dump truck was reported in absence of the temperature gradient (Sargand and Beegle, 1998). Pavement instrumentation in Ohio Road Test indicated that deflections and stresses caused by temperature changes are more severe than those caused by traffic loading (Sargand et al., 1997).

Masad et al. (1996) used the FE code ABAQUS to examine the effect of temperature variations on concrete slabs. The model results indicated that the maximum curling stresses, for the entire range of the linear temperature gradient analyses, were about 28 percent of the concrete modulus of rupture. They reported that nonlinear temperature gradient caused higher tensile stresses than the linear one. The coefficient of friction at the slab/base interface had a minimal effect on curling stress. Their results also showed that the arithmetic addition of curling and thermal expansion stresses was less than the stresses resulting from superposition in case of positive curling, and equal to each other in case of negative curling.

Uddin et al. (1997) examined the effect of pavement discontinuities on the surface deflection of a concrete slab subjected to a linear temperature gradient and statically applied loads. The 3D-FE code ABAQUS was utilized to perform a static analysis by placing $80 \mathrm{kN}$ dual-wheel single axle load at the middle of the slab. The results indicated that thermal gradient and truck loading cause significant fatigue cracking and premature distress in the outer wheel-path. However, the results presented in this study were limited and did not show a good agreement with Westergaard and KENSLAB results. The limited results obtained from the model illustrate that temperature gradient can have a significant influence on pavement response.

A 3D-FEM interface for modeling pavement structures (Kennedy et al., 1994) was developed by the support of the Federal Highway Administration (FHWA). In this parametric model, the user can adjust the layers' thickness and material properties. The model relies on the equation solvers DYNA3D and NIKE3D developed at Livermore National Laboratories in the mid 1970s (Kennedy and Everhart, 1995 and 1996). Model verification was accomplished by using results 
from an instrumented test section constructed in Ohio (Kennedy and Everhart, 1997). The model was loaded with a test vehicle. Dowel bars were simulated with beam elements. Thermal effects were accounted for in the model by adding a thermo-elastic model with temperature dependant material parameters (Kennedy and Everhart, 1998).

Pane et al. (1998) used the 3D-FE code ANSYS to examine the validity of the assumption inherent in the plate bending theory that plane sections remain plane when subjected to nonlinear temperature gradient. Simulation of both dowels bars and tie bars were omitted in this study. Their results indicated that such an assumption is valid for about 95 percent of the slab area that is not close to the free edges.

Davids et al. (1997, 1998) developed a 3D-FE program specifically for rigid pavements. Concrete slabs were modeled using 8-node solid brick elements. An embedded beam element formulation was developed to precisely locate the dowel bar within the finite element mesh irrespective of the slab mesh lines. This model also permits rigorous treatment of dowel looseness, which affects the load transfer efficiency. Later, the program was modified so that a Winkler foundation can be specified between the dowel and concrete instead of explicitly modeling dowel looseness (Davids, 2000). Examining the load transfer efficiency at doweled transverse joints for both curled and flat slabs revealed that slab curling has a large influence on dowel-concrete bearing stress (Davids, 2001). However, both simplified dowel modeling techniques employed in these models are still incapable of predicting the triaxial state of stress that develops in the concrete surrounding the dowel bars.

Shoukry et al. (2002) examined the response of dowel jointed concrete pavements to the combined effect of nonlinear thermal gradient and moving axle load. The general 3D-FE code LS-DYNA was used as the equation solver. All pavement layers as well as dowel bars were modeled using 8-node solid brick elements. Dowel-concrete interfaces as well as slab-base interface were simulated using sliding interfaces with friction that allows for slab-base separation. The 3D-FE computed response to simulated moving axle load was field validated versus measured concrete slab response to a fully loaded moving dump truck. The model results indicated that the stresses induced in concrete slabs due to the combined effect of axle loading 
and temperature gradients are well below the concrete modulus of rupture, therefore are not the primary cause of premature failure of concrete slabs. An increase in slab thickness was shown to be effective in reducing slab stress due to truck loading. It was also shown that edge loading at mid slab length is the most critical loading position of a dowel jointed concrete slab. The authors recommended the importance of including uniform temperature drops as well as contact stresses in dowel-concrete interfaces in pavement analysis and design procedures.

\subsection{Summary}

For a long time rigid pavement simulation suffered from the complexity of the underlying problems involving geometrical nonlinearity due to transverse and longitudinal joints as well as dowels bars, nonlinear material behavior, and the variety of environmental and traffic loading. The classical Westergaard's theory has served as the basis for design and analysis of pavements for decades. Despite its simplicity to apply, its limitations rendered it inadequate for modern mechanistic design (Hammons and Ioannides, 1996). The capabilities of the modeling approach have been demonstrated by $2 \mathrm{D}$-FE models that represented significant improvements over the classical models. However, they are still relying on the same formulation of the medium-thick plate formulation. The oversimplified modeling of the slab and dowel bars in the 2D-FE programs limited their capabilities to the loading conditions that don't cause any axial deformations in the slab neutral plane as uniform temperature changes. Additionally, they cannot be used to study the triaxial state of stress induced at transverse joint regions.

The limitations inherent in 2D-FE programs led many researchers to emerge 3D-FE analysis as a powerful tool capable of capturing details of pavement response that cannot be revealed using 2D-FE programs. However, the scope and complexity of each model was limited because of concerns over computer resources or the required computational time. The major features of the existing 3D-FE models can be summarized as follows:

1. Spring or beam elements have been extensively used for modeling dowel bars. Such modeling limits the capability of the 3D-FE model to reveal the three dimensional nature 
of the dowel concrete contact that leads to the formation of triaxial state of stress near the slab edges (Shoukry and William, 1998). Additionally, dowel-concrete contacts introduce axial dowel forces that resist slab contraction due to uniform temperature drop. Such forces could significantly increase mid slab stress due to temperature drop and may lead to mid slab cracking. Therefore, in order to accurately evaluate the temperatureinduced stresses in concrete slabs, dowel bars and their interfaces with surrounding concrete should be accurately modeled.

2. Under the hypothesis that dowel bars do not produce any resistance to the concrete slab contraction due to uniform temperature drop, slab response to seasonal temperature variations was completely omitted from concrete pavement analysis and design.

3. Although many studies considered nonlinear temperature gradient profile though the slab thickness in pavement analysis, the effect of the magnitude of nonlinearity (deviation of the nonlinear temperature profile from the linear one at the neutral plane) on the temperature-induced stress in concrete slabs has not been studied.

4. No experimental validation has been presented for the response of any of the previous models to temperature variations. Validation of such models was done either by comparing the predicted response to traffic loading only with the measured one and/or comparing the 3D-FE calculated curling stresses with those calculated using Westergaard's closed form solution.

Despite the aforementioned limitations reported in the existing 3D-FE models, it is worth mentioning here that the use of the 3D-FE technique together with the comprehensive field measurements to examine the pavement response helped establish the following facts about the global response of the concrete slabs that were originally predicted by Westergaard's analysis:

1. A wheel load that is applied either at the edge or in the interior of a slab produces the greatest tensile stress at the slab bottom directly under the load. Such stresses are highly localized stresses occurring only within a small region and falling off rapidly in all directions.

2. A given wheel load produces a greater stress at the slab edge than in the interior area. 
3. Stresses induced in concrete slabs due to the combined effect of axle loading and temperature gradients are well below the concrete modulus of rupture, therefore they are not the primary reason for premature transverse cracking of concrete slabs.

4. Slab length and width have an insignificant effect on load-induced response, but may also have some effect on the response due to the combined effect of temperature variations and traffic loading. 


\section{CHAPTER THREE}

\section{FINITE ELEMENT MODEL}

\subsection{Introduction}

This chapter contains a description of the 3D finite element model developed in this study to investigate the temperature effect on dowel jointed Concrete Pavements. The basic feature of this model is the detailed modeling of the dowel bars and their interfaces with the surrounding concrete to capture the triaxial state of stress at the concrete-dowel interface and adequately simulate the concrete-dowel interaction. Boundary conditions, material models, and material loading are presented. Model results indicated that mid-slab stresses increase when the temperature gradient profile through the slab thickness includes a uniform temperature decrease. As the concrete slab curls up or down due to temperature gradient, a state of contact stress develops at the concrete dowel interface that has to be accounted for in concrete pavement design.

\subsection{Pavement Structural Model}

The 3D finite element model developed in this study consists of two dowel jointed concrete slabs supported by base and subgrade as illustrated in Figure 3.1. A $10 \mathrm{~mm}$ wide gap was assumed between the two slabs to allow for slab expansion and contraction. This ensures that dowel bars are the only means of load transfer between adjacent slabs. Ignoring the mechanism of aggregate interlock is based on the arguments that even if aggregate interlock exists, it loses its significance due to wear and slab contraction (Kelleher and Larson, 1989). This argument is also supported by measurements obtained from tests sites in Illinois that showed that aggregate interlock becomes ineffective in transferring load across transverse joints when the joint opening exceeds 0.9 to $1.0 \mathrm{~mm}$ (McKenzie 1978). 
To avoid problems associated with boundary conditions, the concrete slabs were modeled at their full widths of $3.66 \mathrm{~m}$ and the base and subgrade layers were widened $0.61 \mathrm{~m}$ on each side of the slab. No external constraints are applied to the concrete slabs whose contact with the base is maintained by activating the slab's self-weight. The choice of subgrade depth of $1.92 \mathrm{~m}$ is based on the measurements of the depth to bedrock in West Virginia, which varies between 1.0 to $5.0 \mathrm{~m}$ (Shoukry and William, 1999; William and Shoukry, 2000). Non-reflective boundaries are applied at the bottom of the model as well as the the sides of the base and subgrade layers to simulate the semi-infinite extent of the subgrade. Non-reflective boundaries allow propagating the stress waves through the edges, which gives the effect of a continuous medium.

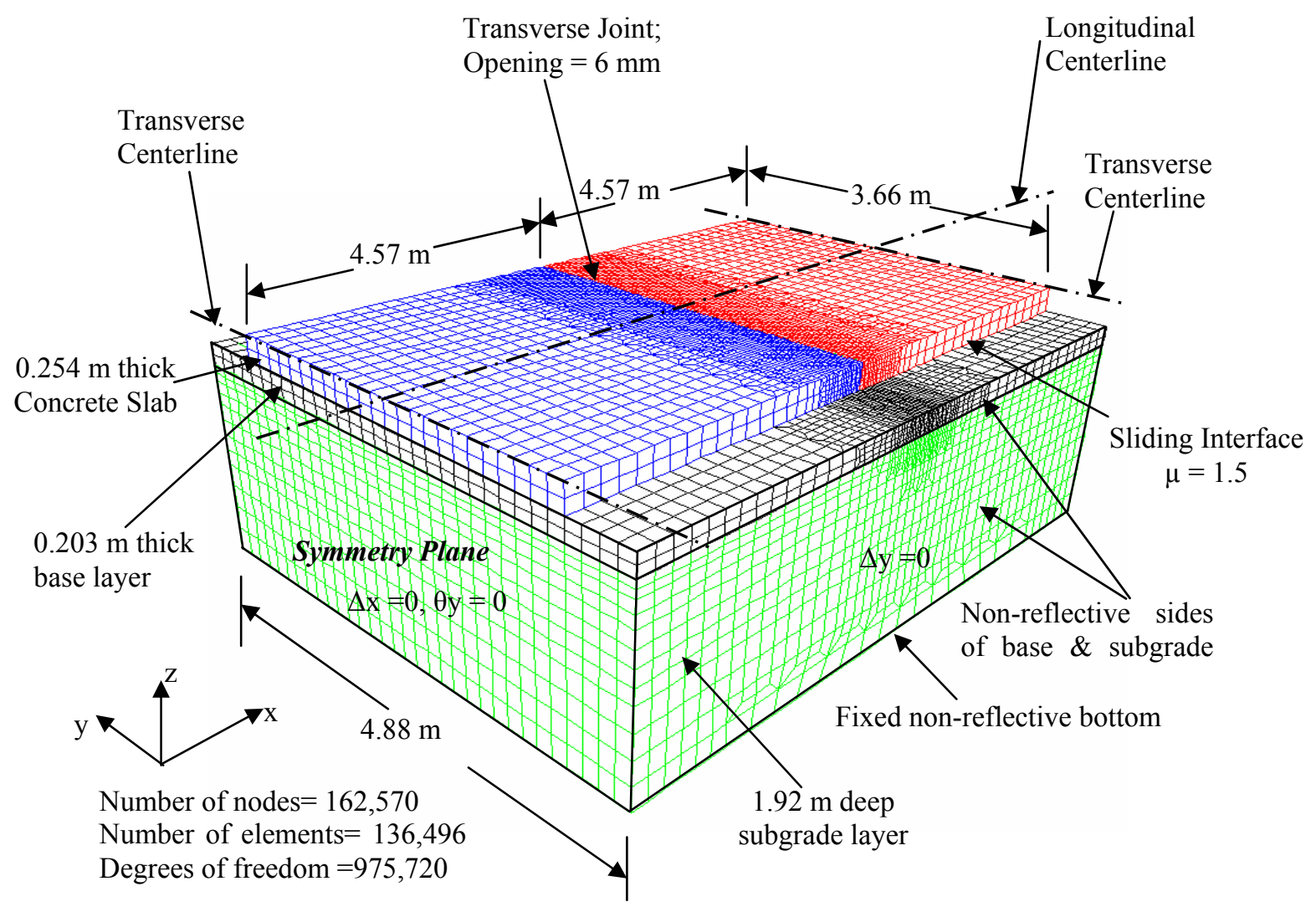

Figure 3.1 Finite Element Mesh.

An extremely fine finite element mesh of 8-node solid brick elements is used to model the slabs and dowels as well as all pavement layers as illustrated in Figures 3.1 and 3.2. The 3D modeling of the dowel bars using fine mesh enables modeling the circular cross-section of the dowel bar, 
which is essential in order to account for the mechanism of dowel contact and the associated states of stress that develop around the dowels due to traffic and/or thermal loading.

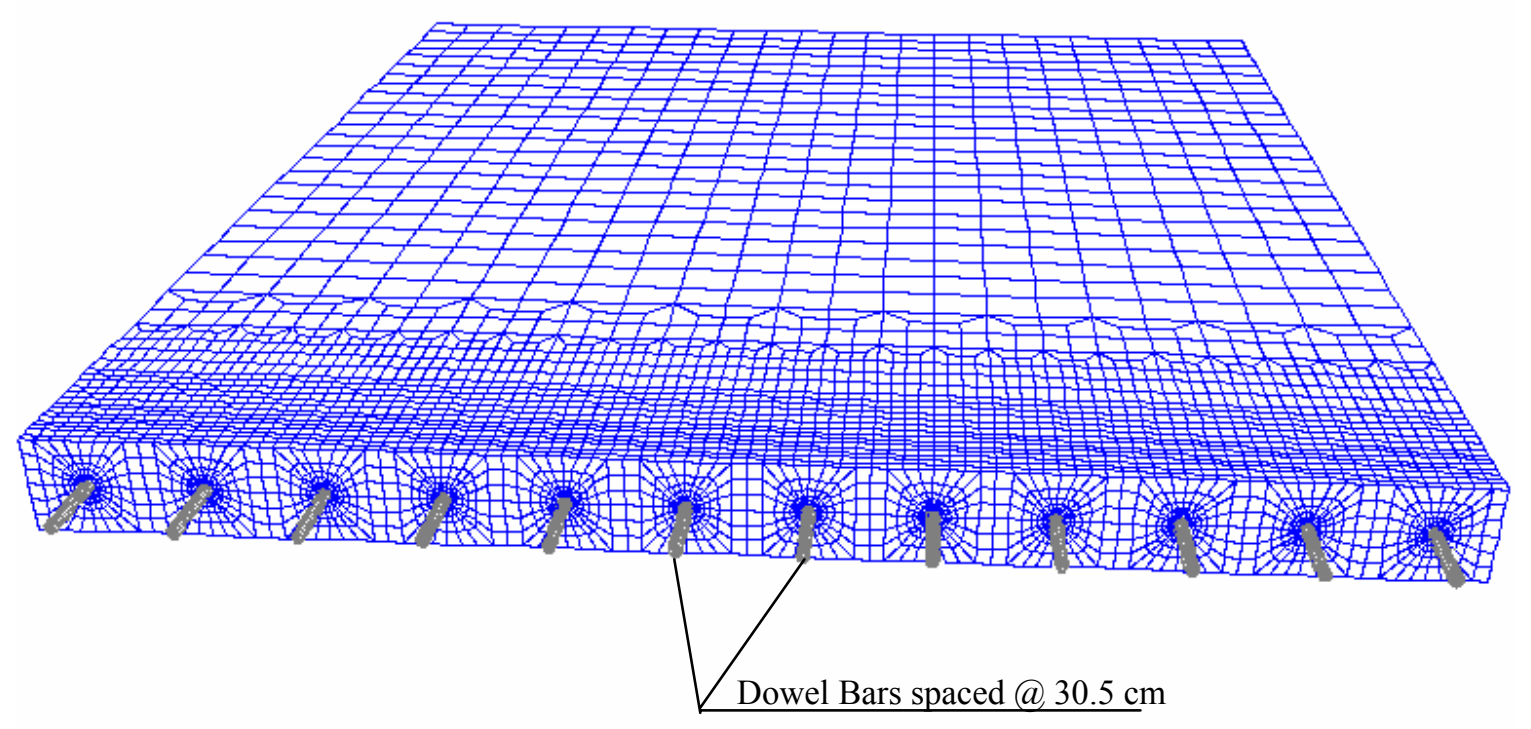

a. Slab Mesh.

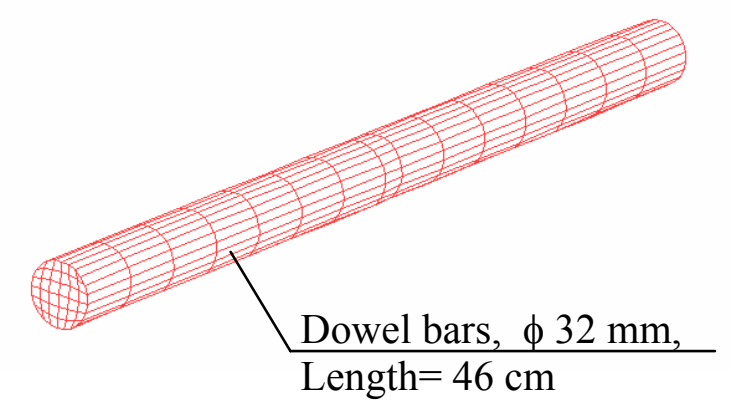

b. Dowel Bar Mesh.

Figure 3.2 Finite Element Mesh for Concrete Slab and Dowel Bars.

\subsection{Contact Interfaces}

The essential function of a dowel bar is to transfer the load between adjacent slabs without introducing axial constraining force that resists free slab contraction. To fulfill this functional 
requirement, concrete construction contractors strive to ensure proper dowel alignment and minimize dowel-concrete bonding through coating the dowels with bond-breaking agents such as oil, tar, or types of wax that resist the heat of hydration of concrete without melting. The bond breaking agents are commonly applied on top of a layer of epoxy coating that provides corrosion protection for the steel dowels and reduces their coefficient of friction with concrete. The efficient application of the above bond-breaking agents introduces initial uniform clearance between the dowel and the concrete socket (Tabatabaie and Barenberg, 1978; Bush, 1995). Thus, theoretically the dowel pullout force should be zero when the slabs are free from distortion due to warping or curling. In this study, epoxy coated dowels covered with a thin layer of bond breaker that introduces a uniform dowel clearance of $0.012 \mathrm{~mm}$ are assumed. Since the dowels are lubricated, the dowel-concrete coefficient of friction is assumed at 0.05 (no data is available in the literature). Contact stresses between the dowel and concrete can only develop when the slab deflects due to applied load and/or thermal gradient. Thus, the magnitudes of contact stresses, computed in this study, represent a lower estimate of their values under the most favorable theoretical conditions of pavement operation, i.e. when dowel-jointed slabs that are neither loaded nor curled and can contract freely without constraints introduced by the dowel bars.

If the dowels do not suffer bending deformation due to external loading or temperature gradient, the concrete slabs can contract freely without interference with the dowels. However, if the slabs curl, the dowel-concrete interface would allow non-uniform and partial contact along the interface of each dowel at any angular position that depends on the dowel position along the transverse joint. Therefore, a sliding interface that allows partial contact between the dowel and concrete surface was utilized in this investigation. This type of interface, implemented in the general-purpose finite element software "LS-DYNA" (Hallquist, 1998), is suitable for the simulation of different possibilities of dowel concrete contact. Dowel contact possibilities may range from localized contacts that can form at two or more locations along the interface (due to dowel bending and concrete surface deformation) to full contact of the cylindrical interfaces with varying degrees of interference should the dowel-concrete clearance be eliminated. In either case, the contacting surfaces may slide against each other when the dowel pulling force exceeds the frictional shear stress at the interface. Since the dowels are modeled as solid round bars, 
Figure 3.2, the localized contact areas can grow in size at any circumferential direction along the interfaces under one or both of the following conditions:

1. Localized elastic deformation of the contacting materials.

2. Localized cracking of the concrete material at the contact spots if the contact stress reaches the modulus of rupture of concrete. This case was made possible by selecting anisotropic-brittle damage material model for concrete as will be described later.

The solution of the contact problem in "LS-DYNA" finite element software is based on satisfying two conditions: the first is that the contacting surfaces may coalesce or separate during the motion of the two bodies and the second is the impenetrability of the two bodies. To satisfy the latter condition: a) the contacting points (nodal points) of the master and slave surfaces move with the same displacement and velocity in the direction normal to the contact interface, b) the momentum is balanced on the contact interface, and c) no tensile traction forces are allowed on the contact interface. Detailed explanation of the contact algorithm can be found in Schweizerhof et al. (1992) and Hallquist (1998).

Sliding interfaces with frictional contact was assumed between the concrete and the subgrade. The coefficient of friction between the concrete slab and the underlying base layer was assumed to be 1.5. Selection of such a value is recommended by Yoder and Witczak (1975), Huang (1993), and AASHTO Pavement Design Guide (1993). As described above, such an interface allows for full or partial contact between the concrete slab and base.

\subsection{Material Models}

\subsubsection{Concrete and Dowels}

Various constitutive models have been developed to describe the behavior of concrete such as Brittle Damage Model (Govindjee et al., 1995), Pseudo Tensor Model (Desai and Siriwardane, 1984; Whirely and Hallquist, 1991), and Concrete Damage Model (Hallquist 1998, 2001). 
These models have been successfully used to simulate the concrete behavior under different loading conditions and loading rates ranging from static to impulse loading (Hallquist, 1998). However, the major drawback in this model is the lack of thermal effects in their formulations. Therefore, they cannot be used to study the behavior of concrete structures under temperature changes. Therefore, the concrete is represented using a thermo-elastic-plastic material model. This model is also suitable for simulating the behavior of the dowel bar material. This material model allows elastic modulus E, Poisson's ratio $v$, coefficient of thermal expansion $\alpha$ and the yield point $\sigma_{\mathrm{y}}$ to change as a function of the current temperature $\mathrm{T}$ :

$$
\begin{aligned}
& E=E(T) \\
& v=v(T) \\
& \alpha=\alpha(T) \\
& \sigma_{y}=\sigma_{y}(T)
\end{aligned}
$$

The thermal strain rate can be defined in terms of the coefficient of thermal expansion as:

$$
\varepsilon_{i j}^{\bullet T}=\alpha \dot{T} \delta_{i j}
$$

where $\delta_{\mathrm{ij}}$ is the Kronecker delta. The constitutive law that relates the elastic co-rotational stress rate, also called Jaumann rate, $\sigma_{i j}^{\nabla}$ to the rate of deformation is

$$
\sigma_{i j}^{\nabla}=C_{i j k l}\left(\varepsilon_{k l}^{\cdot}-\varepsilon_{k l}^{\bullet T}\right)+\theta_{i j}^{\bullet} d T
$$

Where

$$
\theta_{i j}^{\cdot}=\frac{d C_{i j k l}}{d T} C_{k l m n}^{-1} \sigma_{m n}^{\cdot}
$$

and $\mathrm{C}$ is the Temperature dependant elastic stiffness matrix (Hallquist, 1998).

Since the constitutive equations are expressed in the rate form, use was made of the co-rotational stress rate $\sigma_{i j}^{\nabla}$ instead of the time derivative of the Cauchy stress tensor $\sigma_{i j}^{\bullet}$. The reason behind 
this is that the time derivative of the Cauchy stress tensor is not a frame invariant. This means that the material behavior will depend on the choice of the spatial coordinate system. Such behavior is physically unrealistic and thus must be avoided (Belytschko, 1992; Belytschko et al., 2000). The frame invariant rate, also called Jaumann rate, is given by:

$$
\sigma_{i j}^{\nabla}=\sigma_{i j}^{\bullet}-W_{i k} \sigma_{k j}-W_{j k} \sigma_{k l}
$$

Where $\mathrm{W}$ is the vortex tensor, given by:

$$
W_{i k}=\frac{1}{2}\left(\frac{\partial u_{i}}{\partial x_{k}}-\frac{\partial u_{k}}{\partial x_{i}}\right)
$$

Based on Von Mises yield criterion, the model updates the stress elastically then checks if the effective stress violates the isotropic yield function:

$$
\phi=\frac{1}{2} S_{i j} S_{i j}-\frac{\left[\sigma_{y}(T)\right]^{2}}{3} \leq 0
$$

Where $\mathrm{S}$ is the deviator stress tensor and $\sigma_{y}(T)$ is the subsequent yield stress given by:

$$
\sigma_{y}(T)=\sigma_{o}(T)+E_{p}(T) \varepsilon_{e f f}^{P}
$$

The initial yield $\sigma_{o}$ and the plastic hardening modulus $E_{p}$ are temperature dependant. In case of plastic behavior $(\phi>0)$, the deviator stresses are scaled back, in an iterative procedure, to the yield stress by scale factor $f_{s}$ :

$$
S_{i j}^{n+1}=f_{s} S_{i j}^{*}
$$

where

$$
f_{s}=\frac{\sigma_{y}(T)}{\left(\frac{3}{s} S_{i s}^{*} S_{i s}^{*}\right)^{1 / 2}}
$$

and update the plastic strain by the increment

$$
\Delta \varepsilon_{e f f}^{p}=\frac{\left(1-f_{s}\right)\left(\frac{3}{2} S_{i j}^{*} S_{i j}^{*}\right)^{1 / 2}}{G+3 E_{p}}
$$


Temperature variations in concrete pavements usually occur within a range of -20 to $45{ }^{\circ} \mathrm{C}$. Within this range, the material properties for both steel dowels and concrete are found to be not sensitive to temperature (Carette and Malhorta, 1984; Lee et al., 1988; Poh, 2001). Therefore, constants values for Young's modulus, Poisson's ratio, and coefficient of thermal expansion are assumed for both concrete and steel dowels and are listed in Table 3.1.

Table 3.1 Material Properties

\begin{tabular}{|c|c|c|c|}
\hline Layer & Material Model & Property & Value \\
\hline \multirow{6}{*}{$\begin{array}{l}\stackrel{0}{0} \\
\stackrel{0}{0} \\
\ddot{\theta}\end{array}$} & \multirow{6}{*}{ Thermo-Elastic-Plastic } & Density $\left(\mathrm{Kg} / \mathrm{m}^{3}\right)$ & 2400 \\
\hline & & Compressive strength $(\mathrm{MPa})$ & 19.10 \\
\hline & & Tensile strength $(\mathrm{MPa})$ & 2.89 \\
\hline & & Modulus of elasticity (MPa) & 20,684 \\
\hline & & Poisson's ratio & 0.18 \\
\hline & & Coefficient of thermal expansion $\left(/{ }^{\circ} \mathrm{C}\right)$ & $10.8 \times 10^{-6}$ \\
\hline \multirow{5}{*}{ 焉 } & \multirow{5}{*}{ Thermo- Elastic-Plastic } & Density $\left(\mathrm{kg} / \mathrm{m}^{3}\right)$ & 7830 \\
\hline & & Modulus of elasticity (MPa) & $2 \times 10^{5}$ \\
\hline & & Yield Strength (MPa) & 275 \\
\hline & & Poisson's ratio & 0.30 \\
\hline & & Coefficient of thermal expansion $\left(/{ }^{\circ} \mathrm{C}\right)$ & $10.8 \times 10^{-6}$ \\
\hline \multirow{3}{*}{ 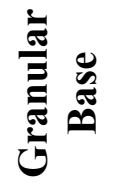 } & \multirow{3}{*}{ Linear Elastic } & Density $\left(\mathrm{kg} / \mathrm{m}^{3}\right)$ & 2100 \\
\hline & & Modulus of elasticity $(\mathrm{MPa})$ & 310 \\
\hline & & Poisson's ratio & 0.30 \\
\hline \multirow{3}{*}{ 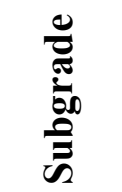 } & \multirow{3}{*}{ Linear Elastic } & Density $\left(\mathrm{kg} / \mathrm{m}^{3}\right)$ & 2040 \\
\hline & & Modulus of elasticity (MPa) & 30.3 \\
\hline & & Poisson's ratio & 0.40 \\
\hline
\end{tabular}

\subsubsection{Base and Subgrade Materials}

The behavior of a granular base or subgrade is known to be nonlinear. Within the range of the load magnitudes applied by axle loading and temperature gradients, the nonlinear response of the base and subgrade does not seem to have a significant influence on the response of the much 
stiffer concrete slab. This is supported by FWD load versus deflection plots (Shoukry and William, 1999) where linear load-deflection relations were observed at all FWD sensor locations. In addition, it was shown that the maximum bearing pressure on top of the base layer due to FWD load was about 0.07 MPa (Shoukry and William, 1999), which is greater than the maximum level of pressure induced in the present 3DFE model. The results from unconfined triaxial tests of a wide range of cohesive and granular soils indicate that the stress-strain relationships are linear up to a deviator stress of $0.35 \mathrm{MPa}$. (Garg, 1997). Based on those findings and consideration of the computational efficiency, elastic material models were used to simulate the material behavior of the base and subgrade layers. The equivalent elastic material properties of each layer may be derived from the corresponding nonlinear constitutive material relations within the range of the operating pressures induced under traffic loading and/or temperature gradient. If nonlinear material modeling of the base and/or subgrade layers becomes necessary (e.g. in studies of loss of slab support), the 3DFE software contains a library of nonlinear material models that include cam-clay, cap, as well as user defined material models. The subgrade and base materials were represented using elastic material models. The material constants used for all layers are listed in Table 3.1.

\subsection{Model Loading}

\subsubsection{Thermal Loading}

Thermal loading is applied to the model by specifying a temperature gradient profile through the slab thickness and running the model in a dynamic relaxation mode that builds up the static stresses and displacements. During this mode, the gravity is activated as body forces. The gravity is specified as base acceleration acting in the vertical direction. After full dynamic relaxation, the model becomes deformed, then loaded with built-up stresses that develop in the concrete slab due to such temperature variations. A data file containing the distorted model and the built-up stresses becomes the starting file to which any magnitudes and configurations of traffic load and/or temperature gradient profile are applied prior to its reprocessing in a static or a dynamic mode. 
Dynamic Relaxation is an explicit iterative technique for the static solution of structural mechanics problems (Belytschko et al., 2000). The technique is based on the fact that static solution is the steady state part of the transient response for a temporal-step pulse (Underwood, 1992). Therefore, in such a technique the load is applied very slowly and the dynamic equation of motion is solved with enough damping so that oscillations are minimized (Belytschko et al., 2000). Figure 3.3 illustrates the effect of the damping ratio on the convergence of the dynamic solution to the static one for a single degree of freedom system. It can be noticed that the dynamic relaxation technique is nothing but a critically damped system, in which the damping matrix $\mathrm{C}$ can be expressed as a function of the diagonal mass matrix by the relation:

$$
C=C_{c r}=2 \omega_{\min } m
$$

where $\omega_{\min }$ is the first natural frequency of the system.

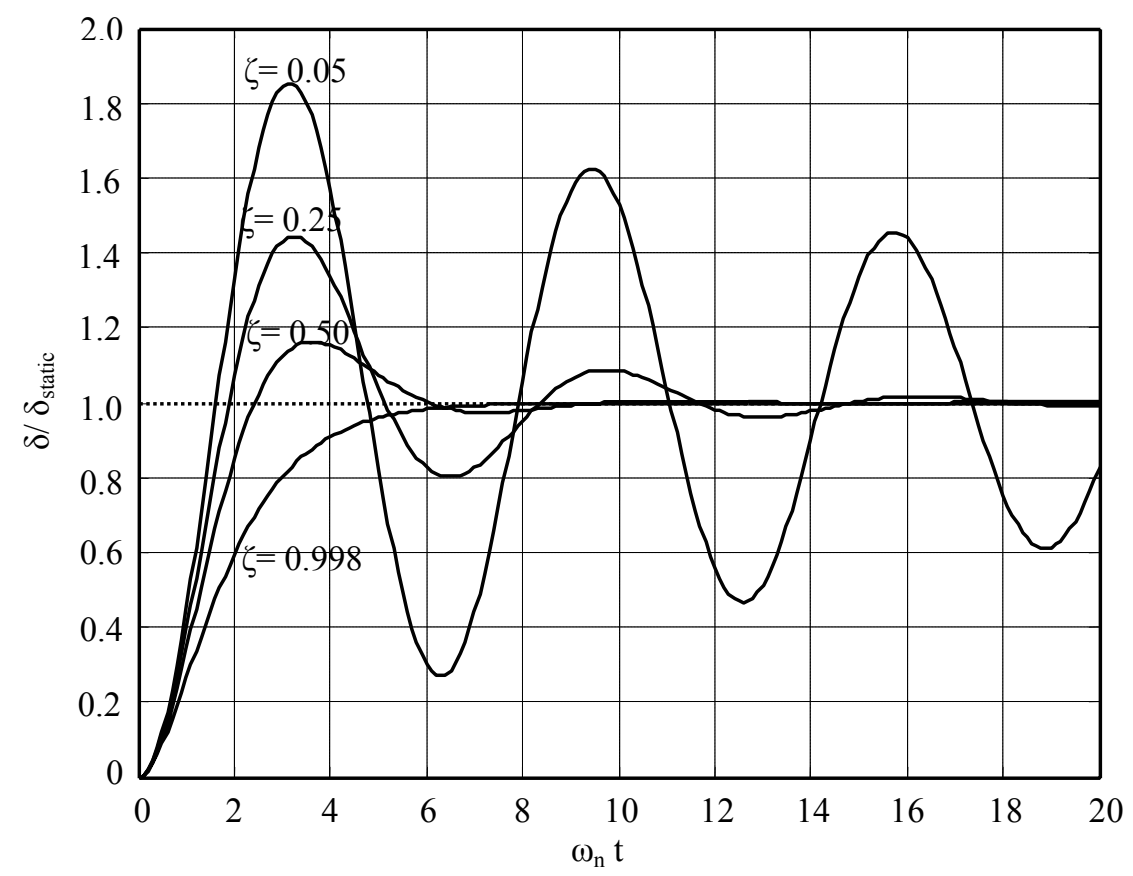

Figure 3.3 Displacement-Time Histories for Different Damping Ratios.

The dynamic relaxation method was found to be effective for problems with highly nonlinear geometric and material behavior, which include limit points or display softening behavior. Because of the explicit nature of the method, all quantities are treated as vectors. In such case, the solution requires a relatively low storage memory compared with that required for implicit 
finite element solution, which allows solving problems with a large number of elements as in a concrete slab with embedded dowel bars. Based on the work of Underwood (1992) and Papadrakis (1981), the dynamic relaxation technique has been implemented in LS-DYNA to solve for different body forces, thermal loads, pressure, and nodal forces (Hallquist, 1998).

\subsubsection{Traffic Loading}

The 3DFE model accepts moving loads; however an equivalent FWD load that simulates the motion of a single axle was used in order to reduce the computation time. The contacts of a dual-tire single axle were modeled using two equivalent FWD loading plates. A 25 millisecond time duration and the maximum amplitude $45 \mathrm{KN}$ of the FWD load, shown in Figure 3.4, is applied to each plate to simulate the pulse caused by a dual-tire single axle that travels at 112 $\mathrm{km} / \mathrm{h}(C R O W, 1998)$.

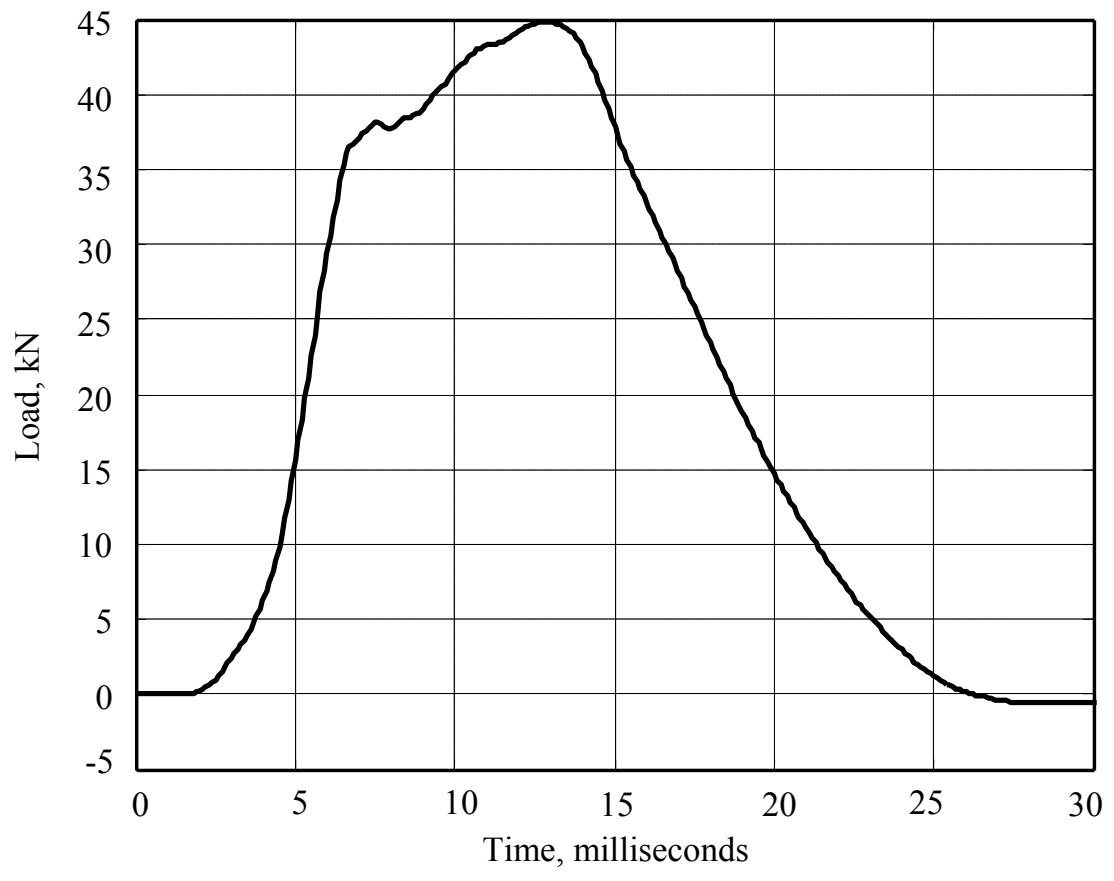

Figure 3.4 Time History of the FWD Applied Load. 
Several model runs were made to select the distance of the centers of the loading plates form the joint edge so that the tensile stresses induced at the slab bottom match those obtained from an earlier model loaded using moving tire contacts that roll at a speed of $112 \mathrm{~km} / \mathrm{hr}$ carrying a total load of $80 \mathrm{kN}$ (Shoukry, 2000). The moving load model was shown to produce top and bottom slab strains that closely matched those measured on the Ohio instrumented test road by Sargand and Breegle (1998). When the edges of the FWD loading plates were $0.075 \mathrm{~m}$ away from the joint edge, both the moving load model and the FWD model produced the match shown in Figure 3.5.

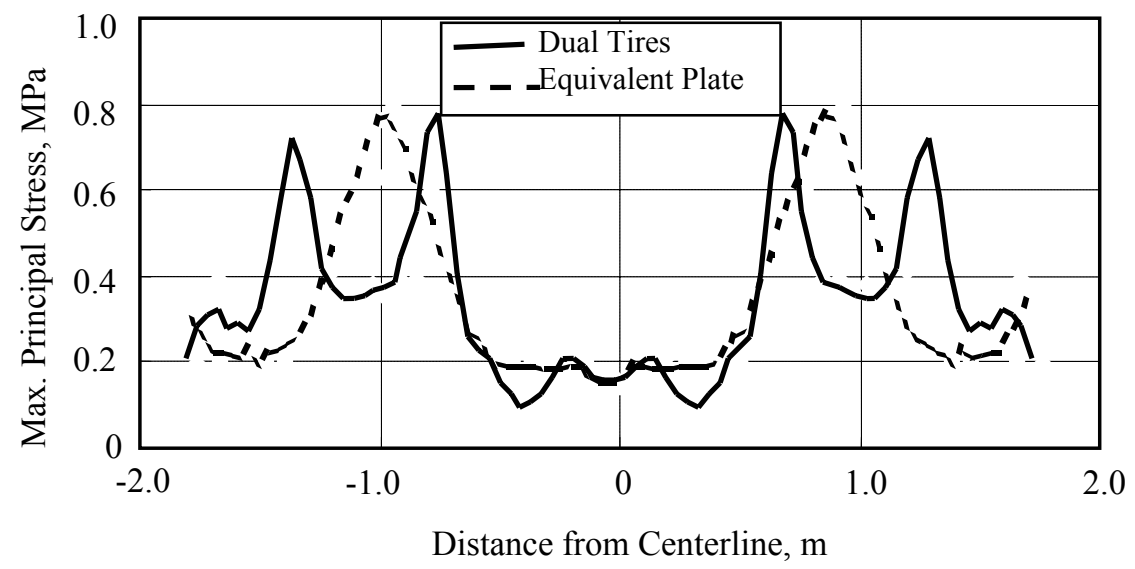

Figure 3.5 Maximum Principal Stress at Slab Bottom along Joint Edge.

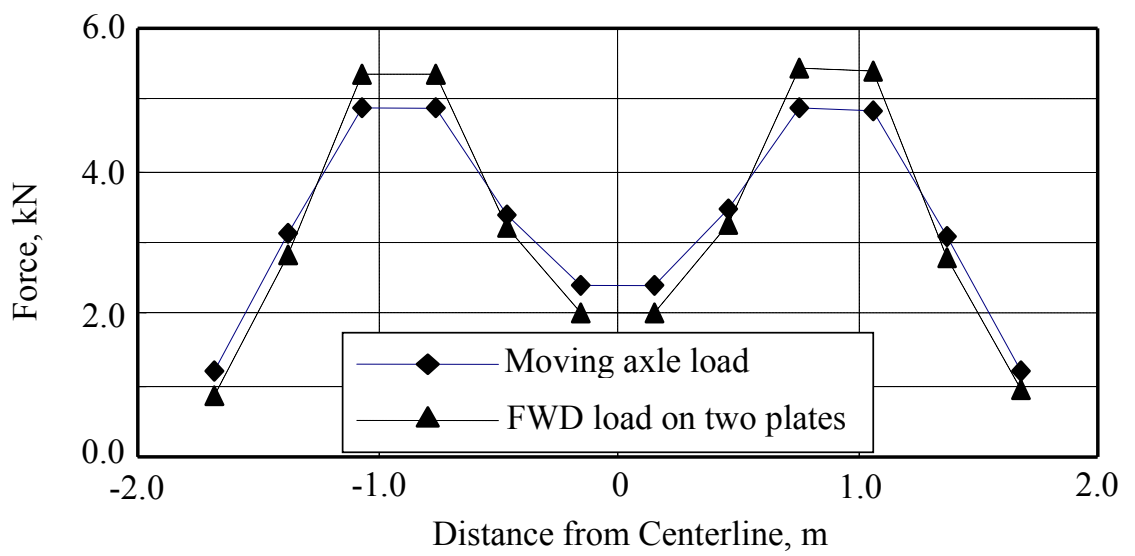

Figure 3.6 Shearing Force Distribution among Dowel Bars.

The difference in the stress profiles from the two models is caused by the difference in the geometry of contacts in each case (two FWD loading plates versus four tire contact patches). 
The loads transmitted by the dowels of each model are compared in Figure 3.6. Remembering that the FWD loading magnitude of $90 \mathrm{KN}$ is 12.5 percent larger than that used in the moving load model $(80 \mathrm{KN})$, the loads transmitted by the wheel-path dowels (dowels number 3, 4, 9, and 10) of the FWD model are 12 percent larger than those of the moving load model. The load transmitted by each dowel is computed from the shear stress that develops at its mid length cross-section. Using Cauchy's stress equation, the shear traction $\tau$ in an element is found from the stress tensor $\boldsymbol{\sigma}$ using the relation:

$$
\tau_{i}=\sigma_{i j} n_{j}
$$

where $\mathbf{n}$ is a unit vector normal to the plane of the mid-section of the dowel. The dowel shearing force is obtained by summing the product of the vertical shear component and the element area for all the elements that form the mid length cross-section of each dowel.

\subsection{Model Results}

Figure 3.7 illustrates by fringes the distribution of the longitudinal stresses on top of the concrete slab due to a negative temperature gradient of $-0.02^{\circ} \mathrm{C} / \mathrm{mm}$. Noticeable is the similarity between tensile and compression stresses developed at the slab top and bottom respectively due to a linear temperature gradient only, and without any change in its mean temperature as shown in Figure 3.7 (a). The most important observation in Figures 3.7 ( $a, b$ and $c$ ) is the increase of the magnitude of the longitudinal stress on the slab top as the uniform temperature drops accompanying the temperature gradient increases. Those tensile stresses can be responsible for the development of mid-slab transverse cracks. Development of such stresses indicates the presence of external restraints on the slab that resist its contraction as its mean temperature decreases. 


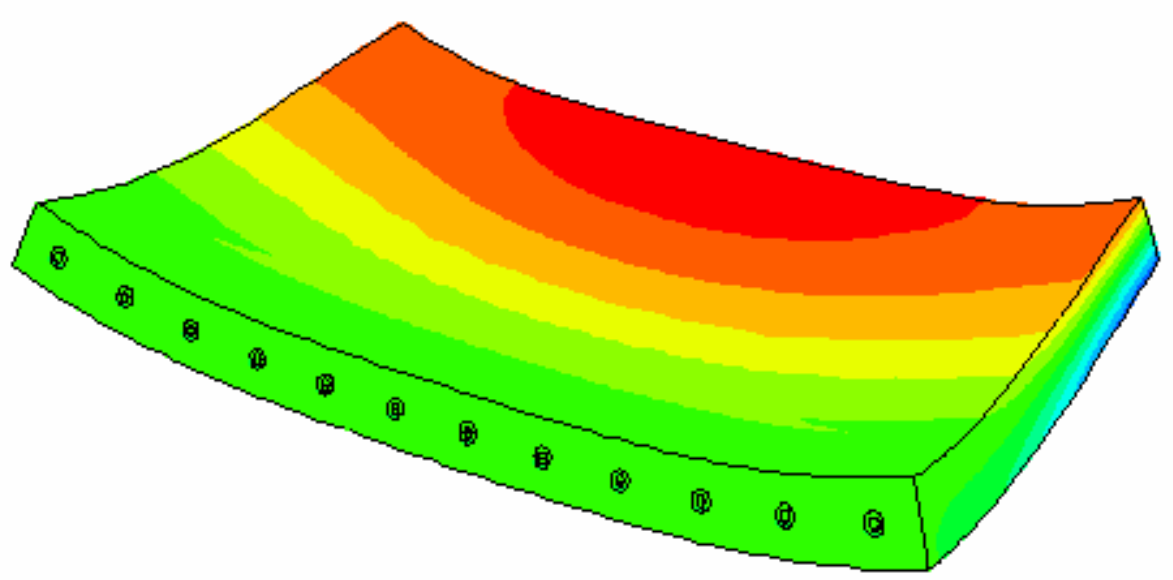

a. Change in mean slab temperature $=0{ }^{\circ} \mathrm{C}$.

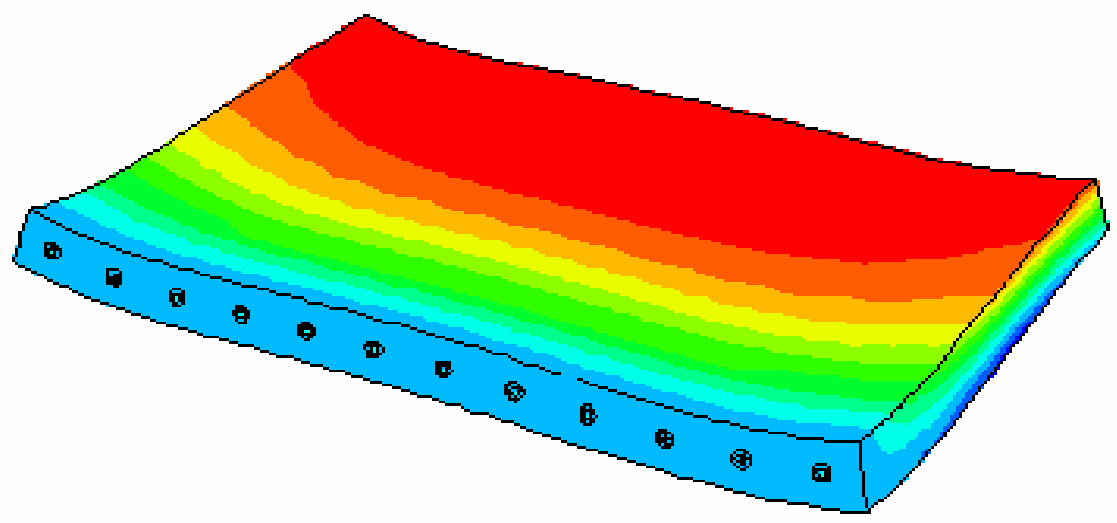

b. Change in mean slab temperature $=-16.7^{\circ} \mathrm{C}$.

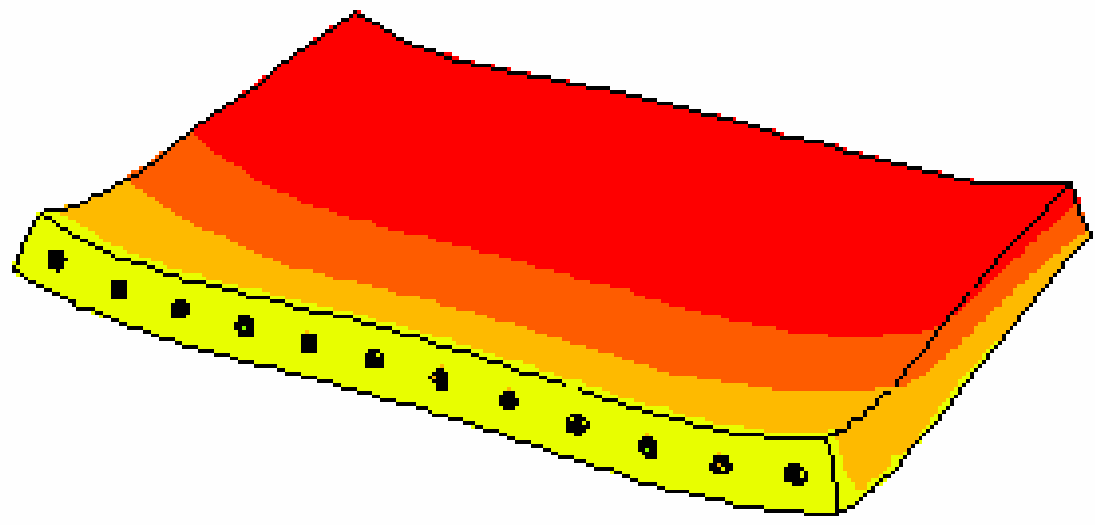

c. Change in mean slab temperature $=-33.3{ }^{\circ} \mathrm{C}$.
Fringe level, $\mathrm{MPa}$

$-0.8074$

$-0.5408$

$-0.2739$

$-0.0694$

0.2600

0.5269

0.7936

Fringe level, $\mathrm{MPa}$

$-0.2985$

$-0.0420$

0.2144

0.4708

0.7274

0.9839

1.2404

Fringe level, $\mathrm{MPa}$

$-4.3706$

$-2.8875$

$-1.8988$

$-0.9101$

$-0.4156$

0.5732

1.5617

Figure 3.7 Fringes of Longitudinal Stresses Due to Temperature Gradient $-0.02{ }^{\circ} \mathrm{C} / \mathrm{mm}$. 

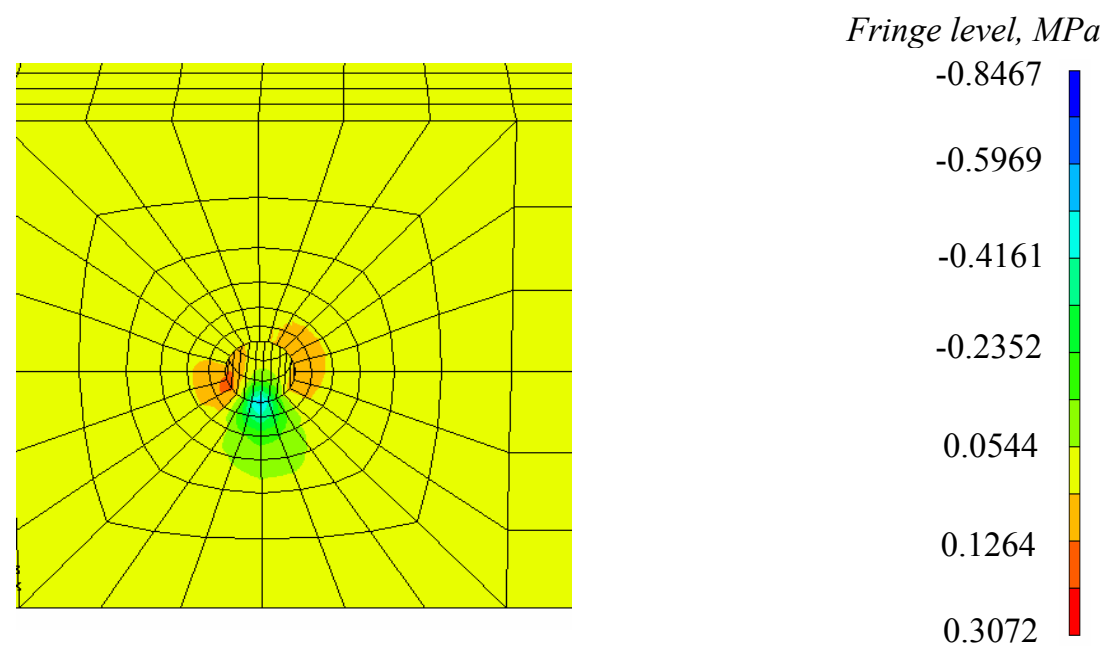
$-0.8467$
$-0.5969$
$-0.4161$
$-0.2352$
0.0544
0.1264
0.3072

a. Change in mean slab temperature $=0{ }^{\circ} \mathrm{C}$.

Fringe level, $\mathrm{MPa}$

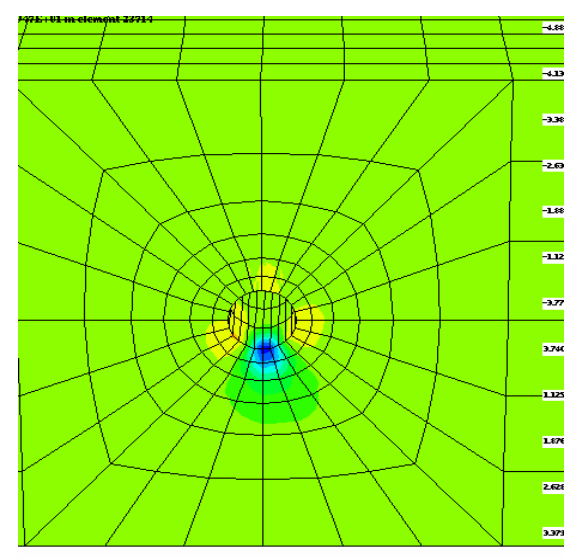

-0.3886
-0.2850
-0.1814
-0.0778
0.0258
0.1293
0.2330

b. Change in mean slab temperature $=-16.67^{\circ} \mathrm{C}$.

Fringe level, $\mathrm{MPa}$

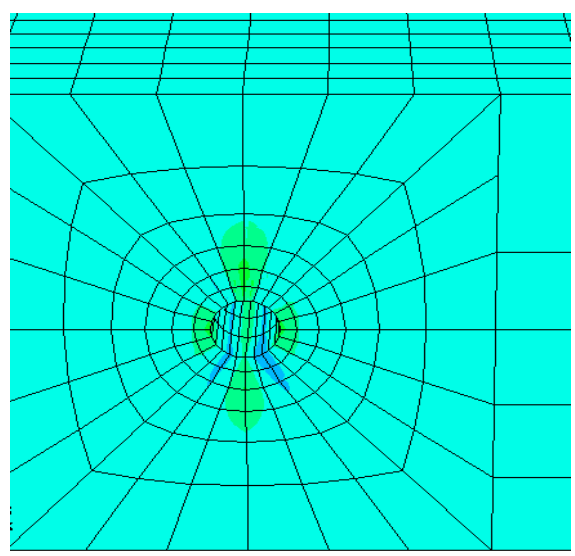

-1.3431
-0.5906
0.1620
0.9142
1.6672
2.4194
3.1723

c. Change in mean slab temperature $=-33.33{ }^{\circ} \mathrm{C}$.

Figure 3.8 Fringes of Vertical Stresses around Dowel Hole due to Temperature Gradient $-0.02{ }^{\circ} \mathrm{C} / \mathrm{mm}$. 
One of the capabilities of the Graphical User Interface of the finite element is the visual inspection of the deflection and stresses that develop in the pavement structure at any instance of time from the start of load application. The distribution of the stresses that developed at any part of the model can be displayed. This capability allowed examining the state of contact stress that develops around the dowel bar hole due to thermal gradient. Figure 3.8 illustrates using fringes the distribution of vertical stresses around the dowel bar hole due to a linear temperature gradient of $-0.02{ }^{\circ} \mathrm{C} / \mathrm{mm}$. In addition to the formation of a compressive stress zone at the point of contact between the dowel bar and the concrete at the bottom of the hole, two zones of tensile stresses developed on both sides of the hole. It is worth mentioning here that such stresses could not be predicted by previous models in which the contact between the concrete and dowel was simulated using one dimensional springs that predicted only the compressive stresses along the line of contact between the dowel and concrete hole.

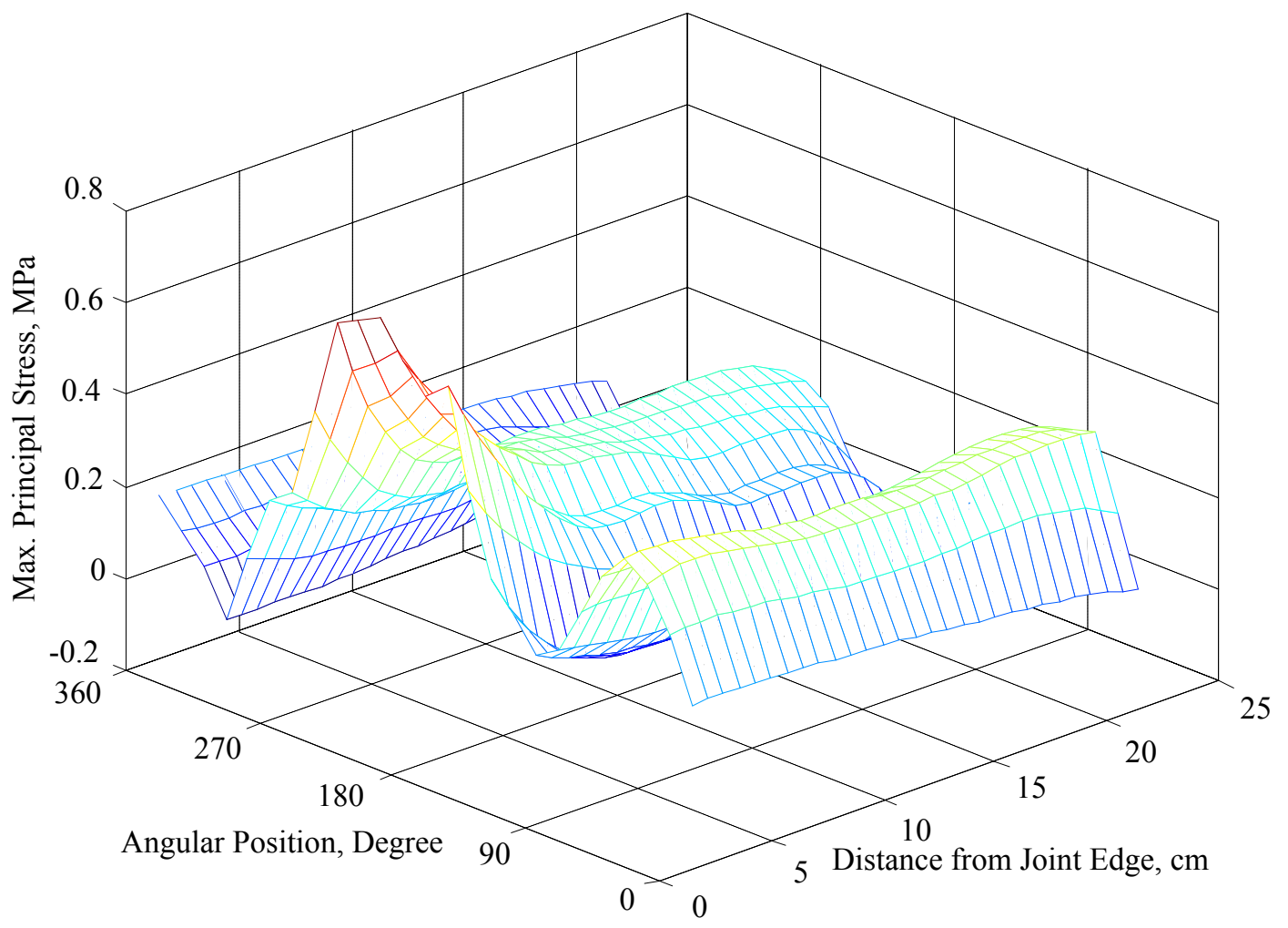

Figure 3.9 Distribution of Maximum Principal Stress around Dowel Bar Hole. 
The distribution of the maximum principal stresses that develop in the concrete surface layer in the direct contact with the dowel bar due to a positive temperature gradient of $+10{ }^{\circ} \mathrm{C}$ is shown in Figure 3.9. The maximum value of tensile stress occurs at the joint surface at an angular position of $180^{\circ}$ (at the top of the dowel socket). The value of such a stress is expected to increase when traffic loads pass over the curled pavement surface, which may lead to premature joint distress (Shoukry et al., 2002). Such tensile stresses are not accounted for in the current design procedures of concrete pavements.

\subsection{Conclusions}

A detailed 3DFE model for dowel jointed concrete pavements has been developed to study the concrete slab response to temperature variations. The detailed modeling of the round dowel bars using 8-node solid brick elements and their interfaces with the surrounding concrete enabled examining the triaxial state of concrete contact stresses that develop at dowel concrete interface. The model results also indicated that the presence of dowel bars at the transverse joints constrains the slab movement due to contraction, which gives rise to high tensile stress at midslab that may lead to mid-slab cracking. 


\section{CHAPTER FOUR}

\section{EXPERIMENTAL VALIDATION OF 3DFE MODEL RESPONSE TO TEMPERATURE VARIATIONS}

\subsection{Introduction}

The most appropriate method for validating the response of 3D Finite Element (3DFE) models of dowel jointed concrete pavements to temperature variations is to compare its theoretical response with an experimentally measured one. The success of such a comparison is only possible when a reliable set of experimental measurements could be obtained. However, the strain measured in concrete slabs due to environmental conditions is not only due to temperature variations, but also due to other nonlinear factors such as construction curling, shrinkage, and moisture. Such nonlinear contributors cannot be accounted for in 3DFE models, therefore the raw measured strains cannot be used to validate the 3 DFE model response. In this study, a new technique is developed to reduce the impact of such strain contributors so that the measured strains could be suitable for comparison with the 3DFE-calculated ones.

\subsection{Pavement Test Section}

The test section was constructed in September 2001 along the east bound of Robert C. Byrd's Highway (Route 33) near Elkins, West Virginia, USA. The $135 \mathrm{~m}$ long section consists of 30 consecutive dowel jointed concrete slabs each is $0.28 \mathrm{~m}$ (11 in.) thick, $4.5 \mathrm{~m}$ (15 ft) long, and 3.6 $\mathrm{m}$ (12 ft) wide. The slabs are placed on top of a $0.10 \mathrm{~m}$ (4 in.) asphalt-stabilized free-drainage base constructed over $0.15 \mathrm{~m}$ (6 in.) compacted gravel. Six slabs out of the thirty were fitted with systems of sensors designed for continuous monitoring of slab response to temperature variations as shown in Figure 4.1. The instrumentation plan was set in order to collect data for several key performance parameters that evaluate the behavior of pavement slabs due to diurnal, seasonal, and structural inputs. For this purpose, strains in various locations along slab 


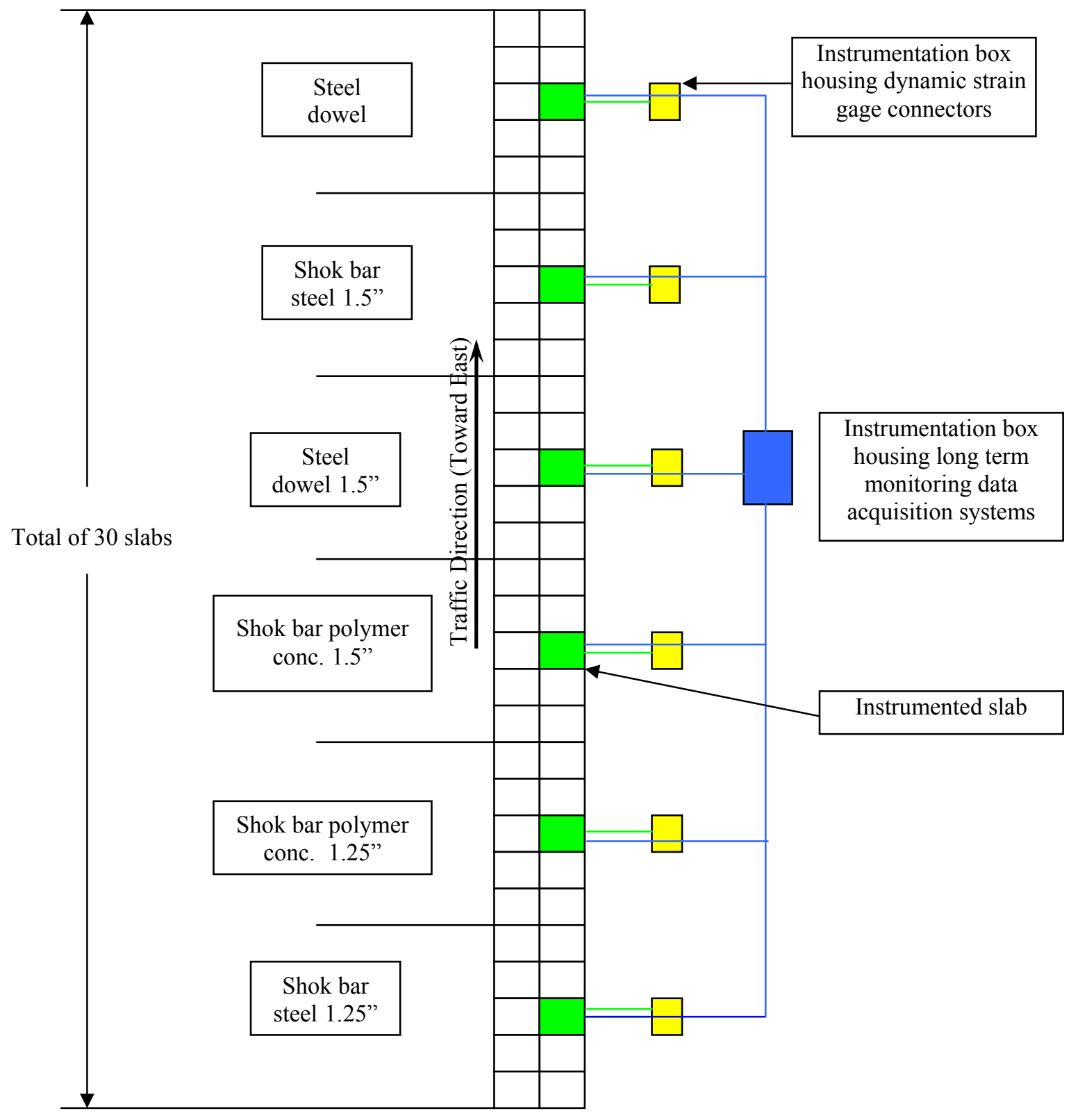

Figure 4.1 Layout of West Virginia Instrumented Pavement Site.

centerlines, joint openings, temperature profiles, dowel bar moments and axial forces were recorded at specific intervals starting at the time of placing concrete. The instrumentation plan was aimed to focus sensors in selected slabs so as to capture the full behavior of slabs in a mechanistic fashion rather than collecting redundancy in data. The selection of the sensors was 
based on their functional characteristics, size, sensitivity, accuracy, and past experience with successful performance. Figure 4.2 illustrates the arrangement of the sensors installed in a typical instrumented slab prior to concrete placement.

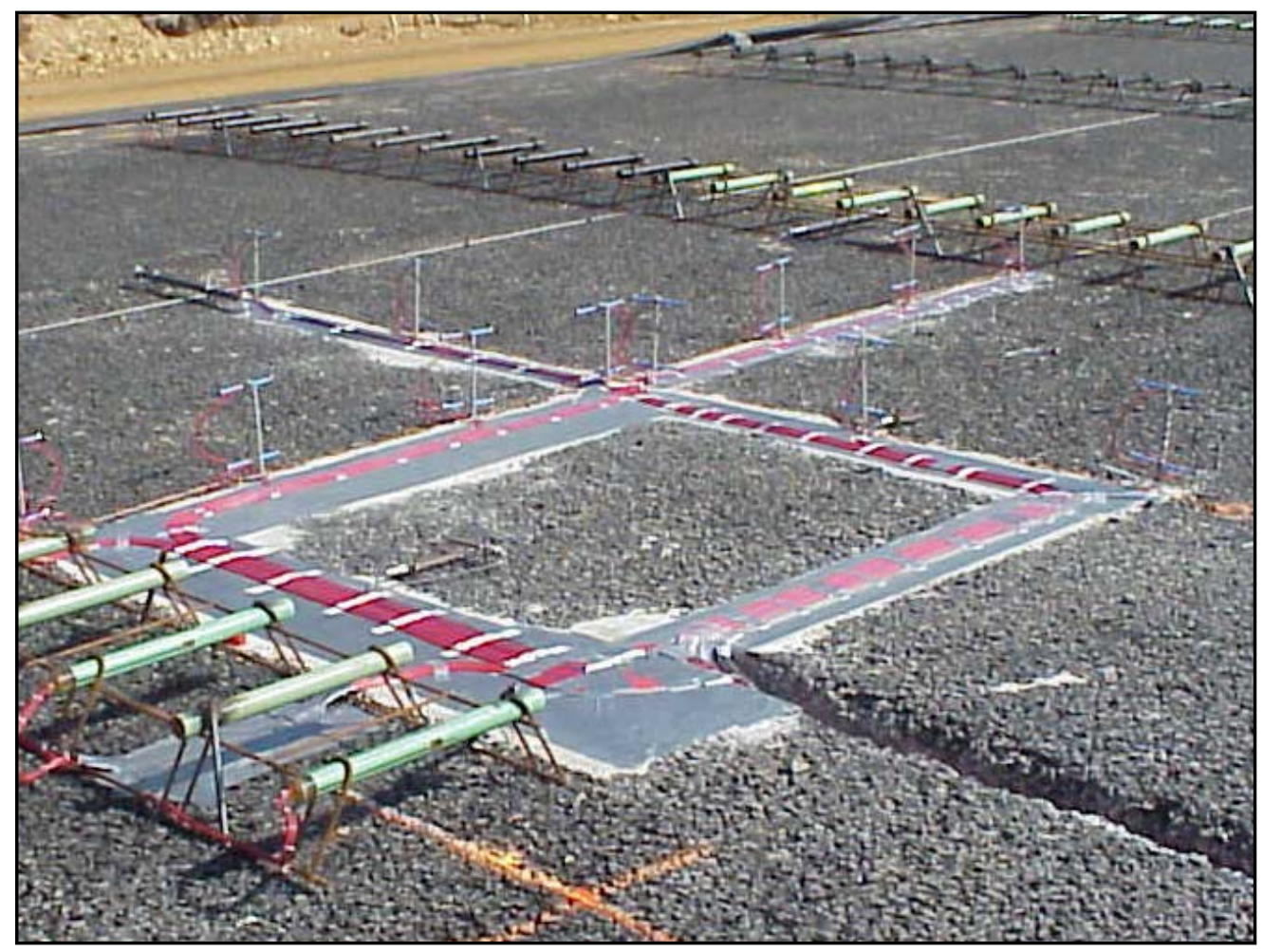

Figure 4.2 Typical Slab Instrumentation Prior to Concrete Placement.

\subsection{Coordinate System}

Due to the large number of sensors buried in each concrete slab, it was necessary to establish a coordinate system to keep track of sensor locations. Therefore, a coordinate system has been established for each instrumented slab. The origin point of each coordinate system was selected to be at the northern-west corner of the slab; therefore the $\mathrm{X}$ axis of the instrumented slab coincides on the centerline of the longitudinal joint. Figure 4.3 illustrates the coordinate system 
of a typical instruments slab together with the sensor arrangement as measured on the site prior to concrete casting.

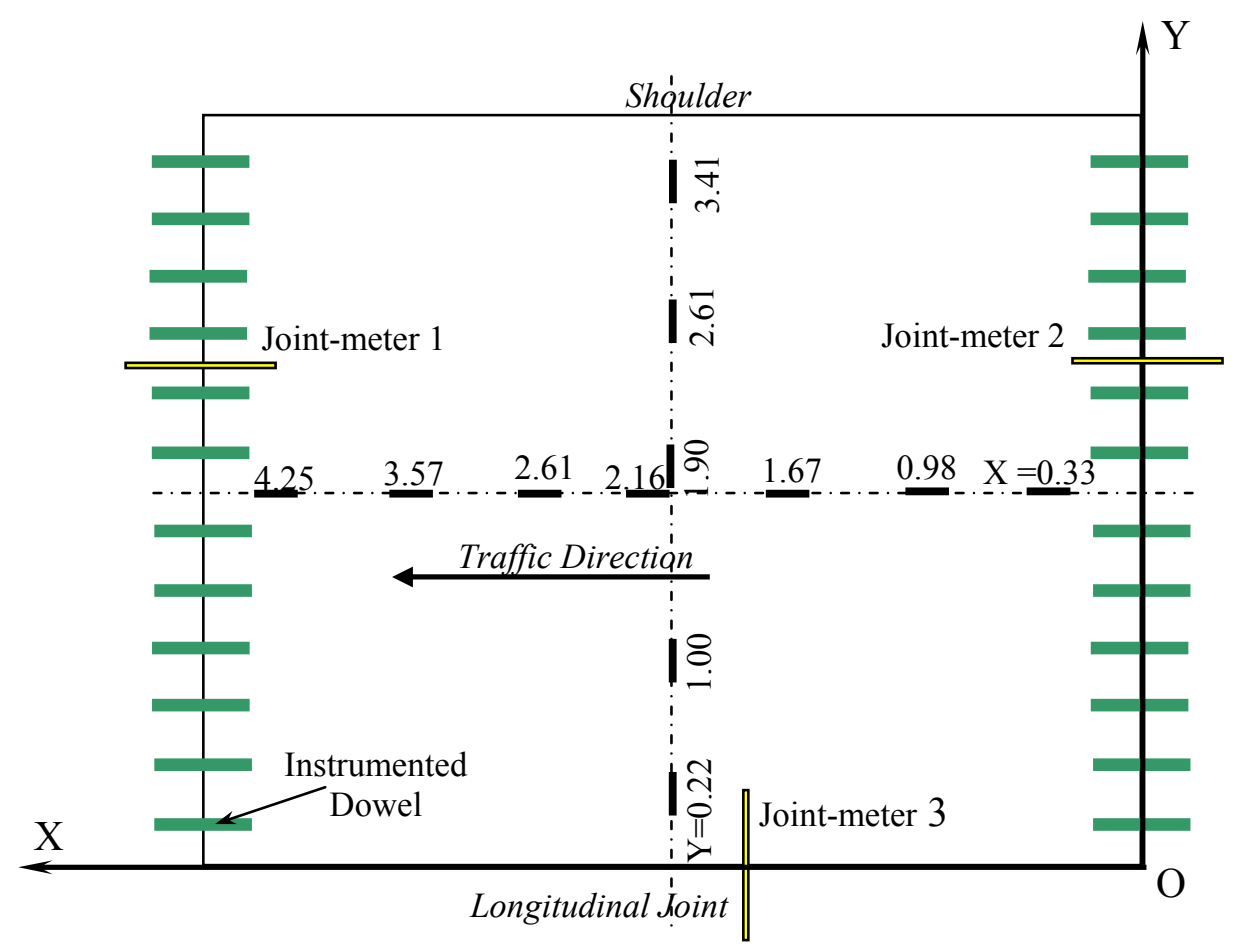

Figure 4.3 Sensors in a Typical Instrumented Slab on Corridor H.

\subsection{Instrumentation}

Figure 4.3 illustrates the layout of various sensors installed in a typical instrumented slab. All seasonal and long-term response sensors are manufactured by Geokon, and are fitted with thermistors that provide the actual temperature at the specific location of the sensor. A temperature correction can therefore be automatically applied to the output strain yielding values that are due to the variation in expansion and contraction of the concrete material. Built up strains due to drying shrinkage of concrete, temperature and moisture variations during and after setting are measured using VCE-4200 vibrating wire embedment strain gages. The embedment strain gages were placed $28 \mathrm{~mm}$ from the slab top and $28 \mathrm{~mm}$ from slab bottom along the slab centerlines at locations indicated in Figure 4.3. The temperature gradient profile is recorded via 
10 thermistor, model YSI 44005, placed at $25.4 \mathrm{~mm}$ intervals through the slab thickness. Crackmeters, model 4430, are installed at transverse and longitudinal joints, as shown in Figure 4.3, to monitor the crack opening at such locations. Special care was addressed to the size and fixtures of sensors in order to limit to any alteration in the physical properties of the pavement section as much as possible, and to resist the inevitable disturbance by the concrete wave due to construction practices. For this purpose sensors were attached to a fixation rod $6 \mathrm{~mm}$ thick that was held in place through the base thickness using a low shrinking cement compound.

Dowel bars were instrumented to monitor the long-term as well as dynamic structural responses. Strain data were collected on the top and bottom of the dowel bar, and post processed to calculate the bending moments and normal forces. To eliminate any localized effects, all instrumented dowels went through a careful procedure in order to mount, seal, and bond the gauges and restore the original shape of the dowel. For measuring bending strains, two specially designed uniaxial vibrating wire strain gauges were fitted in a notch precisely milled into the top and bottom surface of the dowel bar at its center. All wires coming from the gauges were encased and cold welded in shallow grooves that were cut along the length of the bar leading to its end. After proper installation, all gauges were protected against moisture and abrasion by an epoxy coating material that also restored the curvature of the bar. The lead wires coming from the strain gauges were collected at the end of the bar and totally encased in an epoxy cap where connections to the heavy-duty cables were made. Each instrumented dowel was calibrated in the laboratory to check for the accuracy of collected readings and the calculated straining actions versus theoretical calculations.

All cables of various sensors were collected on the top surface of the base forming one bust that was encased in duct tape insuring no friction with the slab or base material as shown in Figure 4.3. The cables were then collected under the shoulder area in a PVC conduit and conveyed from each instrumented slab through a collector conduit to an environmentally sealed instrumentation box. The instrumentation box was centered along the test section and contained the long term monitoring data acquisition equipment. Sensors were connected to six multiplexers that are controlled by the CR10 data logger which stored the data into the logger 


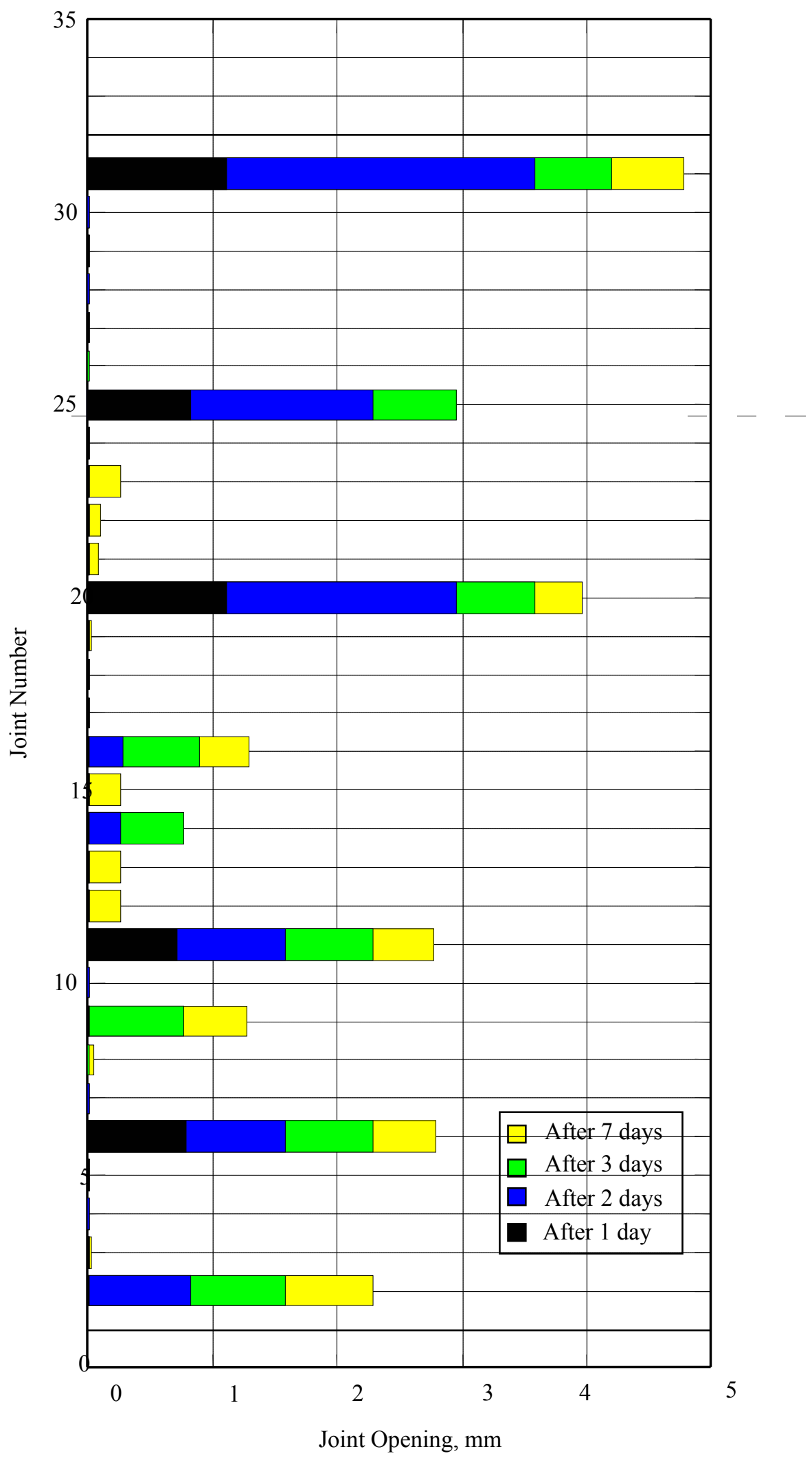

Figure 4.4 Transverse Joint Opening Along Instrumented Pavement Section. 
memory. The data logger is powered by a solar panel which charges a marine battery along with a second battery standing by. Data acquisition started a few minutes before concrete casting and continues to date at a rate of one reading every 20 minutes. Data could be retrieved from any location through a cellular phone module equipped with the data logger and connected to an antenna. The instrumentation plan and installation procedures in the site aimed at having one splice-free cable for each sensor, which was rewarded by collecting noise free signals. It is worth mentioning here that the tested road was opened to traffic in July 2002.

\subsection{Joint Opening}

Transverse joints were formed by saw-cutting a shallow groove approximately $50 \mathrm{~mm}$ in depth five hours after concrete placement. As the concrete slab starts shrinking, cracks initiate from the tip of such opened groove and propagate downward. Visual inspection of the opened cracks during the seven days following concrete placement indicated that the crack width at transverse joints is not constant along the pavement section as illustrated in Figure 4.4. This indicates that the amount of edge constraint differs from transverse joint to another along the road. Therefore, the concrete slab does not contract or expand symmetrically around its center as assumed in all proposed theoretical models including 3DFE analyses. Figure 4.4 also indicates that the amount of joint opening at each transverse joint increases with time during the first week of pavement life.

To have a better insight into the change of the amount of joint opening with time, the timehistory of the joint opening recorded by the crack-meter installed at transverse joint No. 13 is shown in Figure 4.5 (b) together with the corresponding mean slab temperature shown in Figure 4.5 (a). It can be noticed that after an initial increase in the amount of joint opening during the first week to about $0.20 \mathrm{~mm}$, it starts increasing as the temperature decreases during winter until it reaches a maximum value of about $0.6 \mathrm{~mm}$ after 180 days, it then decreases during summer to fluctuate around $0.2 \mathrm{~mm}$ (the initial opening) after 300 days. Such a change in the amount of joint opening with time indicates a change in the amount of constrains along the slab edges due to the presence of dowel bars. This change should be accounted for in the 3DFE simulations in order to have the theoretical response comparable with the experimentally measured one. 


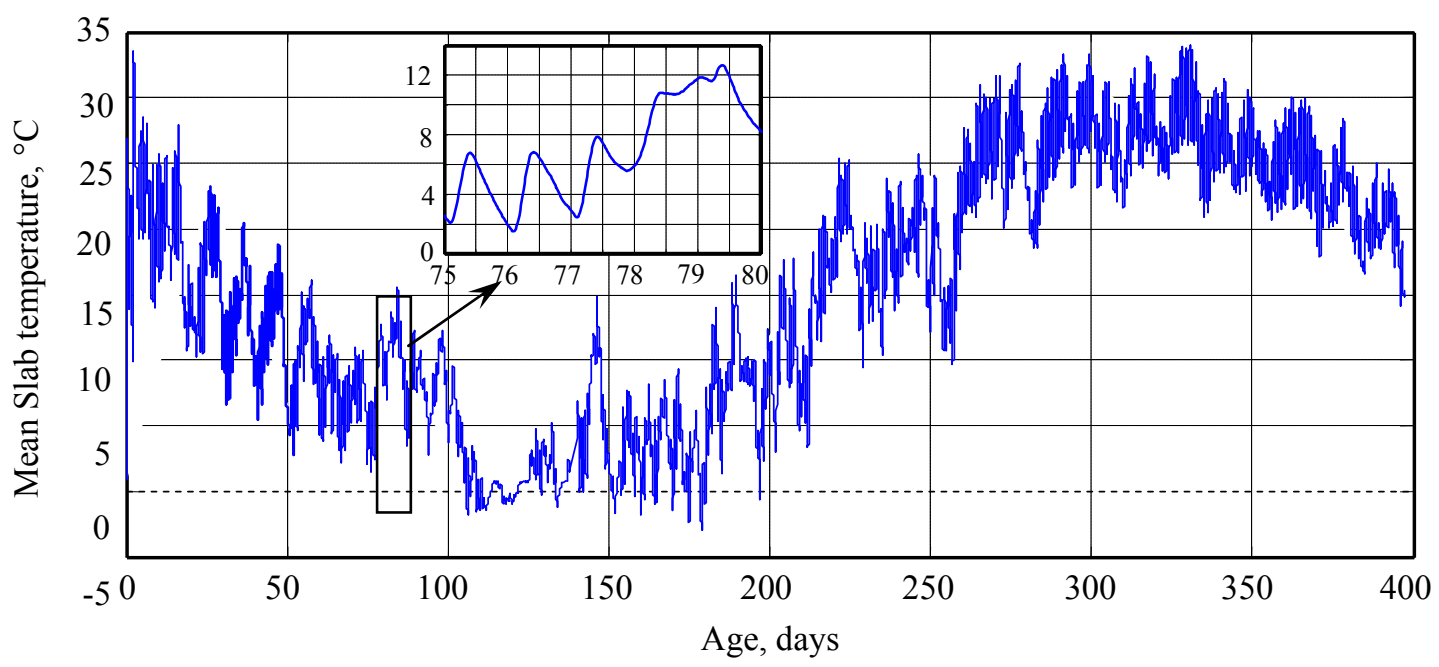

a. Mean Slab Temperature.

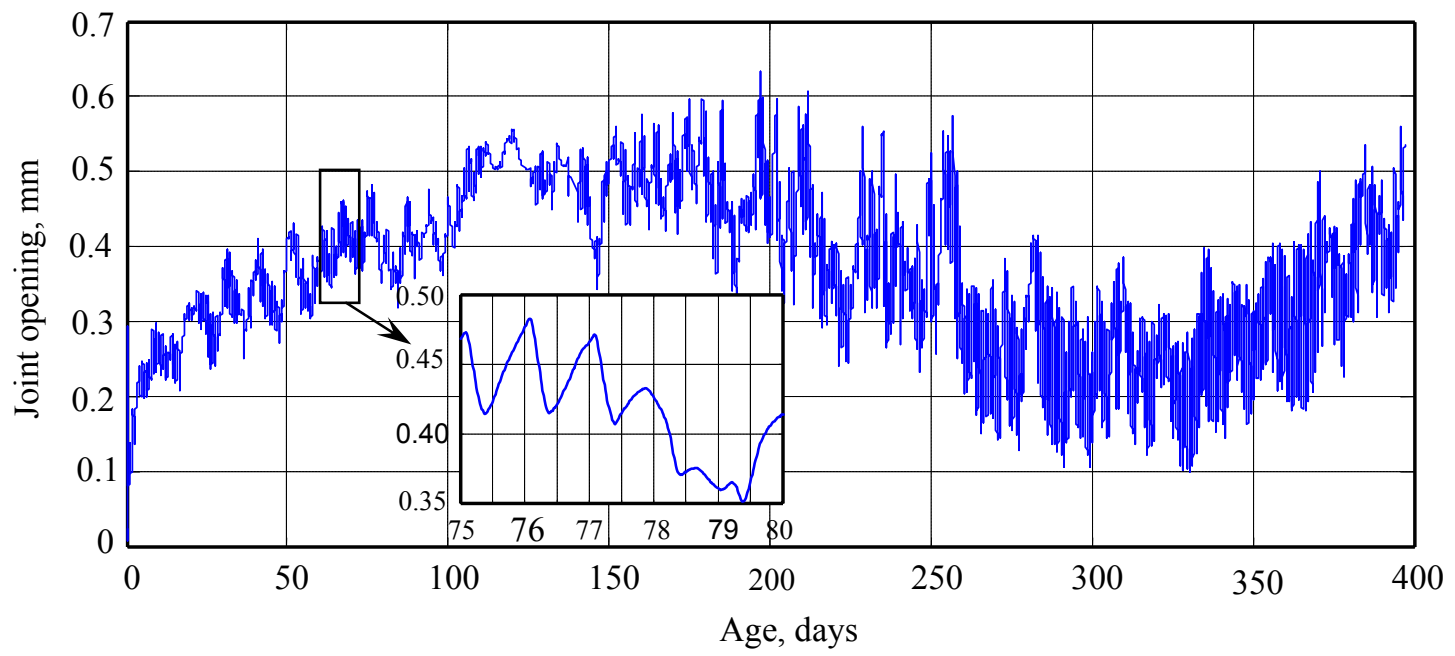

b. Joint Opening.

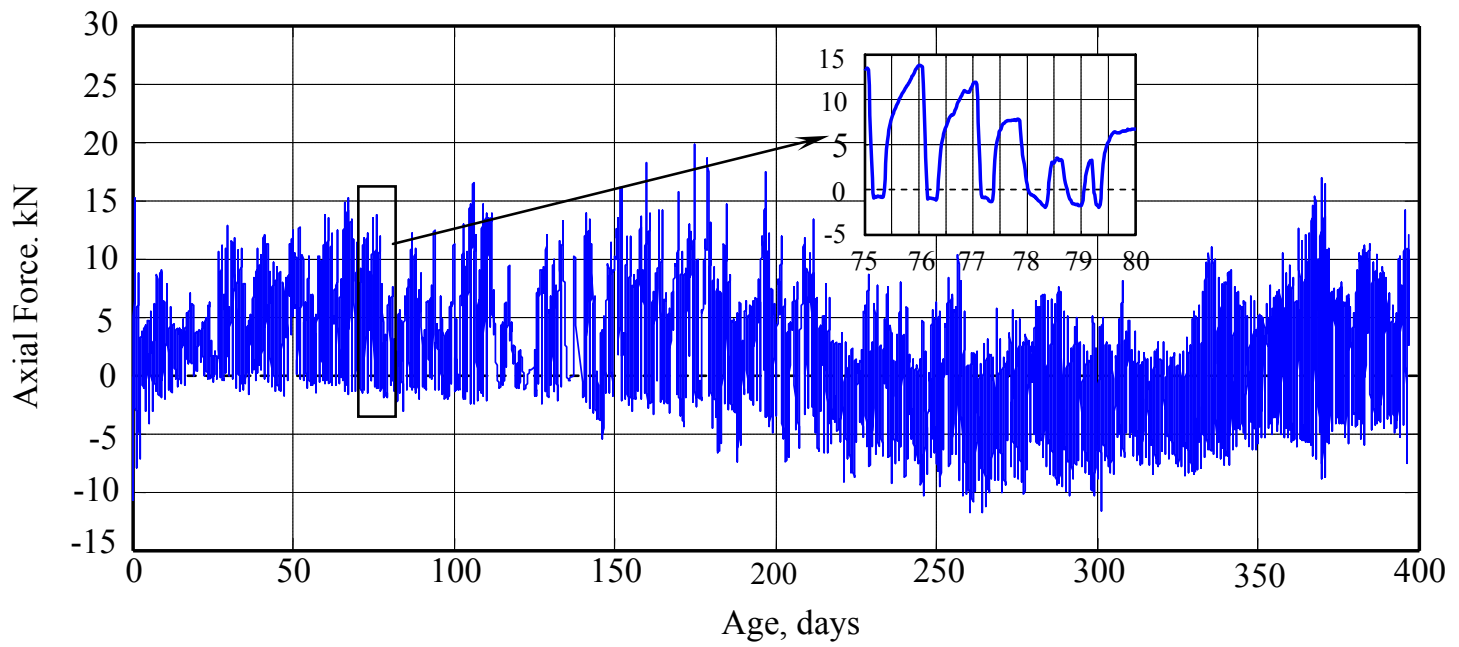

c. Dowel Axial Force.

Figure 4.5 Recorded Mean Slab Temperature, Joint Opening, and Dowel Axial Force. 
If the slab edges are free to move as the temperature changes, the amount of joint opening due to a change in temperature of $\Delta \mathrm{T}$ is given by:

$$
\text { Joint opening }=\alpha \Delta T L
$$

where $\mathrm{L}$ is the joint spacing (AASHTO, 1998). However, due to the dowel bar constraints at the transverse joint, the amount of recoded joint opening is less than such theoretical value. As a result, axial forces develop in dowel bars. The magnitudes of such forces depend on the amount

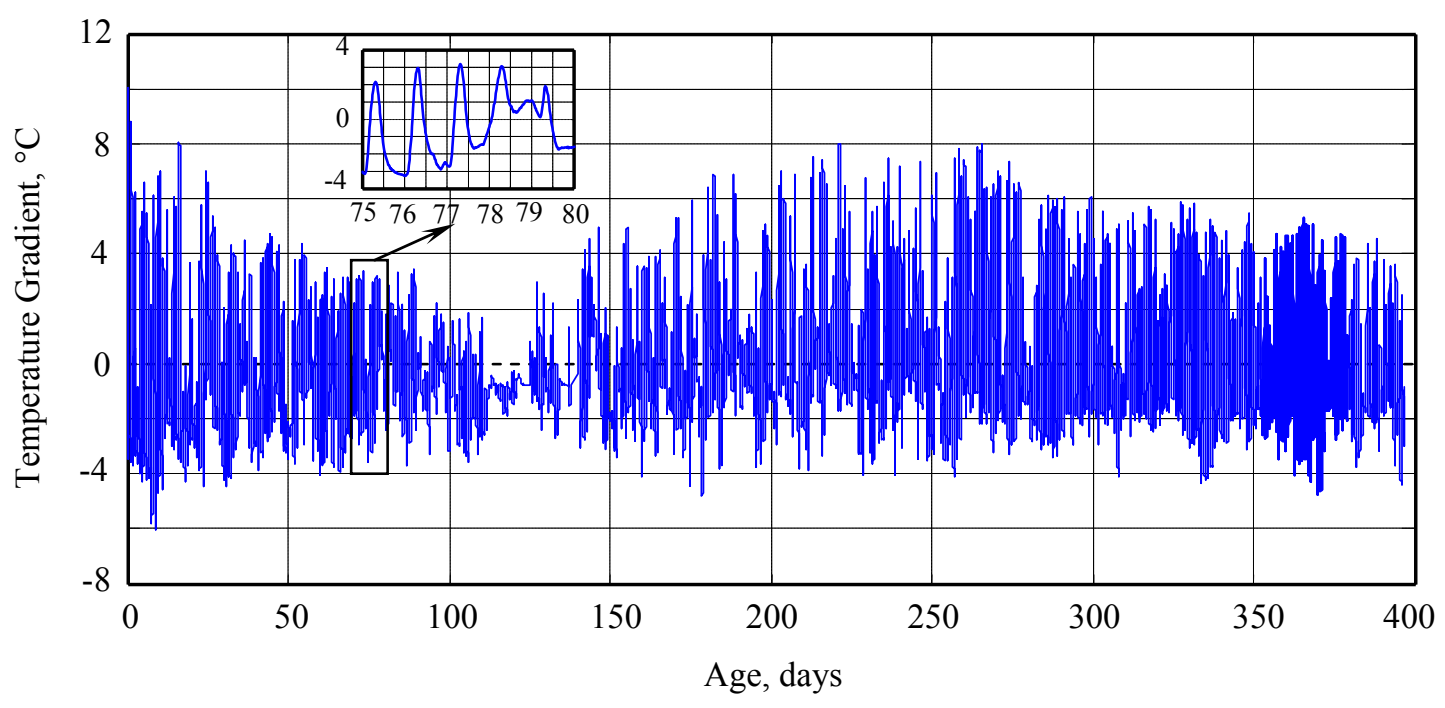

a. Temperature Gradient.

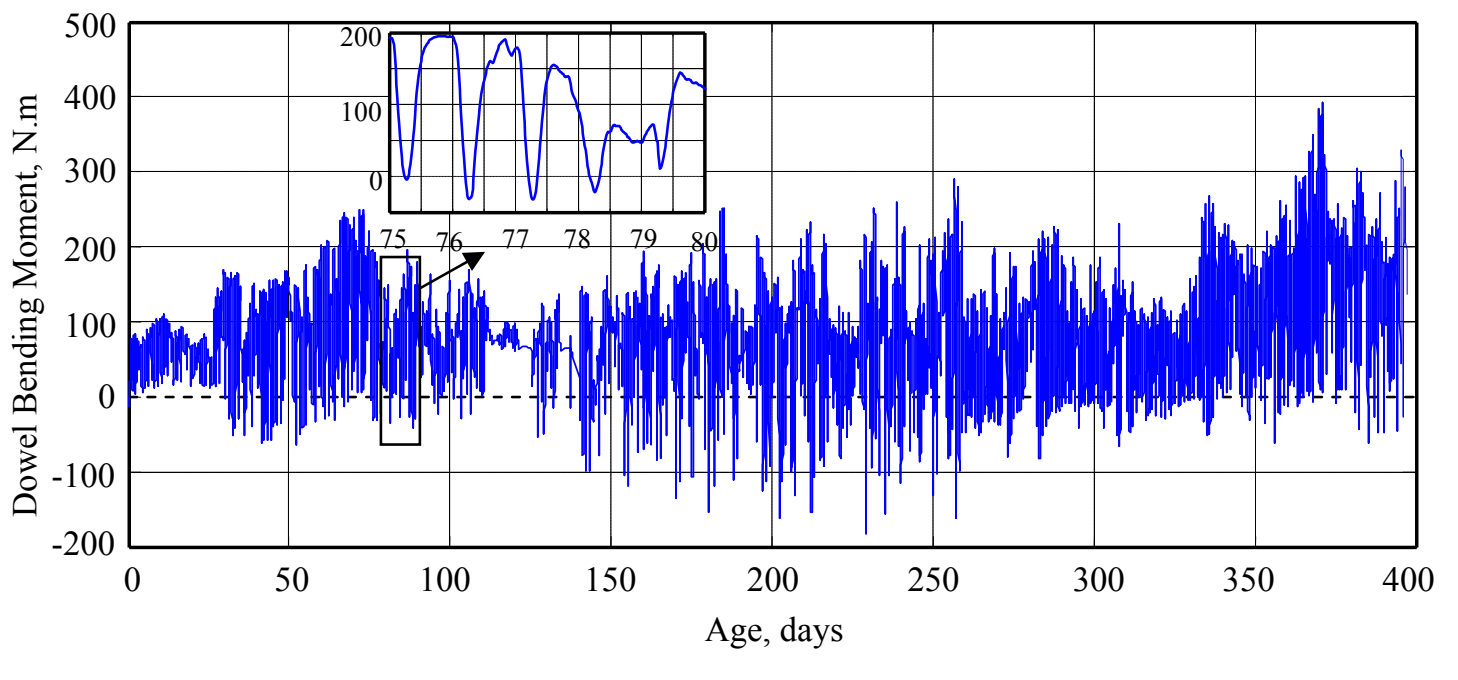

b. Dowel Bending Moment.

Figure 4.6. Recoded Temperature Differential and Dowel Bending Moment. 
of change in mean slab temperature as well as transverse joint opening. Figure 4.5 (c) illustrates the history of the axial force recorded in the corner dowel bar at transverse joint No. 13. It can be noticed that both the measured joint opening and dowel axial force have the same phase. Development of such axial forces in the dowel bars could be explained in terms of:

- Adhesion between the dowel bar surface and the surrounding concrete if the surfaces of dowels are not lubricated adequately prior to concrete casting.

- The hooking effect of the bent dowel due to slab curling as a result of temperature differential between the slab top and bottom.

The constraining effect of the dowel bars at the transverse joint opening is evident from observing the change in recorded dowel bending moment due to the change in the temperature gradient. Figure 4.6 (a) illustrates the time history of the measured difference in slab top and bottom temperatures. Over the monitoring period of 400 days (from September 2001 to November 2002), the difference between slab top and bottom temperatures varied between $-8^{\circ} \mathrm{C}$ to $+11^{\circ} \mathrm{C}$. The time history of dowel bending moments developed in the corner dowel nearest to the shoulder during the same period of pavement life is illustrated in Figure 4.6 (b). A signal blow-up, shown in Figure 4.6 (b), illustrates that the measured dowel bending moment is noise free and that all the up and down oscillations are due to daily changes in the temperature gradient of Figure 4.6 (a).

\subsection{Measured Slab Strains}

Figure 4.7 illustrates the historical built-up of the longitudinal strains measured at two positions along the longitudinal slab centerline: at a distance of $0.33 \mathrm{~m}$ from transverse joints (Figure 4.7 (b)) and at the slab center (Figure 4.7 (c)). Figure 4.7 (a) illustrates the slab temperature history measured at different depths from the surface. At any instance of time, the magnitude of the measured strain near the transverse joint, Figure 4.7 (b) differs from that measured at the slab center, Figure 4.7 (c). Such a difference indicates non-uniform slab distortion along the longitudinal slab centerline. Slab distortion is also evident from Figure 4.6 (c) that illustrates the measured bending moment at the corner dowel nearest to the shoulder. Slab distortion is caused by the effect of non-uniform concrete shrinkage during the curing stage, temperature gradient 
through the slab thickness, and moisture gradient. The amount of distortion resulting from each factor is influenced by the constraining axial forces induced in dowel-concrete sliding, as is evident from Figure 4.5 (c) for the axial force induced in the corner dowel bar. In addition to the aforementioned factors, two construction-method related factors cause slab distortion and were observed in West Virginia Instrumented Road:

1. Transverse joints are formed by saw-cutting a shallow groove 38 to $50 \mathrm{~mm}$ deep. The timing of cutting this groove is critical and is normally done as soon as the surface layer of the slab has solidified enough to support the weight of the operator and his cutting apparatus. This time is approximately 8 to 12 hours after concrete casting, but may be more depending on the contractor's experience. The cutting process relieves the tensile stress at the top 38 to $50 \mathrm{~mm}$ of the slab thickness while the uncut thickness of the slab remains under considerable tensile stress; consequently the slab curls unless the joint cracks fully in a timely manner. Slab curling induced by such a factor becomes permanent as the concrete cures further.

2. The practice of casting the driving and speed lanes together (using one paver) with tie bars inserted between the two lanes causes each two adjacent slabs (after the transverse joints are saw cut) to curl as if they were one slab having double the standard slab width (despite forming the longitudinal joint by saw cutting). This behavior was concluded from measured bending moments in different dowels along a single transverse joint where it was observed that the moment was maximum at the shoulder-side dowel and gradually reduces to its lowest value in the dowel adjacent to the speed lane. This means that the slab curling profile is not symmetrical along its longitudinal centerline.

The result of all the above factors is that the concrete rectangular prism (concrete slab) is significantly distorted. Considering the time dependency of concrete properties during early age (see Figure 4.8), the total magnitude of strain at any point is a nonlinear superposition of the strains produced by all the above factors that are both time and position dependent. A vibrating wire strain gage embedded in concrete, when it was in the plastic state, senses the resultant strain due to all of the above factors. Practically, it is difficult, if not impossible, to isolate the effects of such nonlinear strain contributors: shrinkage, construction curling, and moisture from the 


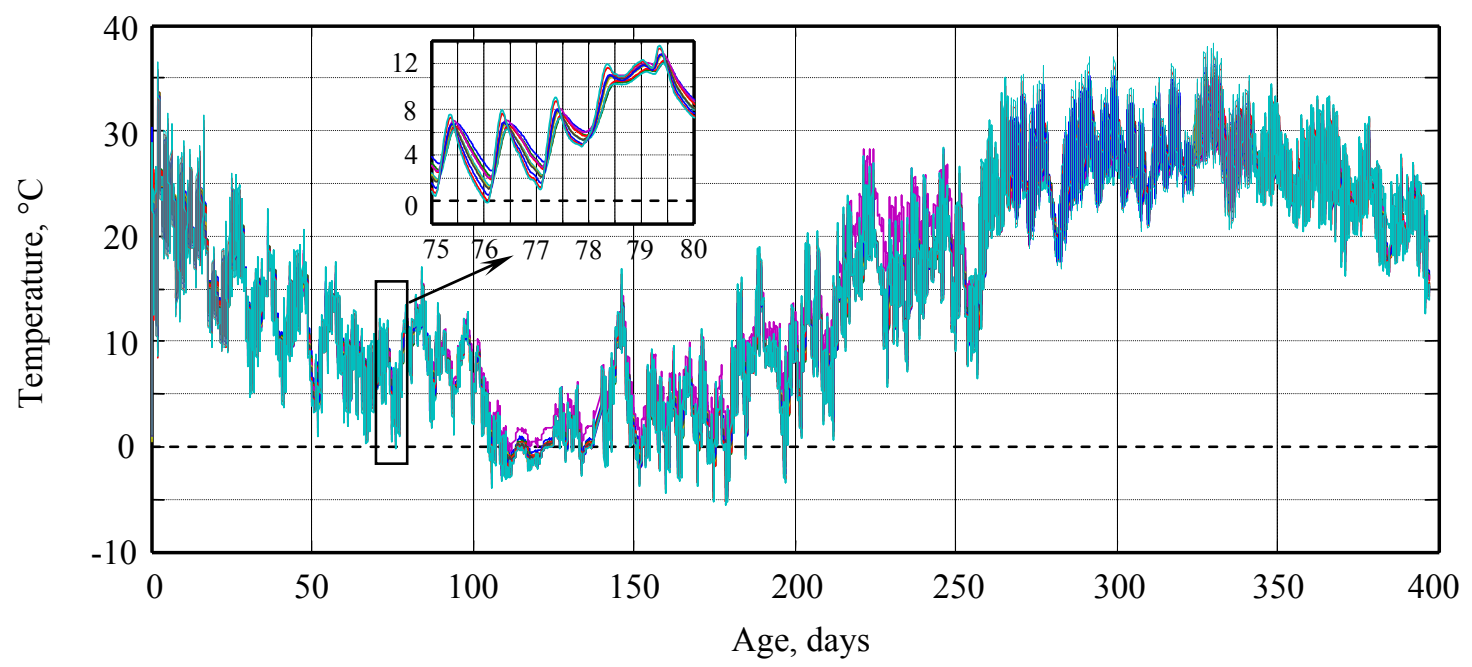

a. Measured Slab Temperature

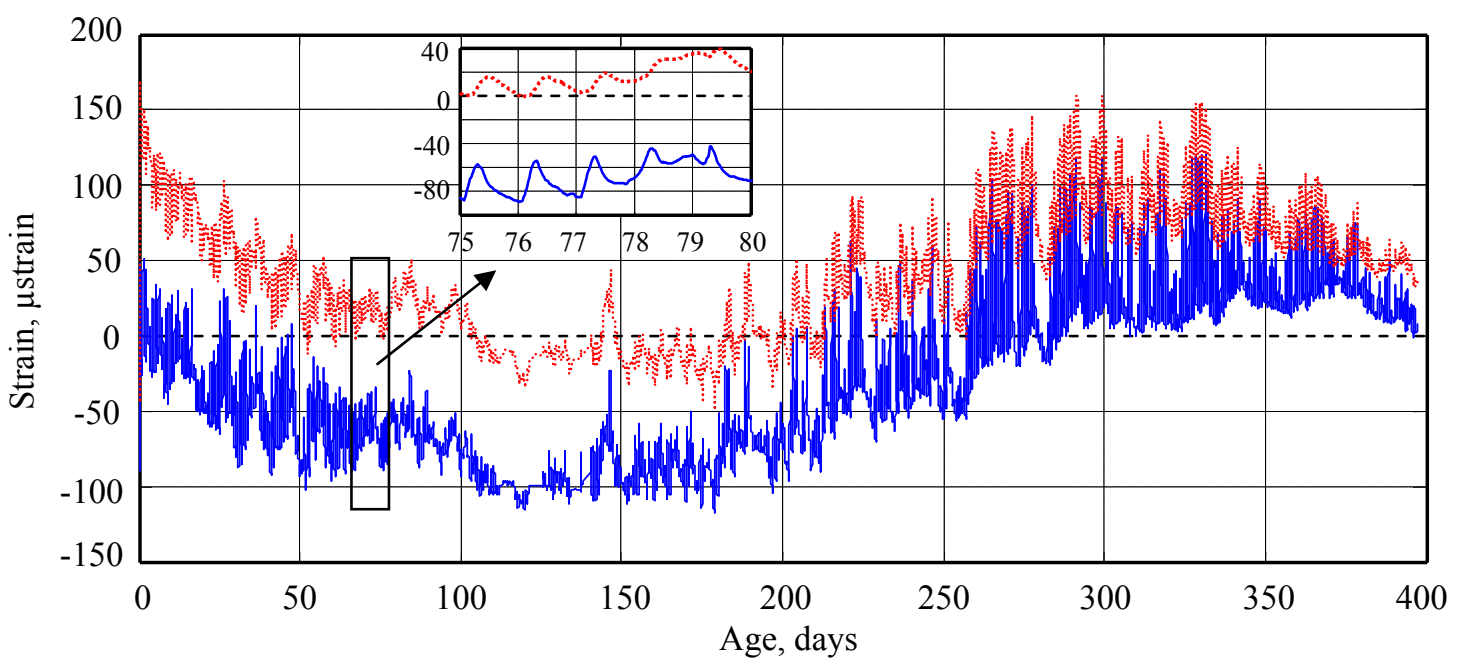

b. Longitudinal Strain at Distance $0.33 \mathrm{~m}$ from Joint.

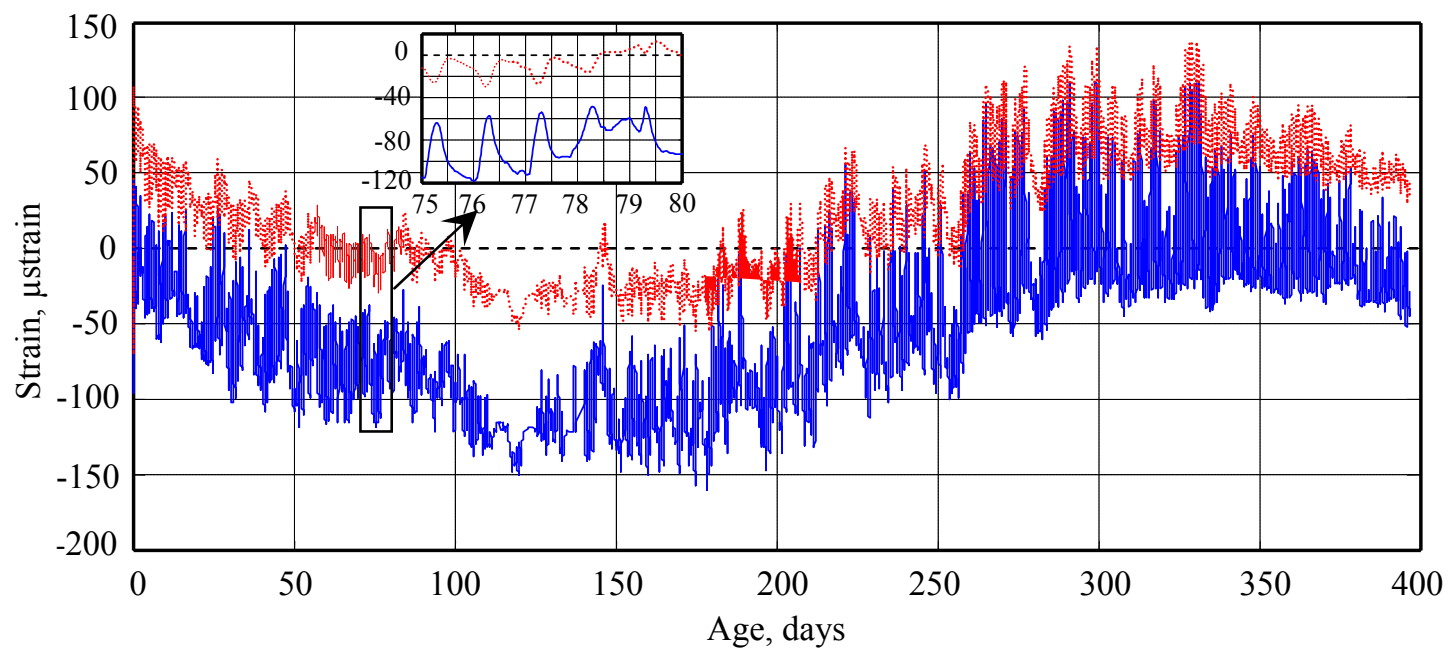

c. Longitudinal Strain at Slab Center.

Figure 4.7 Recorded Temperature Profile and Strain Histories. 
accumulative strain measured at any point within the concrete slab. Since shrinkage, construction curling, and moisture changes are unaccounted for in finite element models, these models are incapable of predicting the measured accumulative strain. Therefore, a direct comparison between the measured and 3DFE-calculated strains is expected to yield a good correlation. Such a comparison can only be made if the strain components due to nonlinear strain contributors: curing, shrinkage, and moisture can be removed from the measured data leaving the strain due to temperature effects. The methodology used in this study to extract from the total measured strain the component due to temperature gradient profile is based on the assumption that the strain components due to concrete curing, construction, and moisture will change at much slower rate than that due to the change in temperature gradient profile and dowel constraining forces. This assumption is valid under dry weather conditions for concrete slabs older than 15 days (see Figure 4.8). Thus, between two reasonably spaced time-instances, it can be assumed that the change in the magnitude of field-measured strain in a concrete slab subjected to dowel constraining forces is primarily caused by the change in the temperature profile through the slab thickness. Thus, verification of 3DFE models can be made by considering the changes in the magnitudes of the measured strains during a time interval of several hours and assuming that such changes are only due to the change in the measured temperature gradient profile through the slab thickness. This way, the experimentally measured data can be used to validate the response of $3 \mathrm{DFE}$ models to temperature variations.

\subsection{Material Testing}

As described in Chapter 3, a thermo-elastic-plastic model, whose material constants were assumed to remain constant with temperature variations, is used for both concrete slabs and dowel bars. The material constants of different pavement layers were adjusted to those obtained for West Virginia instrumented section. Values of such constants were obtained experimentally through laboratory and field-testing. Laboratory tests were performed on cylindrical samples of the concrete mix used in the pavement section to determine the compressive and tensile strengths at different ages. The results of these tests at different ages of concrete are illustrated in Figure 4.8 together with the constituents of the concrete mix used in the pavement section. The slump 
of the concrete varied between 19-25 mm. The elastic modulus of concrete was calculated based on the measured compressive strength of concrete using the ACI relation $\left(\mathrm{E}_{c}=57,000 f_{c}^{0.5}\right)$ where $f_{c}$ is the measured 28-day compressive strength $(A C I, 1999)$. The elastic moduli of the subsequent pavement layers were backcalculated from the pavement surface deflection due to FWD test and tabulated in Table 4.1.

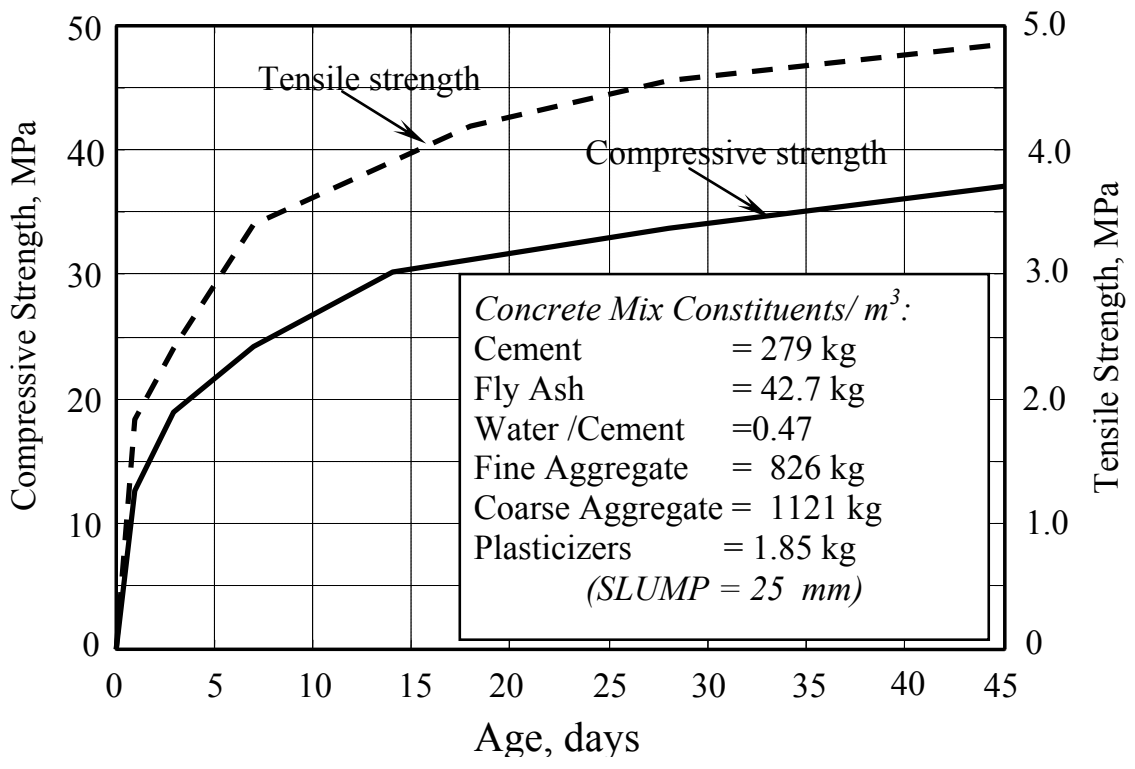

Figure 4.8 Compressive And Tensile Strength of Concrete.

Elastic material models were assumed for the base, subbase, and subgrade layers. The material constants of such layers were backcalculated from the pavement surface deflection due to a Falling Weight Deflectometer (FWD) load applied at the finished pavement surface.

Table 4.1. Material Properties of Pavement Layers.

\begin{tabular}{|l|c|c|c|c|c|}
\hline & Concrete & Dowels & Base & Subbase & Subgrade \\
\hline Density $\left(\mathrm{Kg} / \mathrm{m}^{3}\right)$ & 2400 & 7830 & 1700 & 2100 & 2040 \\
\hline Compressive strength $(\mathrm{MPa})$ & 33.7 & 275 & & & \\
\hline Tensile strength $(\mathrm{MPa})$ & 4.70 & 275 & & & \\
\hline Modulus of elasticity $(\mathrm{MPa})$ & 28,000 & $2 \times 10^{5}$ & 1500 & 4000 & 119.8 \\
\hline Poisson's ratio & 0.18 & 0.30 & 0.40 & 0.40 & 0.45 \\
\hline Thermal expansion coefficient $\left({ }^{\circ} \mathrm{C}\right)$ & $8 \times 10^{-6}$ & $10 \times 10^{-6}$ & & & \\
\hline
\end{tabular}




\subsection{DFE Model Validation}

Slight modifications were made to the 3DFE model, developed in Chapter 3, in order to accommodate the geometrical and material constants specific to West Virginia Smart Road. While the 3DFE model made use of pavement symmetry along a line at mid slab perpendicular to traffic direction, it was necessary to simulate the full length of the slab to incorporate the unsymmetrical measured transverse joint openings recorded from the joint meters shown in Figure 4.9. The base layer is subdivided into two layers: $0.10 \mathrm{~m}$ thick asphalt stabilized gravel placed on top of $0.15 \mathrm{~m}$ thick compacted gravel. Dowel bar modeling and dowel concrete friction coefficient are the same as reported in Chapter 3. However, since the concrete slabs are newly constructed and did not experience any traffic during the first eight months, no looseness was assumed between the dowel bars and surrounding concrete. The material parameters for different pavement layers were adjusted to those obtained for West Virginia instrumented pavement section.

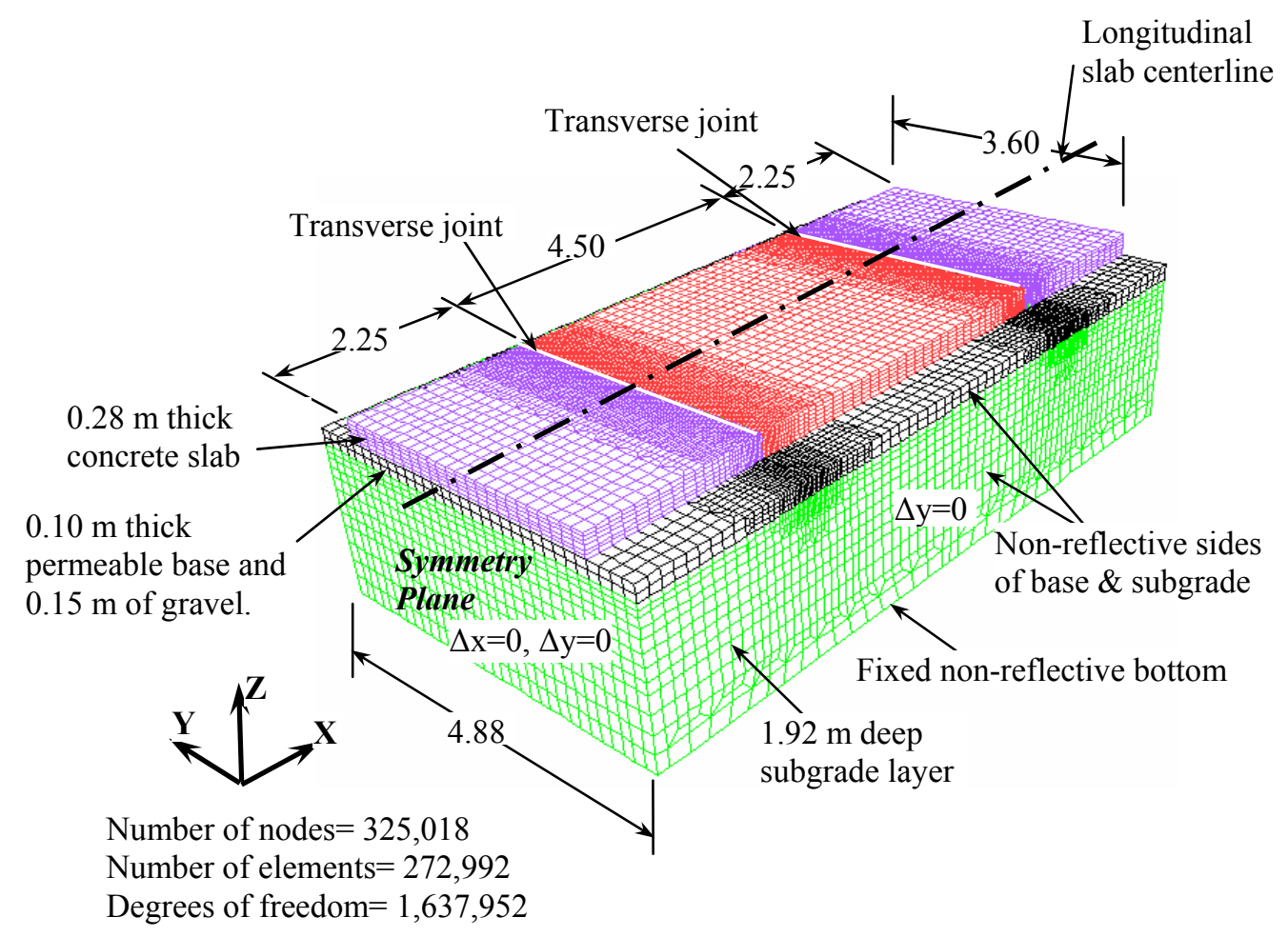

Figure 4.9 Finite Element Model of the WV Instrumented Concrete Pavement 


\subsection{DFE Model Validation Procedures}

Table 4.2 contains a listing of the field-measured data for several time intervals that were used in this study to validate the thermoelastic response of the 3DFE model of Figure 4.9. The following are the procedures used to validate the 3DFE model response to temperature variations in which we consider the experimental data collected 88 days after pavement construction:

1. Referring to Table 4.2, a time interval starting at $\mathrm{T}_{1}$ (December 3, 2001 at 8:20 AM) on day 88 and ending at $\mathrm{T}_{2}$ (December 4, 2001 1:20 PM) is selected. The air temperatures at the beginning and end of this interval are $-5.7{ }^{\circ} \mathrm{C}$ and $7.5^{\circ} \mathrm{C}$ respectively. The data and results for this interval are listed in Table 4.2 (lines 5 to 8) enclosed in a bracket.

2. Shown on line 5 columns 4 to 13 of Table 4.2 are the measured temperatures through the slab depth at $\mathrm{T}_{1}$ those are: $2.3,2.5,3.1,3.7,3.8,4.9,4.1,4.7,5$, and $5.5^{\circ} \mathrm{C}$. The corresponding joint openings at $\mathrm{T}_{1}$ (columns 14 to 16 ) are: $0.460 \mathrm{~mm}, 0.416 \mathrm{~mm}, 0.429$ for joint meters 1, 2, and 3 respectively. The slab Top (T) and Bottom (B) measured longitudinal strains (columns 17 to 30 ) are: $-88,-147,-132,-112,-104,-129,-61$, $141,-43,-111,-97,-101,-61,-104 \mu$ strain. Columns 32 through 41 are the measured slab top and bottom transverse strains at $\mathrm{T}_{1}:-17,-28,-23,-55,-38,-50,-66,-34,-95$, and $-16 \mu$ strain. The bending moment in shoulder-side dowel at $\mathrm{T}_{1}$ is given in column 42 at -176.4 N.m.

3. The values of the above parameters at $\mathrm{T}_{2}$ (the end of the time interval) are listed on line 6 of Table 2 and the change in their values that took place over $T_{1}-T_{2}$ is listed on line 7. The measured temperature profiles at $T_{1}$ and $T_{2}$ are plotted in Figure 4.10 (a). The effective temperature profile, Figure 4.10 (b), is obtained by subtracting the measured profile at $T_{1}$ from that measured at $T_{2}$. The shift of the temperature profiles, shown in Figure 4.10 (a), indicates an average slab temperature increase of approximately $5.4{ }^{\circ} \mathrm{C}$ (change in the temperature of the slab's neutral plane). While the slope and curvature of the effective temperature profile induce slab curling that cause dowel bending, the slab temperature increase causes the slab to expand inducing axial dowel forces that resist slab expansion. Since the selected time interval is relatively small, we assume that the change in joint openings as well as slab top and bottom strains are entirely 
caused by the effective temperature profile shown in Figure 4.10 (b). In other words, we assume that during the time interval under consideration no significant change in concrete maturity, construction curling, or moisture content in concrete have caused a significant change in the slab strains.

4. The effective temperature profile is curve fitted to a polynomial as a function of the distance $\mathrm{Z}$ from the slab top:

$$
T(Z)=69.94 Z^{3}+31.10 Z^{2}+13.61 Z+6.785
$$

Equation 4.2 is used to calculate the temperatures of different nodal points through the depth of the 3DFE slab model.

5. The temperature increase of $5.4{ }^{\circ} \mathrm{C}$ causes the concrete to expand; consequently, the transverse joints close their openings by $-0.055 \mathrm{~mm}$ for each joint (Table 4.2 , columns 14 and 15). Noting that the coefficient of thermal expansion of concrete is $9 \times 10^{-6}$ $\mathrm{mm} / \mathrm{mm} /{ }^{\circ} \mathrm{C}$, the $4.5 \mathrm{~m}$ long slab should have expanded $0.2187 \mathrm{~mm}$. This means that each transverse joint should close $0.10935 \mathrm{~mm}$; however measured data indicate that each joint closed only $0.055 \mathrm{~mm}$. The reduction in joint closure is caused by to factors:

a. Slab curling, arising from various factors, is associated with dowel bar bending that is evident from Figure 4.6 (b). Bent dowels resist slab expansion or contraction, which is also evident from Figure 4.5 (c) for the shoulder-side dowel.

b. The crack initiated by saw cutting of transverse joints does not propagate through the full slab depth causing considerable constraining force that also resists slab expansion and contraction, at least during the first several months after construction. Incomplete cracking of saw-cut transverse joints is a phenomenon that is well known to construction contractors and is thought to significantly contribute to mid-slab transverse cracks (Shoukry et al., 2002 a, b). However, our concern in this study is that it will have a significant influence on measured slab strains.

In this investigation the above factors were accounted for in the 3DFE model by: 


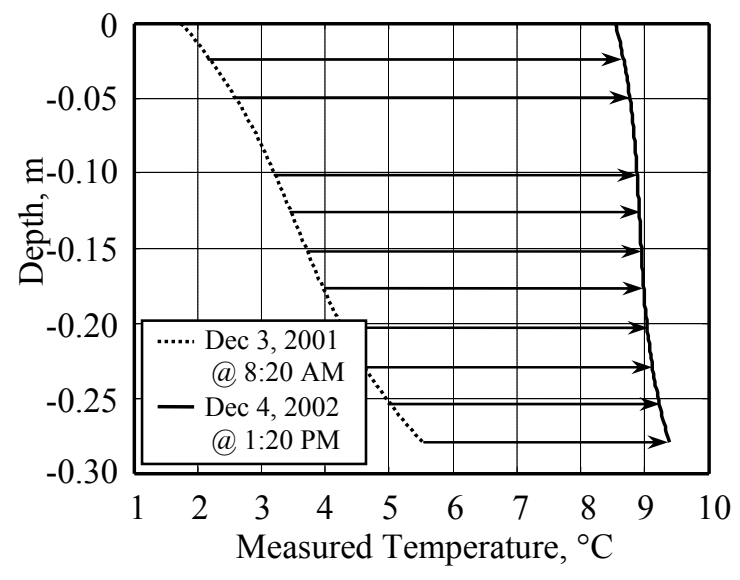

a. Measured Temperature Profiles.

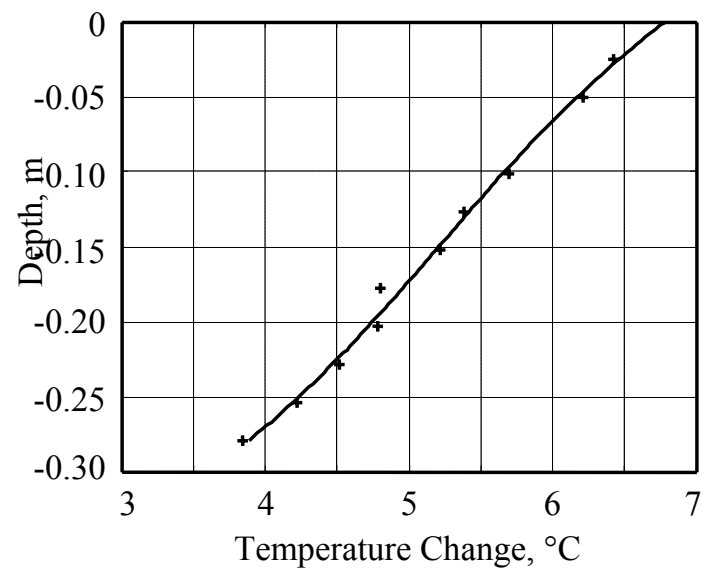

b. Effective Temperature Profile.

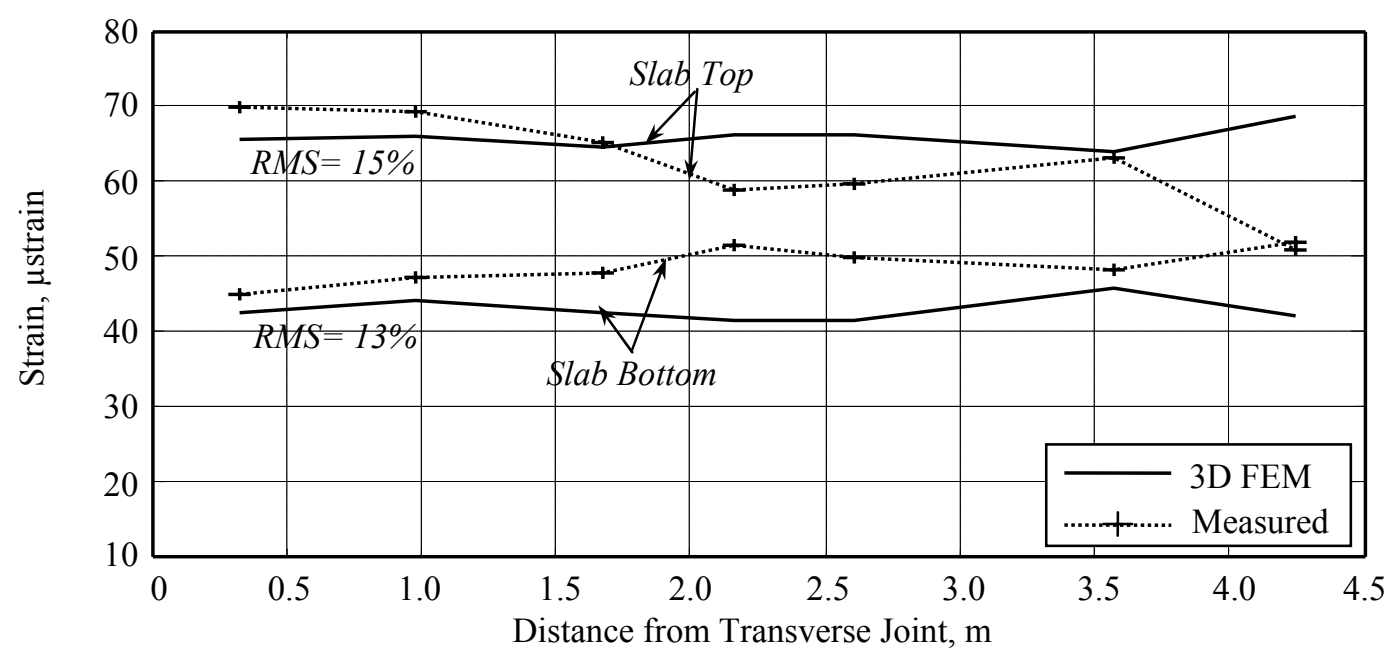

c. Longitudinal Strains.

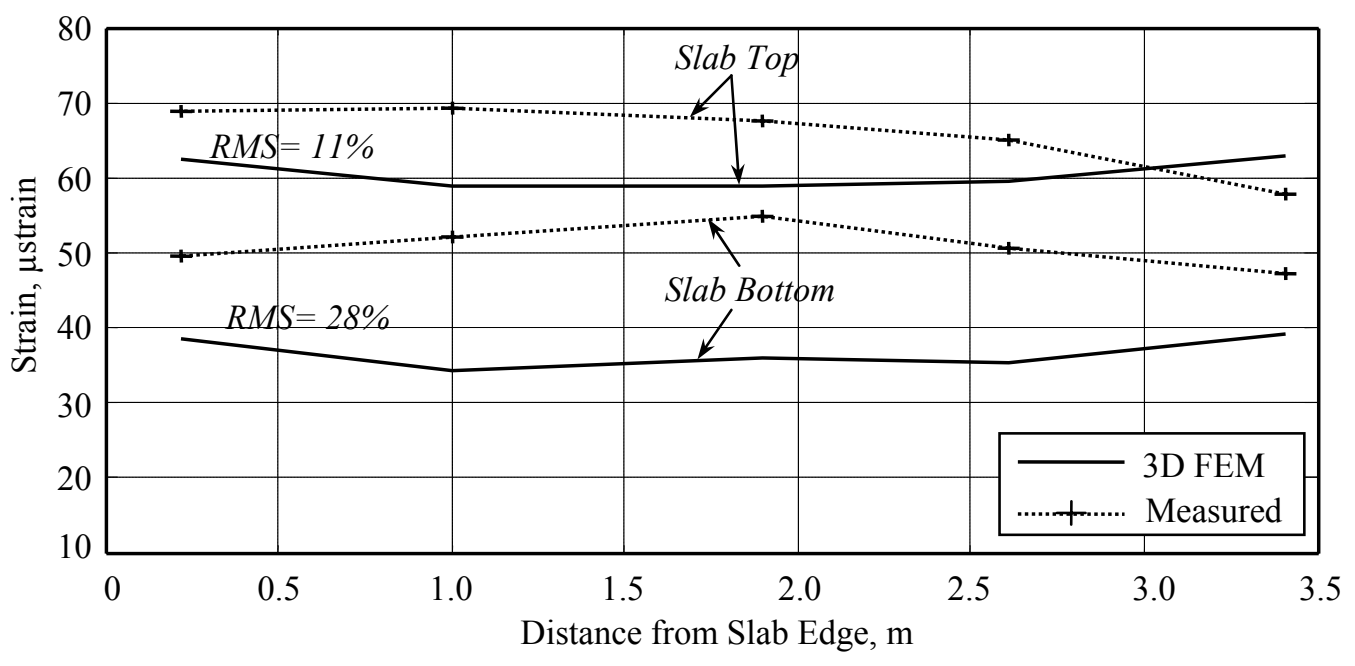

d. Transverse Strains.

Figure 4.10 3DFE-Computed and Measured Strains on Day 88 (December 3, 2001). 


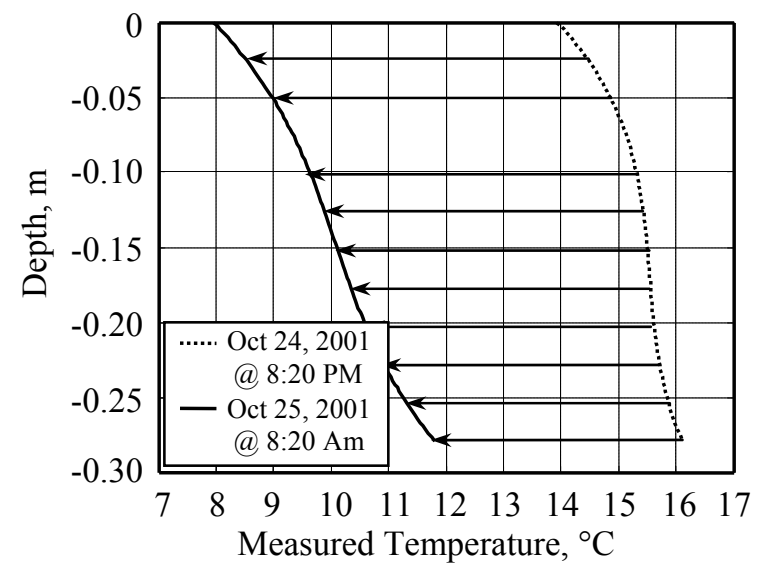

a. Measured Temperature Profiles.

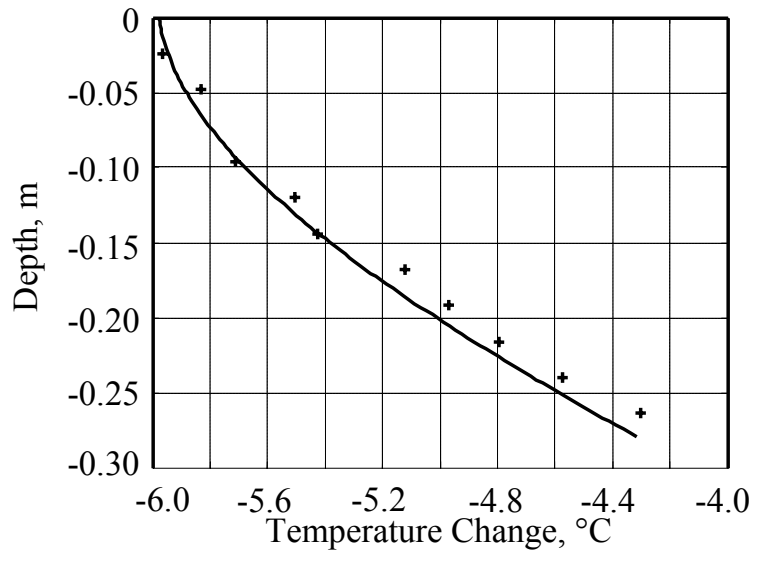

b. Effective Temperature Profile.

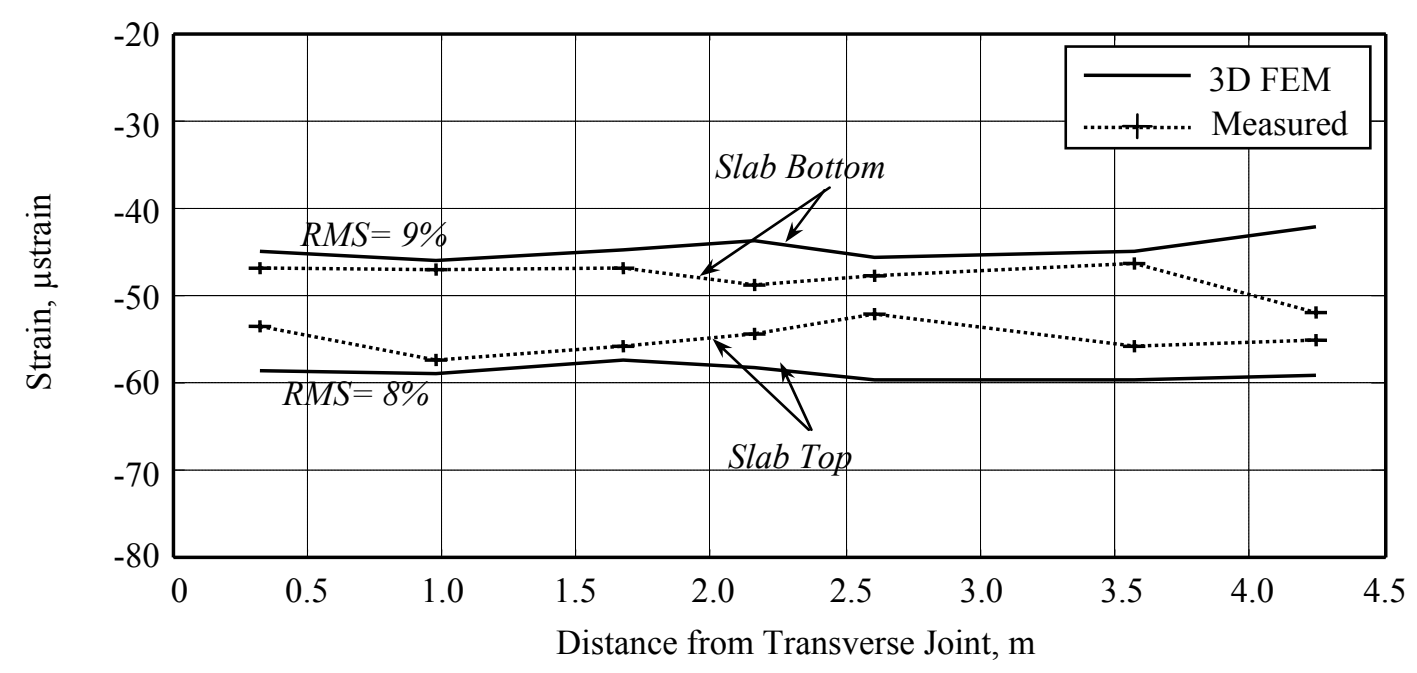

c. Longitudinal Strains.

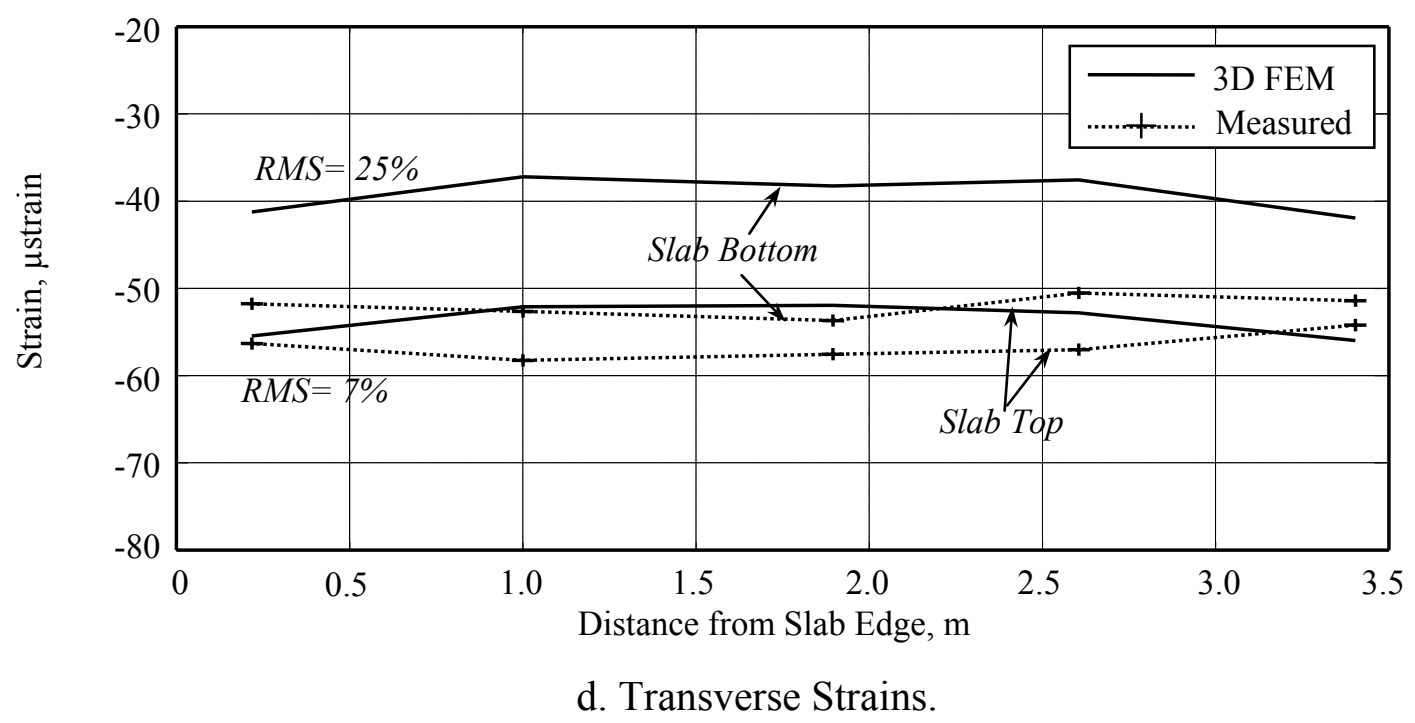

Figure 4.11 3DFE-Computed and Measured Strains on Day 49 (October 21, 2001). 


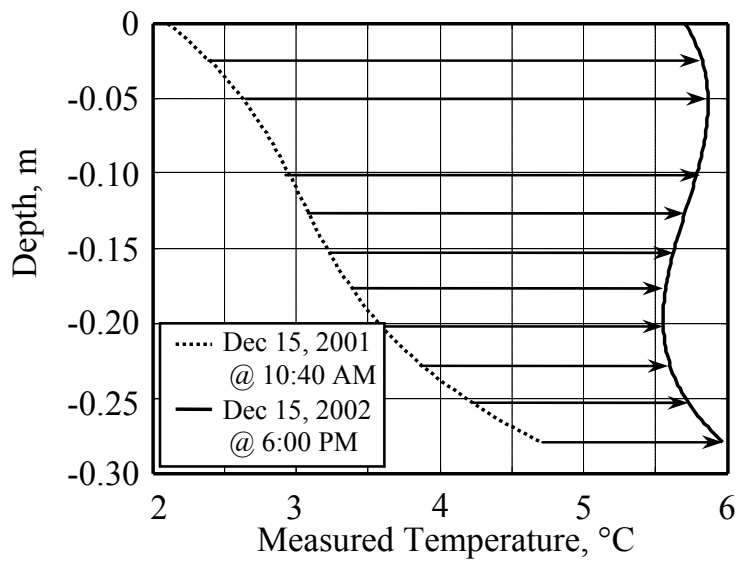

a. Measured Temperature Profiles.

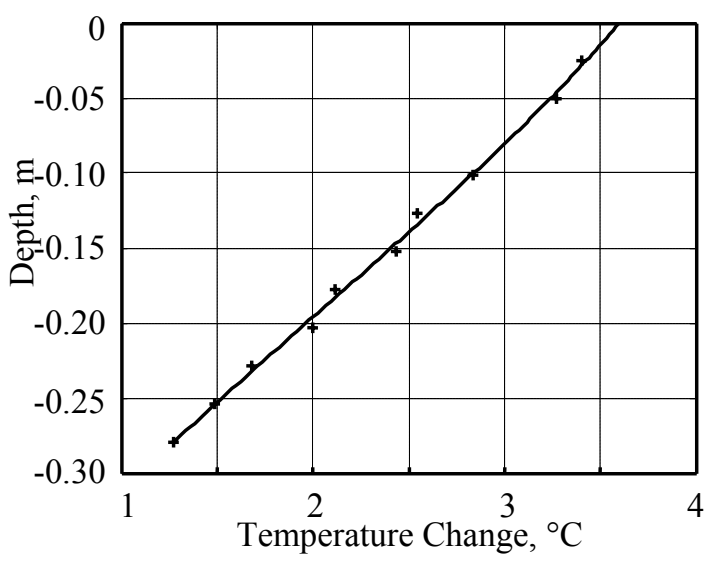

b. Effective Temperature Profile.

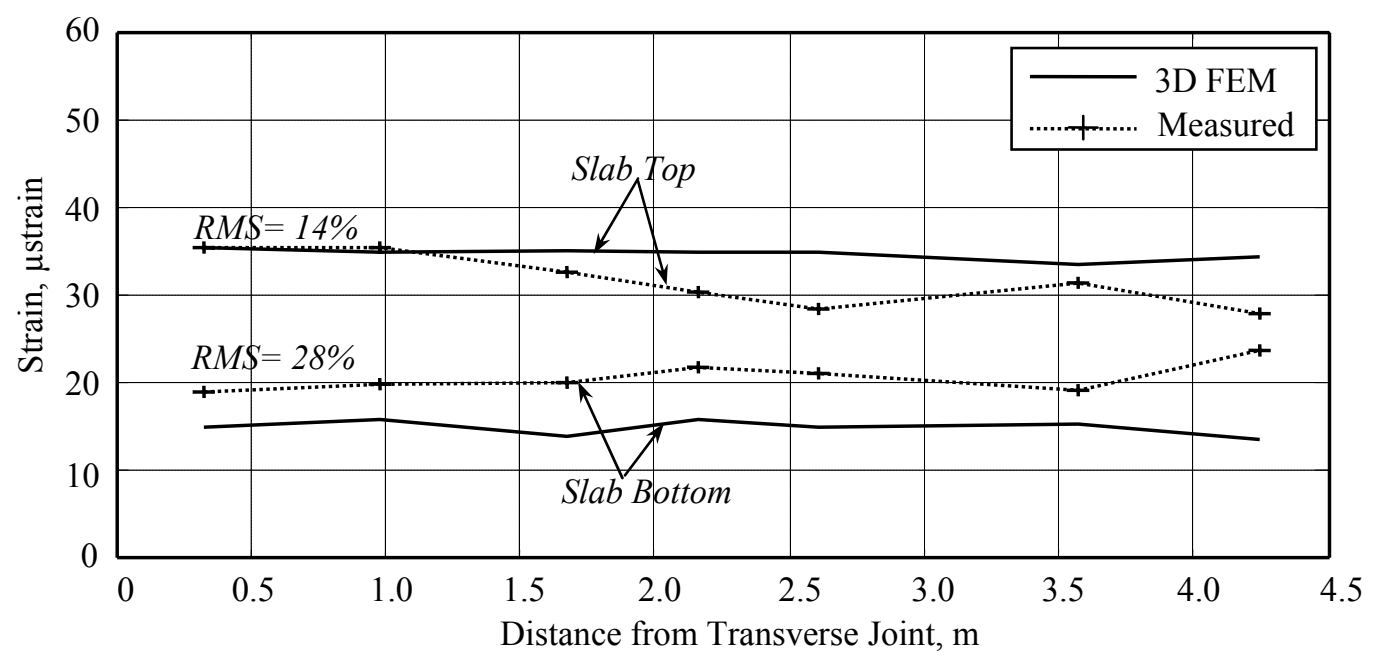

c. Longitudinal Strains.

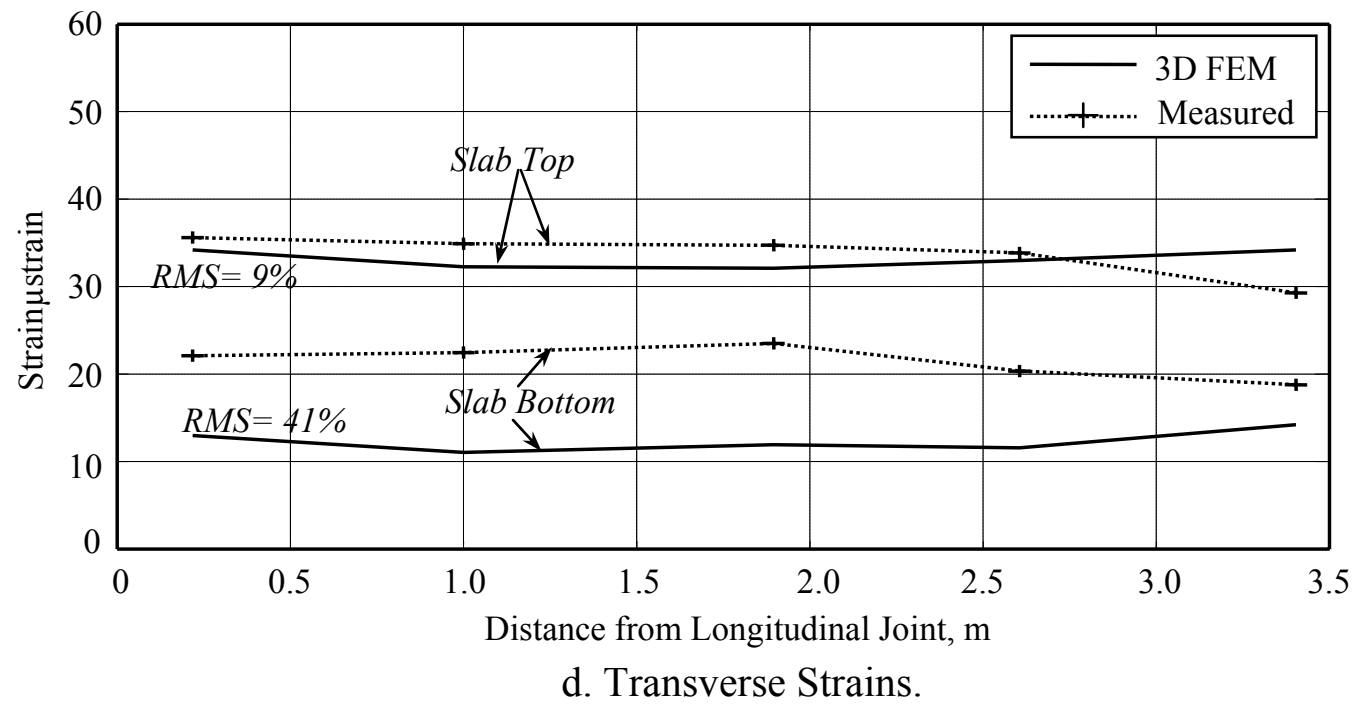

Figure 4.12 3DFE-Computed and Measured Strains on Day 100 (December 15, 2001). 


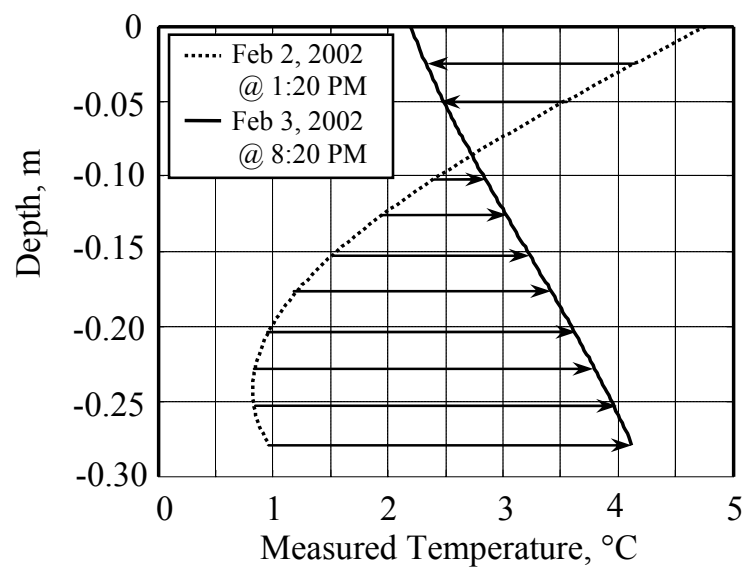

a. Measured Temperature Profiles.

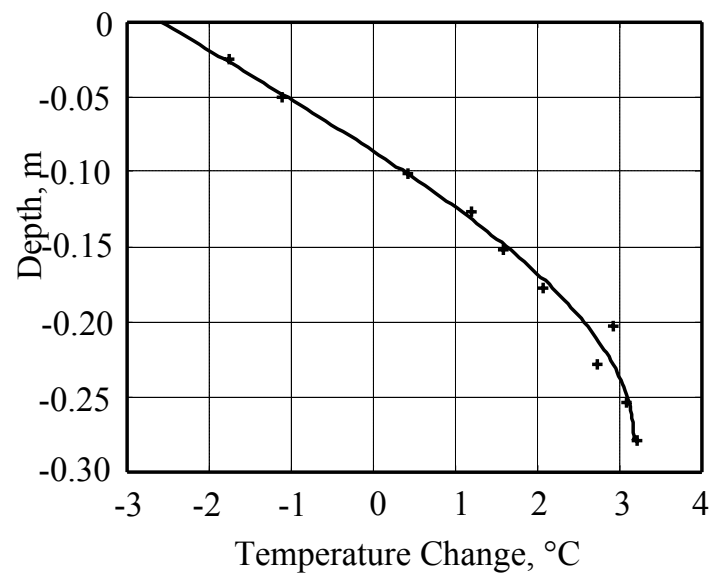

b. Effective Temperature Profile.

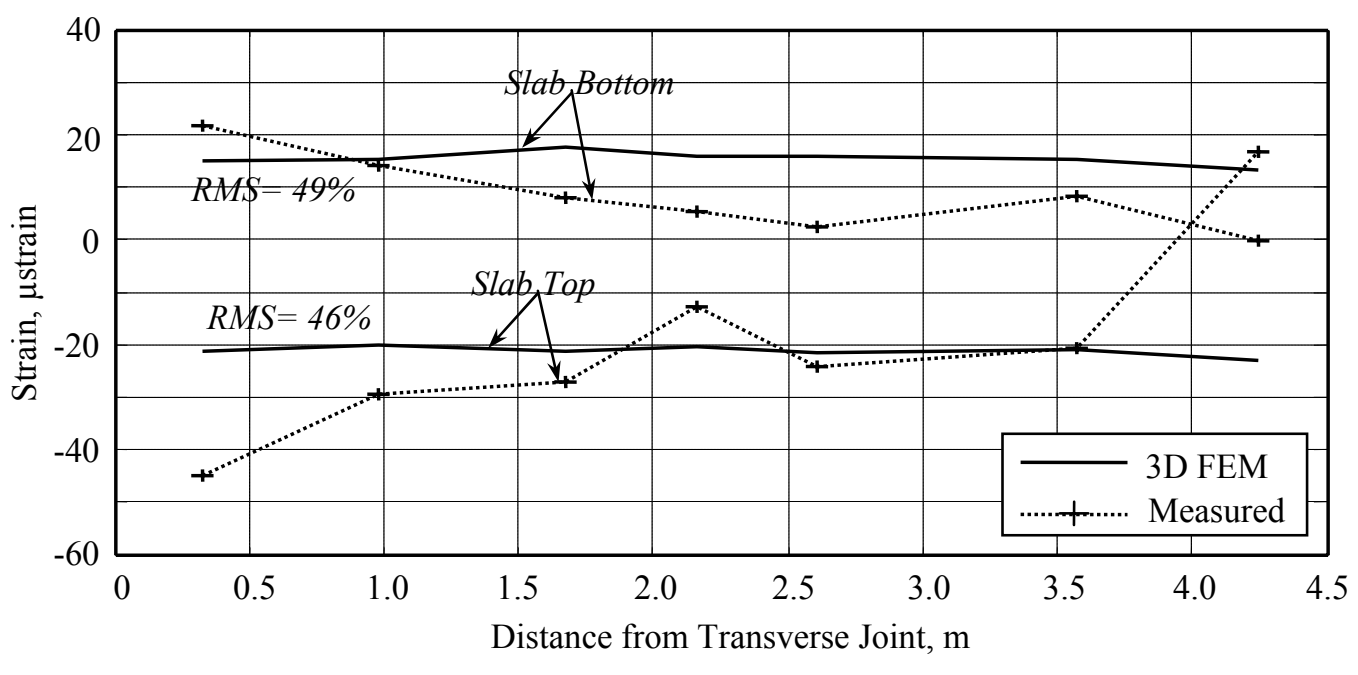

c. Longitudinal Strains.

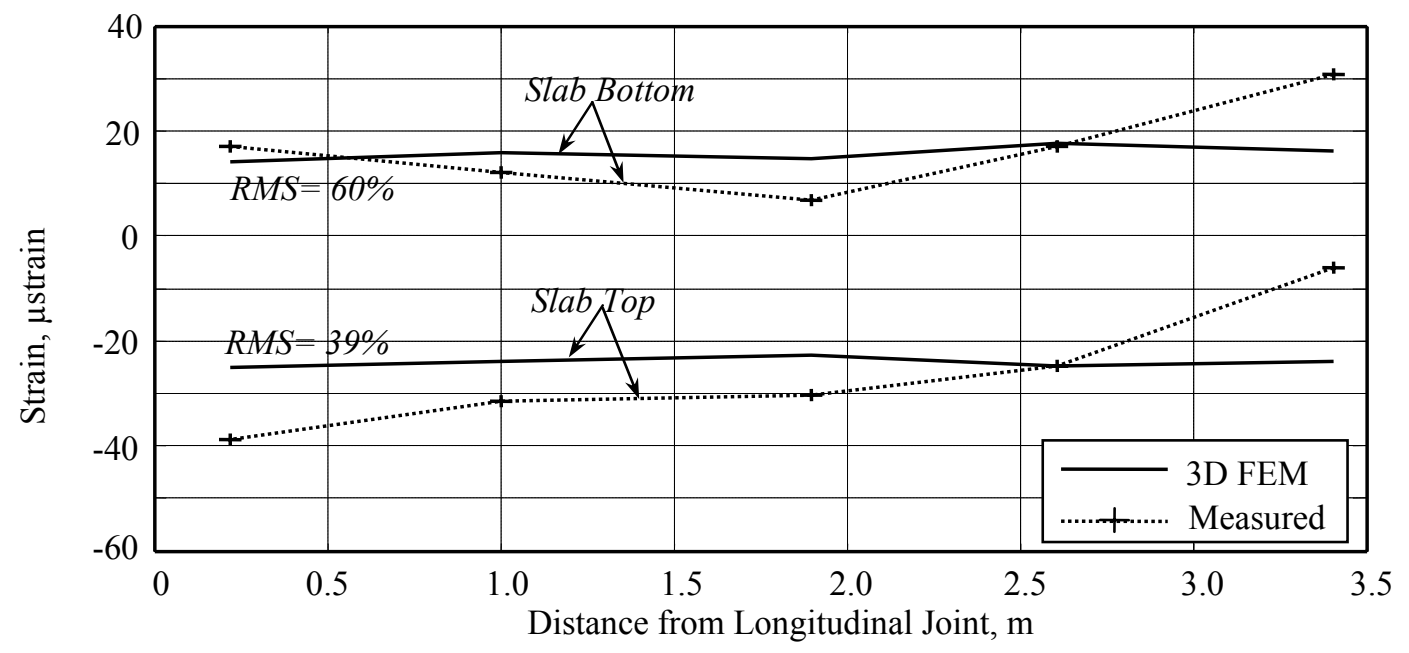

d. Transverse Strains.

Figure 4.13 3DFE-Computed and Measured Strains on Day160 (February 3, 2002). 


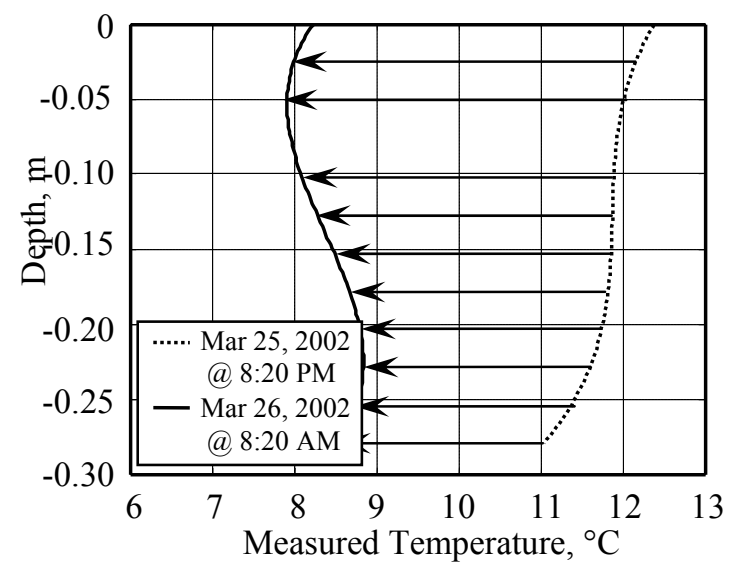

a. Measured Temperature Profiles.

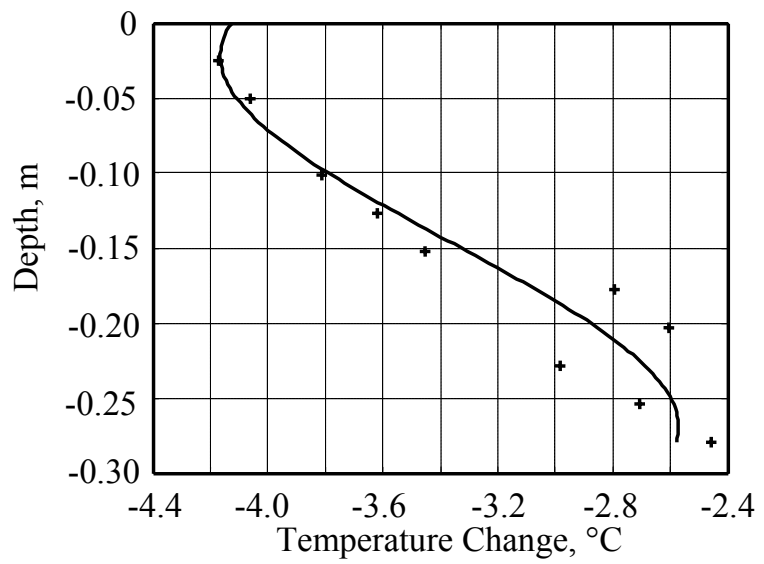

b. Effective Temperature Profile.

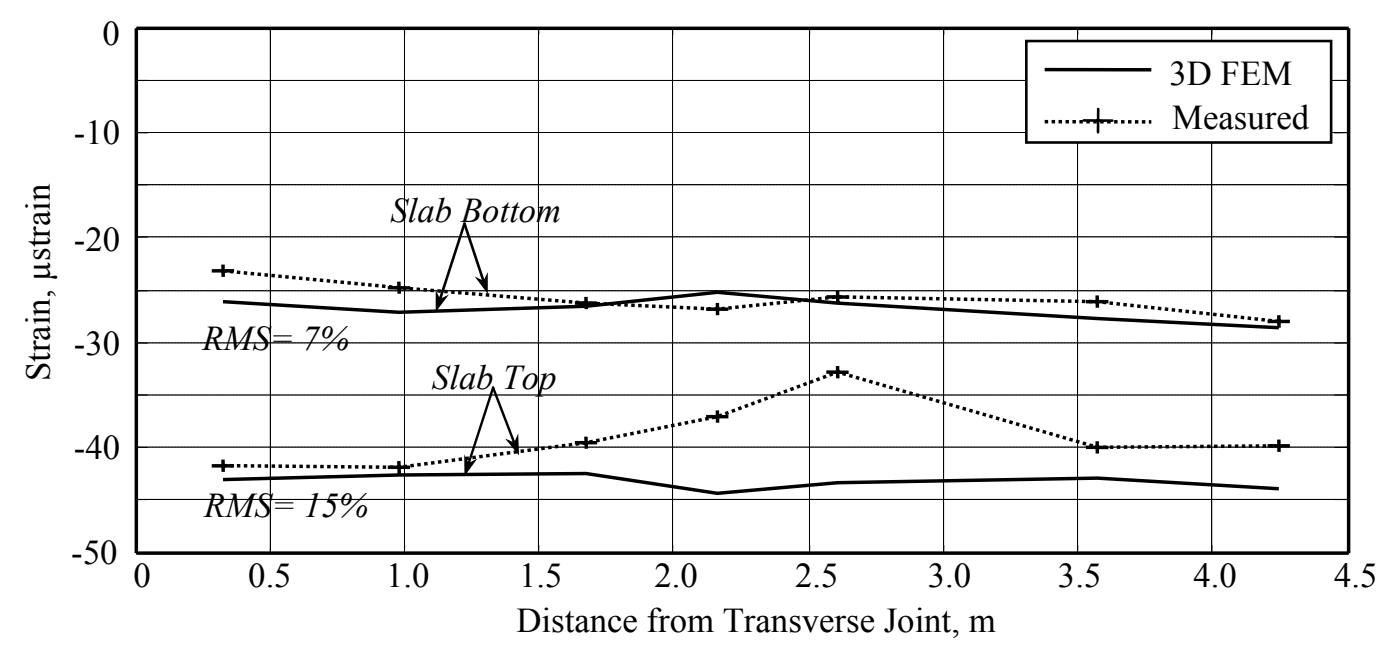

c. Longitudinal Strains.

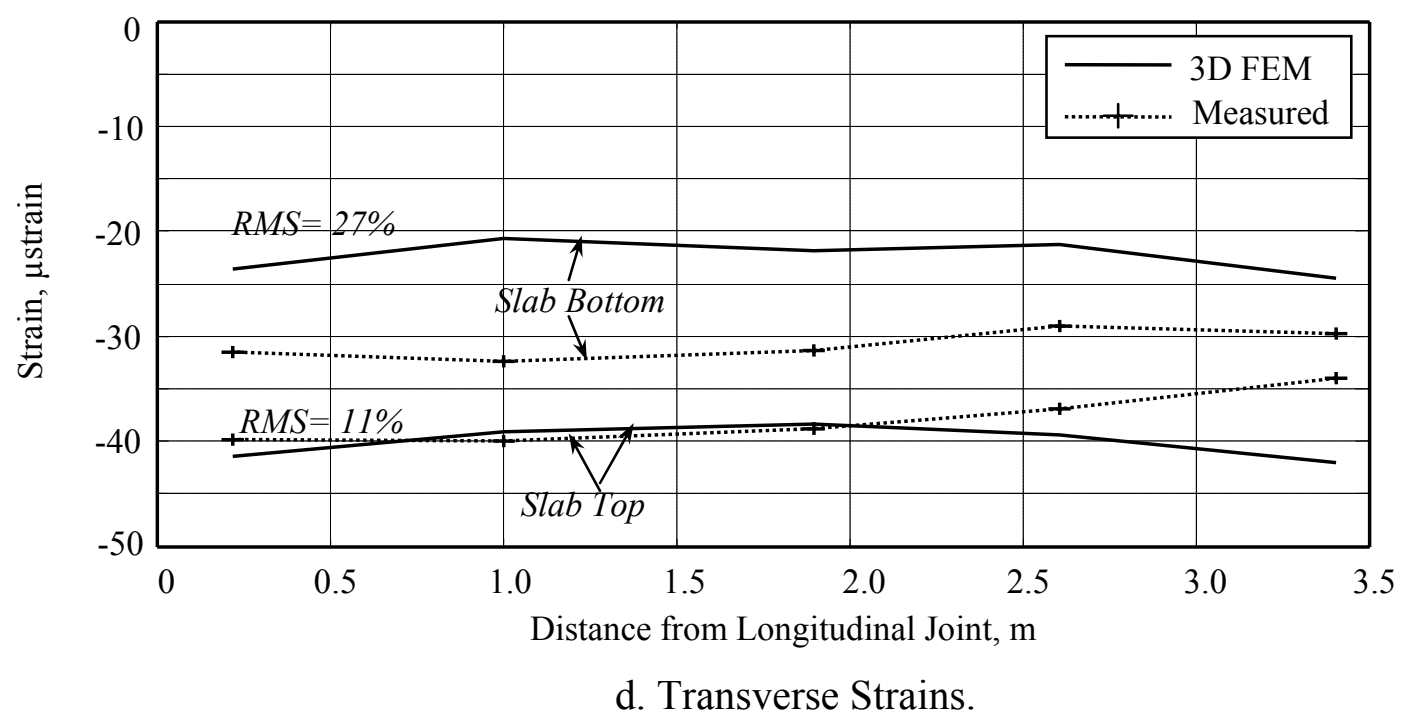

Figure 4.14 3DFE-Computed and Measured Strains on Day 200 (March 25, 2002). 


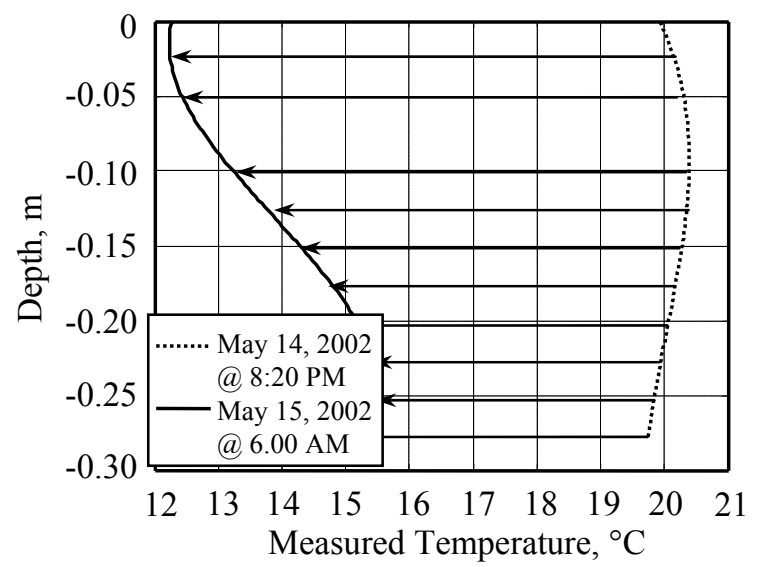

a. Measured Temperature Profiles.

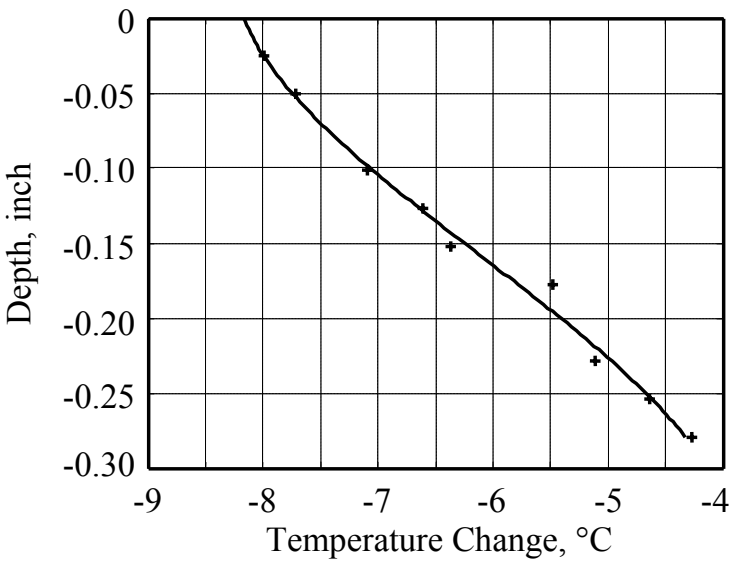

b. Effective Temperature Profile.

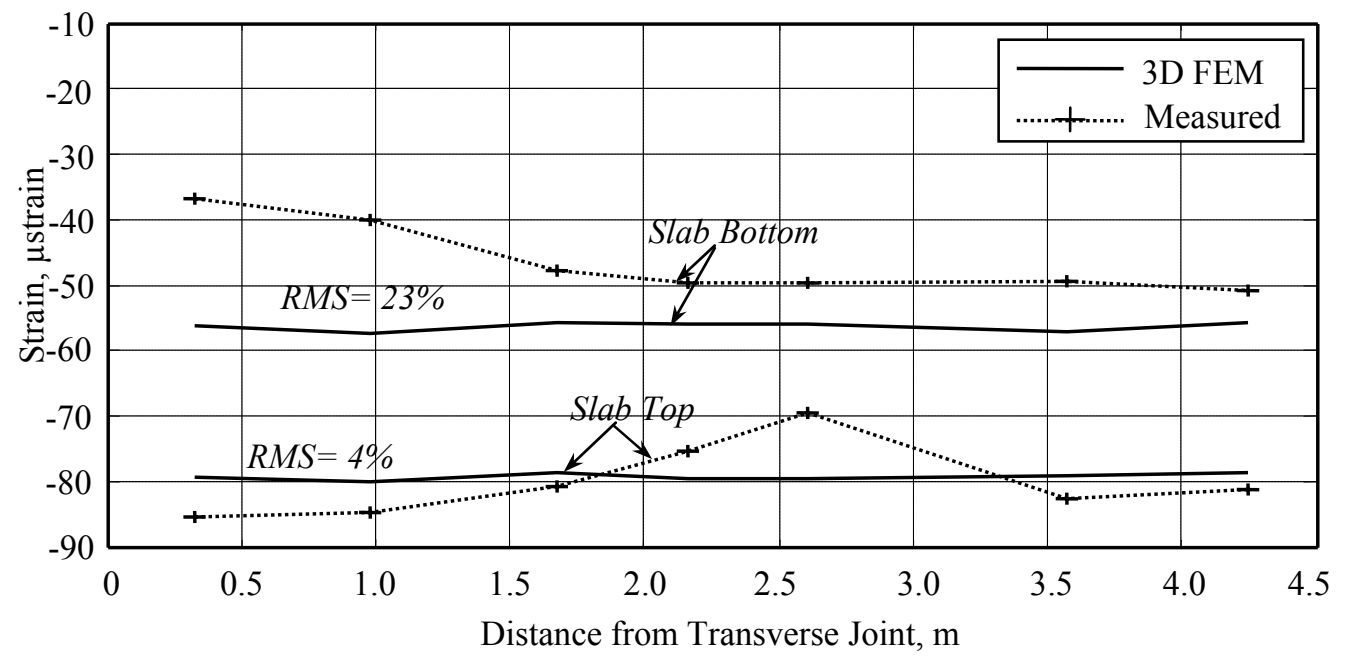

c. Longitudinal Strains.

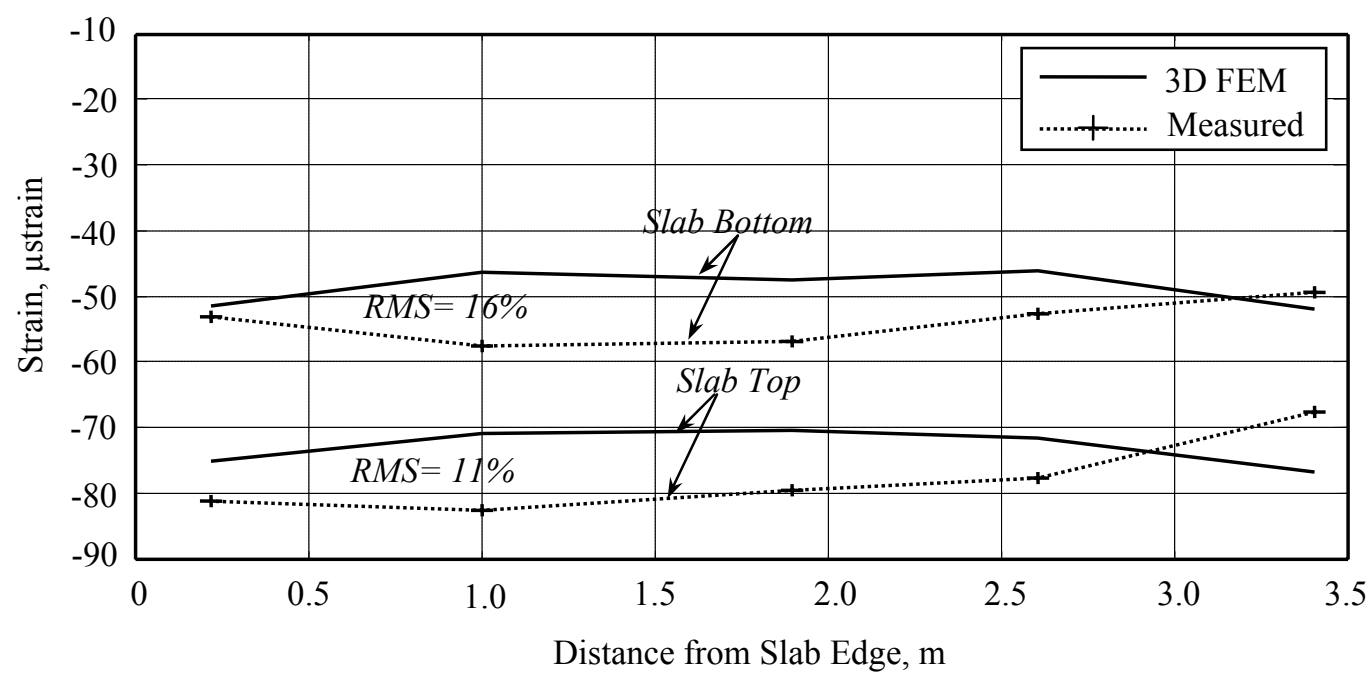

d. Transverse Strains.

Figure 4.15 3DFE-Computed and Measured Strains on Day 250 (May 14, 2002). 
a. Accurate modeling of dowel bars with appropriate frictional interfaces with concrete.

b. Prescribing the displacement magnitude of the nodal points on each transverse joint face as half the measured joint opening in order to simulate the effect of incomplete joint cracking. The reason for specifying only half the measured joint opening is that we assume symmetry along the two mating faces of a joint. The magnitude of displacements of the nodal points along the longitudinal joint face between the driving and speed lane were also limited to half the measured longitudinal joint opening (joint No. 3 in Table 4.2). Since the concrete shoulder of West Virginia Smart Road was placed 24 days after constructing the main line, no constraints were assumed along the longitudinal joint between shoulder and driving lane.

6. The effective temperature profile is applied to the nodal points of the concrete slab using Equation 4.2, and the model is processed using LS-DYNA equation solver. The 3DFE-computed strains are found for all points in the model that correspond to the location of strain gages in the instrumented slab. Both the measured and 3DFEcomputed longitudinal and transverse strains are shown for day 88 in Figure 4.10 (c) and $(\mathrm{d})$.

7. The above procedures are repeated for different time intervals in the months of October, December, February, March, and May. Both the measured data and the 3DFE results are listed in Table 4.2 and illustrated in Figures 4.11 to 4.15. The agreement between the 3DFE-computed and the measured strains is reasonably within the excepted experimental errors.

Figure 4.10 indicates that the change in the strain on both top and bottom of the slab is tensile. This is attributed to the tensile strain component introduced by the temperature rise of $5.4{ }^{\circ} \mathrm{C}$. Figure 4.15 illustrates the change in the slab strain over a time interval on day 250 (May 14, 2002) during which the slab undergoes a drop in its mean temperature associated with positive temperature gradient (see Figure 4.15 (a) and (b)). The temperature changes in this case induce negative change in strain on the slab bottom. The agreement between the measured and the 
3DFE-computed strains is acceptable indicating the success of the approach developed in this study.

The comparison between the 3DFE-computed and experimentally measured strains in Figures 4.10 to 4.15 indicates that the root mean square errors fall within 50 percent. This percentage error applies to 75 percent of the individual points at which the strain was measured and listed in Table 4.2. However, it should be emphasized that strain measurement is sensitive to the accuracy of positioning vibrating wire gages in the concrete slab. While every effort was made to ensure proper positioning of vibrating wire gages used in West Virginia Smart Road, there is no way to assure perfect parallelism between each gage's axis and the top and bottom surfaces of the slab after the concrete is casted and vibrated. Considering all the experimental errors (including gage sensitivity of $\pm 1 \mu$ strain) together with the error in FWD-measured values of material constants and small changes in moisture content in concrete over the interval $T_{1}-T_{2}$, the level of agreement between 3DFE-computed and measured strains as seen from Table 4.2 is reasonable. It will also be noticed from Table 4.2 that the deviation between the 3DFEcomputed and measured transverse strain is larger than that for the longitudinal strain. This is attributed to the effect of the tied shoulder that was placed 24 days after the pavement.

Since the bending moment in steel dowels changes following the change in slab curling, it offers excellent means for checking the accuracy of response of 3DFE models to temperature variations. Steel is an elastic material; therefore, steel dowels are expected to behave linearly over the range of concrete slab deformation due to slab curling. The elastic behavior of steel dowels implies that the change in the magnitude of dowel bending moment over a time interval $T_{1}-T_{2}$ is entirely dependant on the change in slab curvature near the transverse joint. That is, the initial dowel bending moment, measured at the beginning of any time interval is linearly superimposed to that caused by the change in temperature profile that takes place over the same interval. Since the corner dowels suffer the largest bending moment, it was decided to compare the 3DFE-computed dowel bending moment with the measured dowel bending moment in shoulder dowel whose time history is illustrated in Figure 4.6 (b). Because the 3DFE model contained solid representation of dowel bars using 8-node solid brick elements, the dowel bending moment was calculated from the stress profile across the dowel's mid-length cross- 
section. The 3DFE-computed axial stresses in the elements through the cross-section are integrated to obtain the 3DFE-computed dowel bending moment according to the relation:

$$
D B M=\int_{A} \sigma y d A
$$

Where: DBM is the dowel bending moment, $\mathrm{y}$ is the distance of the element center from the dowel's neutral plane, $\sigma$ is the stress at the center of the element and $\mathrm{A}$ is the cross-section of the dowel bar. Both values of the $3 \mathrm{DFE}-$ computed and the measured bending moment in shoulder dowel are listed in the last column of Table 4.2. Figure 4.16 illustrates a remarkable agreement between the measured and calculated bending moment in shoulder-side dowel. The reason for such agreement is that the change in dowel bending moment is independent of the magnitude of dowel bending that existed at time $\mathrm{T}_{1}$. This agreement indicates that the 3DFE model satisfactorily predicts the slab curvature at the transverse joint.

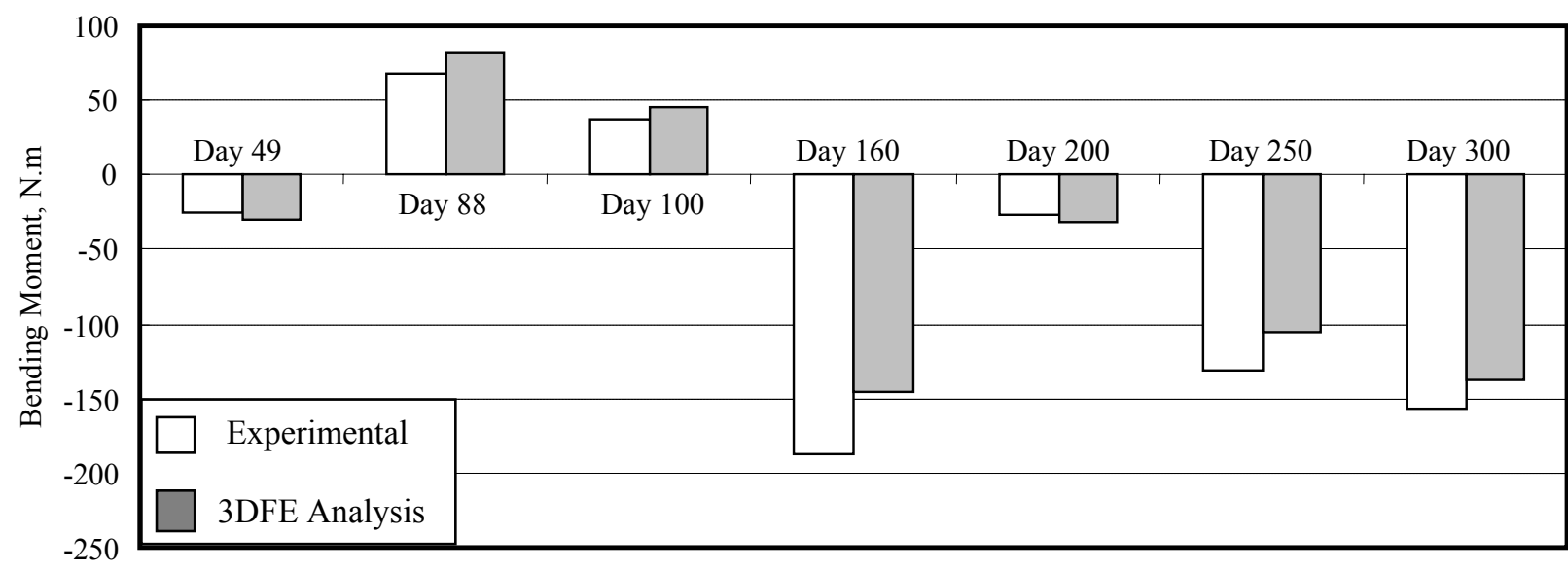

Figure 4.16 3DFE-computed versus measured bending moment in shoulder-side dowel.

\subsection{Conclusions}

A method has been developed to validate the thermoelastic response of 3DFE models of dowel jointed concrete pavements to temperature variations. Although the measured strains include the 
effect of construction curling, shrinkage, and moisture changes that are not accounted for in the 3DFE model, their influence can be significantly reduced by considering the change in the strain that occurs over a short period of time. Comparison between the 3DFE-computed and the measured changes in strains indicate acceptable agreement within the limits of the experimental errors. Compared to the direct measurement of strains, the majority of experimental error sources could be eliminated when considering a comparison between the 3DFE-computed and the measured dowel bending moment. 
Table 4.2. Measured Temperatures, Joint Openings, and Strains.

\begin{tabular}{|c|c|c|c|c|c|c|c|c|c|c|c|c|c|c|c|c|c|c|c|c|c|c|c|c|c|c|c|c|c|c|c|c|c|c|c|c|c|c|c|c|c|c|c|}
\hline & \multirow{4}{*}{ Depth $(\mathrm{mm})$} & \multicolumn{11}{|c|}{ Measured Temperature $\left({ }^{\circ} \mathrm{C}\right)$} & \multirow{3}{*}{\multicolumn{3}{|c|}{\begin{tabular}{|c||} 
Joint opening (mm) \\
Joint No. (l) \\
\end{tabular}}} & \multirow{2}{*}{\multicolumn{14}{|c|}{$\begin{array}{l}\text { Longitudinal Strains ( } \mu \text { strain) } \\
\text { Distance from Transverse Joint, m (2) }\end{array}$}} & \multirow{4}{*}{ 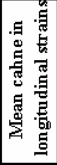 } & \multirow{2}{*}{\multicolumn{10}{|c|}{$\begin{array}{c}\text { Transverse Strains (ustrain) } \\
\text { istance from Longitudinal Joint, } \mathbf{m}(2)\end{array}$}} & \multirow{4}{*}{\multicolumn{2}{|c|}{ 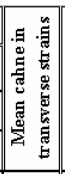 }} & \multirow{4}{*}{\begin{tabular}{|c} 
Bending \\
Moment in \\
Shoulder \\
Side Dowe \\
(N.m)
\end{tabular}} \\
\hline & & \multirow{3}{*}{ Air } & \multirow{2}{*}{\multicolumn{10}{|c|}{ Distance from Slab Top (m) }} & & & & & & & & & & & & & & & & & & & & & & & & & & & & & & & \\
\hline & & & & & & & & & & & & & & & & \multicolumn{4}{|c|}{0.98} & \multicolumn{2}{|c|}{1.67} & \multicolumn{2}{|c|}{2.16} & 2.6 & & 3. & & & 25 & & & 1.22 & 1.0 & & & .90 & & 2.61 & & 3.41 & & & \\
\hline & & & -0.025 & -0.051 & -0.102 & -0.13 & $|-0.152|$. & -0.178 & -0.203 & -0.229 & -0.254 & -0.279 & 1 & 2 & 3 & $\mathrm{~T}$ & B & $\mathrm{T}$ & B & $\mathrm{T}$ & B & $\mathrm{T}$ & B & $\mathrm{T}$ & B & $\mathrm{T}$ & в & $\mathrm{T}$ & B & & $\mathrm{T}$ & B & $\mathrm{T}$ & B & $\mathrm{T}$ & B & $\mathrm{T}$ & B & & \begin{tabular}{l|l}
$\mathrm{I}$ & $\mathrm{B}$ \\
\end{tabular} & & & \\
\hline & 10/24/01 8:20 PM & 10 & 14.6 & 14.7 & 15.2 & 15.6 & 15.7 & 15.6 & 15.3 & 15.9 & 15.9 & 16.1 & 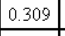 & \begin{tabular}{|l|l|l|l|l|l|}
0.294 & \\
\end{tabular} & \begin{tabular}{|l|l|}
0.300 \\
\end{tabular} & 32 & -56 & -12 & -19 & 9 & -34 & 46 & -40 & 54 & -15 & 13 & -8 & 50 & -9 & & 92 & 68 & 89 & 45 & 73 & 52 & $\begin{array}{l}49 \\
\end{array}$ & 68 & 14 & $\begin{array}{l}48 \\
\end{array}$ & & & -138 \\
\hline o & 10/21/01 1:20 PM & 7 & 8.6 & 8.9 & 9.5 & 10.1 & 10.2 & 10.5 & 10.3 & 11.1 & 11.3 & 11.8 & 0.358 & \begin{tabular}{|c|c|c|}
0.342 & \\
\end{tabular} & 0.352 & -22 & -103 & -69 & -66 & -47 & -81 & -8 & -89 & 2 & -63 & -43 & -54 & -5 & -61 & & 35 & 16 & 31 & -7 & 15 & -2 & -9 & 17 & -4 & 41.36 & 6 & & -164 \\
\hline & Difference & -6.3 & -6.0 & -5.8 & -5.7 & -5.5 & -5.4 & -5.1 & -5.0 & -4.8 & -4.6 & -4.3 & 0.049 & \begin{tabular}{|l|l|l|}
0.048 \\
\end{tabular} & \begin{tabular}{|l|l|}
0.051 \\
\end{tabular} & -54 & -47 & -57 & -47 & -56 & -47 & -54 & -49 & -52. & -48 & -56 & -46 & -55 & -52 & -51 & -56 & -52 & -58 & -53 & -58 & -54 & \begin{tabular}{l|l}
4 & -57 \\
\end{tabular} & -51 & \begin{tabular}{l|l}
1 & -5 \\
\end{tabular} & $54-5$ & & -54 & -26 \\
\hline & 3DFE-Calculated & & & & & & & & & & & & & & & -58 & -45 & -59 & -46 & -58 & -45 & -58 & -44 & -60 & -46 & -60 & -45 & -59 & -42 & -52 & -56 & -41 & -52 & -37 & -52 & -38 & $\begin{array}{l}8-53 \\
\end{array}$ & \begin{tabular}{l|l}
3 & -38 \\
\end{tabular} & \begin{tabular}{l|l}
8 & -5 \\
\end{tabular} & $56-4$ & 42 & -47 & -30 \\
\hline & $12 / 3 / 018$ & -5.7 & 2.3 & 2.5 & 3.1 & 3.7 & 3.8 & 4.9 & 4.1 & 4.7 & 5.0 & 5.5 & \begin{tabular}{l|l|l|l|}
0.46 \\
\end{tabular} & \begin{tabular}{|l|l}
0.416 & \\
\end{tabular} & \begin{tabular}{|l|l}
0.429 \\
\end{tabular} & \begin{tabular}{|l|l|}
-88 \\
\end{tabular} & \begin{tabular}{|l|}
-147 \\
\end{tabular} & -132 & -112 & -104 & -129 & -61 & -141 & $-43-$ & -111 & -97 & -101 & -61 & -104 & & -17 & -28 & -23 & -55 & -38 & -50 & \begin{tabular}{l|l}
0 & -66 \\
\end{tabular} & \begin{tabular}{|l|l|}
5 & -34 \\
\end{tabular} & $\begin{array}{l}4-9 \\
\end{array}$ & \begin{tabular}{l|l}
95 & -1 \\
\end{tabular} & & & -176.4 \\
\hline 冓 & 12/4/01 1:20 PM & 7.5 & 8.7 & 8.8 & 8.8 & 9.1 & 9.0 & 9.7 & 8.8 & 9.2 & 9.2 & 9.4 & 0.405 & \begin{tabular}{|l|l}
0.361 \\
\end{tabular} & \begin{tabular}{|l|l}
0.373 \\
\end{tabular} & -18 & -102 & -63 & -65 & -39 & -81 & -2 & -90 & 17. & -61 & -34 & -53 & -10 & -52 & & 51 & 22 & 46 & $-3 \mid$ & 30 & 4 & -1 & 17 & -3 & $\begin{array}{ll}37 & 3 \\
\end{array}$ & 1 & & -108.3 \\
\hline & Difference & 13.2 & 6.4 & 6.2 & 5.7 & 5.4 & 5.2 & 4.8 & 4.8 & 4.5 & 4.2 & 3.8 & -0.055 & -0.055 & \begin{tabular}{|c|}
-0.055 \\
\end{tabular} & 70 & 45 & 69 & 47 & 65 & 48 & 59 & 51 & 60 & 50 & 63 & 48 & 51 & 52 & 56 & 69 & 49 & \begin{tabular}{|l|}
69 \\
\end{tabular} & 52 & 68 & 55 & \begin{tabular}{|c|c|}
5 & 65 \\
\end{tabular} & 51 & 58 & \begin{tabular}{l|l}
8 & 4 \\
\end{tabular} & & 58 & 68.1 \\
\hline & 3DFE-Calculated & & & & & & & & & & & & & & & 66 & 42 & 66 & 44 & 26 & 65 & 66 & 42 & 66 & 42 & 64 & 46 & 69 & 42 & 53 & 62 & 39 & 59 & 34 & 59 & 36 & 560 & 35 & 63 & \begin{tabular}{l|l}
3 & 38 \\
\end{tabular} & & 49 & 82.8 \\
\hline & 12/15/01 1:40 PM & 2.7 & 2.5 & \begin{tabular}{|l|l|}
2.6 \\
\end{tabular} & 2.8 & 3.3 & 3.3 & 4.7 & \begin{tabular}{|l|l|}
3.4 \\
\end{tabular} & 4.0 & 4.2 & 4.7 & 0.465 & \begin{tabular}{|l|l}
0.419 & \\
\end{tabular} & \begin{tabular}{|l|l|}
0.433 \\
\end{tabular} & -75 & -152 & -124 & -116 & -97 & -130 & -57 & -143 & $-33-$ & -111 & \begin{tabular}{|l|}
-90 \\
\end{tabular} & -102 & -66 & -105 & & -2 & -35 & \begin{tabular}{|l|}
-12 \\
\end{tabular} & \begin{tabular}{|l|}
-60 \\
\end{tabular} & -26 & -53 & \begin{tabular}{l|l}
3 & -56 \\
\end{tabular} & \begin{tabular}{|l|l|}
58 & -38 \\
\end{tabular} & \begin{tabular}{l|l}
8 & -9 \\
\end{tabular} & \begin{tabular}{l|l}
2 & -2 \\
\end{tabular} & & & -99.9 \\
\hline$\stackrel{\square}{\circ}$ & 12/15/01 6:00 PM & 6 & 5.9 & 5.8 & 5.6 & 5.8 & 5.8 & 6.8 & 5.4 & 5.7 & 5.7 & 6.0 & 0.43 & \begin{tabular}{|l|l}
0.394 & \\
\end{tabular} & \begin{tabular}{|l|l|}
0.407 \\
\end{tabular} & -40 & \begin{tabular}{|l|}
-133 \\
\end{tabular} & \begin{tabular}{|l|l|}
-88 \\
\end{tabular} & -96 & -65 & -110 & -27 & -121 & -5 & -90 & \begin{tabular}{|l|}
-59 \\
\end{tabular} & -83 & -38 & -81 & & 34 & -13 & $23 \mid$ & -37 & 8 & -30 & \begin{tabular}{l|l}
0 & -23 \\
\end{tabular} & \begin{tabular}{|l|l|}
3 & -18 \\
\end{tabular} & \begin{tabular}{l|l}
8 & -6 \\
\end{tabular} & $\begin{array}{ll}63 & -3 \\
-3\end{array}$ & 3 & & -61.6 \\
\hline & Difference & 3.3 & 3.4 & 3.3 & 2.8 & 2.5 & 2.4 & 2.1 & 2.0 & 1.7 & 1.5 & 1.3 & -0.035 & \begin{tabular}{|c|}
-0.025 \\
\end{tabular} & \begin{tabular}{|l|l}
0.026 \\
\end{tabular} & 35 & \begin{tabular}{|l|}
19 \\
\end{tabular} & 35 & 20 & 32 & 20 & 30 & 22 & 28 & 21 & 31 & 19 & 28 & 24 & 26 & 36 & 22 & 35 & 22 & 35 & 23 & \begin{tabular}{l|l}
3 & 34 \\
\end{tabular} & 20 & 29 & 9 & & 27 & 38.3 \\
\hline & 3DFE-Calculated & & & & & & & & & & & & & & & 35 & 15 & 35 & 16 & 35 & 14 & 34 & 16 & 34 & 15 & 33 & 15 & 34 & 14 & 25 & 34 & 13 & 32 & 11 & 32 & 12 & 33 & 12 & 34 & $\begin{array}{lll}4 & 1 \\
\end{array}$ & 4 & 23 & 46 \\
\hline & $2 / 2: 021: 20 \mathrm{PM}$ & \begin{tabular}{|l|l|}
14.3 \\
\end{tabular} & 4.1 & 3.6 & 2.3 & 2.0 & 1.6 & 3.6 & \begin{tabular}{|l|l|}
0.8 \\
\end{tabular} & 1.0 & 0.8 & 1.0 & \begin{tabular}{|l|l|}
0.501 \\
\end{tabular} & \begin{tabular}{l|l}
0.436 & \\
\end{tabular} & \begin{tabular}{|l|l|}
0.475 \\
\end{tabular} & \begin{tabular}{|l|}
-29 \\
\end{tabular} & \begin{tabular}{|l|}
-156 \\
\end{tabular} & \begin{tabular}{|l|}
-85 \\
\end{tabular} & -119 & -61 & -129 & -33 & -141 & 2 & -105 & \begin{tabular}{|l|}
-56 \\
\end{tabular} & -99 & -74 & -85 & & 48 & -37 & $26 \mid$ & -59 & 13 & -49 & \begin{tabular}{l|l}
9 & -24 \\
\end{tabular} & \begin{tabular}{l|l}
4 & -42 \\
\end{tabular} & \begin{tabular}{l|l}
2 & -7 \\
\end{tabular} & $84-4$ & 44 & & 60.9 \\
\hline 6 & $2 / 3 / 028: 20 \mathrm{AM}$ & -0.5 & 2.3 & 2.5 & 2.7 & 3.2 & 3.2 & 5.7 & 3.7 & 3.7 & 3.9 & 4.2 & \begin{tabular}{l|l}
0.502 \\
\end{tabular} & \begin{tabular}{|l|l}
0.434 & \\
\end{tabular} & \begin{tabular}{|l|l|}
0.451 \\
\end{tabular} & -74 & \begin{tabular}{|l|}
-134 \\
\end{tabular} & -114 & -105 & -88 & -121 & -46 & -136 & $-22-$ & -102 & -77 & -90 & -57 & -85 & & 9 & -20 & -5 & \begin{tabular}{|c|}
-47 \\
\end{tabular} & -17 & -42 & \begin{tabular}{l|l}
2 & -49 \\
2
\end{tabular} & -25 & \begin{tabular}{l|l}
5 & -8 \\
\end{tabular} & $\begin{array}{ll}30 & -1 \\
\end{array}$ & 13 & & -126.4 \\
\hline & Difference & -15 & -1.8 & -1.1 & 0.4 & 1.2 & 1.6 & 2.1 & \begin{tabular}{|l|}
2.9 \\
\end{tabular} & 2.7 & 3.1 & 3.2 & 0.001 & \begin{tabular}{|c|}
-0.002 \\
\end{tabular} & \begin{tabular}{|l|l|}
-0.023 \\
\end{tabular} & -45 & \begin{tabular}{|l|}
22 \\
\end{tabular} & \begin{tabular}{|l|l|}
-29 \\
\end{tabular} & 14 & -27 & 8 & -13 & 5 & -24 & 2 & \begin{tabular}{|l|}
-21 \\
\end{tabular} & 8 & 17 & 0 & -6 & -39 & 17 & -32 & 12 & -30 & 7 & -25 & \begin{tabular}{|l|l} 
& 17 \\
\end{tabular} & $\begin{array}{l}-6 \\
\end{array}$ & \begin{tabular}{l|l}
6 & 3 \\
\end{tabular} & 1 & -5 & -187.3 \\
\hline & 3DFE-Calculated & & & & & & & & & & & & & & & -22 & 15 & -20 & 15 & -22 & 17 & -20 & 15 & -21 & 15 & -21 & 15 & -23 & 13 & -3 & -25 & 14 & \begin{tabular}{|l|} 
\\
\end{tabular} & 15 & -23 & 14 & \begin{tabular}{l|l}
4 & -24 \\
\end{tabular} & $\begin{array}{l}17 \\
\end{array}$ & -2 & \begin{tabular}{l|l}
23 & 1 \\
\end{tabular} & 4. & -5 & -146 \\
\hline & 3/25/02 8:20 PM & 10.6 & 12.1 & 12.1 & 11.8 & 11.9 & 11.8 & 13.5 & 12.0 & 11.4 & 11.2 & 11.2 & 0.408 & \begin{tabular}{|l|l}
0.371 \\
\end{tabular} & 0.366 & 26 & -64 & -15 & -31 & 6 & -47 & 43 & -58 & 66. & -29 & 18 & 16 & 30 & -7 & & 109 & 58 & 97 & 35 & 81 & 43 & \begin{tabular}{l|l}
3 & 47 \\
\end{tabular} & 53 & 8 & \begin{tabular}{l|l}
8 & 6 \\
\end{tabular} & 4 & & -60.7 \\
\hline aे & 3/26/01 8:20 AM & 12.3 & 8.0 & 8.0 & 8.0 & 8.3 & 8.3 & 10.7 & \begin{tabular}{|l|l|}
9.4 \\
\end{tabular} & 8.5 & 8.5 & 8.5 & \begin{tabular}{|l|l|}
0.464 \\
\end{tabular} & \begin{tabular}{|l|l}
0.418 \\
\end{tabular} & \begin{tabular}{|l|l|}
0.399 \\
\end{tabular} & -16 & \begin{tabular}{|l|}
-87 \\
\end{tabular} & \begin{tabular}{|l|}
-57 \\
\end{tabular} & -56 & -34 & -74 & 6 & -85 & 33 & -54 & \begin{tabular}{|l|}
-22 \\
\end{tabular} & -42 & -10 & -35 & & 69 & 27 & 57 & 3 & 42 & 11 & \begin{tabular}{l|l}
1 & 10 \\
\end{tabular} & 24 & \begin{tabular}{l|l}
4 \\
\end{tabular} & \begin{tabular}{l|l}
26 & 3 \\
\end{tabular} & 5 & & 3 \\
\hline 煦 & Difference & 1.7 & -4.2 & -4.1 & -3.8 & -3.6 & -3.5 & -2.8 & \begin{tabular}{|l|}
-2.6 \\
\end{tabular} & -3.0 & -2.7 & -2.7 & \begin{tabular}{|l|l}
0.056 \\
\end{tabular} & \begin{tabular}{|l|l|}
0.047 & \\
\end{tabular} & \begin{tabular}{|l|l|}
0.033 \\
\end{tabular} & -42 & \begin{tabular}{|l|}
-23 \\
\end{tabular} & \begin{tabular}{|l|}
-42 \\
\end{tabular} & -25 & -40 & -26 & -37 & -27 & -33 & -26 & -40 & 26 & -40 & -28 & -32 & -40 & -31 & -40 & -32 & -39 & -31 & \begin{tabular}{l|l}
1 & -37 \\
\end{tabular} & -29 & \begin{tabular}{l|l}
9 & -3 \\
\end{tabular} & $34-3$ & 30 & -34 & -27.5 \\
\hline & 3DFE-Calculated & & & & & & & & & & & & & & & -43 & -26 & -43 & -27 & -42 & -26 & -44 & -25 & -43. & -26 & -43 & -27 & -43 & -28 & -35 & -41 & -24 & -39 & -21 & -38 & -22 & \begin{tabular}{l|l}
2 & -39 \\
\end{tabular} & -21 & $\begin{array}{l}1 \\
\end{array}$ & $41-2$ & 24 . & -31 & -31.1 \\
\hline & 5/14/02 8:20 PM & 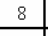 & 20.2 & 20.3 & 20.3 & 20.5 & 20.4 & 22.5 & 19.8 & 20.1 & 19.8 & 19.7 & 0.322 & \begin{tabular}{|l|l}
0.319 \\
\end{tabular} & \begin{tabular}{|l|l} 
& \\
\end{tabular} & 81 & 4 & 48 & 36 & 68 & 19 & 111 & 12 & 133 & 38 & 83 & 55 & 99 & 71 & & 169 & 134 & 165 & 113 & 151 & 123 & \begin{tabular}{l|l}
3 & 112 \\
\end{tabular} & \begin{tabular}{c|c|c} 
& 132 \\
\end{tabular} & \begin{tabular}{l|l}
2 & 81 \\
\end{tabular} & $\begin{array}{lll}1 & 14 \\
\end{array}$ & 44 & & -75.1 \\
\hline Nָ & 5/15/02 6:00 AM & 7.8 & 12.2 & 12.6 & 13.2 & 13.9 & 14.0 & 17.0 & 16.1 & 15.0 & 15.2 & 15.5 & 0.448 & \begin{tabular}{|l|l}
0.429 \\
\end{tabular} & $0.361 \mid$ & -4 & -33 & -37 & -4 & -12 & -29 & 35 & -37 & 64. & -12 & 0 & 5 & 17 & 20 & & 88 & 81 & 82 & 56 & 71 & 66 & \begin{tabular}{l|l}
6 & 35 \\
\end{tabular} & 79 & 13 & \begin{tabular}{l|l}
3 & 9 \\
\end{tabular} & 4 & & -206.2 \\
\hline & \begin{tabular}{|l} 
Difference \\
\end{tabular} & -0.2 & -8.0 & -7.7 & -7.1 & -6.6 & -6.4 & -5.5 & -3.8 & -5.1 & -4.6 & -4.3 & 0.126 & \begin{tabular}{|l|l}
0.11 \\
\end{tabular} & \begin{tabular}{|l|l|}
0.075 \\
\end{tabular} & -85 & \begin{tabular}{|l|}
-37 \\
\end{tabular} & \begin{tabular}{|l|}
-85 \\
\end{tabular} & -40 & -81 & -48 & -75 & -50 & -69. & -50 & -83 & & -81 & -51 & -63 & -81 & -53 & -83 & \begin{tabular}{|l|}
-58 \\
\end{tabular} & -80 & -57 & \begin{tabular}{|c|c|}
7 & -78 \\
\end{tabular} & \begin{tabular}{|l|l|} 
& -53 \\
\end{tabular} & \begin{tabular}{l|l}
3 & -6 \\
\end{tabular} & 68 & & -66 & -131 \\
\hline & 3DFE-Calculated & & & & & & & & & & & & & & & $|-79|$ & -55 & \begin{tabular}{|c|}
-80 \\
\end{tabular} & -57 & -79 & \begin{tabular}{l|l}
-55 \\
\end{tabular} & -79 & -59 & -80 & -55 & -79 & 31 & -80 & -55 & -68 & -75 & -52 & 71 & \begin{tabular}{|l|}
-46 \\
\end{tabular} & -70 & -48 & \begin{tabular}{l|l}
8 & -72 \\
\end{tabular} & -46 & & $76 \mid-5$ & & -61 & 100 \\
\hline
\end{tabular}

(1) Joints No. 1 and 2 are transverse joints, and joint No. 3 is the longitudinal joint between the driving and speed lanes.

(2) $\mathrm{T}$ indicates strain gages placed $28 \mathrm{~mm}$ from the slab top.

B indicates strain gages placed $28 \mathrm{~mm}$ from the slab bottom. 


\section{CHAPTER FIVE}

\section{TEMPERATURE-INDUCED STRESSES IN DOWEL JOINTED CONCRETE PAVEMENTS}

\subsection{Introduction}

Westergaard's solution represents the only closed form solution that predicts the stresses in concrete pavements due to linear temperature gradient through the slab thickness. Additionally, it is currently utilized by pavement design specifications to calculate the temperature-induced stress in concrete slab. Due to the inherent assumptions in Westergaard's analysis discussed in Chapter 2, its applicability to dowel jointed concrete pavements should be examined. To achieve this objective, the results of the 3D Finite Element model were compared with those obtained using Westergaard's analyses to calibrate Westergaard's Equations. To facilitate the comparison with Westergaard's results, only linear gradient is applied. The influence of finite slab width, dowel bars, slab weight, and slab-base interface separation is discussed. The role of dowel bars in activating large magnitude of stresses due to uniform temperature drop is discussed and the stresses induced in different slab lengths due to temperature change are computed.

\subsection{Terminology}

The 3DFE model does not require separation of the temperature profile into a gradient component and a component of uniform temperature change. This separation is needed only for Westergaard's thermal stress equations. The term "positive gradient" is used when the temperature of the slab top is larger than that of the slab bottom. Similarly, "negative gradient" is the term used when the temperature of the slab top is less than that of the bottom. In either case, the temperature of the middle plane is assumed (in Westergaard's analysis) to remain unchanged. For example, $+10^{\circ} \mathrm{C}$ gradient defines a condition in which the slab top may be at 
$35^{\circ} \mathrm{C}$ and the slab bottom at $25{ }^{\circ} \mathrm{C}$. The same gradient of $+10^{\circ} \mathrm{C}$ is also found when the temperature of the slab top is $6{ }^{\circ} \mathrm{C}$ and that of the bottom is $-4{ }^{\circ} \mathrm{C}$. A uniform temperature change applied to that slab means that the temperature through the slab thickness changes by the same amount throughout the slab depth.

\subsection{Curling Deflection}

Figure 5.1 illustrates the deflection profiles that a concrete slab takes due to the application of positive and negative linear gradients of $+10^{\circ} \mathrm{C}$ and $-10^{\circ} \mathrm{C}$ respectively. The choice of a linear gradient allows comparing the model results with those obtained using the closed form solution of Westergaard (1927). The deflection profiles of Westergaard can be computed using the following relations (Westergaard 1927):

a. Slab deflection along the transverse center line:

$$
\delta_{t}=-\delta_{o} \frac{2 \cos \lambda \cosh \lambda}{\sin 2 \lambda+\sinh 2 \lambda}\left[(-\tan \lambda+\tanh \lambda) \cos \frac{y}{l \sqrt{2}} \cosh \frac{y}{l \sqrt{2}}+(\tan \lambda+\tanh \lambda) \sin \frac{y}{l \sqrt{2}} \sinh \frac{y}{l \sqrt{2}}\right]
$$

where: $\lambda=\frac{b}{l \sqrt{8}}$

$$
\begin{aligned}
& l=\text { radius of relative stiffness }=\sqrt[4]{\frac{E h^{3}}{12\left(1-v^{2}\right) k}} \\
& \delta_{O}=\frac{l^{2}(1+v) \alpha t}{h}
\end{aligned}
$$

$E=$ Modulus of elasticity of the slab.

$v=$ Poisson's ratio.

$k=$ Modulus of subgrade reaction (we use the AASHTO 1995 charts to evaluate $k$ ).

$\alpha=$ Coefficient of thermal expansion of concrete.

$h=$ Slab thickness.

$t=$ Temperature difference of the slab top from bottom $\left(\mathrm{t}_{\mathrm{top}}-\mathrm{t}_{\mathrm{bottom}}\right)$. 
$b=$ Slab width.

$y=$ Distance along the $\mathrm{Y}$ axis (perpendicular to traffic direction).

b. Slab deflection along the longitudinal centerline of the slab:

$$
\delta_{l}=-\delta_{o} \sqrt{2} \cos \left(\frac{x}{l \sqrt{2}}+\frac{\pi}{4}\right) e^{-\frac{x}{l \sqrt{2}}}
$$

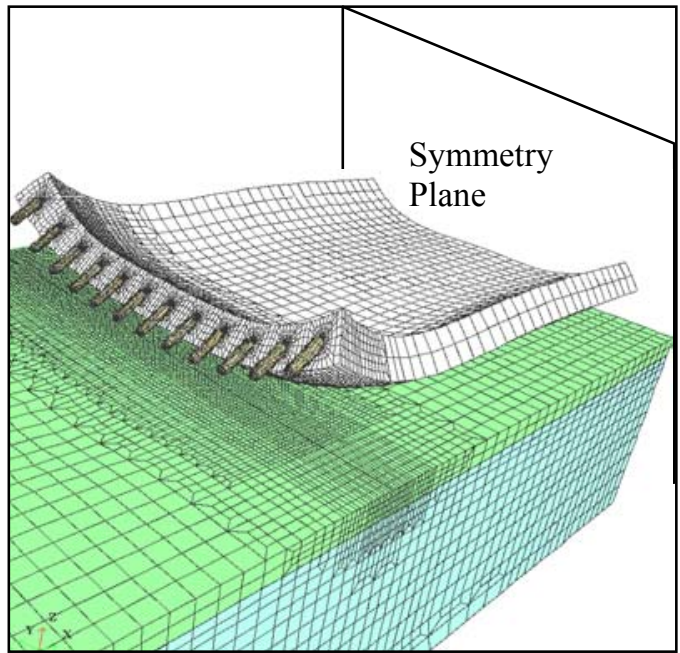

a. Gradient $-10{ }^{\circ} \mathrm{C}$

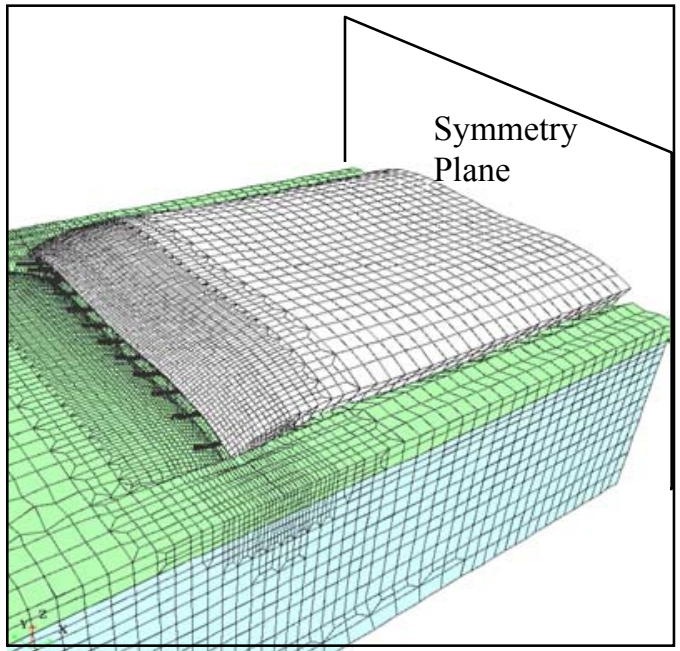

b. Gradient $+10{ }^{\circ} \mathrm{C}$

Figure 5.1 Deformed Slab Mesh.

Figures 5.2, 5.3, and 5.4 illustrate the deflection profiles obtained for 4.57, 6.1, 7.62, and $9.14 \mathrm{~m}$ long slabs for both types of gradient. The solid curve in each figure is the deflection obtained using Equations 1 or 2 according to the direction of the stress under consideration.

While Westergaard's solution is based on the assumptions of semi-infinite slab, infinite strip, full subgrade support, Winkler foundation, and no slab weight, the finite element solution is for a dowel-jointed slab of finite length and width supported on an elastic foundation with a slab-base interface that allows separation as indicated in Figure 5.1. The dowel bars tend to obstruct the slab curling thus reducing the slab deflection as illustrated in Figure 5.2 (at zero distance from 


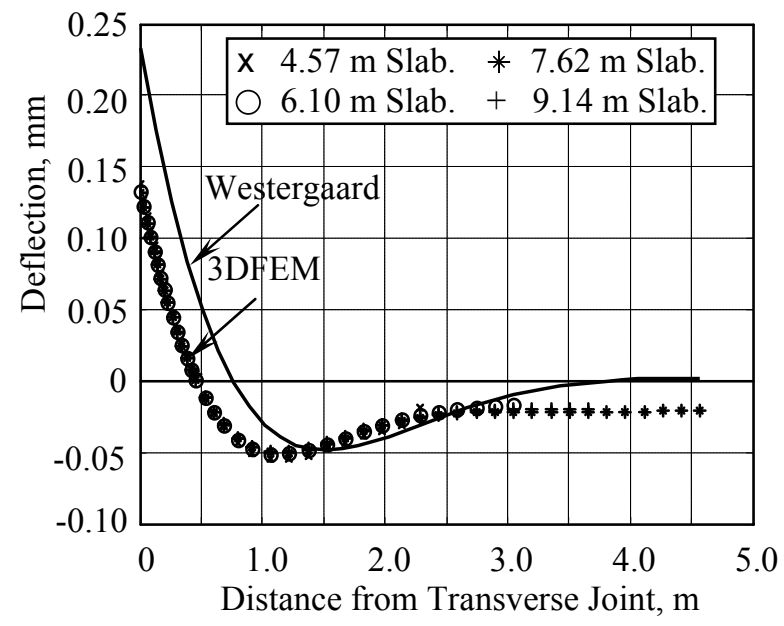

a. Gradient $-10^{\circ} \mathrm{C}$

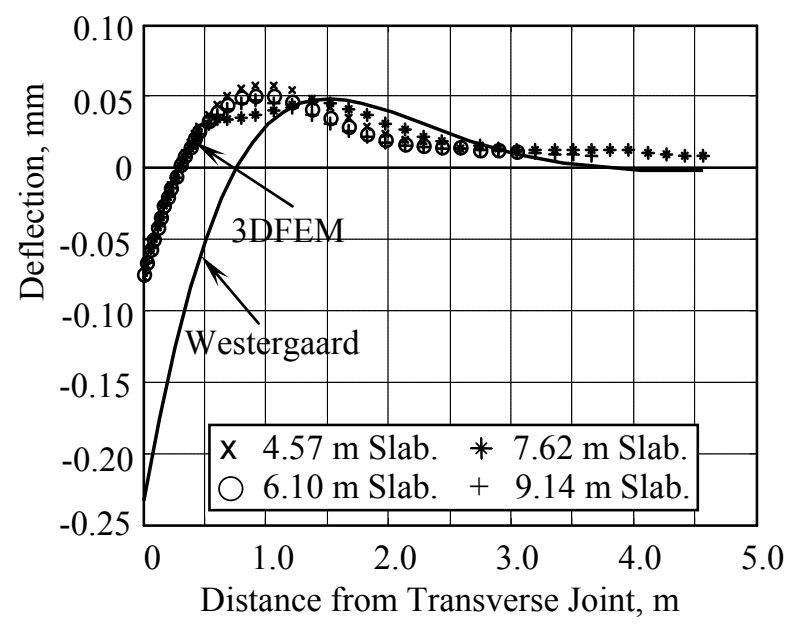

b. Gradient $+10{ }^{\circ} \mathrm{C}$

Figure 5.2 Slab Deflection along Longitudinal Centerline.

the transverse joint) and Figure 5.3. Figure 5.2 reveals that the slab weight acts in the middle portion of the slab to change the direction of the slope of the deflection curve, in the case of +10 ${ }^{\circ} \mathrm{C}$, while it reduces the overall transverse deflection in the case of $-10{ }^{\circ} \mathrm{C}$. Figure 5.2 (case of $10{ }^{\circ} \mathrm{C}$ ) indicates that the slab weight has caused a global settlement of the slab illustrated by a slight drop of the deflection curve below the zero line. The slab separation from the base at the joint edge is illustrated in Figures 5.1, 5.2, 5.3 and 5.4 (case of $-10^{\circ} \mathrm{C}$ ) by the positive deflection recorded from the finite element results. The longitudinal deflection profiles, illustrated in Figure 5.2, are typical of the experimentally measured profiles reported in Hveem, 1949 as shown in Figure 5.5. To facilitate the comparison in Figure 5.5, both the measured and 3DFEcomputed profiles shown in Figure 5.5 are normalized using the relation:

$$
\text { Normalized profile }=\left(\delta-\delta_{\min }\right) /\left(\delta_{\max }-\delta_{\min }\right)
$$

Where $\delta$ is the measured or $3 \mathrm{DFE}$-computed deformation at any point; $\delta_{\max }$ and $\delta_{\min }$ are the maximum and minimum profile deviations. The above normalization neutralizes the magnitude of temperature gradient making the comparison between slab profiles subjected to different magnitudes of temperature gradients. Plots in Figure 5.5 reveal that in both cases, the slope of 
the slab deflection curve reverses its direction as one moves away from the transverse joint to the slab center.

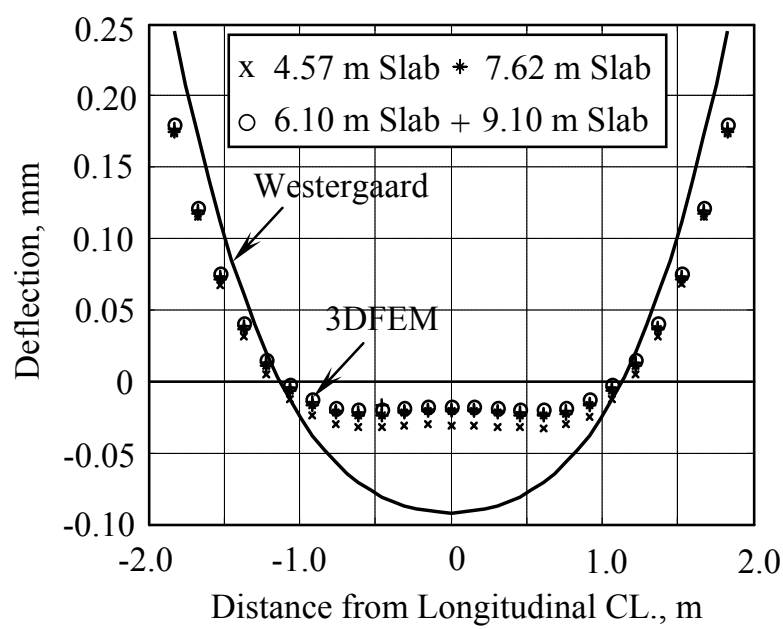

a. Gradient $-10^{\circ} \mathrm{C}$

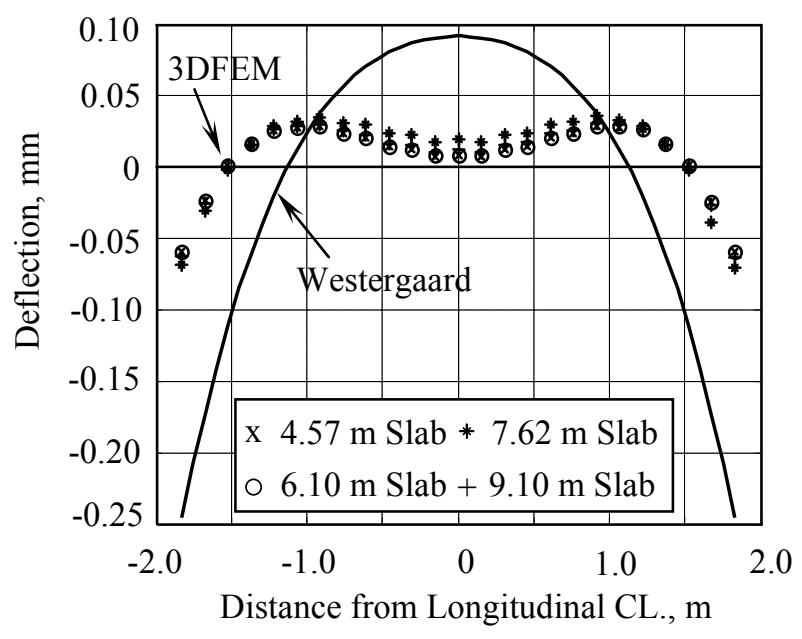

b. Gradient $+10^{\circ} \mathrm{C}$

Figure 5.3 Deflection at Mid-Slab along Transverse Centerline.

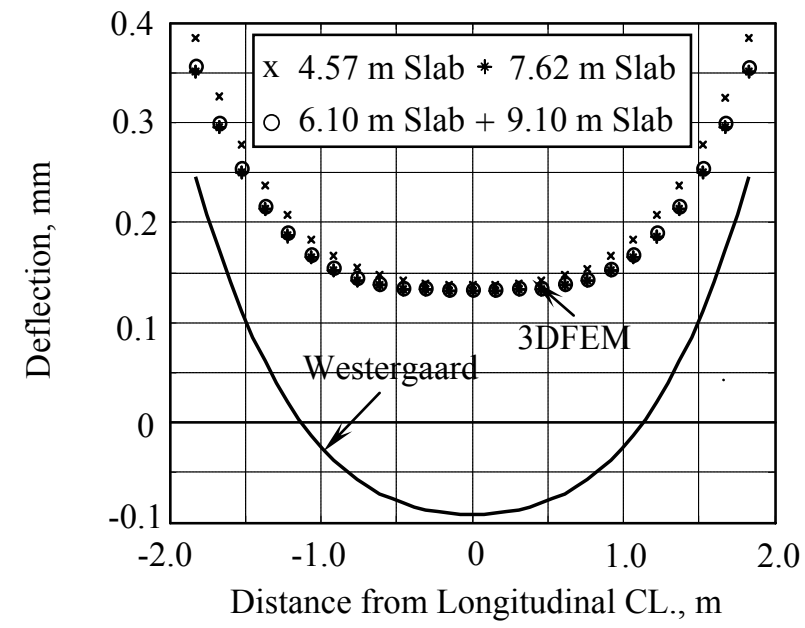

a. Gradient $-10^{\circ} \mathrm{C}$

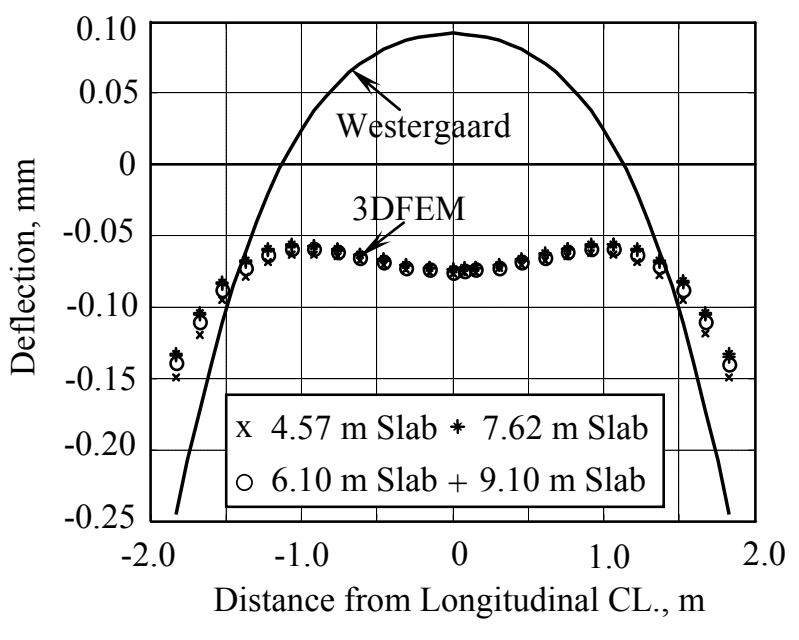

b. Gradient $+10^{\circ} \mathrm{C}$

Figure 5.4 Deflection Profile along Transverse Joint.

In the 3DFE model, as the slab loses support due to the thermal gradient, the reaction from the supporting base is no longer proportional to the slab deflection as was assumed in Westergaard's analysis. This reaction will be distributed over a smaller area of the slab bottom instead of the entire area. In the case of negative thermal gradient, the slab will be supported over its middle 
portion while the joints and slab side-edges deflect upwards (Figure 5.1 (a)). The high pressure caused by subgrade reaction on the middle portion, the weight of the unsupported slab edges, and the dowel bars at the transverse joints will act together to reduce the slab curvature in the middle. Inclusion of the slab weight in the 3DFE analysis reduced the deflection at the longitudinal slab edges from that calculated by Westergaard. In view of the deflection patterns observed in Figures 5.1 to 5.4, it is easy to postulate that a soft base may offer more uniform slab support than a rigid one, although the bending deflection may increase.

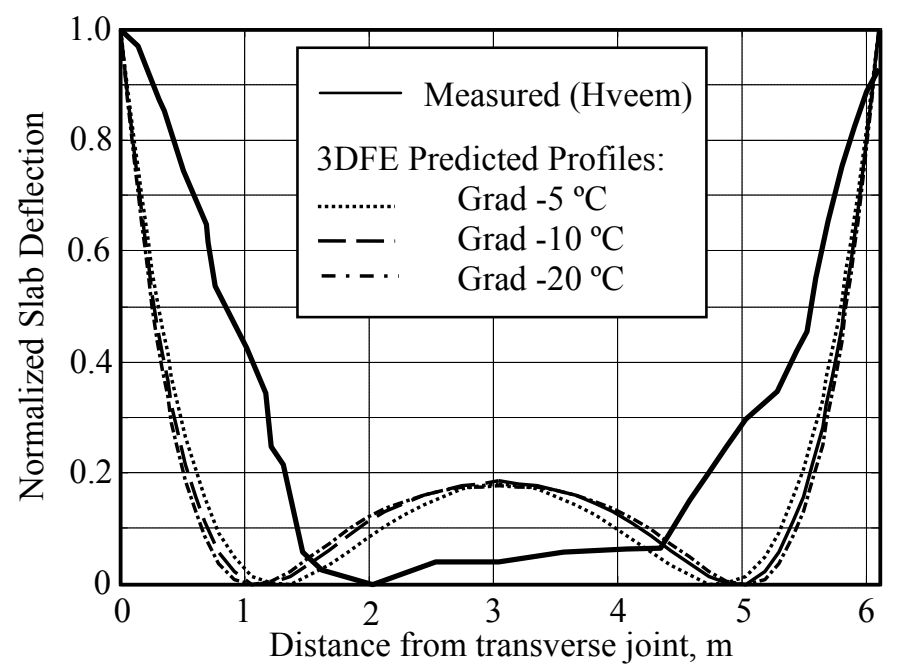

Figure 5.5 Measured Versus 3DFE-computed Slab Profiles.

In the case of the positive gradient, the slab edges deflect down into the base, as shown in Figure 5.1 (b), causing the base reactions to be concentrated at the slab longitudinal edges and transverse joints. The magnitude of the base reaction at mid slab will vary depending on the stiffness of the base layer. The higher reaction over the slab edges and the opposite force exerted by the weight of unsupported mid-slab region would act together to reduce the joint deflection with respect to the slab center (see Figures 5.3 and 5.4 for the case of $+10^{\circ} \mathrm{C}$ ).

Perhaps the most important observation in Figures 5.2 to 5.4 is that both the 3DFE results and Westergaard's closed form solution indicate that the change in slab length from 4.57 to $9.14 \mathrm{~m}$ did not influence the shape or magnitude of the slab-deflection, due to curling, along the longitudinal centerline, transverse centerline, or the doweled joint edge. This implies that the 
magnitude of loss of slab support at the transverse joint (due to linear gradient) is independent of the slab length. Similarly, the dowel bending deflection is also independent of slab length. The consequence of this observation will become clear as we examine the stress distributions.

\subsection{Curling Stresses}

The 3DFE-computed longitudinal and transverse stresses for different slab lengths were compared with the corresponding Westergaard-calculated stresses according to the following relations (Westergaard, 1927):

$\sigma_{o}=\frac{E \alpha t}{2(1-v)}$

$\sigma_{x}=\sigma_{o}\left[1-\sqrt{2} \sin \left(\frac{x}{\sqrt{2} l}+\frac{\pi}{4}\right) e^{-\frac{x}{\sqrt{2} l}}\right]$

$\sigma_{y}=\sigma_{o}\left[1-\frac{2 \cos \lambda \cosh \lambda}{\sin 2 \lambda+\sinh 2 \lambda}\left((\tan \lambda+\tanh \lambda) \cos \frac{y}{l \sqrt{2}} \cosh \frac{y}{l \sqrt{2}}+(\tan \lambda-\tanh \lambda) \sin \frac{y}{l \sqrt{2}} \sinh \frac{y}{l \sqrt{2}}\right)\right]$

Where: $\sigma_{\mathrm{o}}$ is the stress at the slab center (the point of intersection between the longitudinal and transverse centerlines), $\sigma_{\mathrm{x}}$ is the longitudinal stress in the direction of the longitudinal centerline, and $\sigma_{\mathrm{y}}$ is the transverse stress in the direction of the transverse centerline. Equations 5.5 and 5.6 were developed for a semi-infinite slab and infinite strip respectively. Bradbury, 1938 suggested that the maximum stress in a finite length slab might be evaluated by applying Equation 5.6 (for the infinite strip) once in the $\mathrm{y}$ direction and once in the $\mathrm{x}$ direction and summing the result as follows:

$\sigma_{x}=\frac{E \alpha t}{2\left(1-v^{2}\right)}\left(C_{x}+v C_{y}\right), \quad \quad \sigma_{y}=\frac{E \alpha t}{2\left(1-v^{2}\right)}\left(C_{y}+C_{x}\right)$ 
Where $\mathrm{C}_{\mathrm{x}}$ and $\mathrm{C}_{\mathrm{y}}$ are determined from Bradbury's 1938, chart.

Comparison of the 3DFE-computed transverse stress (positive in tension), due to $+10{ }^{\circ} \mathrm{C}$ gradient, with that obtained using Equation 5.6 is shown for different slab lengths in Figures 5.6$a$ and $b$. At mid-slab the 3DFE solution differs by 9.4 percent from that obtained using Equation 5.6. As we move along the longitudinal centerline of the slab, towards the joint edge, the deviation from Equation 5.6 increases until it reaches a maximum of 16 percent at the doweled transverse joint. This indicates that dowel bars introduced additional stress at the transverse joint. The transverse stress obtained for the case of $-10{ }^{\circ} \mathrm{C}$ gradient is equal in profile and opposite in sign to that found for $+10{ }^{\circ} \mathrm{C}$ gradient.

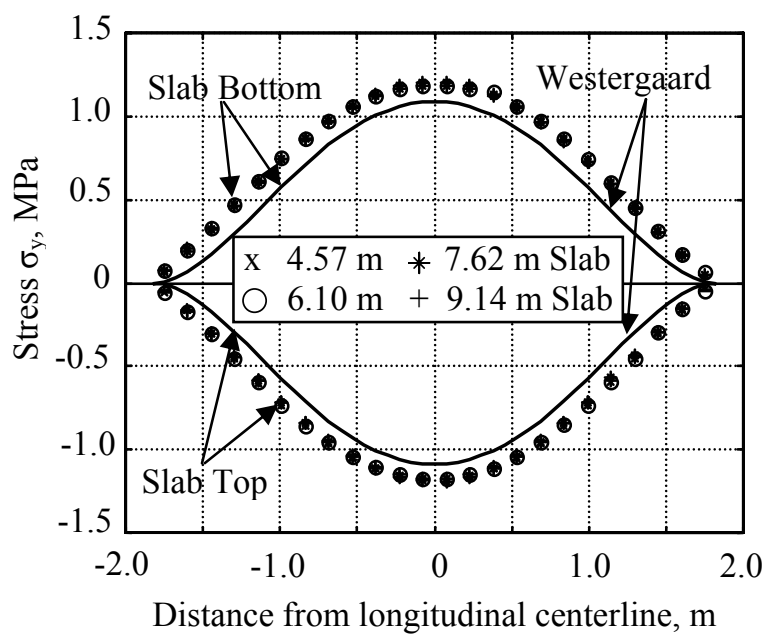

a. $\sigma_{\mathrm{y}}$ along mid-slab.

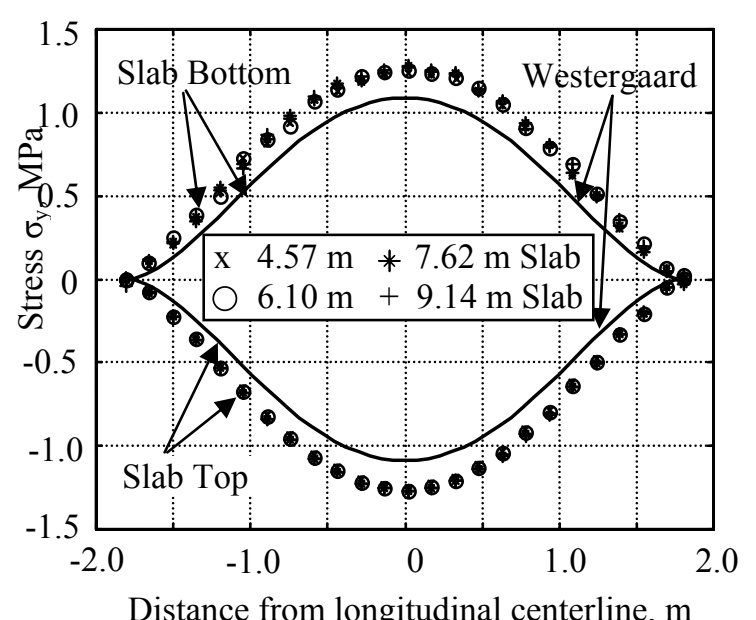

Distance from longitudinal centerline, $\mathrm{m}$

b. $\sigma_{\mathrm{y}}$ along transverse joint.

Figure 5.6 Transverse Stress Due to Positive Gradient of $+10^{\circ} \mathrm{C}$. (The discrete points show the 3DFE-computed stress)

The maximum tensile transverse stresses obtained from the 3DFE model for different slab lengths are compared with those found using Bradbury's chart and Equation 5.6 in Table 5.1. The 3DFE model produced slightly larger maximum stresses that may be attributed to the effects of slab weight, interface separation, and dowel bars that were neglected in Westergaard's analysis and subsequently in Bradbury's chart. Similar to Equation 5.6 and Bradbury's results, the 3DFE model did not show significant sensitivity to slab length within the range considered in this study. 
Table 5.1 Maximum Transverse Stress at Mid Slab for $-10^{\circ} \mathrm{C}$ Gradient.

\begin{tabular}{cccc}
\hline Slab Length $(\mathrm{m})$ & 3DFE & Westergaard's Eq. 5.6 & Bradbury's Chart \\
\hline 4.57 & 1.2053 & 1.0882 & 1.1408 \\
\hline 6.10 & 1.1876 & 1.0882 & 1.1449 \\
\hline 7.32 & 1.1874 & 1.0882 & 1.1354 \\
\hline 9.14 & 1.1842 & 1.0882 & 1.1298 \\
\hline
\end{tabular}

The 3DFE-computed distribution of the longitudinal normal stress along the slab centerline is shown in Figure 5.7 (a) and b for different slab lengths. Figure 5.7 also illustrates the longitudinal stress calculated using Westergaard's Equation 5.5. The 3DFE results indicate that the slab length did not have a significant effect on the longitudinal stress, which is in excellent agreement with Westergaard's Equation 5.5. Up to a distance of approximately $95 \mathrm{~cm}$ $\approx \ell \sqrt{2}$ both the 3 DFE model and Equation 5.5 produced values of longitudinal stress that differ by less than $8 \%$. After that distance, the 3DFE longitudinal stress starts to show increasing deviation from the stress given by Equation 5.5.

Table 5.2 Maximum Longitudinal Stress at Mid Slab for $-10^{\circ} \mathrm{C}$ Gradient.

\begin{tabular}{cccc}
\hline Slab Length $(\mathrm{m})$ & 3DFE & Westergaard's Eq. 4.5 & Bradbury's Chart \\
\hline 4.57 & 1.2235 & 1.4210 & 1.3892 \\
\hline 6.10 & 1.1141 & 1.4210 & 1.4129 \\
\hline 7.32 & 1.1133 & 1.4210 & 1.3436 \\
\hline 9.14 & 1.1226 & 1.4210 & 1.3090 \\
\hline
\end{tabular}

Table 5.2 illustrates a numerical comparison between the maximum longitudinal stress obtained from the 3DFE model and the corresponding stresses obtained using Equation 5.5 and Bradbury's chart. The results of Figure 5.7 and Table 5.2 indicate that Westergaard's longitudinal curling equation overestimates the longitudinal stress due to temperature gradient. This is the same conclusion that was reached by Iwama 1963, who found that (based on experimental measurements) a multiplier of 0.7 should be applied to Equation 5.5. Nishizawa, 1998 suggested that this factor should be modified to 0.75 for reinforced concrete pavements. The 3DFE data in Table 5.2 suggest that this multiplier should be 0.78 , however if such 
multiplier is applied to Equation 5.5, the deviation between the 3DFE and Westergaard's results increases near the joint, i.e. at distances less than $\ell \sqrt{2}$. To rectify this situation, both the angle and exponent terms of equation 5.5 should be adjusted. Based on the 3DFE-results it was found that Westergaard's longitudinal curling stress given by Equation 5.5 should be modified to:
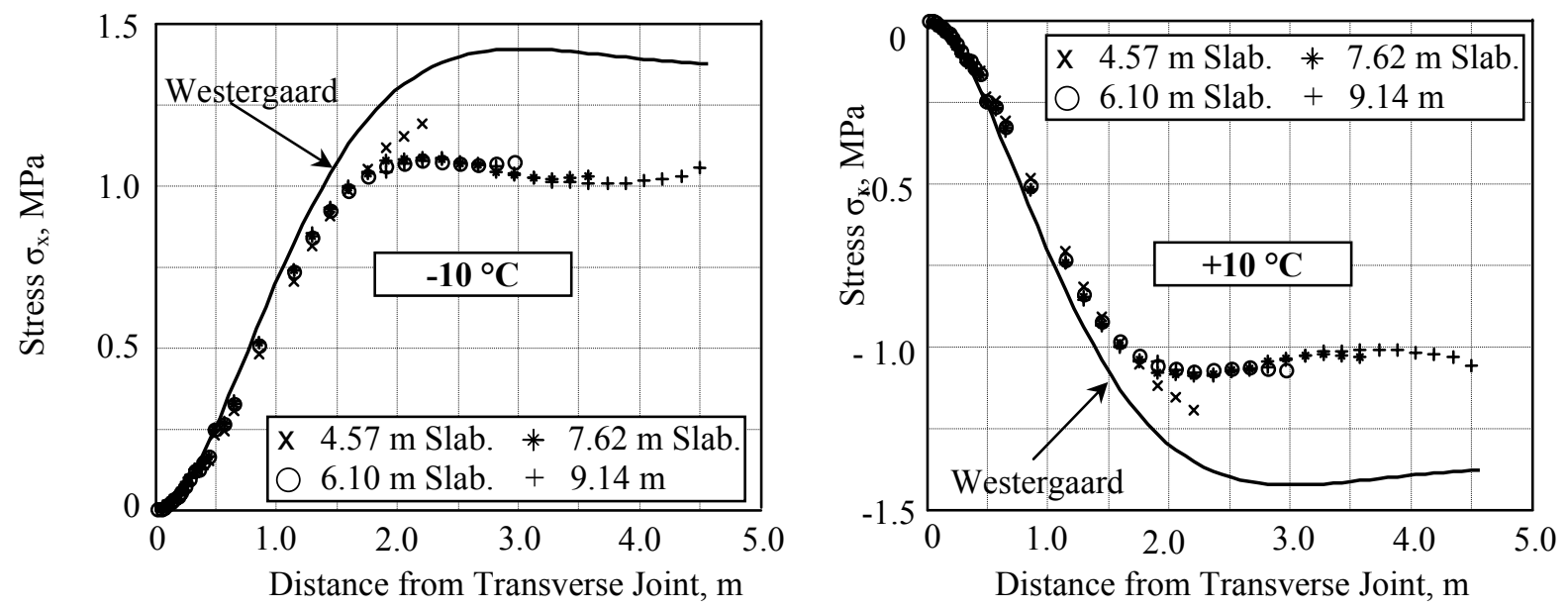

a. Slab Top.
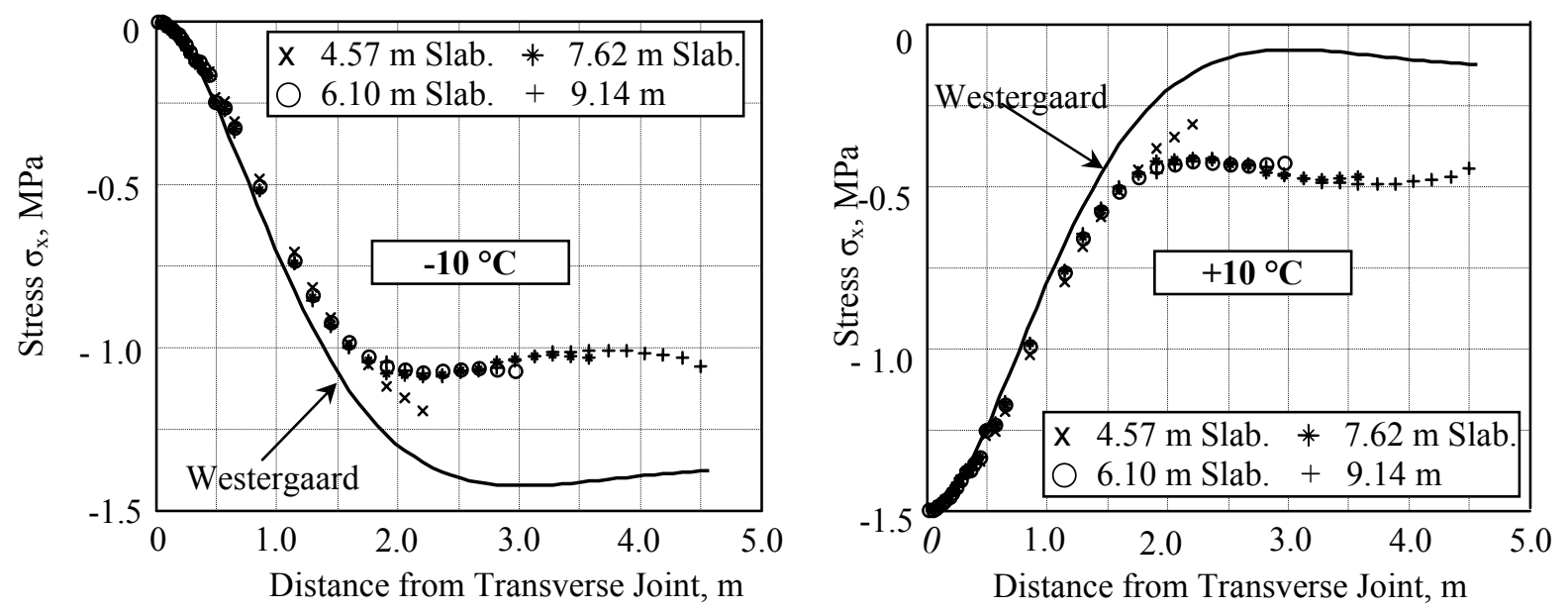

b. Slab Bottom

Figure 5.7 Comparison of 3DFE-Computed Longitudinal Stress $\sigma_{\mathrm{x}}$ with Westergaard's Solution. 
$\sigma_{x}=0.78 \sigma_{o}\left[1-\sqrt{2} \sin \left(\frac{1.52 x}{l \sqrt{2}}+\frac{\pi}{4}\right) e^{-\frac{1.52 x}{l \sqrt{2}}}\right]$

Figure 5.8 illustrates a comparison between the 3DFE-computed longitudinal stress and the corresponding stresses obtained using Equation 5.8 for different slab lengths subjected to negative gradients of $-5,-10$, and $-20{ }^{\circ} \mathrm{C}$. The results indicate that the maximum longitudinal stress is approximately linearly proportional to the temperature gradient; i.e doubling the gradient would double the stress. It is worth mentioning that the stresses due to negative thermal gradient were found to be equal in magnitude and opposite in direction to those due to the positive gradient as illustrated in Figure 5.7.

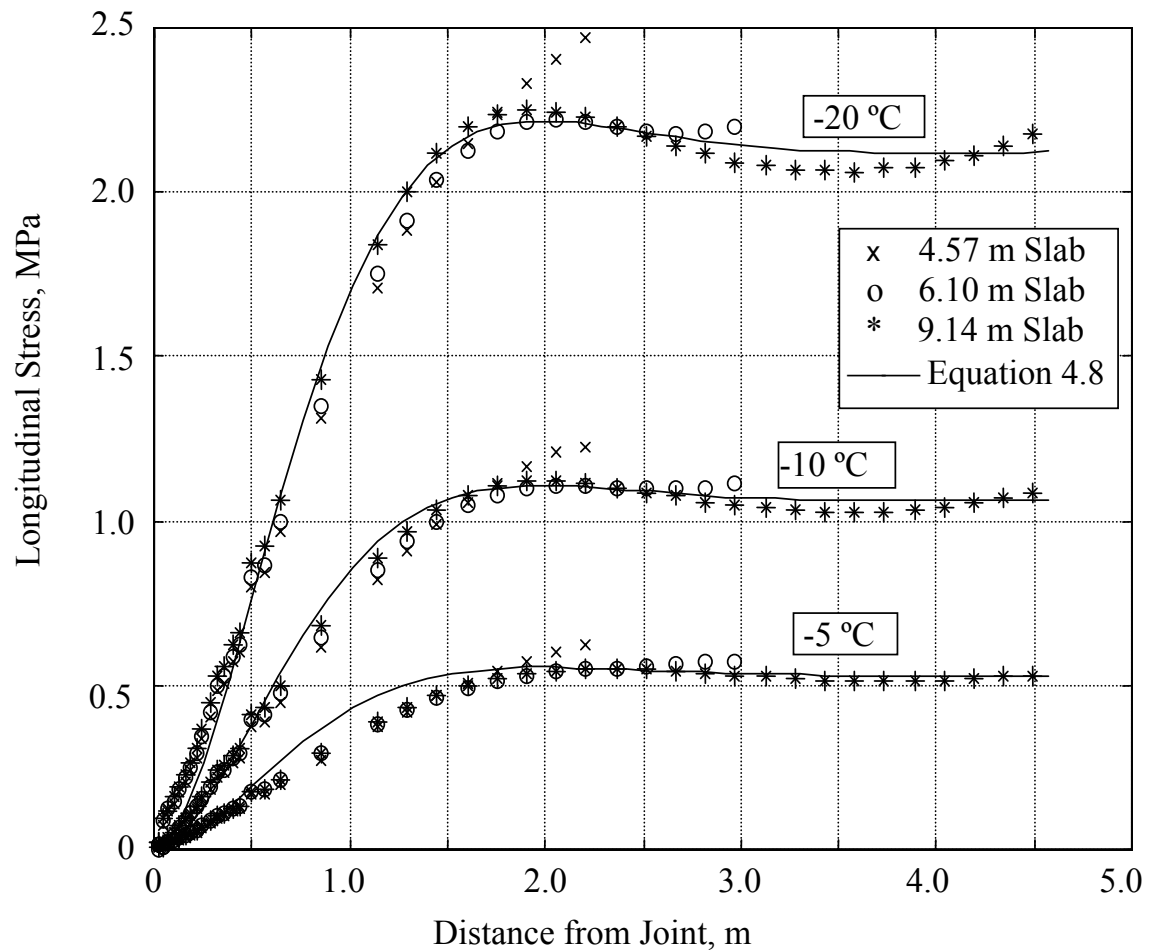

Figure 5.8 Effect of Magnitude of Temperature Gradient on Longitudinal stress. (The discrete points show the 3DFE-computed stress) 


\subsection{Discussion}

The comparison between the 3DFE model results indicates a remarkable qualitative agreement with Westergaard's curling deflection and stress formulation. The quantitative differences can be traced to the simplifying assumptions made by Westergaard to obtain a closed form solution. The 3DFE model results for the transverse stress at mid-slab length agreed both qualitatively and quantitatively with Westergaard results. On the other hand, the quantitative difference observed in the case of the longitudinal stress is of the same magnitude as the experimentally observed difference reported by Iwama (1963) and Nishizawa et al. (1998). The above comparison indicates that the 3DFE model, developed in this study, is suitable for the prediction of the magnitudes of curling stresses without making any of the assumptions used in Westergaard's formulation. On the other hand, Westergaard's equations can predict the magnitude and distribution of the curling stresses (after using the correction of Equation 5.8) without the need for $3 \mathrm{DFE}$ analysis. This last statement was shown to be valid, at least, for dowel jointed concrete slabs of any lengths between $4.57 \mathrm{~m}$ and $9.14 \mathrm{~m}$.

The results from the 3DFE model, in which the concrete slab is of finite width and length, indicate that the maximum transverse stress exceeds the longitudinal stress at the slab center. This is expected since Westergaard's analysis of longitudinal stress is based on the assumption of an infinite slab width. This assumption makes the transverse strain equal to zero along the longitudinal centerline. The 3DFE model is free of such an assumption. Therefore, the transverse strain has a finite value at mid slab that makes the 3DFE-computed stresses larger than that of Westergaard in accordance to the theory of thermoelasticity (Timoshenko, 1987).

According to the results listed in Tables 5.1 and 5.2, the 3DFE model, Westergaard's curling stress equations, and Bradbury's chart agree that the concrete slab length has an insignificant influence on the magnitude of curling stresses anywhere in the slab. If we accept any of the three curling stress evaluation methods, then the immediate conclusion is that curling cannot be used to explain the documented Long Term Pavement Performance (LTPP) program observations that the number of transverse cracks increase as the slab length increases (Smith et al., 1998). Moreover curling stresses, calculated using any of the methods cited in this paper, are 
incapable of explaining the development of a transverse crack in a $6.1 \mathrm{~m}$ slab, in absence of any traffic loading, while an adjacent $4.57 \mathrm{~m}$ long slab that has the same thickness and is subjected to the same temperature distribution remains intact. Figure 5.8 indicates that a temperature gradient of $-10{ }^{\circ} \mathrm{C}$ associated with another $-10^{\circ} \mathrm{C}$ of equivalent moisture gradient and built-in curling would not be sufficient to induce transverse cracks in any of the slabs studied. However, even if the total magnitude of the temperature and moisture gradients is large enough, slabs of different lengths will reach the fracture stress together.

\subsection{Effect of Uniform Temperature Change}

The basic assumption made by Westergaard in his analysis of thermal stresses is that change in the temperature distribution through the slab thickness can be separated into a gradient component and a uniform temperature component. Traditionally, the gradient component received the most attention as the uniform temperature component was postulated to cause small stresses in accordance with the subgrade drag theory (Yoder and Witczak 1975). This argument is correct as long as there are no other external forces, other than friction, that resist slab contraction due to uniform temperature change. However, if dowel bars are placed at the transverse joints the situation becomes completely different. Since both the temperature gradient and the uniform temperature change take place simultaneously, the dowel bars bend as the slab contracts. Contraction of a curled slab will be resisted by bent dowels introducing additional tensile stresses that have not been previously accounted for in the literature on thermal stresses in rigid pavements. The bent dowels (due to curling) act as anchors that restrict the slab from contraction as illustrated in Figure 5.9. Subsequently the bent dowels will cause the stresses in the slab to change with every degree of increase or decrease in uniform temperature.

The separation of temperature change into two components, gradient and uniform cannot lead to a correct evaluation of the thermal stresses under the circumstances of slab constraints. When the slab temperature is $20^{\circ} \mathrm{C}$ on top and $30^{\circ} \mathrm{C}$ on the bottom, stresses will be different from those induced if the temperature on top was $5{ }^{\circ} \mathrm{C}$ and $15{ }^{\circ} \mathrm{C}$ on the bottom. Moreover, the seasonal change in temperature will influence the magnitude of thermal stresses in the slab. A 


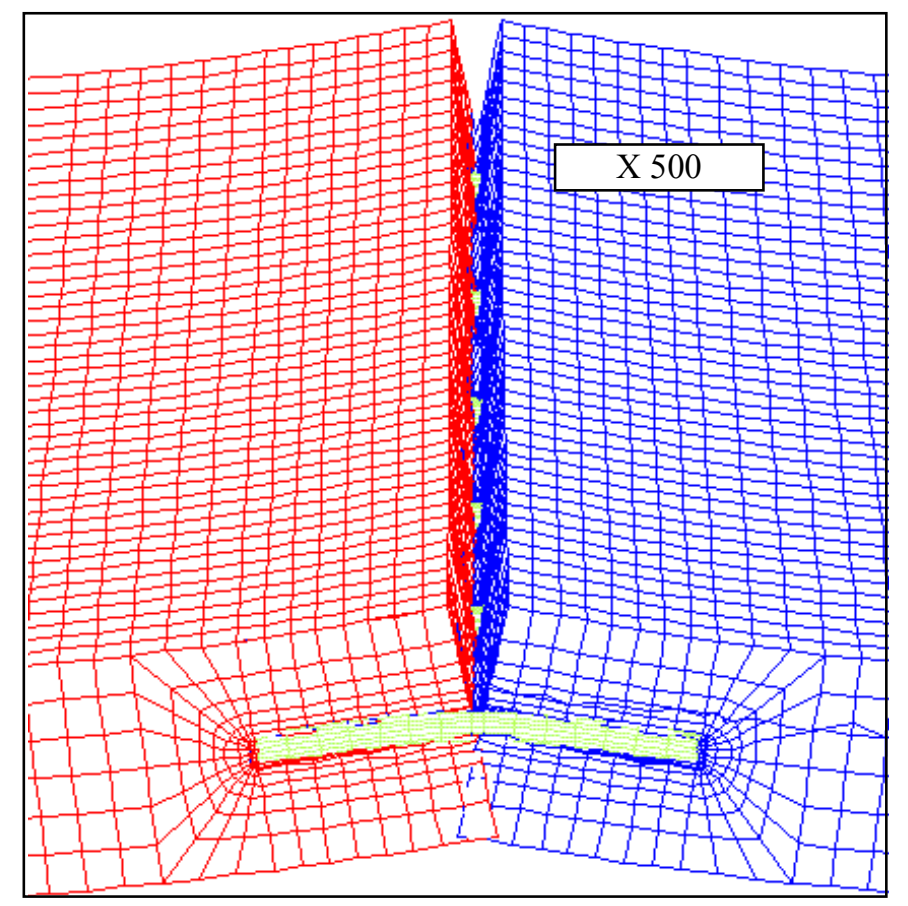

Figure 5.9 Cross-Section Through the Center Dowel of a Curled Slab.

slab constructed in the summer is expected to carry tensile stresses throughout the cold winter irrespective of the magnitude of the thermal gradient. Similarly, a slab placed in the morning on a hot summer day may undergo tensile stress during the cold night when the ambient temperature drops. In all of these situations, the frictional characteristics of the dowel-concrete interfaces and the amount of dowel looseness will have a significant influence on the stresses induced in the slab due to temperature change. This leads to the conclusion that current $2 \mathrm{D}$ and $3 \mathrm{D}$ finite element models of rigid pavements cannot be used for the assessment of stresses in dowel jointed concrete pavements unless they include a detailed modeling of dowel bars and dowel concrete interfaces. The solution's accuracy depends on the proper simulation of a three-dimensional dowel-concrete interface that models friction contact and separation along the full length of the cylindrical dowel-concrete interface for each dowel along the transverse joint. The 3DFE model developed in this study was designed with these requirements in mind. Figure 5.10 illustrates that the bending deflection of dowel bars along the transverse joint will vary according to the dowel position. This can also be seen from the curves of Figure 5.4. 


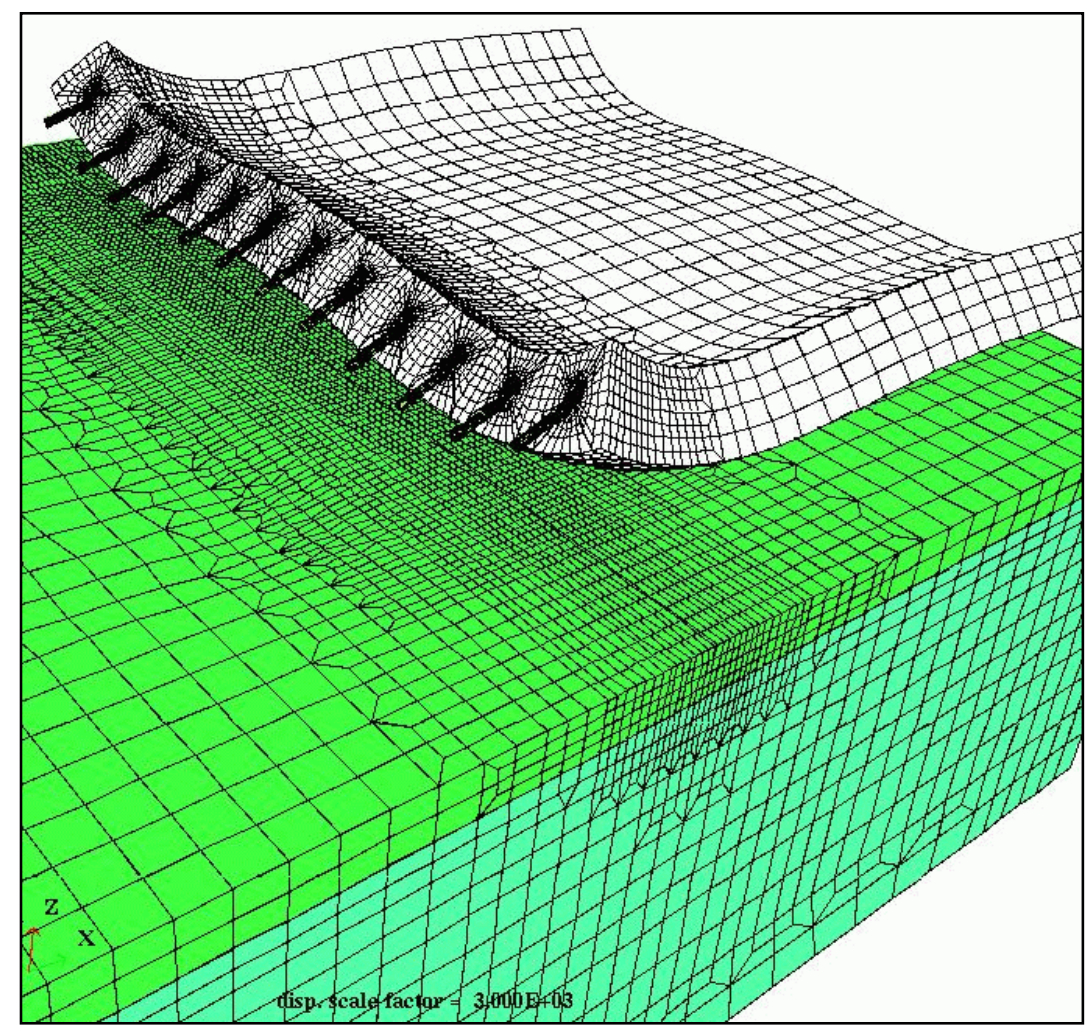

Figure 5.10 Deformation of Dowel Bars Along Transverse Joint (X3000).

Figure 5.11 illustrates the transverse and longitudinal stresses induced in a concrete slab due to a uniform temperature change of $-16.67^{\circ} \mathrm{C}$ combined with a temperature gradient of $-10{ }^{\circ} \mathrm{C}$. The model handles the temperature change from a reference temperature value that was assumed to be constant through the slab thickness (only for the purpose of demonstration). Figure 5.11 also reveals a definite influence of the slab length on both the longitudinal and transverse stresses. The tensile transverse stress on the slab top, shown in Figure 5.11 (a), is much smaller than the tensile longitudinal stress in Figure 5.11 (b). This indicates that mid-slab cracking will be in the transverse direction. Figure 5.11 (b) illustrates that a temperature drop of $-16.67{ }^{\circ} \mathrm{C}$ increased the tensile stress in the $9.14 \mathrm{~m}$ slab by 151 percent compared to the curling case shown in Figure 5.7 (a). The $-16.7{ }^{\circ} \mathrm{C}$ uniform drop is relatively small considering that the ambient temperature variation could easily exceed $50^{\circ} \mathrm{C}\left(90^{\circ} \mathrm{F}\right)$ from summer construction to winter. It is important to remember that the results of Figure 5.11 were obtained with the assumption that a clearance of 
25 microns exists between each dowel and the surrounding concrete. If the dowel-concrete bonding is strong due to any reason, the magnitude of the tensile stresses would increase.
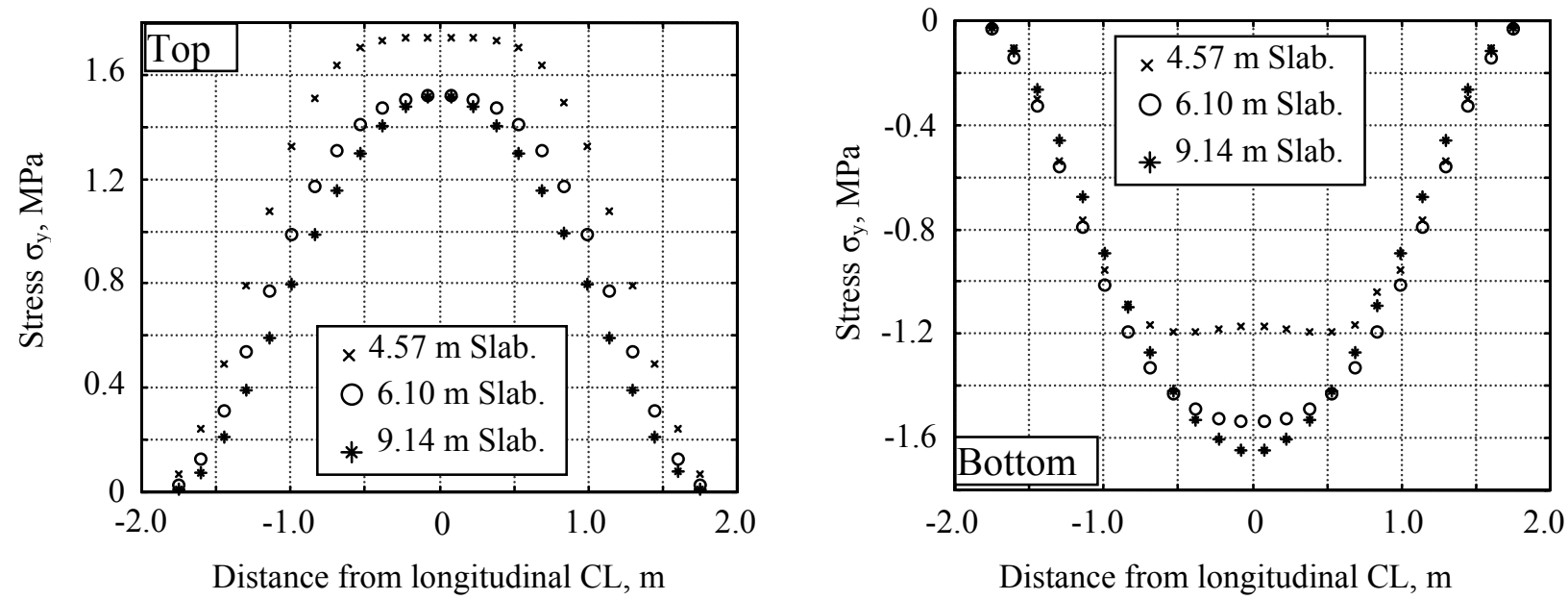

a. Transverse stresses along transverse centerline.
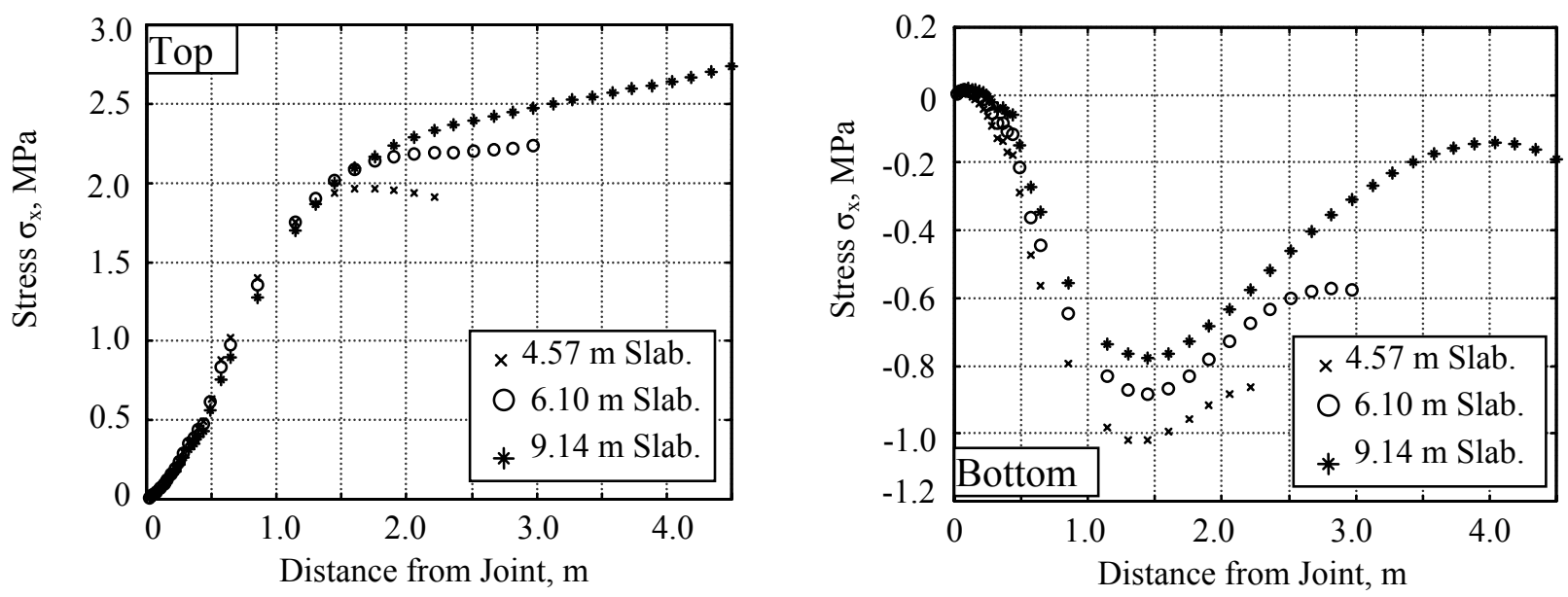

b. Longitudinal stresses along longitudinal centerline.

Figure 5.11 Stresses Due to $-10{ }^{\circ} \mathrm{C}$ Linear Gradient Combined With $-16.67{ }^{\circ} \mathrm{C}$ Uniform Drop.

The 3DFE model results revealed that the longitudinal stresses in three slabs of lengths 4.57, 6.10 , and $9.14 \mathrm{~m}(15,20$, and $30 \mathrm{ft})$ subjected to the same temperature gradient of $-10{ }^{\circ} \mathrm{C}\left(18^{\circ} \mathrm{F}\right)$, will reach the modulus of rupture of concrete at uniform drops of $-50,-33.3$, and $-16.7{ }^{\circ} \mathrm{C}(-90$, 60 , and $-30^{\circ} \mathrm{F}$ ) respectively. Those uniform temperature magnitudes will change by changing 
the dowel-concrete bond characteristics, the magnitude and profile of the temperature gradient, and the material properties of concrete including Poisson's ratio. The results indicate the dependency of mid-slab transverse cracking on the slab length on one hand and a better performance of the $4.57 \mathrm{~m}(15 \mathrm{ft})$ long slab on the other hand.

\subsection{Conclusion}

Westergaard's longitudinal curling stress equation should be corrected in accordance with Equation 5.8, while the transverse curling stress equation produces results that are in close agreement with the 3DFE model results. However, curling stresses in doweled concrete slabs are small in comparison with the additional stress induced due to a uniform temperature change. Therefore, Westergaard's curling stress equations should not be used for more than what they were intended for i.e. calculation of curling stress that is only a component of the overall thermal stress in a concrete slab. The uniform temperature component in a dowel jointed concrete slab gives rise to tensile stress sufficient to initiate transverse cracks and correlates well with slab length. Only through considering the actual temperature profile in a concrete slab, could field observations of the relation between mid-slab transverse cracking and slab length be explained. 


\section{CHAPTER SIX}

\section{NONLINEAR TEMPERATURE GRADIENT EFFECTS IN DOWEL JOINTED CONCRETE SLABS}

\subsection{Introduction}

In Chapter 5, 3DFE analysis was utilized to examine the model response to linear temperature gradient profile, the model response showed an excellent agreement with Westergaard's (1927) curling equations (see also William and Shoukry, 2001). However, doubts were raised regarding the applicability of such an agreement to the cases of nonlinear temperature gradient profiles, the pavement response to which is least understood. In this chapter, the effect of nonlinearity in Temperature Gradient Profile (TGP) on strain, slab profile, and stress that develop in a dowel jointed concrete slab is examined using nonlinear 3D Finite Element (3DFE) modeling. Results indicate that the nonlinearity in temperature gradient profile has its maximum effect on the longitudinal stress near the end of the embedded parts of dowel bars, i.e. at transverse joints. A temperature gradient profile that includes a uniform temperature drop is shown to induce a large magnitude of tensile thermal stress at mid slab. This stress is unaffected by nonlinearity in the temperature gradient profile and depends on the magnitude of uniform temperature drop and the difference between slab top and bottom temperatures. Dowel bar bending due to slab curling causes significant edge restraint to slab contraction and expansion.

\subsection{Gradient Nonlinearity Characterization}

Measured TGP through the thickness of a concrete slab has been traditionally visualized as the sum of two components: gradient and uniform components (Westergaard, 1927). Referring to Figure 6.1, the difference between slab top and bottom temperatures $\left(T_{t}-T_{b}\right)$ is used to quantify 
the magnitude of the TGP described by the curve $T_{t} T_{m} T_{b}$. To quantify the nonlinearity of a TGP, a hypothetical mid-thickness temperature " $\mathrm{T}_{\mathrm{th}}$ " is found from:

$$
\mathrm{T}_{\mathrm{th}}=\mathrm{T}_{\mathrm{t}}+\left(\mathrm{T}_{\mathrm{b}}-\mathrm{T}_{\mathrm{t}}\right) / 2=\left(\mathrm{T}_{\mathrm{t}}+\mathrm{T}_{\mathrm{b}}\right) / 2
$$

Obviously, if the TGP is linear, $\mathrm{T}_{\text {th }}$ becomes the actual measured mid-thickness temperature $\mathrm{T}_{\mathrm{m}}$. The difference between $T_{\text {th }}$, and $T_{m}$, may be used to quantify the magnitude of nonlinearity $\tau$ of a TGP so that:

$$
\tau=\mathrm{T}_{\mathrm{m}}-\mathrm{T}_{\mathrm{th}}
$$

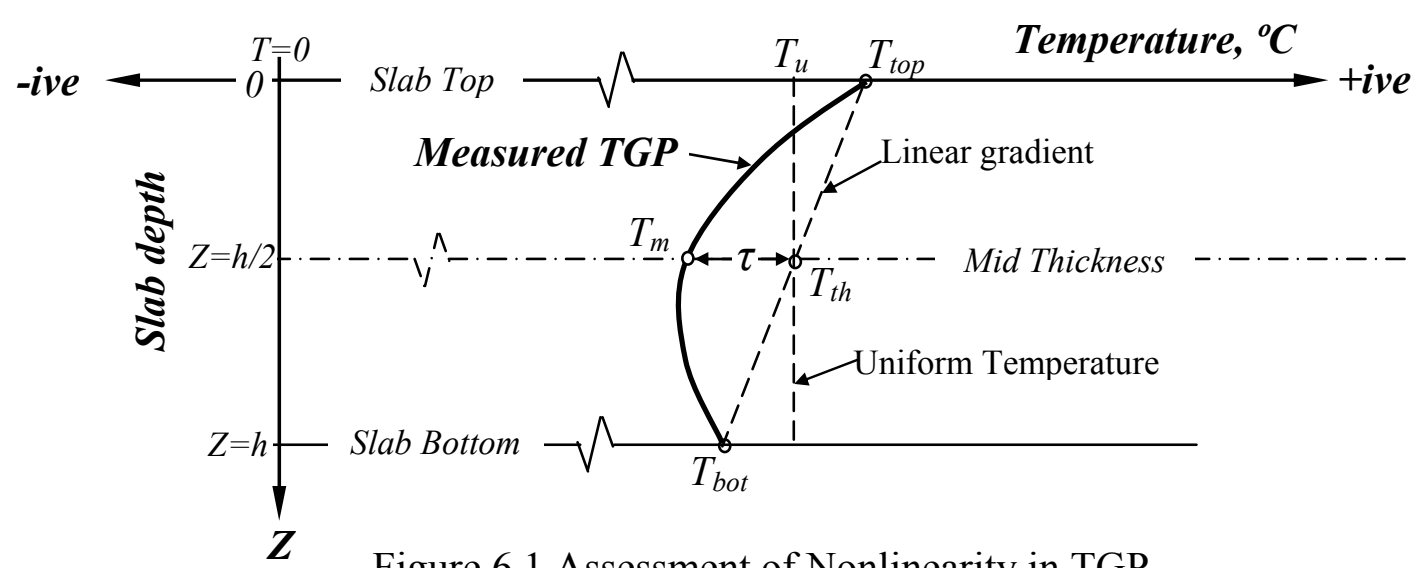

Figure 6.1 Assessment of Nonlinearity in TGP.

Referring to Figure 6.1, seasonal changes in temperature cause the measured TGP to translate and change slope along the temperature axis in either positive or a negative direction, depending on whether the ambient temperature increases or decreases respectively. Thus, seasonal temperature changes may be quantized by the increase or decrease in the magnitude of the uniform temperature $\mathrm{T}_{\mathrm{u}}$, expressed as $\mathrm{T}_{\mathrm{th}}$ that can be obtained from Equation 6.1 .

Since the 3DFE model, used in this study, accepts any nonlinear temperature gradient profile, the above classification is used only for the limited purpose of quantifying the magnitude and 
nonlinearity of a TGP. This facilitates the investigation of the change in slab strain, profile, or stress as $\tau$ varies for a specific nonlinear magnitude of TGP quantized by $\left(T_{t}-T_{b}\right)$.

\subsection{Effect of TGP Nonlinearity on Slab Strain}

The effect of nonlinearity in a gradient of magnitude $-10^{\circ} \mathrm{C}$ on through-thickness strain profile of a $0.254 \mathrm{~m}$ (10 in.) thick slab is illustrated in Figure 6.2. The effect of dowel bars is manifested through the nonlinearity in the strain profiles of Figure 6.2 (a) and (b). Since the free edge of the transverse joint does not restrain the longitudinal deformation of the slab, the nonlinearity in

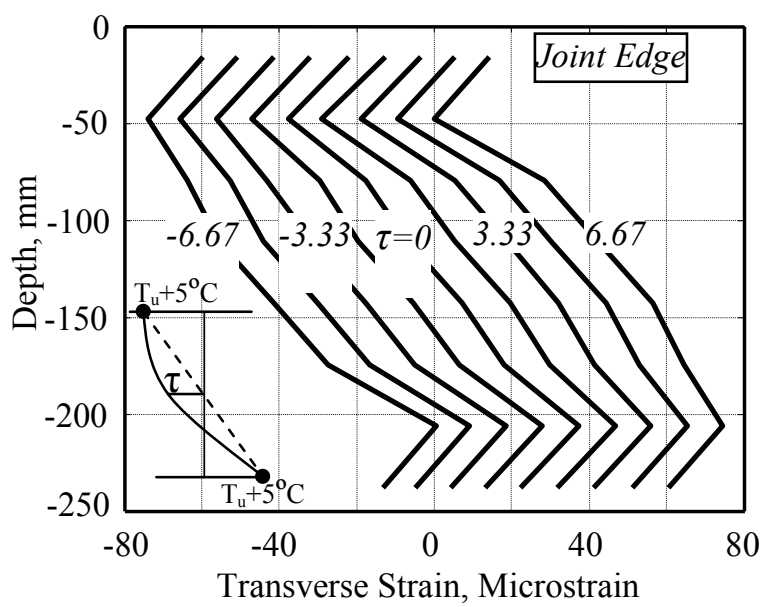

a. Transverse Strain at Slab Edge.

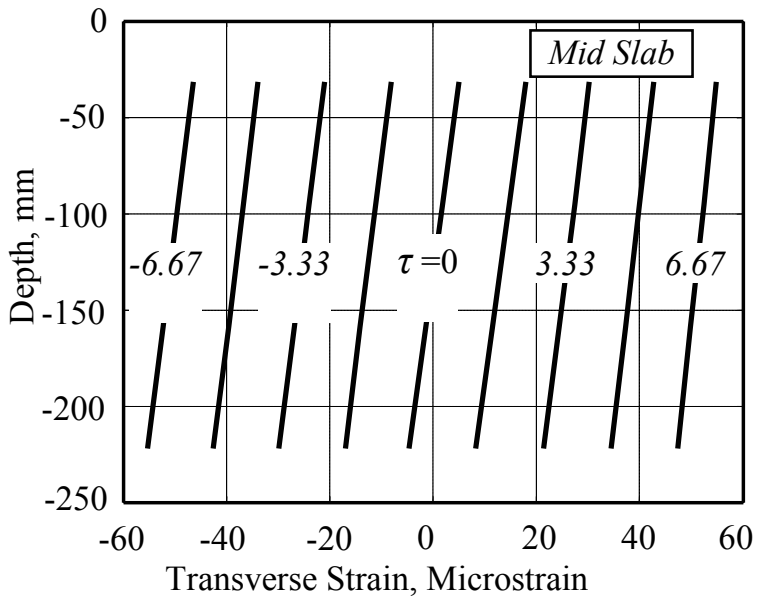

c. Transverse Strain at Slab Edge.

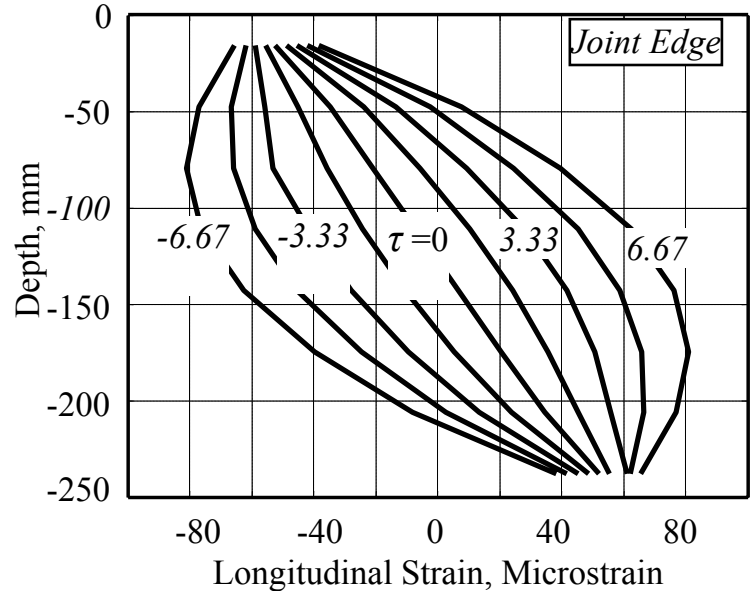

b. Longitudinal Strain at Slab Edge.

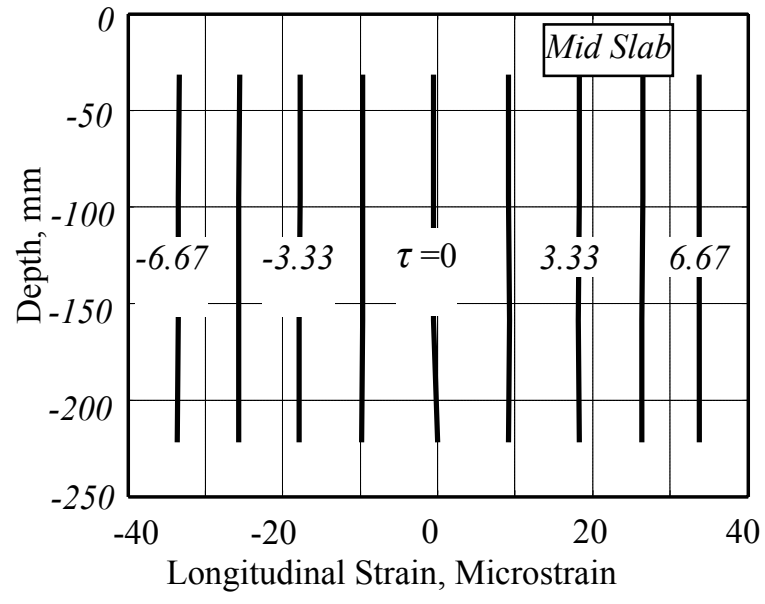

d. Longitudinal Strain at Slab Edge.

Figure 6.2 Through-Thickness Strain Profile. 
longitudinal strain profiles in Figure 6.2 (b) follows the corresponding nonlinearity in TGP. For a linear gradient, i.e. $\tau=0$, the corresponding longitudinal strain changes linearly through the slab thickness.

Figures 6.2 (c) and (d) reveal that the strain profiles at mid slab are linear and of magnitudes less than that at the joint edge. Since the concrete slab is unconstrained by tie bars along its longitudinal edges, it can freely curl along its transverse centerline. Thus, the transverse strain at mid slab changes linearly through the thickness, as shown in Figure 6.2 (c). The longitudinal strain, on the other hand, is constant through the slab thickness, as shown in Figure 6.2 (d). This indicates that the dowel bars and slab weight tend to flatten the slab profile at mid slab. Nonlinearity in TGP causes the longitudinal strain profile at mid slab to translate in proportion to the magnitude of $\tau$, however the strain remains constant through the slab thickness. The magnitudes of mid slab transverse and longitudinal strains, measured at mid slab thickness, are linearly proportional to TGP nonlinearity as seen from Figure 6.3. When the temperature gradient is linear, i.e. $\tau=0$, the longitudinal and transverse strains at mid slab thickness are also zero. The results of Figure 6.2 illustrate the significance of using 8-node solid brick elements in modeling dowel jointed concrete slabs.

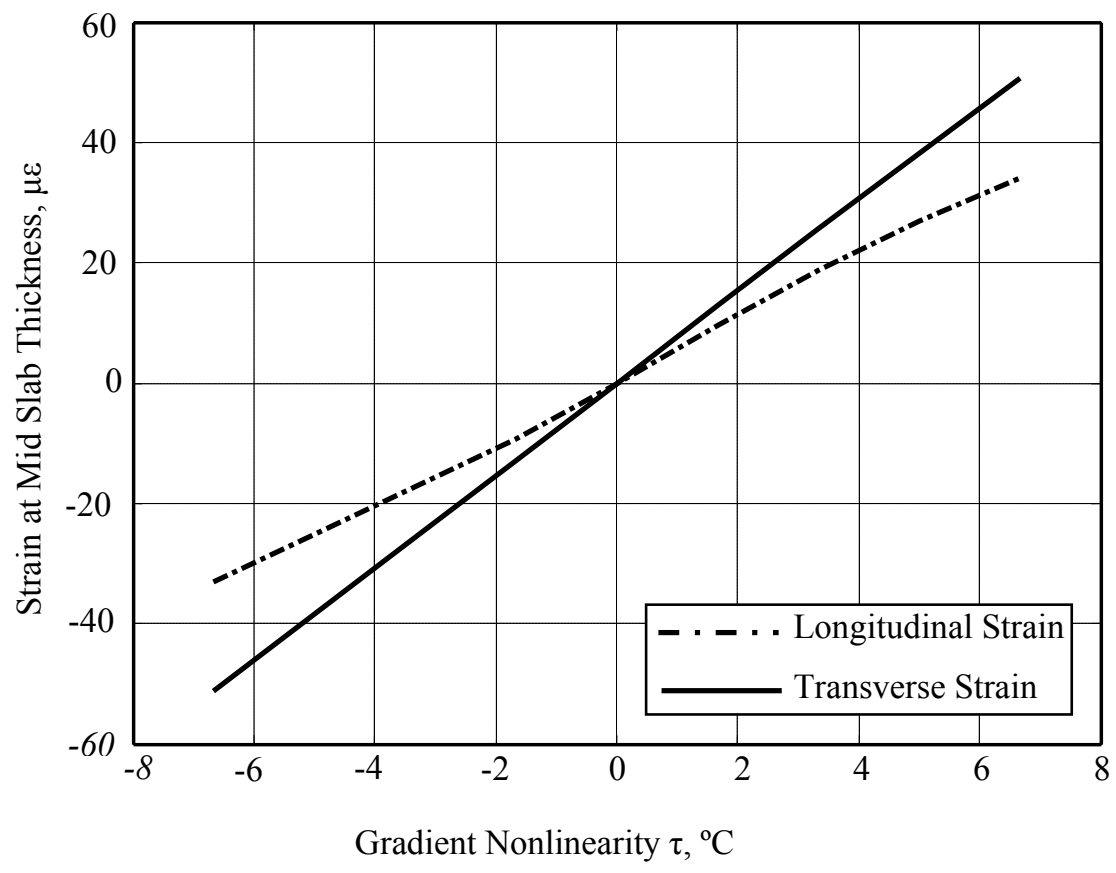

Figure 6.3 Effect of TGP Nonlinearity on Strain at Mid Slab. 
Figure 6.4 illustrates the deformed slab profile due to different magnitudes of nonlinearity in TGP. In all cases, minimum deflection of the slab occurs at a distance of $85 \mathrm{~cm}$ from the transverse joint edge. This distance is approximately four times the length of the embedded part of any dowel bar and approaches the value of $l \sqrt{2}$, where $l$ is the radius of relative stiffness. Following that distance, the slope of the slab profiles reduces and approaches zero at mid slab where the slab profiles become uncurled with deflections proportional to the magnitude of nonlinearity in TGP.

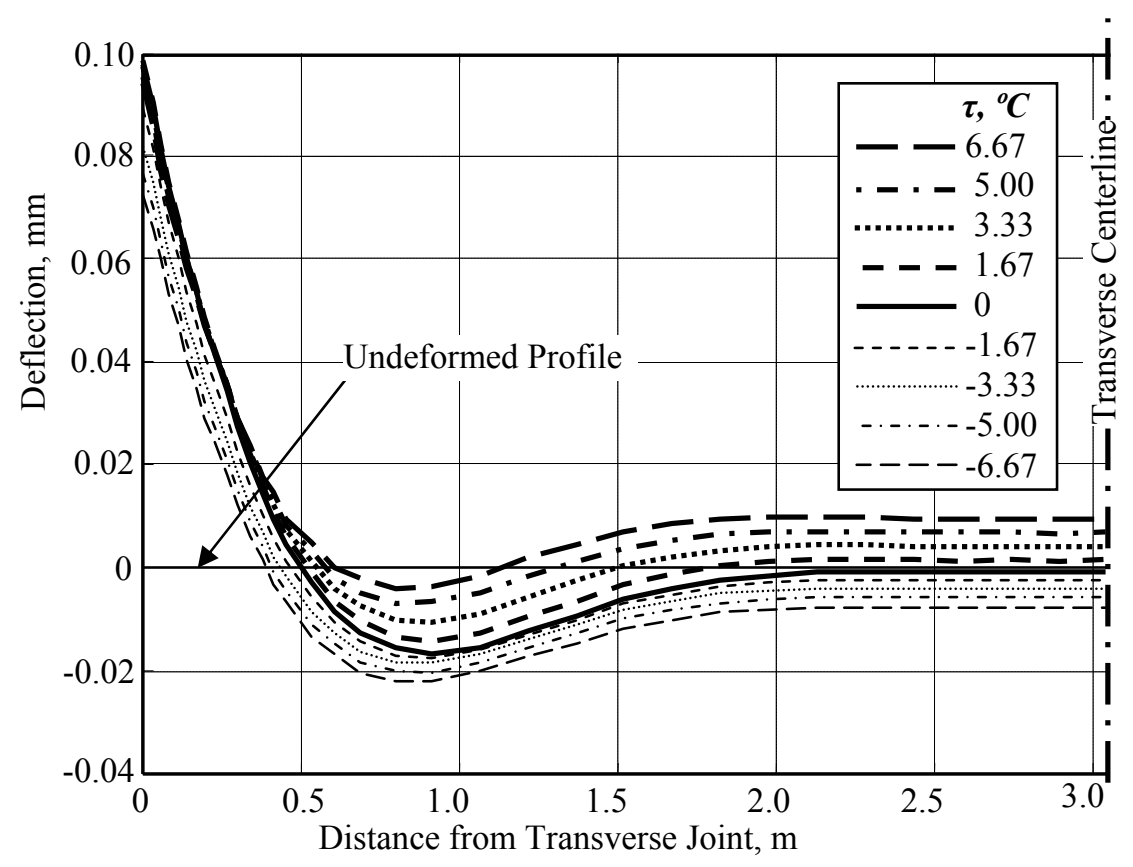

Figure 6.4 Effect of TGP Nonlinearity on Longitudinal Slab Profile.

For the same nonlinearity in TGP, the 3DFE model reveals that the magnitude of the change in slab thickness differs at the transverse joint from that measured at mid slab. Figure 6.5 illustrates that such a phenomenon occurs only when the gradient is nonlinear, while for linear gradient ( $\tau=$ 0 ), the change in thickness is uniform over the area of the slab. For any level of gradient nonlinearity, the change in the slab thickness at the transverse joint is approximately 40 percent larger than at mid slab. For negative nonlinearity in TGP, the slab thickness is larger at mid slab than at the transverse joint, while the opposite is true for positive nonlinearity in TGP. This 
phenomenon affects measured longitudinal and transverse strains in instrumented concrete slabs and was first observed in the strain data collected from the instrumented section in Elkins, West Virginia.

An expression for the change in slab thickness can be derived for a quadratic nonlinear TGP of the form:

$T(z)=A+B x+C z^{2}$

Where from Figure 1:

$A=T_{t}$

$B=(1 / h)\left(3 T_{t}+T_{b}-4 T_{m}\right)$, and

$C=\left(2 / h^{2}\right)\left(T_{t}+T_{b}-2 T_{m}\right)$

Substituting in Equation 5.3:

$T(z)=T_{t}+(z / h)\left(3 T_{t}+T_{b}-4 T_{m}\right)+2(z / h)^{2}\left(T_{t}+T_{b}-2 T_{m}\right)$

At the slab center, we will assume that the deformation through the slab thickness is unidirectional, i.e. the effect of lateral deformation is ignored since the concrete elements are confined by surrounding elements. The change of slab thickness $\delta_{\mathrm{c}}$ at the slab center can be obtained from:

$\delta_{c}=\int_{-h}^{0} \varepsilon d z=\int_{-h}^{0} \alpha T(z) d z=\alpha h\left(T_{t h}+\frac{2}{3} \tau\right)$

Where $\alpha$ is the coefficient of thermal expansion of concrete. At the transverse joints, Equation 6.5 should be modified to include the effect of the free edge. This is achieved through introducing Poisson's ratio $v$ that account for the deformation in the horizontal direction. The resulting expression can be written as: 
$\delta_{j o \text { int }}=c \alpha h(1+2 v)\left(T_{t h}+\frac{2}{3} \tau\right)$

The constant c, in Equation 6.6, is introduced to account for the nonlinearity in the strain-thickness relation at the slab edge and the geometric nonlinearity due to the presence of the dowel bars at transverse joints. This constant is 1.05 , found by fitting the 3DFE results to Equation 6.6 as shown in Figure 6.5.

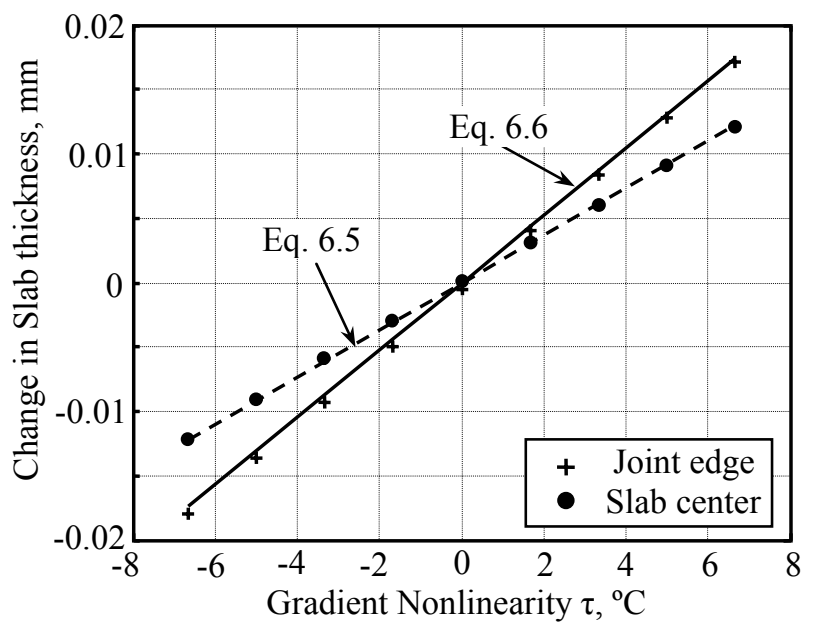

Figure 6.5 Effect of TGP Nonlinearity on Slab Thickness.

\subsection{Effect of TGP Nonlinearity on Slab Stress}

The impact of TGP nonlinearity on the longitudinal stresses measured on top and bottom of the slab is illustrated in Figure 6.6. The stress profiles of Figure 6.6 (a) and (b) display a uniform plateau in the middle portion of the slab for different levels of TGP nonlinearity. Away from the slab center, the longitudinal stress is primarily influenced by the difference between slab top and bottom temperatures (TGP magnitude). At mid slab, every degree Centigrade increase or decrease in TGP nonlinearity produces corresponding increase or decrease of $20 \mathrm{kPa}$ in the 
longitudinal stress. Near the transverse joint, the tensile stress on the slab top, Figure 6.6(a), shows a significant increase with the increase in $\tau$. As TGP nonlinearity increases from 0 to $6.67^{\circ} \mathrm{C}$, the tensile stress, measured $0.28 \mathrm{~m}$ away from the joint, increases from 0.28 to $1.8 \mathrm{MPa}$, i.e. $540 \%$. Since dowel bars are embedded to a depth of $0.22 \mathrm{~m}$, the increase in tensile stress due to TGP nonlinearity is thought to be responsible for the most common form of transverse joint distress, i.e. concrete fractures that take place near the ends of the embedded part of each dowel. It is well established that a negative gradient magnitudes generally produce tensile stress on the slab top and compressive stress at the slab bottom (Westergaard, 1927). The results of Figure 6.6 indicate that TGP nonlinearity did not change this behavior away from the doweled transverse joints. However, up to $0.50 \mathrm{~m}$ from the transverse joint edge, TGP nonlinearity may cause the stress to be either tensile or compressive on both top and bottom of the slab.

Based on the work of Westergaard (1927) the author showed (Chapter 5, William and Shoukry 2001) that the maximum longitudinal stress $\sigma_{\mathrm{o}}$ induced due to a linear temperature gradient of magnitude $\Delta^{\circ} \mathrm{C}$ applied to a finite length-dowel-jointed concrete slab could be calculated from:

$$
\sigma_{0}=0.79 \frac{E \alpha \Delta}{2(1-v)}
$$

Referring to Figure 6.6, Equation 6.7 is applicable only for the case where $\tau=0$. In order to arrive at a generalized form of Equation 6.7 applicable for cases where the TGP is nonlinear, the maximum longitudinal stresses for different values of gradient nonlinearity are shown in Figure 6.7 as a ratio of the maximum stress for the linear gradient case obtained from Equation 6.8. The resulting curve is characterized by the following regression equation:

$$
\sigma_{\max }=\sigma_{0}\left[1-A \tan ^{-1}(B \psi)\right]
$$

Where:

$\sigma_{\max }=$ Maximum longitudinal stress due to TGP nonlinearity $\tau^{\circ} \mathrm{C}$.

$\sigma_{\mathrm{o}}=$ Maximum longitudinal stress obtained from Equation 5.8.

$\psi=$ Dimensionless TGP nonlinearity expressed as a ratio of the gradient magnitude $=\tau / \Delta$. 


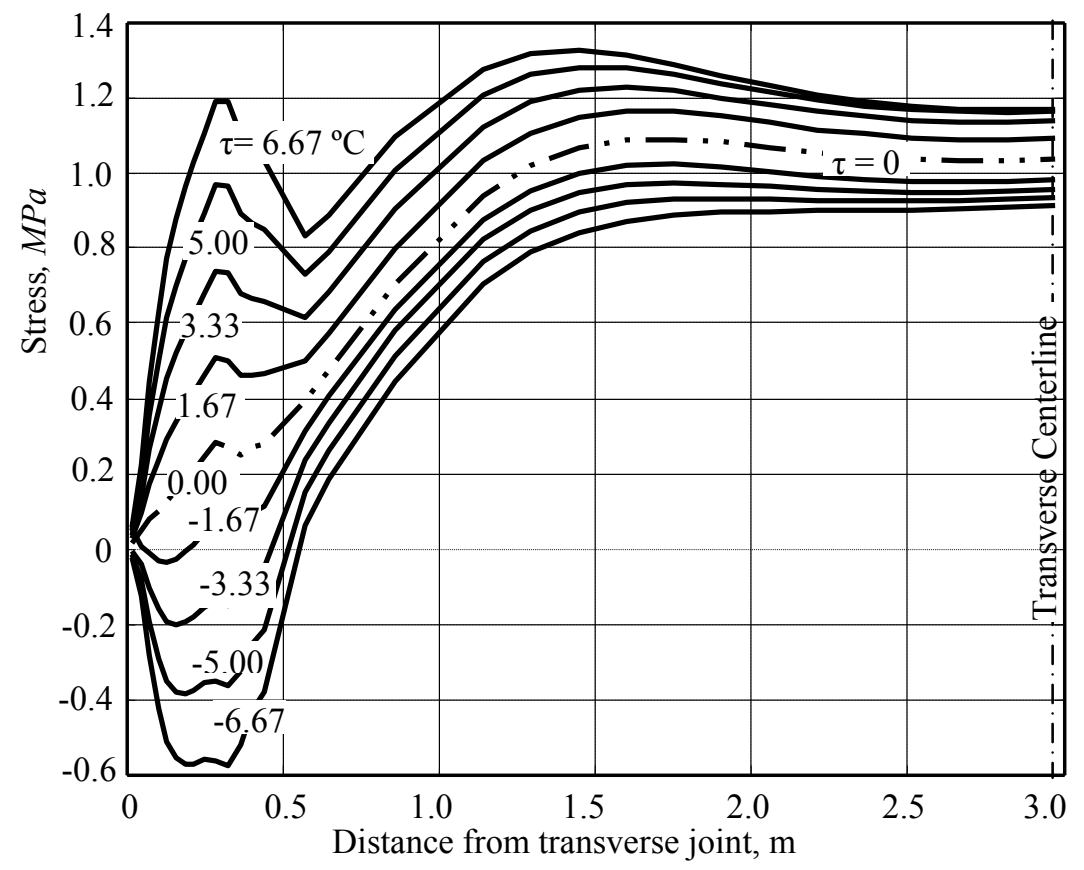

a. Slab Top

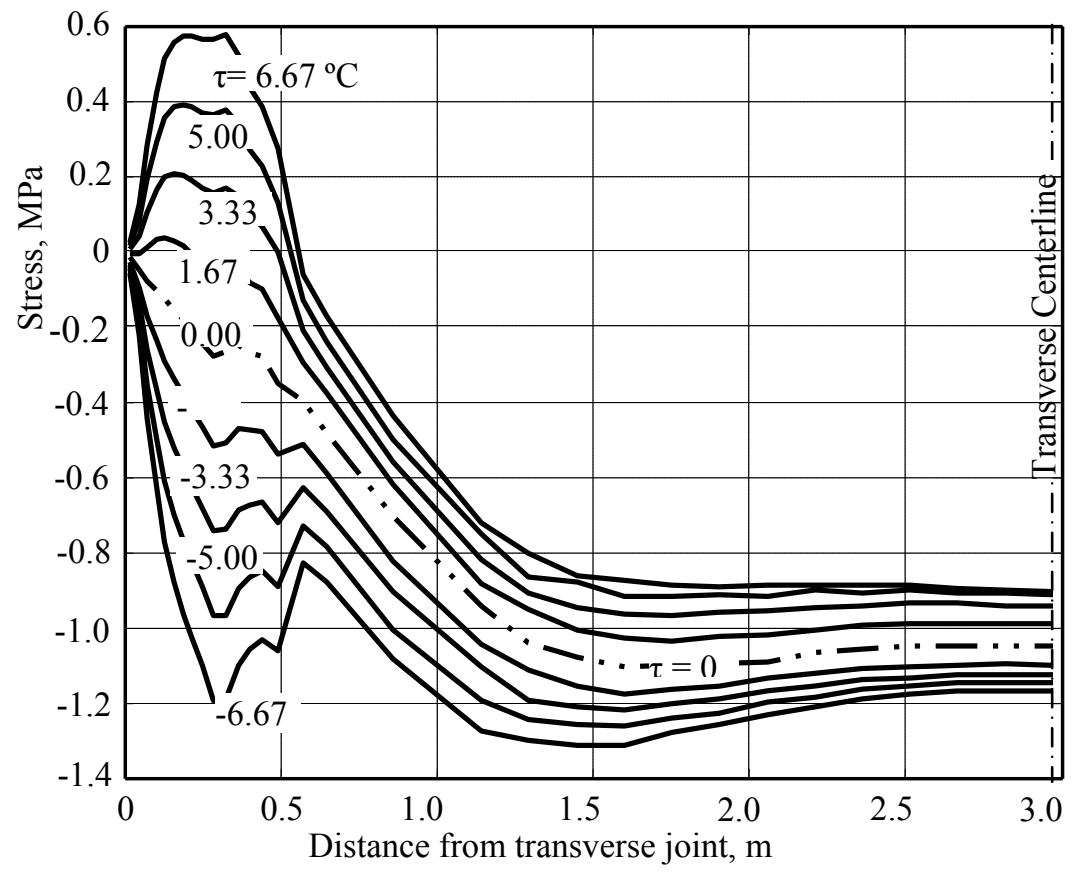

b. Slab Bottom

Figure 6.6 Effect of TGP Nonlinearity on Longitudinal Stress. 
$\mathrm{A}$ and $\mathrm{B}$ are regression constants: $\mathrm{A}=0.21, \mathrm{~B}=4.2$ for $\psi<0$; and $\mathrm{A}=0.17, \mathrm{~B}=4.0$ for $\psi>0$

Figure 6.7 illustrates that Equation 6.8 fits all cases of TGP nonlinearity cases examined in this study.

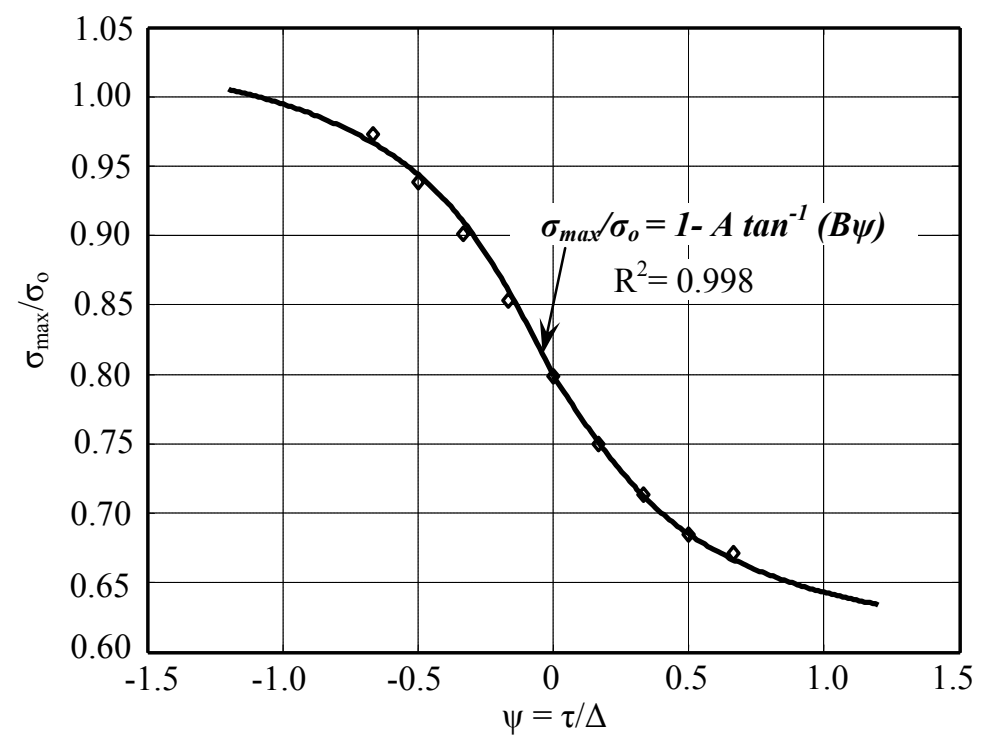

Figure 6.7 Effect of TGP Nonlinearity on Maximum Longitudinal Stress.

\subsection{Uniform Temperature Changes}

Figures 6.8 and 6.9 illustrate the distribution of longitudinal stresses induced in a concrete slab subjected to the same TGPs used in Figure 6.6 with the exception that each TGP includes a temperature drop $\mathrm{T}_{\mathrm{u}}=-16.67{ }^{\circ} \mathrm{C}$ and $-33.3{ }^{\circ} \mathrm{C}$ respectively . The same $3 \mathrm{DFE}$ model is used to produce the data of Figures 6.6, 6.8 and 6.9, where the coefficient of slab base friction remains the same at 1.5. To eliminate the possibility that any increase in slab stress, observed in Figures 5.8 and 5.9, arises due to contraction of concrete-sockets around the dowels, a uniform diameteral dowel-concrete clearance of $0.025 \mathrm{~mm}$ was assumed in both figures. Since the same magnitudes and nonlinearity of gradient profiles were used in Figures 6.6, 6.8 and 6.9, the large 


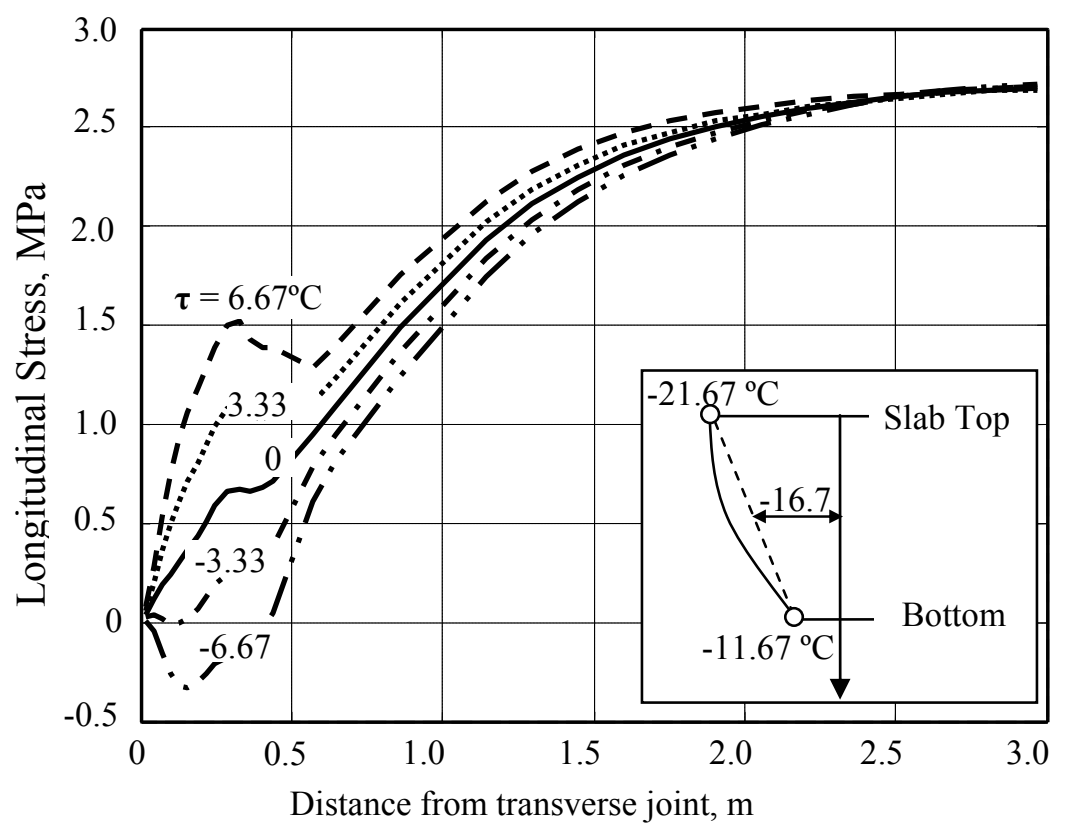

a. Slab Top

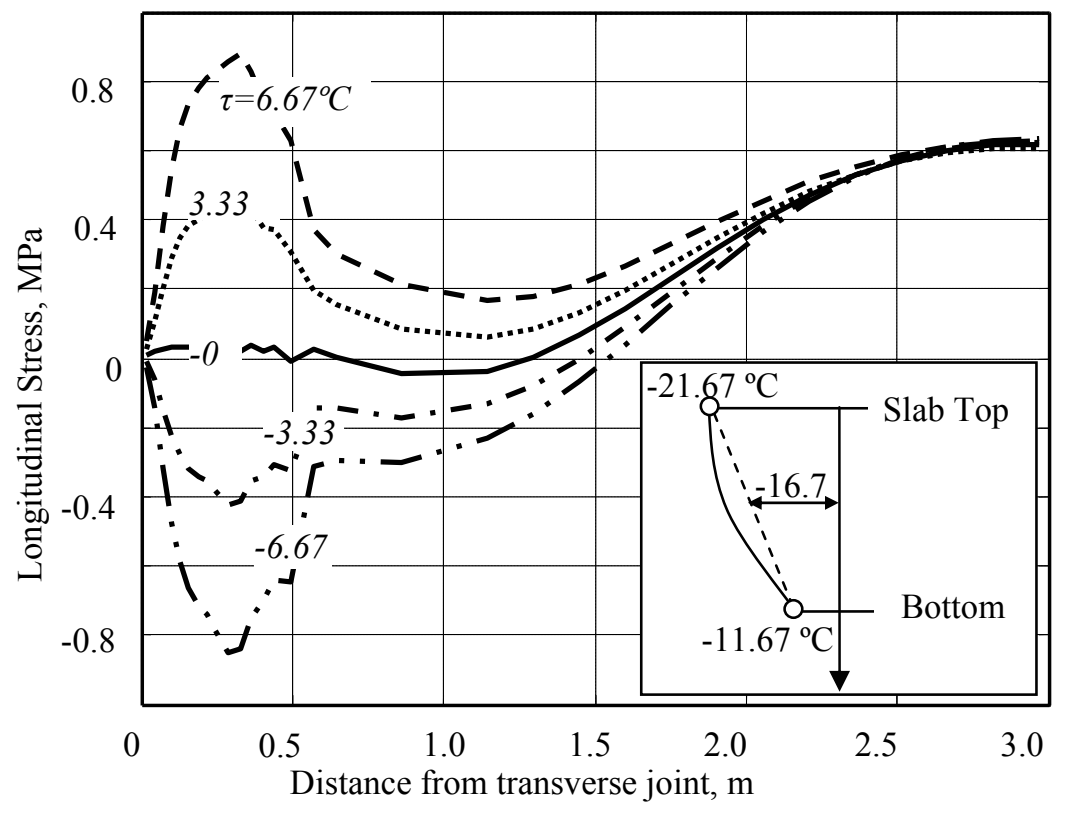

b. Slab Bottom

Figure 6.8 Effect of $-16.7^{\circ} \mathrm{C}$ Uniform Temperature Drop. 


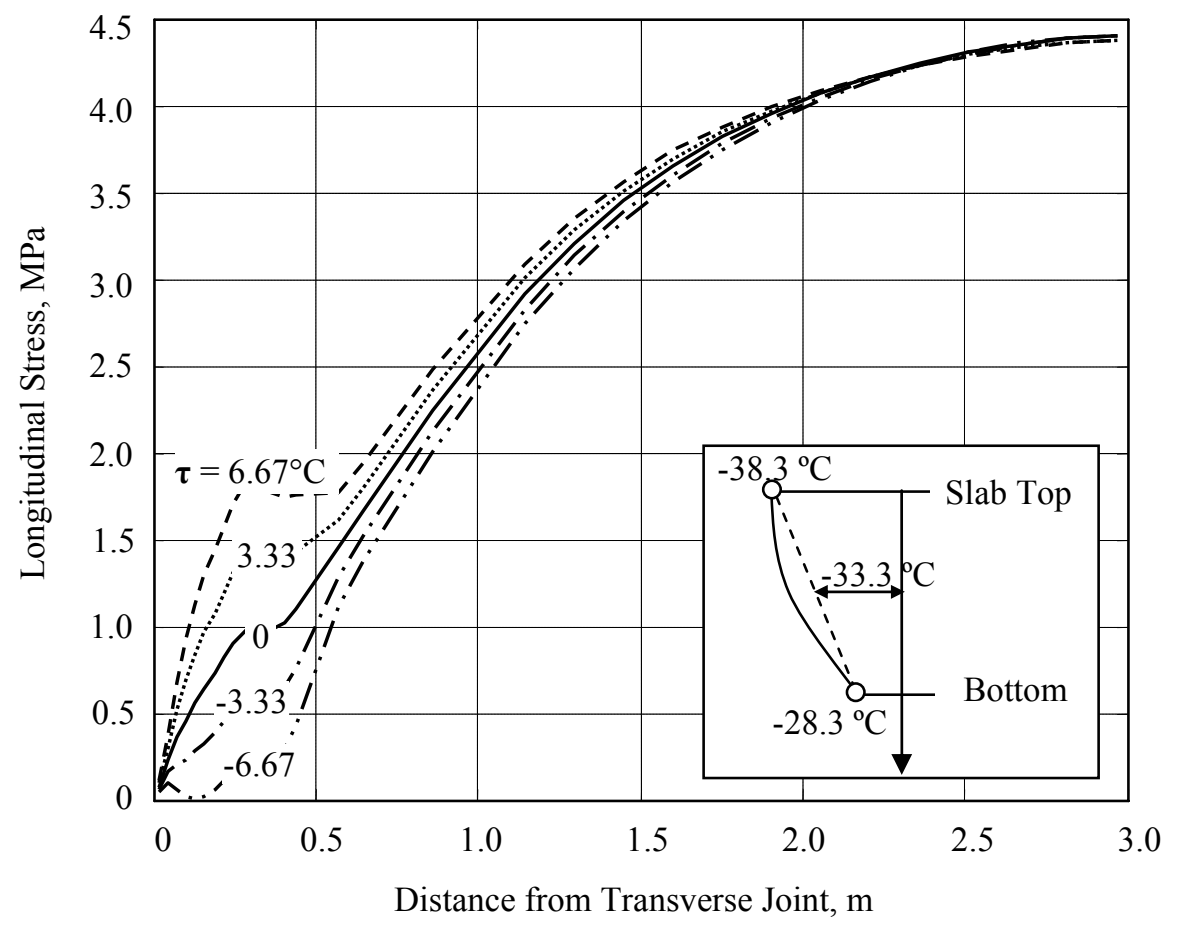

a. Slab Top

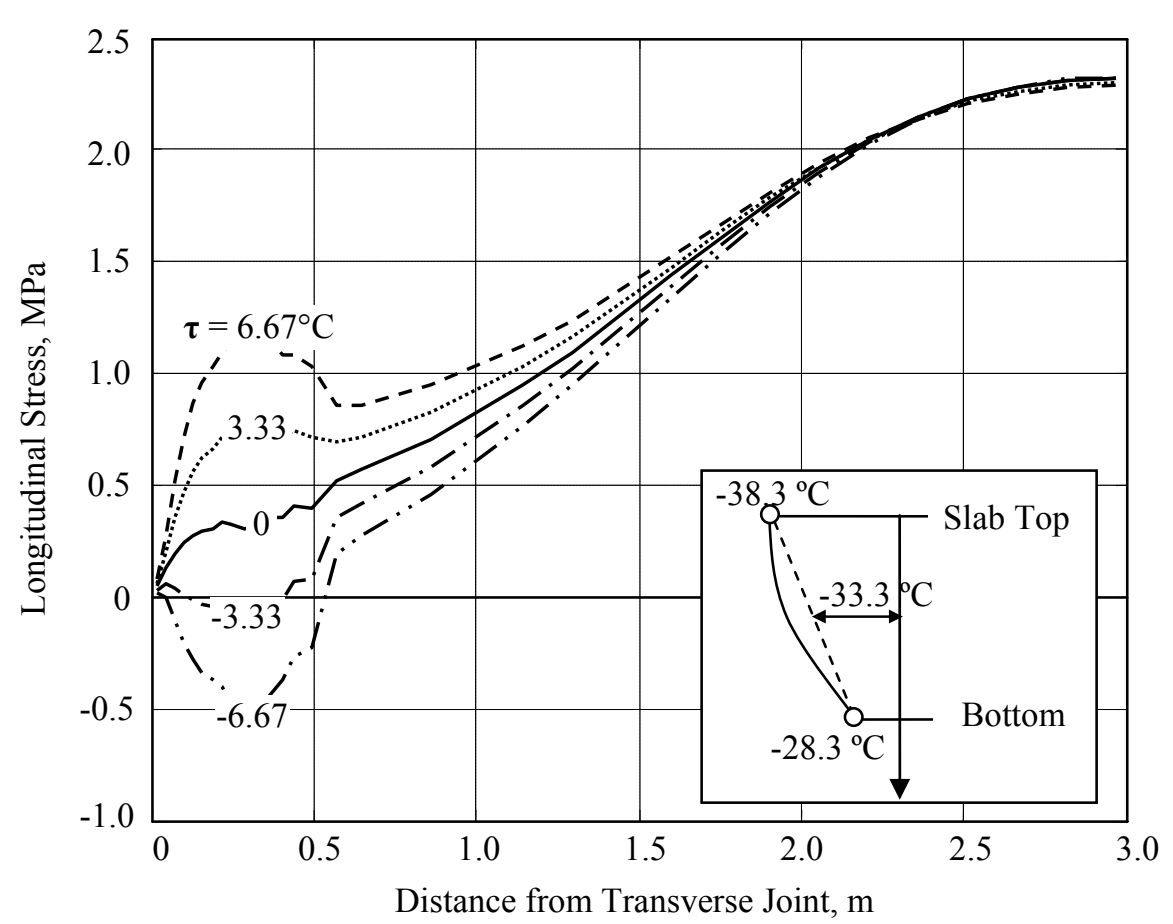

b. Slab Bottom

Figure 6.9 Effect of $-33.3{ }^{\circ} \mathrm{C}$ Uniform Temperature Drop. 
differences in longitudinal stress profiles and magnitudes can only be attributed to the introduction of the uniform temperature drops of $-16.67^{\circ} \mathrm{C}$ and $-33.3{ }^{\circ} \mathrm{C}$. Further, due to the relatively large magnitude of uniform dowel-concrete clearance, assumed in the 3DFE model, the 140 percent increase in mid-slab stress, observed in Figure 6.8, can only be attributed to the fact that bent dowels (due to slab curling) introduced a significant slab constraining force that resists slab contraction due to uniform temperature drop. It can be seen from Figure 4.6 (b) that dowel bending develops as soon as the concrete is placed. Concrete weight, differential shrinkage, moisture gradient, and TGP are the major factors that cause the dowel bending shown in Figure 4.6 (b) and result in the axial dowel force illustrated in Figure 4.5 (c).

Perhaps the most interesting observation in Figures 6.8 and 6.9 is that at mid-slab the stress is tensile on both slab top and bottom, despite the relatively large negative temperature gradient profile. Field measured top and bottom strains from the instrumented Highway section confirm this finding. Under dowel restraining force, the slab is pulled as the concrete shrinks due to curing or compressed due to a temperature drop at nighttime. If the slab is imagined as a thick plate resting on a rough surface, each dowel bar represents a nonlinear frictional spring that constrains the in-plane slab deformation.

The longitudinal stress profiles in Figures 6.8 and 6.9 indicate that TGP nonlinearity is mostly noted near transverse joints. The magnitude of mid-slab longitudinal-stress is not sensitive to nonlinearity of TGP; therefore, only gradient magnitude and uniform temperature changes are the primary factors that influence mid slab stress. The former affects dowel bar bending, while the latter causes corresponding slab length changes. Since the amount of slab contraction due to temperature drop depends on slab length, it is plausible to postulate that mid-slab stress is dependent on slab length. This point will be further investigated in Chapter Seven.

\subsection{Conclusions}

Nonlinearity in temperature gradient profile may increase or decrease the curling stress in a concrete slab. While it has a significant influence on thermally induced stresses at doweled 
transverse joints, its influence on mid slab stress is negligible. Both field-measured and 3DFEpredictions confirm that dowel bars introduce a significant restraint to slab contraction and expansion due to uniform temperature changes. The restraining action of dowel bars is produced by the bending of dowel bars, due to slab curling, which takes place even when the concrete is in a plastic state. Even when significantly large uniform dowel-concrete clearance is present, dowel bar restraining action remains significantly high.

The importance of avoiding linear superposition in slab stress calculations has been highlighted. 3DFE models used to investigate thermal and/or mechanical loading response of rigid pavements should include detailed dowel bar modeling together with dowel-concrete interfaces and slab-base friction. The TGPs, used in such models, should be "as measured" i.e. they should not be modified by any break down into uniform and gradient components. A new method to validate the thermal response of 3DFE models was presented in this study using data from instrumented shoulder-side dowel bars. 


\section{CHAPTER SEVEN}

\section{EFFECT OF DESIGN PARAMETERS ON THE 3D FINITE ELEMENT PREDICTED THERMAL STRESSES}

\subsection{Introduction}

The focus of this chapter is to examine the effect of changing some selected design parameters: length, axle loading, slab thickness, dowel bar diameter, and characteristics of the concrete dowel interface on the state of thermal stresses induced in dowel jointed concrete slabs. The results of this parametric study will be used to determine the most optimized slab dimensions that minimize the chance of premature mid-slab transverse cracking and enhance pavement service life.

\subsection{Effect of Concrete Slab Length}

Under the restraining action of dowel bars at transverse joints, mid-slab longitudinal stress showed a dependency on slab length as illustrated in Chapter Five. To further study the effect of the slab length on the state of thermal stress induced in the concrete slab, slabs of lengths: 3.66 $\mathrm{m}, 4.57 \mathrm{~m}, 6.10 \mathrm{~m}, 7.24 \mathrm{~m}$, and $9.15 \mathrm{~m}$ were considered in 3DFE models. A constant temperature gradient of $-10^{\circ} \mathrm{C}$ was applied to the slabs in the 3DFE model combined with a uniform temperature drop varying from 0 to $-50{ }^{\circ} \mathrm{C}$, and the resulting stresses were plotted in Figure 7.1.

Figures 7.1 (a) and (b) illustrate that the dominant stress for $6.10 \mathrm{~m}, 7.24 \mathrm{~m}$ and $9.14 \mathrm{~m}$ long slabs is the longitudinal stress while for $3.66 \mathrm{~m}$. the transverse stress is dominant. For a $4.57 \mathrm{~m}$ long slab, the magnitudes of both the transverse and longitudinal stresses are close to each other 
up to $50{ }^{\circ} \mathrm{C}$. Longitudinal stress, Figure 7.1 (a) in slabs of lengths $4.57 \mathrm{~m}, 6.10 \mathrm{~m}, 7.24 \mathrm{~m}$ and $9.14 \mathrm{~m}$ will approach the concrete modulus of rupture at temperature drops of approximately -50 , $-20,-16$, and $-15{ }^{\circ} \mathrm{C}$ respectively inducing mid slab cracking. The $3.66 \mathrm{~m}$ long slab will be more susceptible to longitudinal cracking as seen from Figure 7.1 (b). As seen from Figure 7.1 (c), the $4.57 \mathrm{~m}$ long slab produces the least magnitude of maximum principal stress at all temperature drops considered in this study. This leads to the conclusion that the best slab length for minimizing the possibility of mid slab cracking is $4.57 \mathrm{~m}$. The same conclusion was independently confirmed from the analyses of field data obtained form Long Term Pavement Program LTPP (Smith et al., 1998).

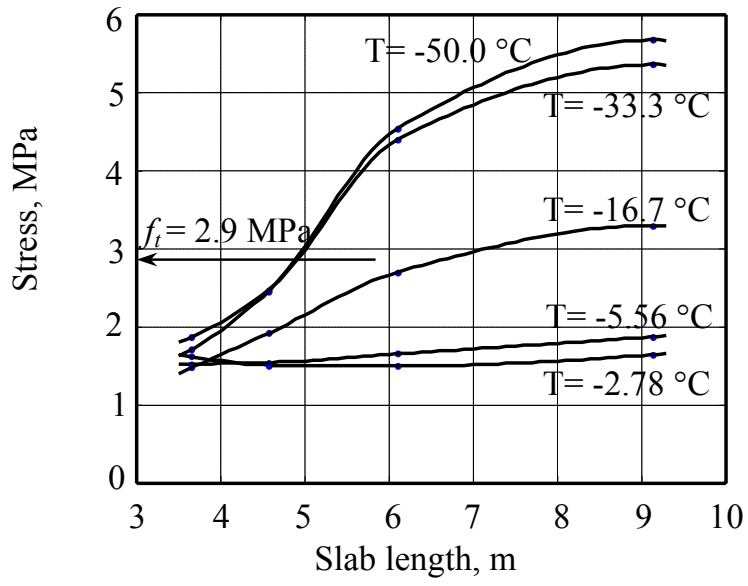

a. Longitudinal Stress

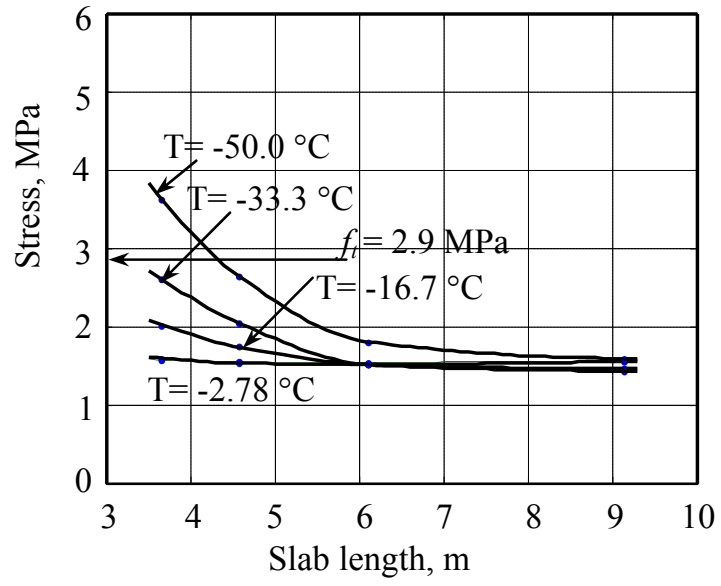

b. Transverse Stress

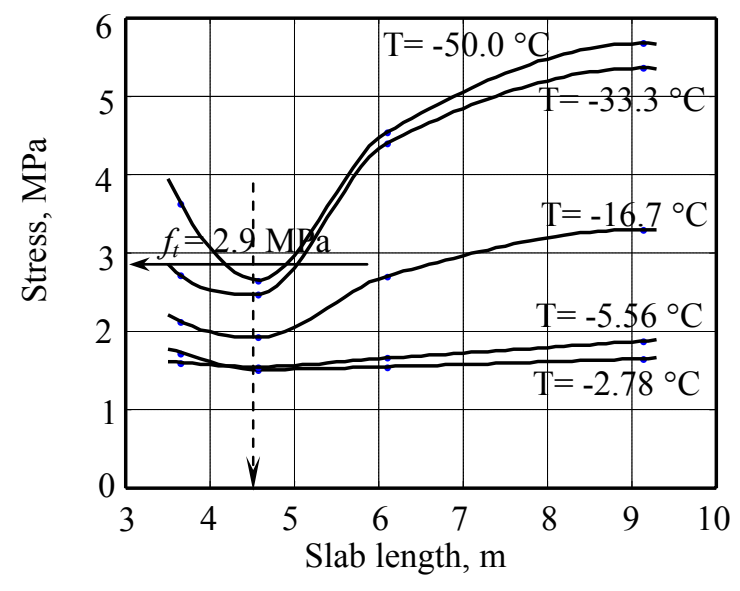

c. Max. Principal Stress

Figure 7.1 Effect of Slab Length. 


\subsection{Effect of Traffic Loading}

Joint axle loading is expected to produce higher mid-slab stresses when applied on an initially curled slab due to a negative temperature gradient (Khazanovich et al., 2000; Hansen et al., 2002). The objective of this study is to investigate the combined effect of temperature variations and traffic loads on mid-slab stress. As a first step, the effect of a built-in negative temperature gradient on the stresses induced in $3.66 \mathrm{~m}, 4.57 \mathrm{~m}$, and $6.10 \mathrm{~m}$ long concrete slabs subjected to single axle loading at a transverse joint is examined. Next, uniform temperature drops of varying magnitudes are added to the temperature gradient under the same axle loading conditions and the resulting stresses are compared. As described in Chapter Three, the contact dual tire was modeled using two equivalent FWD loading plates, each subjected to a 25 millisecond pulse load of magnitude $45 \mathrm{KN}$ that simulates the moving wheel load.

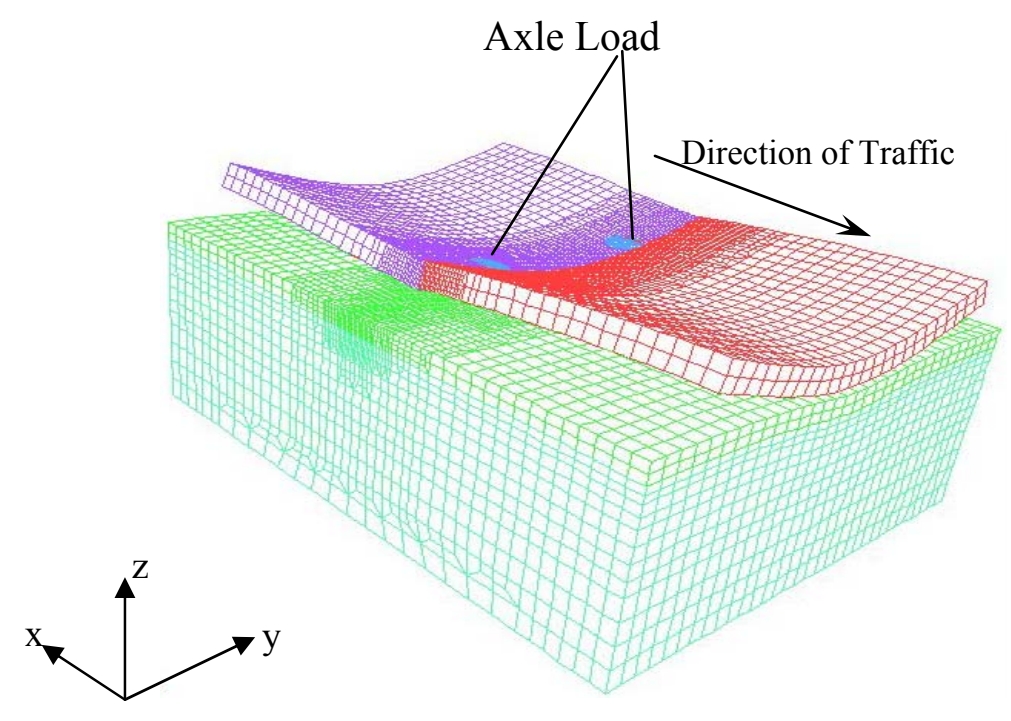

Figure 7.2 Deformed Slabs Due to Negative Gradient and Joint Loads.

\subsubsection{Effect of Negative Temperature Gradient}

Under the effect of negative temperature gradient, the transverse joints curl up while the middle portion of the slab remains in contact with the base layer. Application of the axle loads at 
transverse joints will flatten the curled slab, as illustrated in Figure 7.2, creating a tensile stress at the slab top. The magnitude of such stress depends on the amount of thermal gradient through the slab thickness.

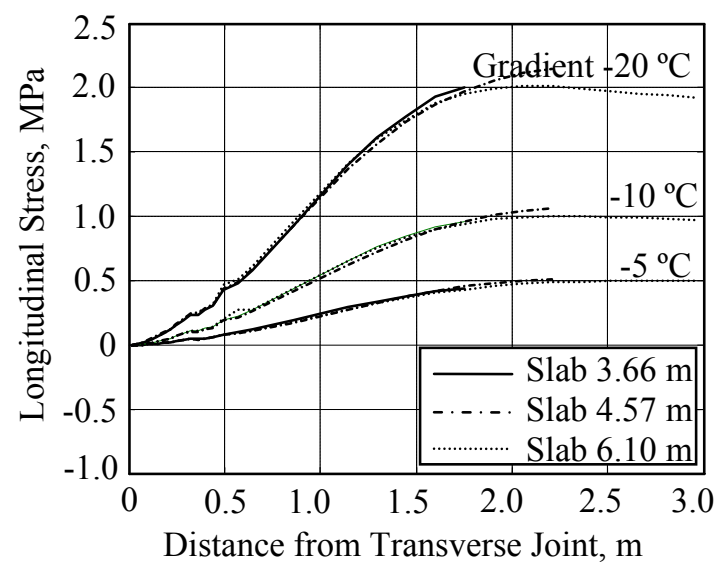

a. Along Wheel-path

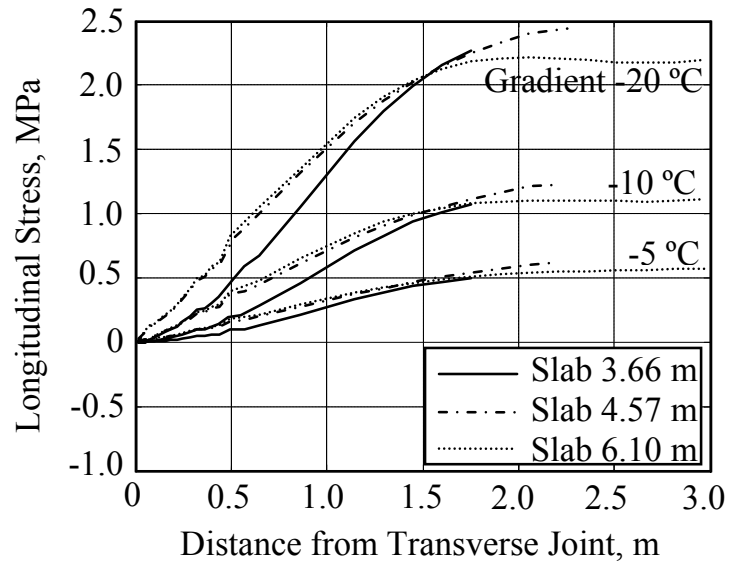

b. Along Centerline

Figure 7.3 Longitudinal Stress Distribution at Slab Top Due to Temperature Gradient.

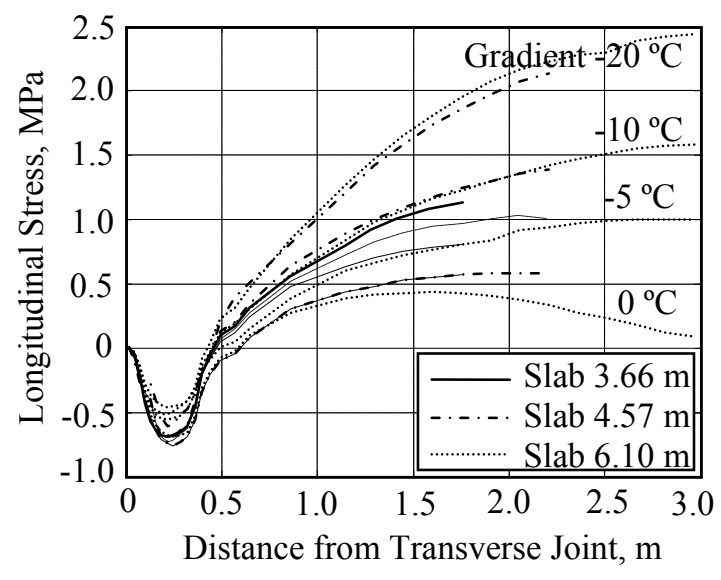

a. Along wheel-path

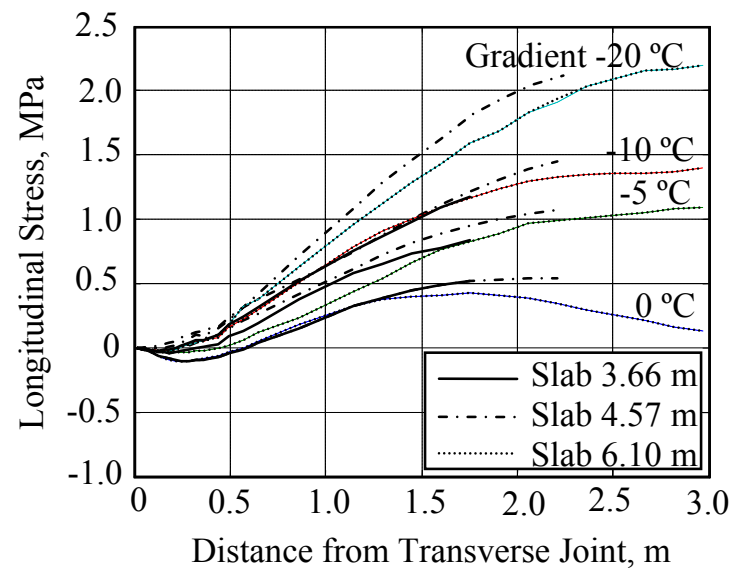

b. Along centerline

Figure 7.4 Longitudinal Stress Distribution Due to Temperature Gradient and Axle Loading.

The distributions of built-in thermal stresses on the slab top due to thermal gradients: $-5,-10$, and $-20{ }^{\circ} \mathrm{C}$ along the wheel-path and slab centerline are shown in Figures 7.3 (a) and 7.3 (b) respectively. It can be noticed that mid-slab stresses found for different slab lengths are very close to each other for the same gradient magnitude. This indicates that the slab length, for the 
range of lengths and temperature gradients studied, has a insignificant influence on the magnitude of mid-slab thermal stress.

Figures 7.4 (a) and 7.4 (b) illustrate the distributions of the longitudinal stresses due to the combined effect of negative thermal gradient and joint axle loading. The effect of axle loading is manifested through the formation of a localized compressive zone under the position of load application near the transverse joint. Formation of such a stress zone confirms the localized effect of the wheel load reported in Westergaard (1926) as well as the subsequent research studies throughout the past seven decades. The application of axle loads at the curled transverse joints did not result in a significant difference in mid-slab stresses. The increase in mid slab stress due to the application of axle loading (obtained by comparing the results of Figures 7.3 (a) and 7.4 (a) is less than $0.45 \mathrm{MPa}$ for all gradient magnitudes. As seen from Figure 7.4 (a), for the case of $-20{ }^{\circ} \mathrm{C}$, the stress induced at mid slab may lead to transverse mid-slab cracking by fatigue irrespective of the slab length. Therefore, premature transverse cracking of $6.10 \mathrm{~m}$ long slabs observed in many states in the United States cannot be explained by the combined effect of temperature gradient and axle loading. Such fatigue-induced transverse cracking may take place if the slab length was $4.57 \mathrm{~m}$ or even $3.66 \mathrm{~m}$.

\subsubsection{Effect of Uniform Temperature Drop}

The contribution of mean slab temperature change to the critical stress leading to mid-slab transverse cracking is illustrated in Figure 7.5 for the case of negative temperature gradient of $-10{ }^{\circ} \mathrm{C}$ that occurs simultaneously with two different magnitudes of uniform temperature drops: -16.67 and $-33.33{ }^{\circ} \mathrm{C}$. The effect of temperature drop is shown, in Figure 7.5 , for the same magnitude of axle loading applied at the transverse joints of $3.66 \mathrm{~m}, 4.57 \mathrm{~m}$, and $6.1 \mathrm{~m}$ long slabs.

Comparison of the results shown in Figures 7.5 (a) and 7.5 (b) indicate that the stresses along the wheel path are slightly larger than along the slab centerline. It can be seen from Figure 7.5 (b), that the effect of wheel loading is localized under the position of load application. Referring to 


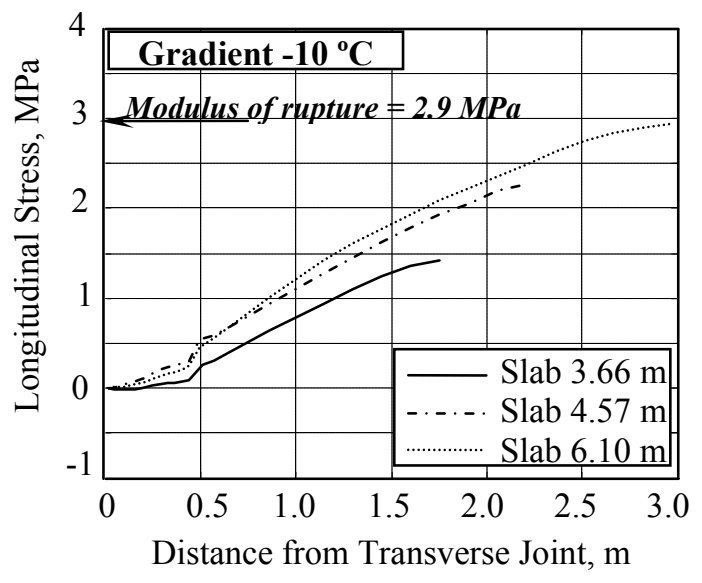

(i) Drop $-16.67^{\circ} \mathrm{C}$

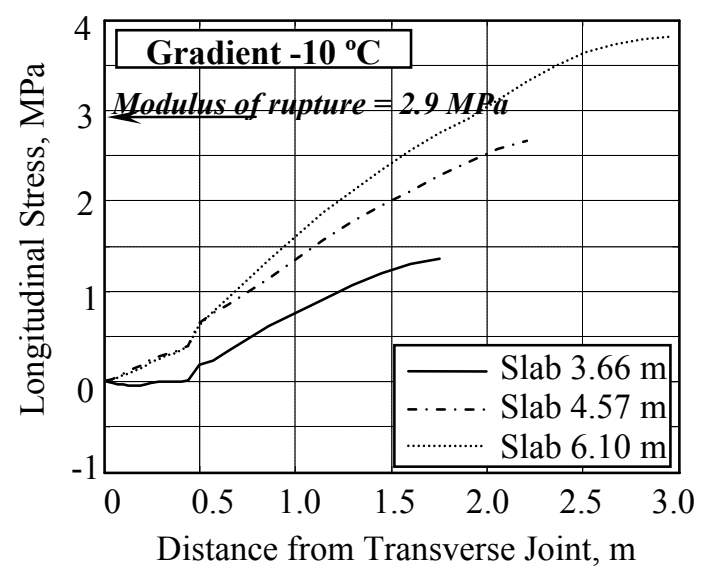

(ii) Drop $-33.33^{\circ} \mathrm{C}$

a. Along Slab Centerline

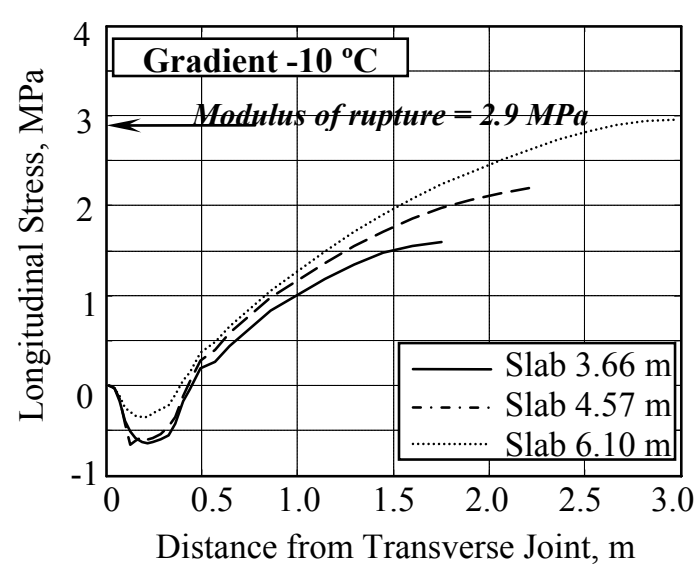

(i) Drop $-16.67^{\circ} \mathrm{C}$

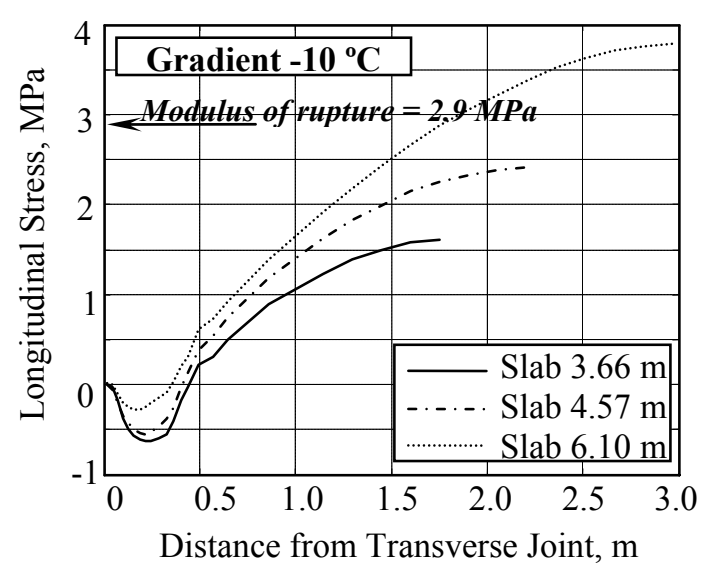

(ii) Drop $-33.33^{\circ} \mathrm{C}$

b. Along Wheel-Path

Figure 7.5 Effect Of Uniform Temperature Drop and Axle Loading on Longitudinal Stresses.

Figure 7.4 (b) for the case of $0.0{ }^{\circ} \mathrm{C}$ gradient, it is shown that the longitudinal stress induced by axle loading is in the order of $0.5 \mathrm{MPa}$. Figure 7.4 (a) indicates that a gradient of $-10{ }^{\circ} \mathrm{C}$ will result in increasing the mid slab longitudinal stress to approximately $1.5 \mathrm{MPa}$. With the introduction of a uniform temperature drop of $-16.67^{\circ} \mathrm{C}$, in Figure 7.5 (b), the total longitudinal stress increases along the wheel path by 40,70 , and 150 percent for $3.66,4.57$, and $6.10 \mathrm{~m}$ long slabs respectively. This indicates that the effect of axle loading magnitude on the total stresses induced in dowel jointed concrete slabs is small compared to the thermal effects. It also 
indicates that long slabs are much more susceptible to mid slab transverse cracking than shorter ones. This is seen from comparing the results of Figure 7.4 (a), with those of Figure 7.5 (b).

To examine the effect of slab length, the longitudinal, transverse and maximum principal stresses induced at mid-slab in thermally deformed concrete slabs due to joint axle loading are plotted in Figure 7.6. It can be noticed that $4.57 \mathrm{~m}$ is still the optimum slab length to minimize the chance of transverse or longitudinal cracking.

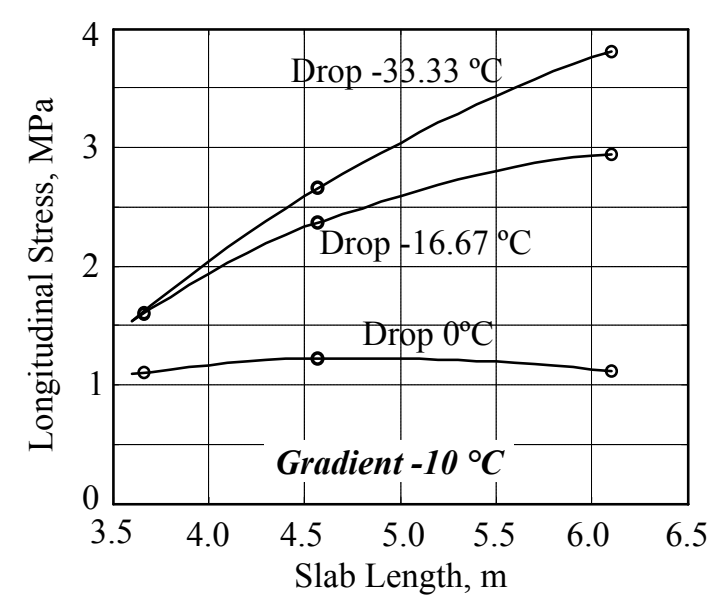

a. Longitudinal Stress

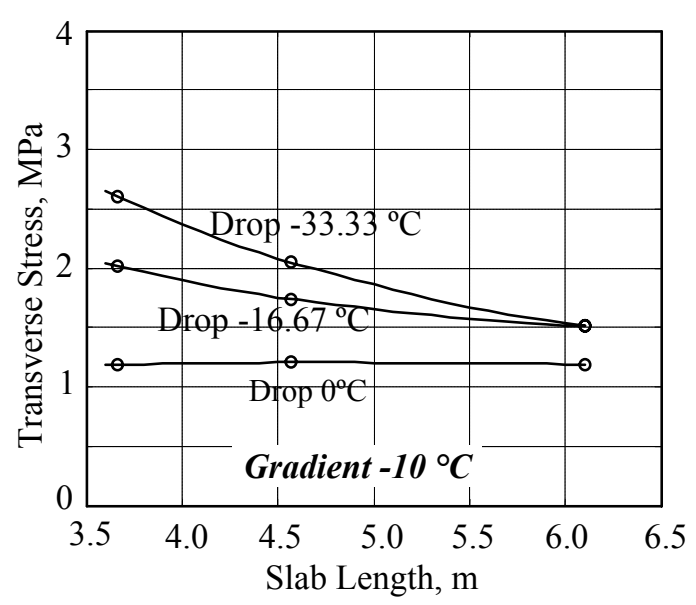

b. Transverse Stress

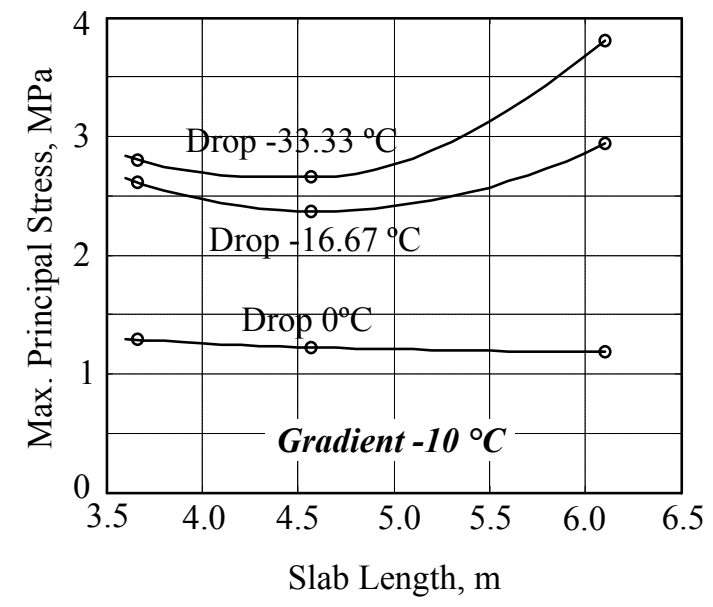

c. Max. Principal Stress

Figure 7.6 Effect of Slab Length and Uniform Temperature Drop on Mid-Slab Stress 


\subsection{Effect of Slab Thickness}

The selection of slab thickness is controlled by structural and economical factors. The general belief is that thicker slabs can sustain higher loads with less damage and longer service life. Although such an argument is applicable when considering the effect of traffic loading only, the effect of changing the slab thickness on the state of stress induced in the concrete slab due to temperature variations is not questionable. In this study, the slab thickness in the 3DFE model with slab length of $4.57 \mathrm{~m}$ was changed to examine its effect on the 3DFE-calculated stresses. Five thicknesses: $0.204 \mathrm{~m}, 0.228 \mathrm{~m}, 0.254 \mathrm{~m}, 0.279 \mathrm{~m}$ and $0.305 \mathrm{~m}$ were considered.

The AASHTO Pavement Design Guide (1998) recommended that the value of design temperature gradient induced in a concrete slab be proportional to the slab thickness. Therefore as a first step, a temperature gradient of $-0.02{ }^{\circ} \mathrm{C} / \mathrm{mm}$ was applied to the concrete slabs in the 3DFE models and the resulting longitudinal stress profiles are illustrated in Figure 7.7. As the slab thickness increases, the magnitude of longitudinal stress induced at the slab top, illustrated in Figure 7.7 (a), or at slab bottom, shown in Figure 7.7 (b), increases. Such an increase in the stress magnitude is attributed to the fact that as the slab thickness increases, the magnitude of the temperature differential between the slab top and bottom proportionally increases. Figures 7.7 (a) and (b) also indicate the magnitude of curling stresses induced in concrete slabs with different thickness is proportional to the slab thickness, which agrees with Westergaard's Equation (1927).

Figure 7.8 illustrates the 3DFE-calculated longitudinal stresses profiles induced in concrete slabs due to temperature gradient of $-0.02{ }^{\circ} \mathrm{C} / \mathrm{mm}$ that occurs simultaneously with a uniform temperature drop of $-33.33^{\circ} \mathrm{C}$. The plots in Figure 7.8 (a) indicate a slight increase in mid-slab longitudinal stress as the slab thickness increases at the slab top. However, a large difference can be observed in the longitudinal stresses at the slab bottom, Figure 7.8 (b). Uniform temperature drop and the restraining force from bent dowel bars are the main stress contributors in the stress profiles shown in Figure 7.8. The slab bottom experiences varying amount of frictional forces depending on the slab thickness. This explains the wide variations in the stress profiles obtained at the slab bottom for different slab thicknesses shown in Figure 7.8 (b). However, the stresses at the slab top, which is a free surface, are less sensitive to the change in the slab thickness. 


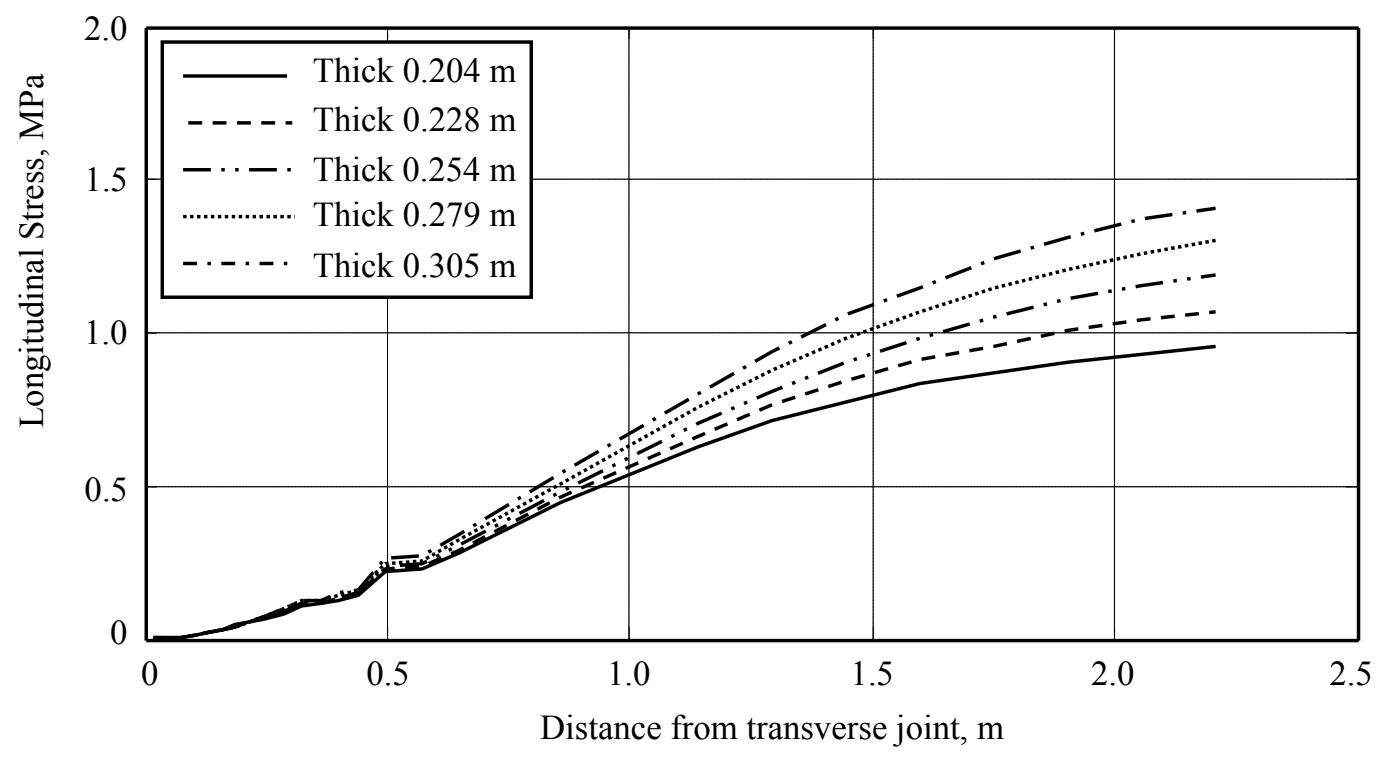

a. Slab Top

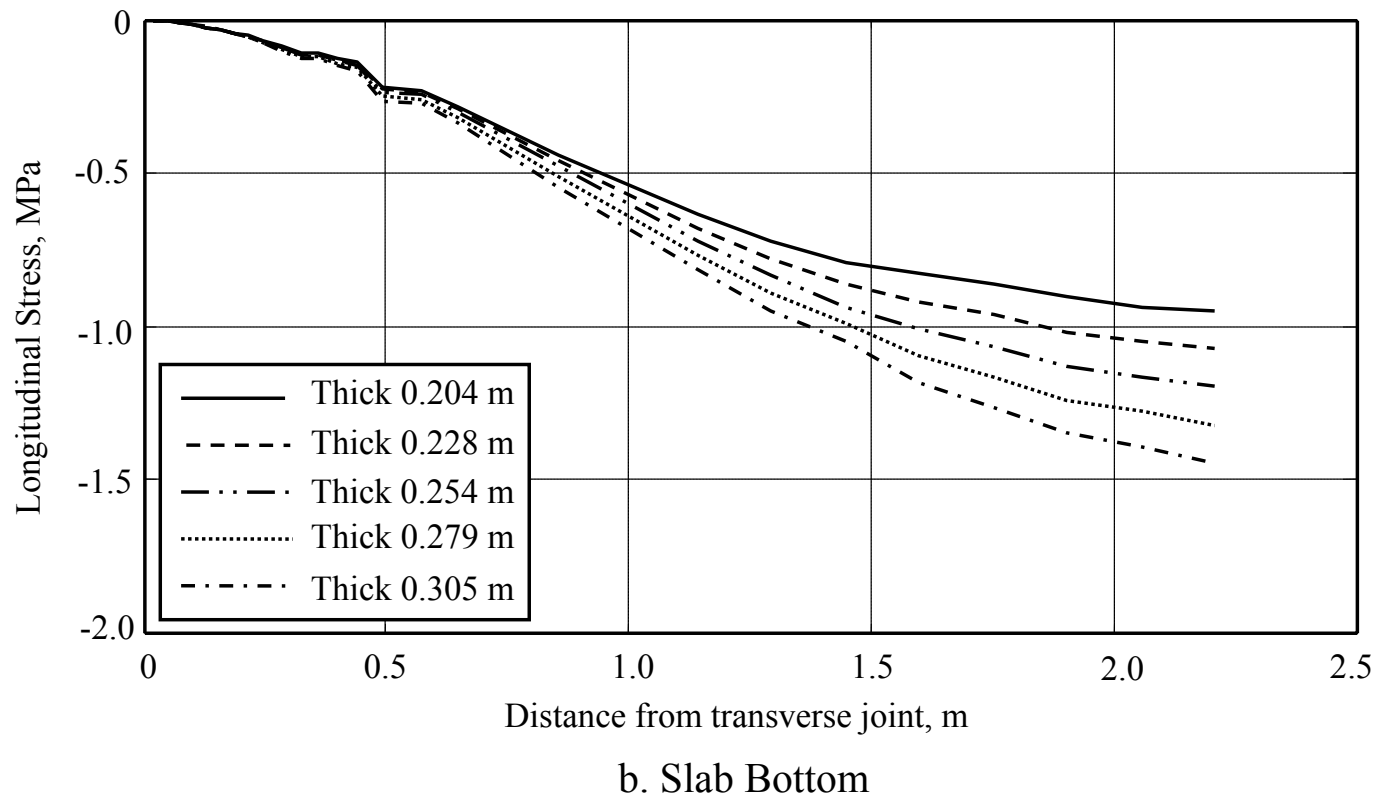

Figure 7.7 Effect of Slab Thickness on Longitudinal Stress Profile along Slab Centerline. (Temperature Gradient $-0.02{ }^{\circ} \mathrm{C} / \mathrm{mm}$ )

The maximum tensile stresses developed in concrete slabs of different thicknesses are illustrated by the bar chart in Figure 7.9. It can be noticed that changing the slab thickness from $0.2 \mathrm{~m}$ to $0.3 \mathrm{~m}$ (50 percent) resulted in an increase of eight percent in the maximum tensile stress on the slab top. The uniform temperature drop component represents the main cause of stress in the 


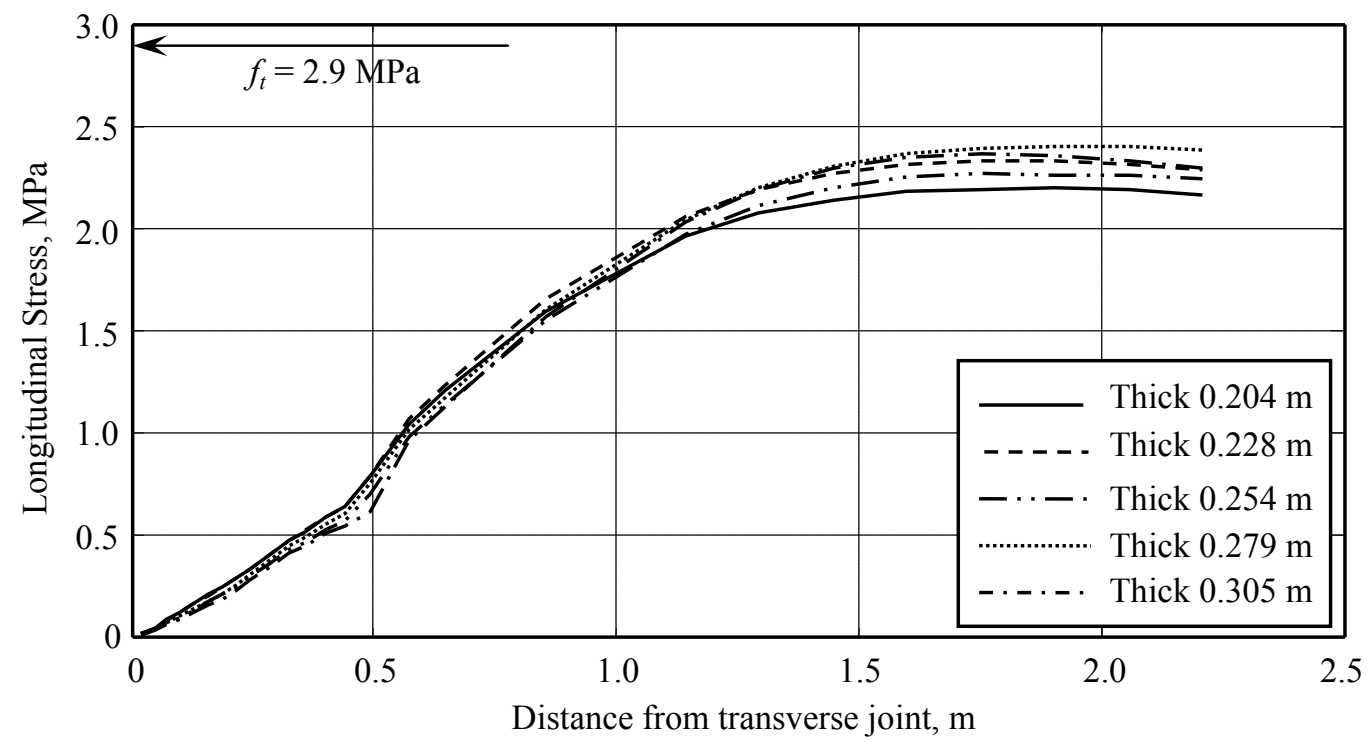

a. Slab Top

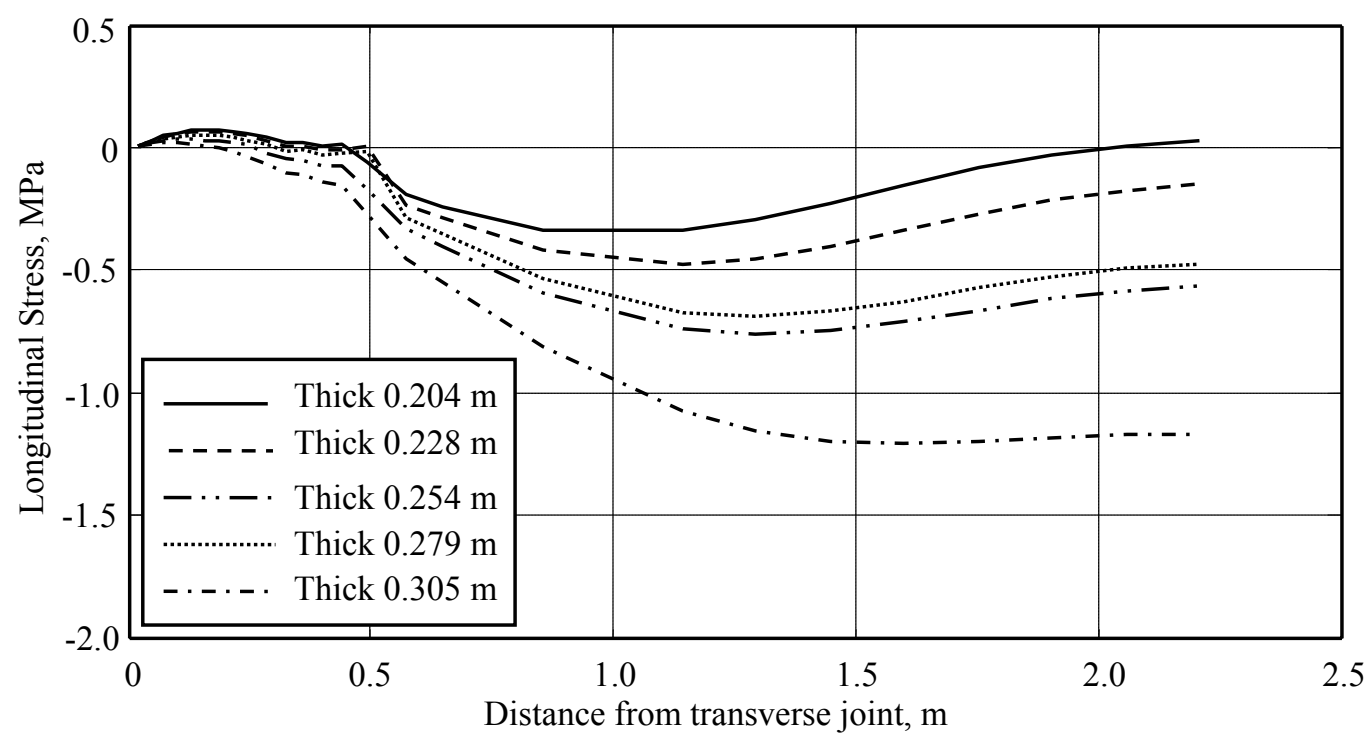

b. Slab Bottom

Figure 7.8 Effect of Slab Thickness on Longitudinal Stress Profile along Slab Centerline.

(Gradient $-0.02{ }^{\circ} \mathrm{C} / \mathrm{mm}$ Combined with Uniform Temperature Drop of $-33.3^{\circ} \mathrm{C}$ )

concrete slab and the resulting stress from such a component is uniform through the slab thickness. Thus, increasing the slab thickness did not reduce the stress in the concrete slab. Therefore, increasing slab thickness is not beneficial in reducing the potential of mid-slab transverse cracking. 


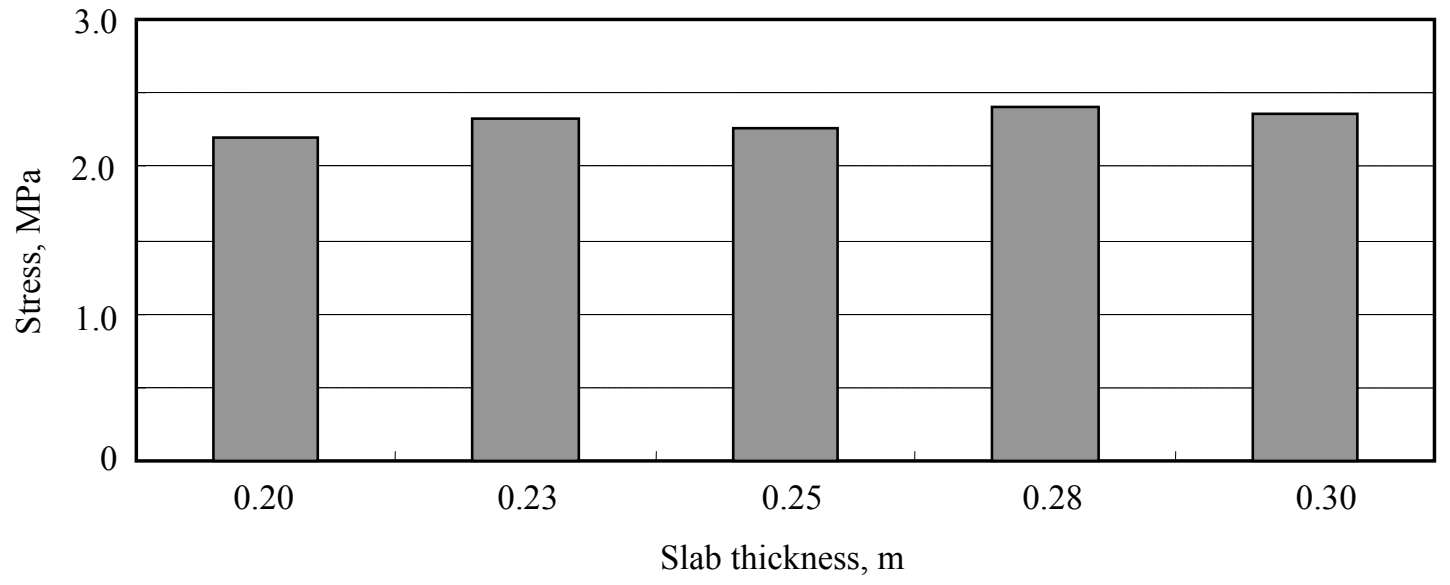

Figure 7.9 Effect of Slab Thickness on Maximum Tensile Stress.

Based on the aforementioned results, the concrete slab thickness should be designed to sustain the projected number of equivalent single axle loads expected to pass over the pavement section during its service life. Transverse joints should be spaced such that resulting temperatureinduced stresses should be less than the concrete modulus of rupture to minimize the chance of mid-slab transverse cracking.

\subsection{Effect of Dowel Bar Diameter}

Dowel bar bending due to slab curling constitutes the main restraint to slab contraction and expansion due the change in its mean temperature. The magnitudes of the bending moments developed in dowel bars depend on their stiffness. Therefore, dowel bar diameter is expected to influence the state of stress induced in the concrete slab due to temperature variations. In this study, the dowel bar diameter used in the 3DFE model is increased from $32 \mathrm{~mm}$ to $38 \mathrm{~mm}$ (the most two common diameters currently used in pavement construction). The finite element mesh, slab dimensions, boundary conditions, material properties, and initial dowel clearance of 25 microns were kept the same for both models. 


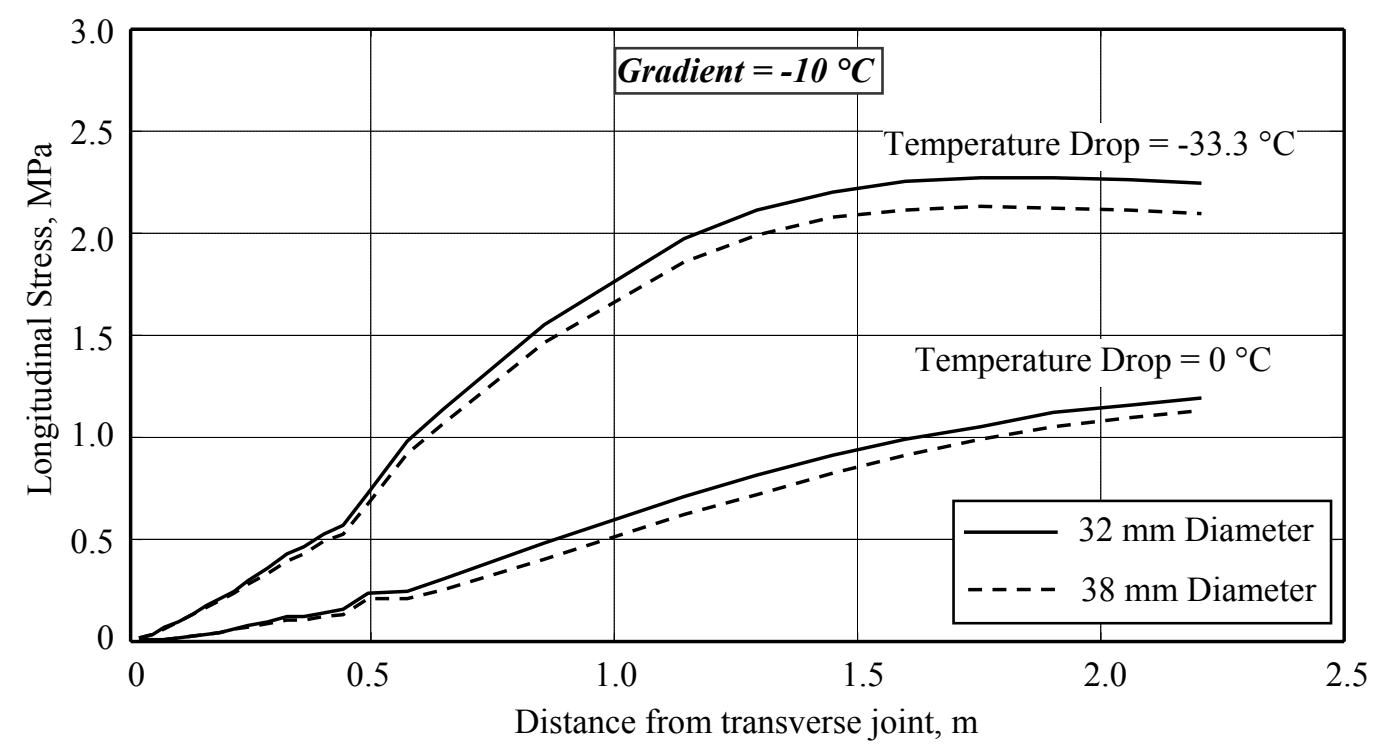

a. Slab Top

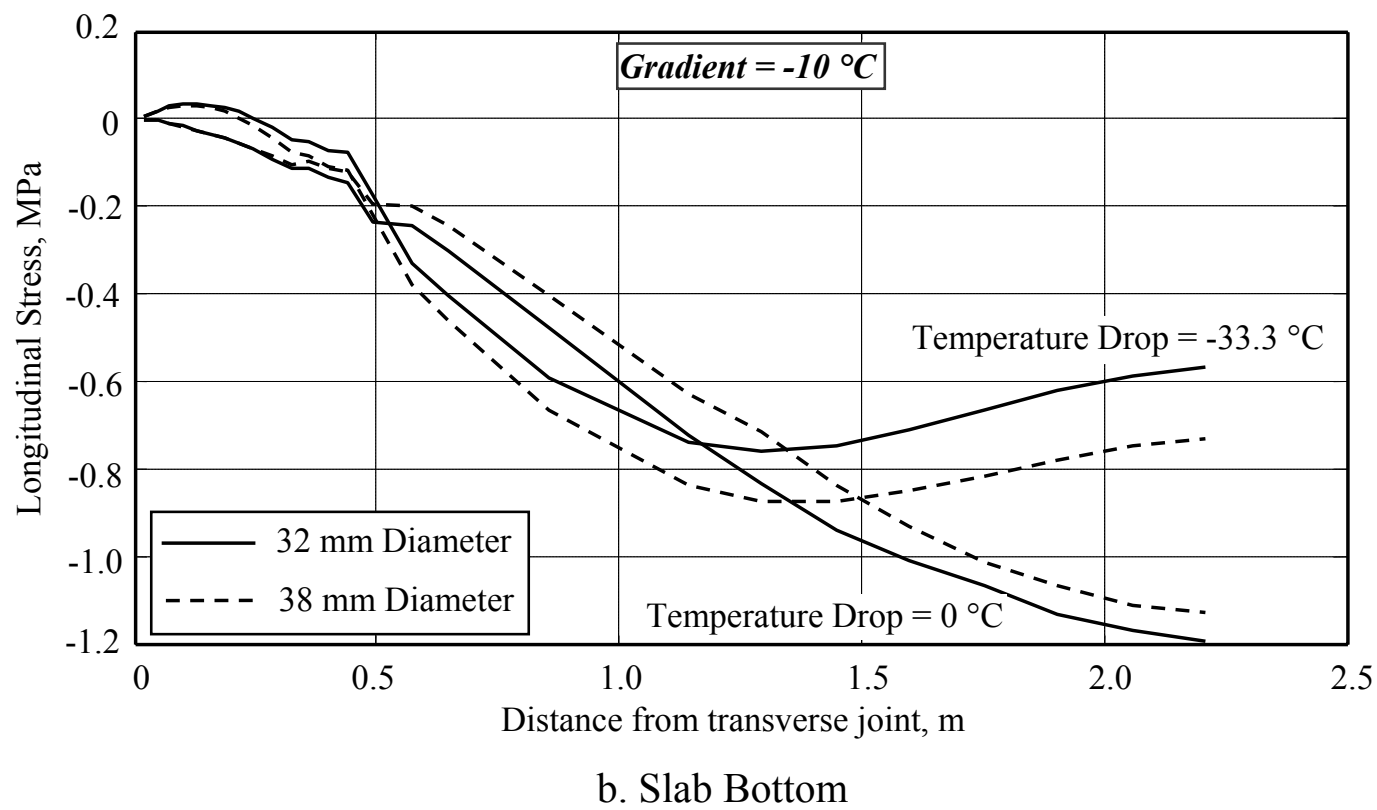

Figure 7.10 Effect of Dowel Bar Diameter on Longitudinal Stresses.

Figure 7.10 illustrates the distribution of longitudinal stresses along the slab longitudinal centerline obtained for two cases:

1) Temperature gradient of $-10^{\circ} \mathrm{C}$; 
2) Temperature gradient of $-10{ }^{\circ} \mathrm{C}$ combined with a uniform temperature drop of $-33.3^{\circ} \mathrm{C}$.

It can be noticed that increasing the dowel bar diameter from $32 \mathrm{~mm}$ to $38 \mathrm{~mm}$ (41 percent increase in the steel weight) resulted in a five percent decrease in mid-slab longitudinal stress for the first loading case, and seven percent reduction in the second case. Such a reduction in the stresses is due to the fact that dowel bars of larger dowels provide more resistance to slab curling, hence they suffer less bending. This is evident from the larger contact stress at the concrete-dowel interface shown in Figure 7.11. Therefore, the concrete slab has less constraint to contract as its mean temperature decreases when using dowel bars with larger diameters at transverse joints.

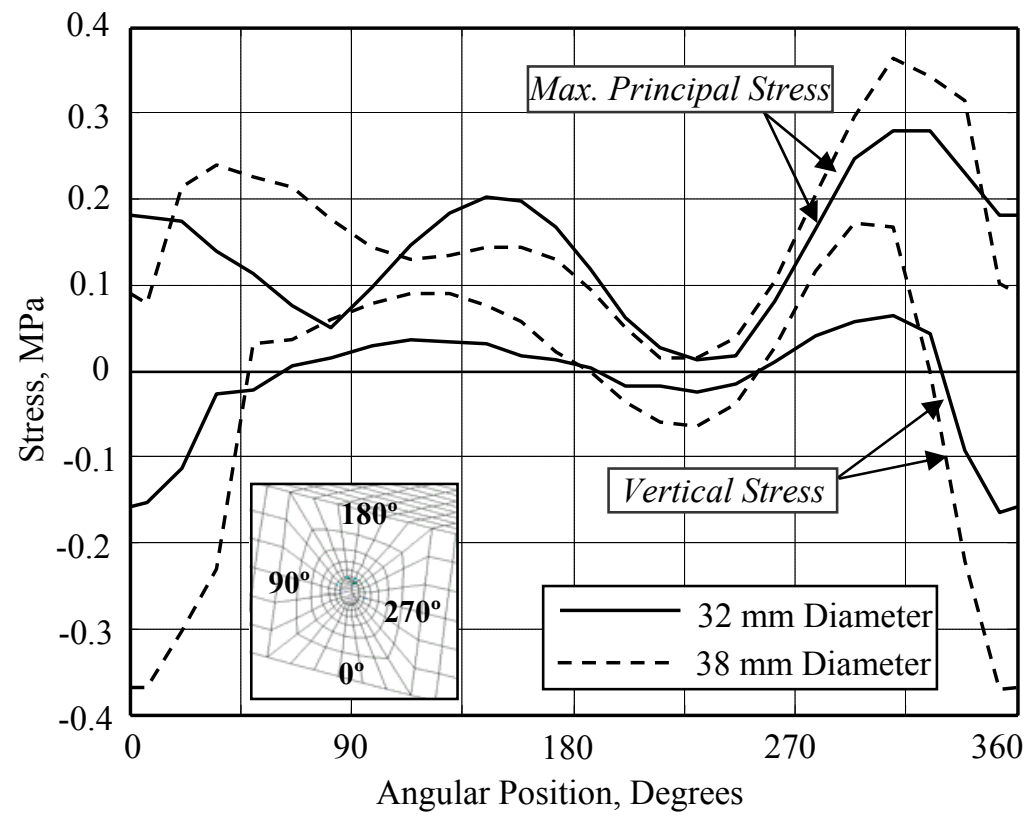

Figure 7.11 Effect of Dowel Bar Diameter on Dowel-Concrete Contact Stress.

The reduction in the longitudinal stresses gained by using larger dowel bars, Figure 7.11, is relatively small compared with the increase of the steel weight required for the dowel bars. Therefore, using dowel bars with a larger diameter to reduce the chance of mid-slab cracking is not recommended from an economical point of view. Additionally, results in Figure 7.11 indicate that slabs provided with larger dowels are more susceptible to faulting at transverse 
joints than slabs with smaller dowel diameters; a finding that agrees with the results from the LTPP programs, which indicated that average faulting is higher for $32 \mathrm{~mm}$ than that of $28 \mathrm{~mm}$ (Kazanovitch et al., 1998).

\subsection{Effect of Concrete-Dowel Interface}

The longitudinal stresses obtained earlier in this study are based on the assumption that dowel bars are epoxy coated and well lubricated with a thin layer of bond-breaking agent, which introduces a radial clearance of 12 microns between the dowel bars and concrete sockets. This case represents the most favorable condition of a functioning transverse joint that provides least resistance for slab contraction. To examine the effect of such an assumption of the concretedowel interface on the state of stress induced in concrete slab due to temperature variations, two additional cases for such an interface are assumed in the 3DFE model:

1. Sliding interface with no initial clearance.

2. Fully bonded interface between dowels and concrete.

Figure 7.12 illustrates a comparison between the longitudinal stresses along the longitudinal slab centerline due to a temperature gradient of $-10{ }^{\circ} \mathrm{C}$ for the three different interface conditions. It can be noticed that the stresses in the slab with loose dowels are 15 percent higher than those with intact dowels (sliding interface without looseness). The reason for this is the fact that the dowel clearance allows larger slab bending, which agrees with the behavior of the slab with loose dowels reported in the literature (Guo, 1992, Davids, 2000). However, the presence of a fully bonded interface between the dowels and the surrounding concrete resulted in a seven percent increase the longitudinal stresses when compared with the stress developed in a slab with intact dowels.

Figure 7.13 illustrates a comparison between the longitudinal stresses along the concrete slab due to the same temperature gradient of $-10^{\circ} \mathrm{C}$ but combined with a uniform temperature decrease of $-33.3{ }^{\circ} \mathrm{C}$ in the mean slab temperature. No significant difference can be observed between the stress profiles obtained for the cases of sliding interface. However, bonding the interface 
between the dowels and surrounding concrete raised mid-slab stress by 115 percent, which will lead to mid-slab cracking.

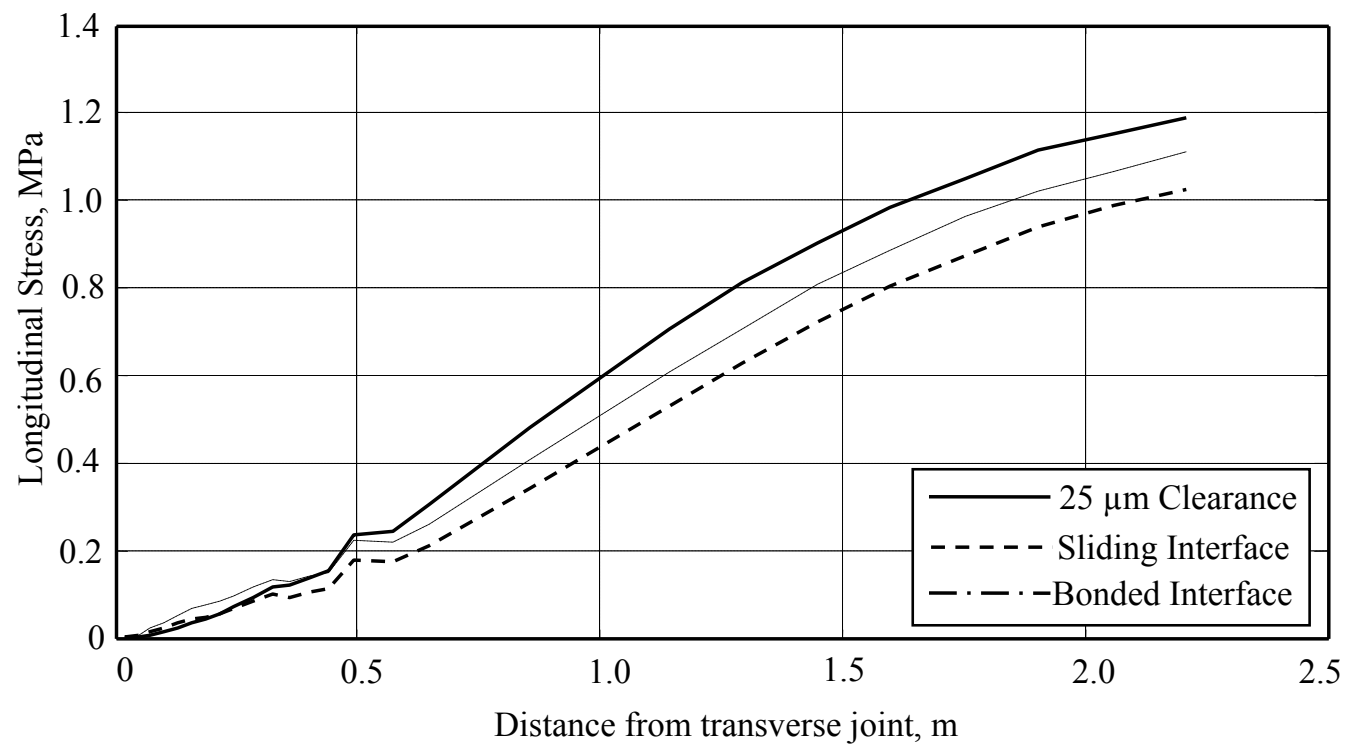

a. Slab Top

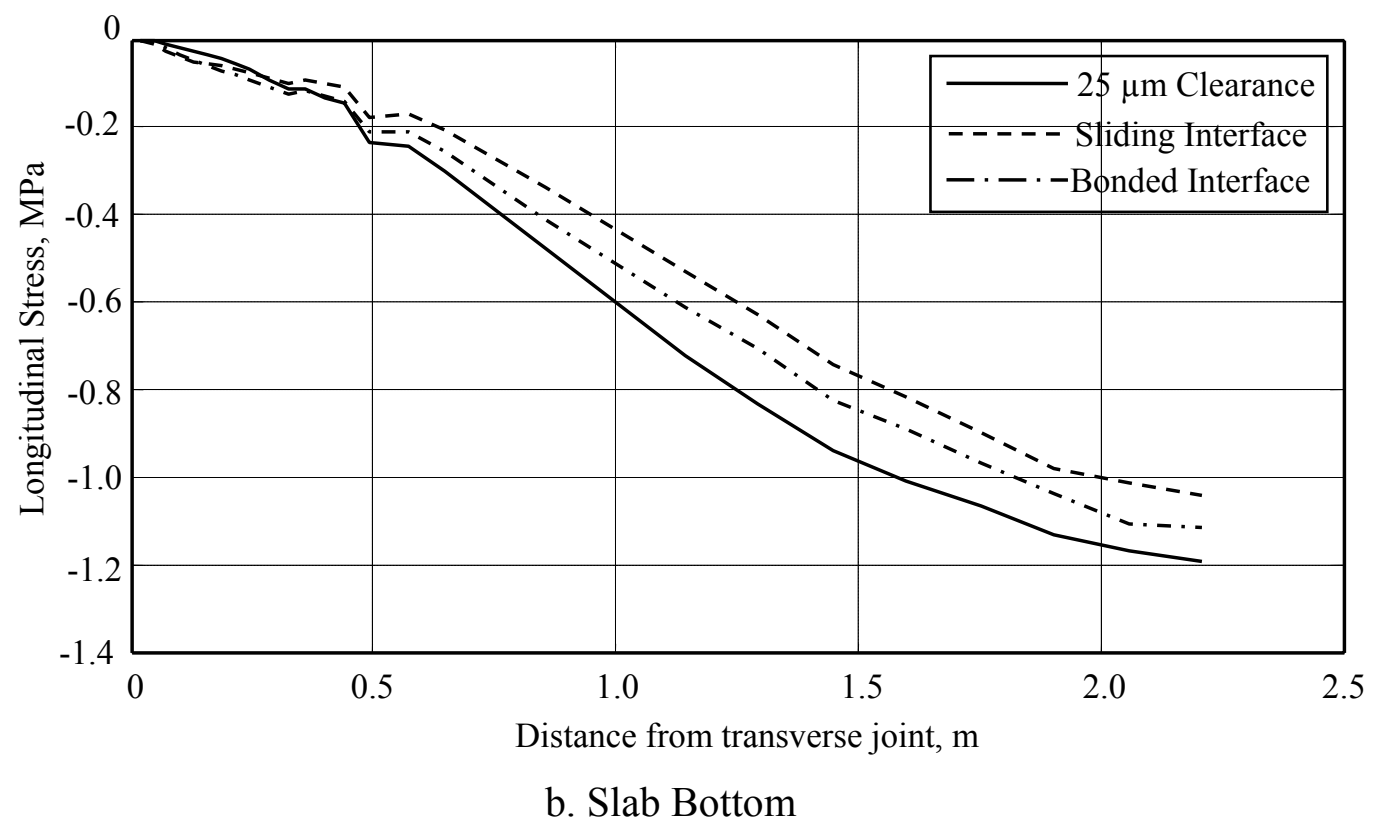

Figure 7.12 Effect of Concrete-Dowel Interface on Longitudinal Stresses in the Slab. (Temperature Gradient $-10^{\circ} \mathrm{C}$ ) 


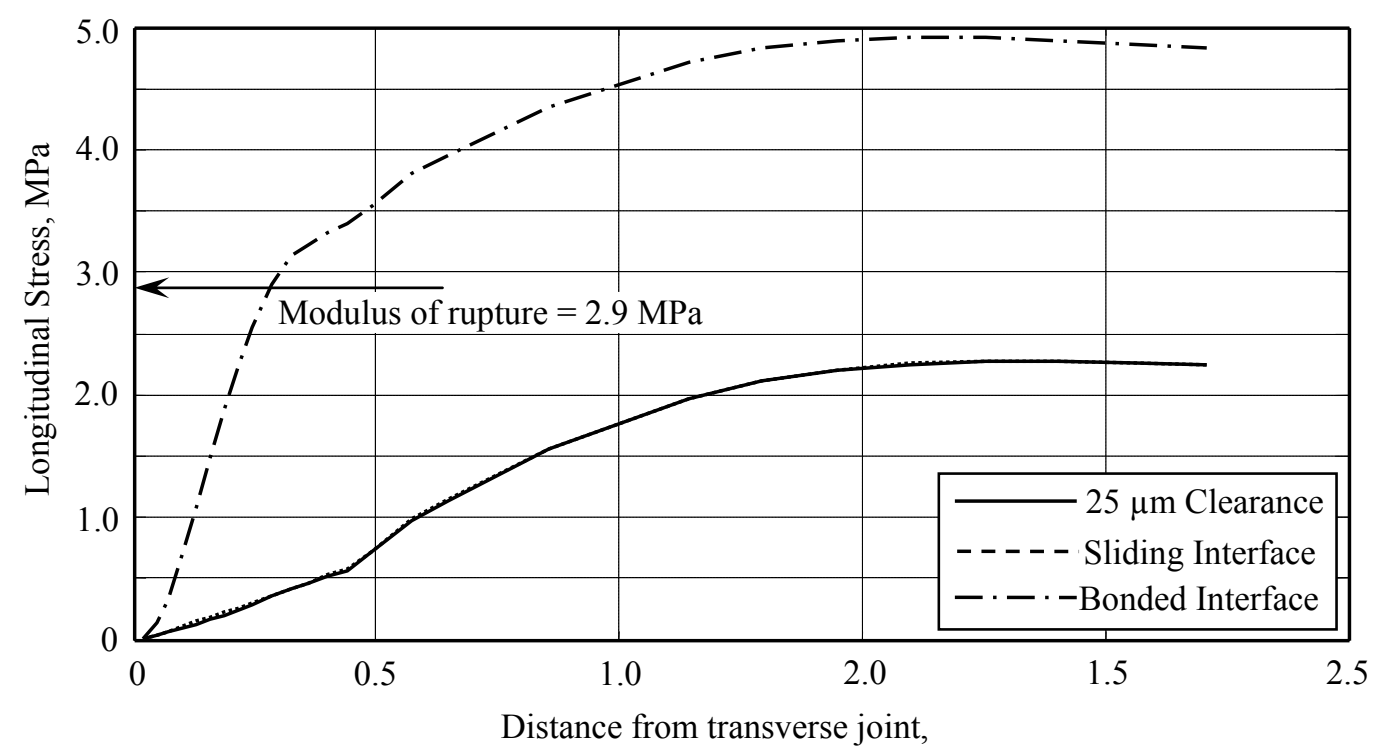

a. Slab Top

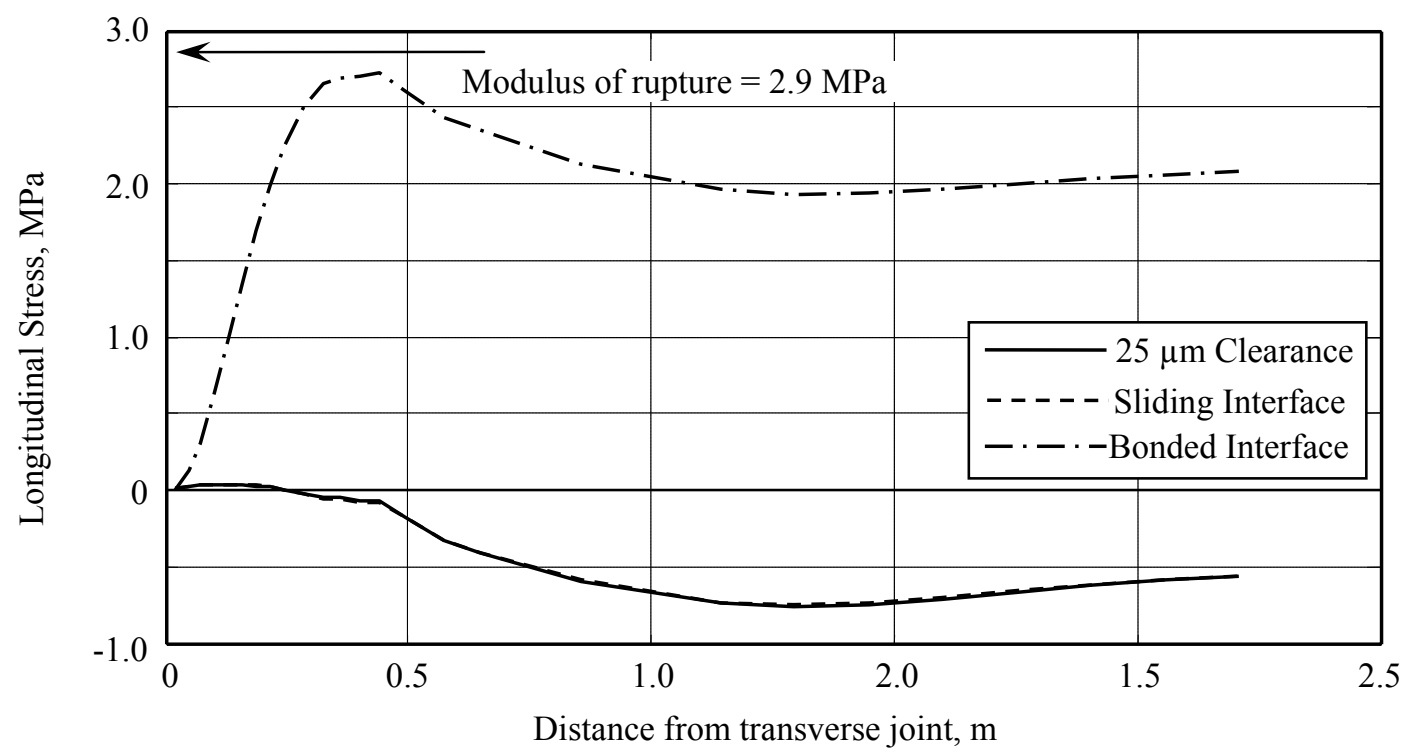

b. Slab

Figure 7.13 Effect of Concrete-Dowel Interface on Longitudinal Stresses in the Slab. (Gradient $-10^{\circ} \mathrm{C}$ Combined with $-33.3{ }^{\circ} \mathrm{C}$ Uniform Drop)

Stresses obtained for sliding and bonded interfaces represent the lower and upper limits for the stresses that could develop in concrete slabs. Practically, bonding forces exist between the dowel bars and the concrete, the magnitude of which depends on the concrete shrinkage as well as the type and thickness of bond-breaker applied prior to construction and its thickness. Such a bond could be broken with repetitive movement of the slab due to expansion and contraction, creating 
dowel looseness. Therefore, the characteristics of the concrete-dowel interface vary with time through the pavement service life. Hence, it seems appropriate to determine the range of stresses that could take place in the slab due to temperature when designing concrete pavements.

\subsection{Conclusions}

The effects of changing some design parameters have been examined and the following was concluded:

1. The slab length that is most resistant to mid-slab cracking is $4.57 \mathrm{~m}$. Slabs that are longer will likely develop transverse cracking, while shorter slabs are likely to show longitudinal cracking.

2. Single axle load applied at transverse joints of thermally deformed slabs have their maximum effect under the wheel load near the transverse joint. However, its effect on mid-slab stress is very small compared to the effect of temperature variation. Therefore, axle loading cannot cause a top-down crack in absence of an unrealistically large magnitude of negative temperature gradient.

3. 3DFEM results showed that longitudinal stresses in concrete slabs due to temperature variations were found to be insensitive to the change of slab thickness.

4. Increasing the dowel bar diameter from $32 \mathrm{~mm}$ to $38 \mathrm{~mm}$ slightly reduced mid-slab stresses, however concrete-dowel contact stresses significantly increased as the dowel diameter increased. Thus, using dowels with a larger diameter is not recommended.

5. Results indicated that applying bond-braking agents at the concrete dowel interface can significantly reduce the magnitude of thermal stresses induced in concrete slabs. 


\section{CHAPTER EIGHT}

\section{CONCLUSIONS}

\subsection{Conclusions}

This study focuses on examining the state of stress that develops in dowel jointed concrete slabs due to temperature variations and identifying the contribution of the temperature-induced stresses in initiating premature cracking in concrete slabs. The work of this study included the development of a detailed 3DFE model whose main feature is the detailed modeling of dowel bars and their interfaces with the surrounding concrete at transverse joints. The study included the development of a methodology to validate the thermoelastic response of 3DFE models of dowel jointed concrete pavements to temperature variations. Based on the theoretical and experimental results presented in this study, the following conclusions can be withdrawn:

1. The corrected Westergaard's thermal stress formula arrived at in this study is suitable for the calculation of longitudinal curling stress, but the temperature gradient is not the only source of thermal stresses in concrete pavements.

2. Dowel bars introduce significant restraints to slab contraction and expansion due to uniform temperature changes. The restraining action of dowel bars is produced by bending of dowel bars due to slab curling as well as the clamping force between the concrete and dowel bars; this takes place even when the concrete is in a plastic state.

3. Temperature gradient combined with uniform temperature changes cause cracking of relatively long concrete slabs in the transverse direction.

4. Current design tools and methods severely underestimate the magnitude of stresses in dowel jointed concrete pavements. 
5. Nonlinearity in temperature gradient profiles may increase or decrease the curling stress in concrete slabs. While its maximum effect on thermally induced stress is observed near transverse joints, its effect on mid-slab stress is negligible.

6. Since the temperature-induced strain contains a component due to uniform temperature variation; it seems difficult or impossible to use the measured slab profile to predict the state of strain in a concrete slab.

7. Considering that slab contraction due to temperature decreases in its mean temperature, 3DFE model results confirmed the correlation between mid-slab transverse cracking and slab length observed in the Long Term pavement Performance (LTPP) field studies.

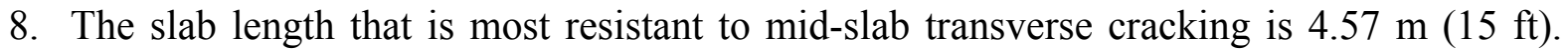
Slabs of lengths longer than $4.57 \mathrm{~m}$ will likely develop transverse cracks, while shorter slabs will be susceptible to longitudinal cracking.

9. The effect of applying joint axle loading on a thermally deformed concrete slab has been examined. While axle load has a significant influence on thermally induced stresses at transverse joints under the position of load application, its influence on mid slab stress is negligible. Therefore, it cannot cause top-town cracking in absence of a large negative thermal gradient that raises the tensile stress at the slab top to reach the concrete modulus of rupture. The mid-slab stress in such cases was found to be insensitive to the slab length; therefore, it does not explain the field observed dependency of mid-slab cracking and slab length.

10. Increasing the concrete slab thickness is not helpful in reducing temperature-induced stress in concrete pavements. Therefore, the slab thickness should be calculated to sustain the expected number of axle loading passing on the pavement section during its service life. 
11. Increasing the dowel bar diameter from $32 \mathrm{~mm}$ to $38 \mathrm{~mm}$ reduced mid-slab stresses by five percent; however concrete-dowel contact stresses significantly were doubled as the dowel diameter increased. Thus, the dowel diameter should be designed to transfer the traffic loading between adjacent slabs; any increase in the dowel diameter would result in higher stresses at the transverse joints, which leads to joint faulting.

12. Characteristics of the concrete-dowel interface significantly affect the stresses induced in concrete slabs due to temperature variations. Bond-breaking agents must be selected and applied carefully to the epoxy coated dowels to ensure that there is no bond between such dowels and the surrounding concrete.

The experience gained from using 3D finite element modeling technique in this study can be summarized as follows:

1. 3D Finite element modeling of dowel jointed concrete pavements must include detailed 3D modeling of dowel bars and their interfaces with concrete.

2. Use of the dynamic relaxation technique in solving the static response of the 3DFE model to temperature variations significantly reduces the CPU processing time for the 3DFE model. This allowed using a large number of fine elements to model the concrete surrounding the dowel bar, which enabled modeling the circular shape of the dowel bars and their interfaces with concrete.

3. 3D finite element models cannot be used to predict the accumulated strain measured in a concrete slab through its life, since the current constitutive models of concrete materials do not account for the effect of moisture changes and shrinkage. 


\subsection{Future Work}

1. The work presented on this study is based on the assumption that temperature changes occur very slowly and have a static effect on the concrete slab. However, temperature changes continuously during the day. Therefore, additional research work is needed to investigate its dynamic effect on the response of dowel jointed concrete pavements.

2. A detailed constitutive model is needed for concrete that should account for the temperature changes, moisture variations, shrinkage, material nonlinearity, as well as the post cracking behavior. Such a model will enable simulating the accumulative strains as well as crack propagation in concrete slabs with repetitive cycles of temperature variations.

3. Additional research work is needed to measure the bonding forces between the dowel bars and the surrounding concrete and identify means to reduce or eliminate such forces. This research is currently undergoing in the Intelligent Structures Laboratory at West Virginia University. 


\section{REFRENCES}

1. American Association of State Highway and Transportation Officials (1986). AASHTO Guide for Design of Pavement Structures.

2. American Association of State Highway and Transportation Officials (1993). AASHTO Guide for Design of Pavement Structures.

3. American Association of State Highway and Transportation Officials (1998). Supplement: AASHTO Guide for Design of Pavement Structures-Part II Rigid Pavement design and Rigid Pavement Joint Design.

4. American Concrete Institute (1999). Building Code Requirements for Structural Concrete (318-99) and Commentary (318R-99). Reported by ACI Committee 304, American Concrete Institute, Farmington Hills, Michigan.

5. Bathe, K.J. (1996). Finite Element Procedures. Prentice-Hall, Inc., Upper Saddle River, New Jersey.

6. Beckemeyer, C.A., L. Khazanovitch, and H.T. Yu (2002). Determining the Amount of Built-in Curling in JPCP. Presented at the $81^{\text {st }}$ Annual Meeting of Transportation Research Board, National Research Council, Washington, D.C.

7. Beegle, D.J., and S.M. Sargand (1995). Three-Dimensional Finite Element Modeling of Rigid Pavement. Final Report No. ST/SS/95-002, Ohio Department of Transportation, Federal Highway Administration, Columbus, Ohio.

8. Belytschko, T. (1992). An Overview of Semidiscretization and Time Integration Procedures. Computational Methods for Transient Analysis, Mechanics and Mathematical 
Methods, a Series of Handbooks Third Edition, Vol. (1), Edited by T. Belytschko and T.J.R. Hughes, pp. 1-65.

9. Belytschko, T., W.K. Liu, and B. Moran (2000). Nonlinear Finite Element for Continua and structures. John Wiley and Sons, LTD, West Sussex, England.

10. Boley, B.A., and J.H. Weiner (1985). Theory of Thermal Stresses, Robert E. Krieger Publishing Company, Inc., Malabar, Florida.

11. Bontz, D.P., J.R. Clifton, C.F. Ferraris, and E.J. Barboczi (2002). Transport Properties and Durability of Concrete: Literature Review and Research Plan. Report No. FHWA-RD-00073, Federal Highway Administration, McLean, Virginia.

12. Bradbury, R.D. (1938). Reinforced Concrete Pavements. Wire Reinforcement Institute, Washington, D.C.

13. Bush, N.J. (1995). Development of Empirical-Mechanistic Based Faulting Models in the Design of Plain Concrete Pavements. Ph.D. Dissertation, Texas A \& M University, College Station, Texas.

14. Carette, G.G., and V.M. Malhotra (1985). Performance of Dolostone and Limestone Concretes and Sustained High Temperatures. Temperature Effects on Concrete, ASTM STP 858, Edited by T.R. Naik, American Society for Testing and Materials, Philadelphia, pp. $38-67$.

15. Channakeshava, C., and F. Barzegar, and G.Z. Voyiajis (1993). Nonlinear FE Analysis of Plain Concrete Pavements with Doweled Joints. Journal of Transportation Engineering, ASCE, Vol. 119, No. 5, pp.763-781. 
16. Chou, Y.T. (1981). Structural Analysis Computer Programs for Rigid Multicomponent Pavement Structures with Discontinuities: WESLIQUID and WESLAYER. Technical Report GL-81-6. Vicksburg, MS: U.S. Army Engineer Waterways Experiment Station.

17. Choubane B., and M. Tia (1992). Nonlinear Temperature Gradient Effect on Maximum Warping Stresses in Rigid Pavements, Transportation Research Record No. 1370, Transportation Research Board, National Research Council, Washington, D.C., pp.11-19.

18. Choubane, B., and M. Tia (1995). Analysis and Verification of Thermal-Gradient Effects on Concrete Pavement. Transportation Research Record No. 1370, ASCE, Vol. 121, No. 1, pp.75-81.

19. Cook R.D., D.S. Malkus, and M.E. Plesha (1989). Concepts and Applications of Finite Element Analysis. Third Edition. John Wiley \& Sons, Inc., New York, USA.

20. Crovetti, J.A. (1999). Cost-Effective Concrete Pavement Cross-sections. Interim Report No. WI/SPR-12-99, Wisconsin Department of Transportation.

21. CROW (1998). Deflection Profile not a Pitfall Anymore. CROW Information and Technology Center for Transportation and Infrastructures, The Netherlands.

22. Darter, M.I., J.M. Becker, M.B. Snyder, and R.E. Smith (1985). Portland Cement Concrete Pavement Evaluation System (COPES). NCHRP Report 277, National Cooperative Highway Research Program, Transportation Research Board, National Research Council, Washington, D.C.

23. Darter, M.I., K. T. Hall, and C. M. Kuo (1995). Support Under Portland Cement Concrete Pavements. NCHRP Report 372, Transportation Research Board, National Research Council, Washington, D. C. 
24. Davids, W.G., and G.M. Turkiyyah (1997). Development of Embedded Bending Member to Model Dowel Action. Journal of Structural Engineering, ASCE, Vol. 123, No. 10, pp.1312-1320.

25. Davids, W., G.M. Turkiyyah, and J. Mahoney (1998). EverFE-Rigid Pavement 3D Finite Element Analysis Tool. Transportation Research Record No. 1629, Transportation Research Board, National Research Council, Washington, D.C., pp. 41-49.

26. Davids, W.G. (2000). Effect of Dowel Looseness on Response of Jointed Concrete Pavements. Journal of Transportationl Engineering, ASCE, Vol. 126, No. 1, pp. 50-57.

27. Davids, W.G. (2001). 3D Finite Element Study on Load Transfer at Doweled Joints in Flat and Curled Rigid Pavements. The International Journal of Geomechanics, Vol. 1, No. 2, pp. 309-323.

28. Desai, C.S., and Siriwardane, H.J. (1984). Constitutive Laws for Engineering Materials, with Emphasis on Geologic Materials. Englewood Cliffs, Prentice-Hall, New Jersey.

29. Dutt, H.H. (1992). Three-Dimensional Cum Infinite Element Analysis of Pavement Joint for Mechanical and Environmental Loading. Ph.D. Dissertation, Illinois Institute of Technology.

30. ERES (2000). Evaluation of Pennsylvania I-80 JPCP Performance in PennDot Districts 10 and 3-0. Final Draft Report for the American Concrete Pavement Association.

31. Faraggi, V., C. Jofre, and C. Kraemer (1987). Combined Effects of Traffic Loads and Thermal Gradients on Concrete Pavement Design. Transportation Research Record No. 1136, Transportation Research Board, National Research Council, Washington, D.C., pp. 108-118. 
32. Farrel, F.B., and H.R. Patrick (1953). The Capital Investment in Highways. Proceedings of Highways Research Board No. 32, National Research Council, Washington, D.C.

33. Federal Highway Administration, FHWA (1990). Concrete Pavement Joints. U.S. Department of Transportation, Federal Highway Administration, Technical Advisory: T 5040.30, Washington, D.C.

34. Friberg, B. F. (1938). Load and Deflection Characteristics of Dowels in Transverse Joints of Concrete Pavements. Proceedings of Highways Research Board No. 18, National Research Council, Washington, D.C., pp. 140-154.

35. Friberg, B.F. (1955). Pavement Research, Design, and Prestressed Concrete. Proceedings of Highways Research Board No. 34, National Research Council, Washington, D.C., pp. 65-84.

36. Garg, N. (1997). Mechanistic-Empirical Evaluation of the Mn/Road Low-Volume Road Test Sections. Ph.D. Dissertation, University of Illinois, Urbana, Illinois.

37. Govindjee, S., G.J. Kay, and J.S. Simo (1995). Anisotropic Modeling and Numerical Simulation of Brittle Damage in Concrete. International Journal of Numerical Methods in Engineering, Vol. 38, pp. 3611-3633.

38. Guo, H. (1992). Mathematical Modeling of Dowel Load transfer Systems. Ph.D. Dissertation, Department of Civil and Environmental Engineering, Michigan State University.

39. Guo, H., J. Sherwood, and M. Snyder (1995). Component Dowel Bar Model for Load Transfer System. Journal of Transportation Engineering, ASCE, Vol. 121, No. 3, pp.289298. 
40. Hall, K.T. (2000). State of the Art and Practice in Rigid Pavement Design. CD: In Transportation in the New Millennium: State of the Art and Future Directions, Perspective from TRB Standing Perspectives, Transportation Research Board, National Research Council, Washington, D.C.

41. Hallquist, J. (1998). LS-DYNA Theoretical Manual. Livermore Software Technology Corporation, Livermore, California.

42. Hallquist, J. (2001). LS-DYNA User Manual, Part II. Livermore Software Technology Corporation, Livermore, California.

43. Hammons, M.I., and A.M. Ioannides (1996). Developments in Rigid Pavement Response Modeling. Technical Report GL-96-15, Waterways Experimental Station, U.S. Army Corps of Engineers, Vicksburg, Mississippi.

44. Hammons, M.I. (1997). Development of an Analysis System for Discontinuities in Rigid Airfield Pavements. Technical Report GL-97-3, Waterways Experimental Station, U.S. Army Corps of Engineers, Vicksburg, Mississippi.

45. Hansen, W., D.L. Smiley, Y. Peng, and E.A. Jensen (2002). Validating Top-Down Premature Transverse Cracking in Jointed Plain Concrete Pavement (JPCP). CD Proceedings of the $81^{\text {st }}$ Annual Meeting of Transportation Research Board, TRB, National Research Council, Washington, D.C.

46. Harik, I.E., P. Jianping, H. Southgate, and D. Allen (1994). Temperature Effects on Rigid Pavements. Journal of Transportation Engineering, ASCE, Vol. 120, No. 1, pp. 127-143.

47. Heath, A.C., and J.R. Roesler (2000). Top-Down Cracking of Rigid Pavements Constructed with Fast-Setting Hydraulic Cement Concrete. Journal of Transportation Research Board No. 1712, Transportation Research Board, National Research Council, Washington, D.C., pp. 3-12. 
48. Heinriches, K.W., Liu, M.J., Darter, M.I., Carpenter, S.H., and Ioannides, A.M. (1989). Rigid Pavement Analysis and Design. Federal Highway Administration Report No. FHWA-RD-068.

49. Highway Research Board, HRB (1962). The AASHO Road Test, Pavement Research Report No. 5, Highway Research Board, Special Report 61E, New York.

50. Huang, Y.H. (1993). "Pavement Analysis and design,” Prentice Hall, Englewood, N.J.

51. Huang, Y.H. and S.T. Wang (1974). Finite Element Analysis of Rigid Pavements with Partial Subgrade Contact. Transportation Research Record No. 485, Transportation Research Board, National Research Council, Washington, D.C., pp. 39-54.

52. Hutchinson, R.L. (1966). Basis for Rigid Pavement Design for Military Airfields. Miscellaneous Report No. 5-7, Ohio River Division Laboratories, Cincinnati, Ohio.

53. Hveem, F.N. (1949). A Report of an Investigation to Determine Causes for Displacement and Faulting at Joints in Portland Cement Concrete Pavements on California Highways. Technical Report, California Department of Transportation, California.

54. Imbsen, R.A., D.E. Vandershaff, R.A. Schamber, and R.V. Nuutt. Thermal Effects in Concrete Bridge Superstructures. National Cooperative Highway Research Program Report 276, Transportation Research Board, National Research Council, Washington, D.C.

55. Ioannides, A.M., and J.P. Donnelly (1988). Three-Dimensional Analysis of Slab on Stress-Dependant Foundation. Transportation Research Record No. 1196, Transportation Research Board, National Research Council, Washington, D.C., pp. 72-84. 
56. Ioannides, A.M., Y.H. Lee and L. M.I. Darter (1990). Control of Faulting Through Shear Load Transfer Mechanism. Transportation Research Record No. 1286, Transportation Research Board, National Research Council, Washington, D.C., pp. 49-56.

57. Ioannides, A.M., and L. Khazanovitch (1998). Nonlinear Temperature Effects on Multilayered Concrete Pavements. Journal of Transportation Engineering, ASCE, Vol. 124, No. 2, pp. 128-136.

58. Iwama, S. (1964). Experimental Studies on the Structural Design of Concrete Pavement. Pavement Laboratory Public Works Research Institute, Ministry of Construction, Japan.

59. Kavalenko, A.D. Thermoelasticity: Basic Theory and Applications. Wolters-Noordhoff Publishing, Groningen, The Netherlands.

60. Kazanovitch, L., Darter M., Bartlett, R., and McPeak T. (1998). Common Characteristics of Good and Poorly Performing PCC Pavements. Report No. FHWA-RD-97-131, Federal Highway Administration, McLean, Virginia.

61. Kelleher, K., and R.M. Larson (1989). The Design of Plain Doweled Jointed Concrete Pavements. Proceedings of the Fourth International Conference on Concrete Pavement Design and Rehabilitation, Purdue University, West Lafayette, Indiana, pp. 279-292.

62. Kennedy, J.C., R.D. Everhart, T.P. Forte, and J.A. Hadden (1994). Development of a Governing Primary Response Model (GPRM) for Airport Pavement Design and Analysis. Final Report to Volpe National Transportation Systems Center, Contract No. VA2043 DTRS-57-89-D-00006.

63. Kennedy, J.C., and R.D. Everhart (1995). Dynamic Compliant Boundary. Final Report to Turner Fairbanks Highway Research Center, Contract No. DIFH 61-93-C-00055, Technical Work Request No. 1. 
64. Kennedy, J.C., and R.D. Everhart (1996). Comparison of Predicted Pavement Structural Response with Field Measurement Data. Final Report to Turner Fairbanks Highway Research Center, Contract No. DIFH 61-93-C-00055, Technical Work Request No. 3.

65. Kennedy, J.C., and R.D. Everhart (1997). Thermal Effects on Pavement Response. Final Report to Turner Fairbanks Highway Research Center, Contract No. DIFH 61-93-C-00055, Technical Work Request No. 5.

66. Kennedy, J.C., and R.D. Everhart (1998). Warping and Curling of Rigid Pavements, A Mechanistic Approach Implemented in UMPAD. Final Report to Turner Fairbanks Highway Research Center, Contract No. DIFH 61-93-C-00055, Technical Work Request No. 6 .

67. Khazanovich, L. (1994). Structural Analysis of Multi-Layered Concrete Pavement Systems. Ph.D. Dissertation, University of Illinois at Urbana, Illinois.

68. Khazanovitch, L., H.T. Yu, and C. Beckemeyer (2000). Application of ISLAB2000 for Forensic Studies. Proceeding of the $2^{\text {nd }}$ International Symposium of 3D Finite Element for Pavement Analysis, Design, and Research, Charleston, West Virginia, pp. 433-450.

69. Korovesis, G.T. (1990). Analysis of Slab-On-Grade Pavement Systems Subjected to Wheel and Temperature Loadings. Ph.D. Dissertation, University of Illinois at Urbana, Illinois.

70. Kushing, J.W., and W.O. Fremont (1940). Design of Load Transfer Joints in Concrete Pavements. Proceedings of Highways Research Board No. 20, National Research Council, Washington, D.C., pp. 481-493.

71. Lee, G.C. T.S. Shih, and K.C. Chang (1988). Mechanical Properties of Concrete at Low Temperature. Journal of Cold Regions Engineering, ASCE, Vol. 2, No. 1, pp. 13-24. 
72. Liang, R.Y., Y.Z. Niu (1998). Temperature and Curling Stress in Concrete Pavements: Analytical Solutions. Journal of Transportation Engineering, ASCE, Vol. 124, No. 1, pp. 91-100.

73. Masad, E., R. Taha, and B. Muhunthan (1996). Finite-Element Analysis of Temperature Effects on Plain-Jointed Concrete Pavements. Journal of Transportation Engineering, ASCE, Vol. 122, No. 5, pp. 338-398.

74. McCullough, B.F., and R.O. Rasmussen (1999-a). Fast-Track Paving: Concrete Temperature Control and Traffic Opening Criteria for bonded Concrete Overlays Volume I: Final Report. Report No. FHWA-RD-98-167, Federal Highway Administration, McLean, Virginia.

75. McCullough, B.F., and R.O. Rasmussen (1999-b). Fast-Track Paving: Concrete Temperature Control and Traffic Opening Criteria for Bonded Concrete Overlays Volume II: HIPERPAV User's Manual. Report No. FHWA-RD-98-168, Federal Highway Administration, McLean, Virginia.

76. McGhee, K.H. (1995). Design, Construction, and Maintenance of PCC Pavement Joints, NCHRP Synthesis No 211, National Cooperative Highway Research Program, Transportation Research Board, National Research Council, Washington, D.C.

77. McKenzie, L.J. (1978). Behavior of Plain PCC Pavement with Skewed joints Randomly Spaced. Final Report No. FHWA-IL-PR-79, Illinois Department of Transportation, Bureau of Material and Physical Research, Illinois.

78. NCHRP (1973). Design, Construction and Maintenance of PCC Pavement Joints. NCHRP Synthesis No 19, National Cooperative Highway Research Program, Transportation Research Board, National Research Council, Washington, D.C. 
79. Nishizawa, T., T. Fukuda, and S. Matsuno (1989). A Refined Model of Doweled Joints for Concrete Pavement Using FEM Analysis. Proceedings of the $4^{\text {th }}$ International Conference on Concrete Pavement Design and Rehabilitation, Perdue University, West Lafayette, Indiana.

80. Pane, I., W. Hansen, and A.R. Mahmoud (1998). Three-Dimensional Finite Element Study on Effects of Nonlinear Temperature Gradients in Concrete Pavements. Transportation Research Record No. 1629, Transportation Research Board, National Research Council, Washington, D.C., pp. 58-66.

81. Papadrakis, M. (1981). A Method for the Automated Evaluation of the Dynamic Relaxation Parameters. Computer Methods in Applied and Engineering, Vol. 25, pp.3548.

82. Pickett, G., and G.K. Ray (1951). Influence Charts for Concrete Pavements. Transactions, American Society of Civil Engineers, Vol. 13, No. 5, pp. 371-379.

83. Poh, K.W. (2001). Stress-Strain-Temperature Relationship for Structural Steel. Journal of Materials in Civil Engineering, ASCE, Vol. 13, No. 5, pp. 371-379.

84. Rollings, R.S., and D. W. Pittman (1992). Field Instrumentation and Performance Monitoring of Rigid Pavements. Journal of Transportation Engineering, ASCE, Vol. 118, No. 3, pp. 361-370.

85. Sargand, S.M., G.A. Hazen, C.C. Bazeley, J.R. Copley, and M.E. George (1997). Instrumentation of Rigid Pavement System. Report No. FHWA/Oh-97/001, Ohio Department of Transportation, Federal Highway Administration, Columbus, Ohio.

86. Sargand, S.M., and D.J. Breegle (1998). Three-Dimensional Finite Element Software Development and Verification Case Study. Paper Presented at the First National 
Symposium of 3D Finite Element for Pavement Analysis and Design, Charleston, West Virginia.

87. Schweizerhof, K., Nelson L., and Hallquist, J.O. (1992). Crashworthiness Analysis in the Automotive Industry. International Journal of Computer Applications in Technology, Special Issue on the Industrial Use of Finite Element Analysis, Vol. 5, Nos. 2, 3, 4, pp. 134-156.

88. Shi, X.P., T.F. Fua, and S.A. Tan (1993). Warping Stresses in Concrete Pavements on Pasternak Foundation. Journal of Transportation Engineering, ASCE, Vol. 119, No. 6, pp. 905-913.

89. Shoukry, S.N., and G.W. William (1998). 3D FEM Analysis of Load Transfer Efficiency. Proceedings of the First National Symposium of 3D Finite Element for Pavement Analysis and Design, Charleston, West Virginia, pp. 40-46.

90. Shoukry, S.N., and G.W. William (1999). Performance Evaluation of Backcalculation Algorithms through 3D Finite Element Modeling of Pavement Structures. Journal of Transportation Research Board No. 1655, Transportation Research Board, National Research Council, Washington, D.C., pp. 152-160.

91. Shoukry, S.N. (2000). Backcalculation of Thermally Deformed Concrete Pavements. Journal of Transportation Research Board No. 1716, Transportation Research Board, National Research Council, Washington, D.C., pp. 64-72.

92. Shoukry, S.N. (2002). West Virginia Instrumented Concrete Pavement: Curling and Temperature Induced Strains During the First 90 Days. Presented at the Data Analysis Working Group, $81^{\text {st }}$ Annual Transportation Research Board Meeting, Washington, D.C.

93. Shoukry, S.N. M. Fahmy, J. Prucz, and G. William (2002). 3D Finite Element Modeling of Rigid Pavement Response to Moving Load and Nonlinear Temperature Gradient. 
Proceedings: $3^{\text {rd }}$ International Symposium on 3D Finite Element for Pavement Analysis and Design, Amsterdam, The Netherlands, pp. 401-422.

94. Shoukry, S.N., G.W. William, and M. Riad (2002). Characteristics of Contact Stresses in Doweled Transverse Joints. The International Journal of Pavement Engineering, Vol. 3, No. 2, pp. 117-129.

95. Smith, K.D., M.J. Wade, D.G. Peshkin, L. Khazanovich, and M.I. Darter (1998). Performance of Concrete Pavements Volume II-Evaluation of In service Concrete Pavements. Report No. FHWA-RD-91-110, Federal Highway Administration, McLean, Virginia.

96. Snyder, M. (1989). Dowel Load Transfer Systems for Full-Depth Repairs of Jointed Portland Cement Concrete Pavements. Ph.D. Dissertation, University of Illinois, Urbana, Illinois.

97. Strategic Highway Research Program, SHRP (1993). Distress Identification Manual for the Long-Term Pavement Performance Project. SHRP-P-338, National Research Council, Washington, D.C.

98. Stutzman, P.E. (1999). Deterioration of Iowa Highway Concrete Pavements: A Petrographic Study. National Institute of Standards and Technology, Internal Report NISTIR 6399, U.S. Department of Commerce.

99. Sutherland, E.C. (1940). Discussion of "Design of Load Transfer Joints in Concrete Pavements, by J.W. Kushing and W.O. Fremont". Proceedings of Highways Research Board No. 20, National Research Council, Washington, D.C., pp. 494-497.

100. Tabatbaie, A.M., and E.J. Barenberg (1978). Finite-Element Analysis of Jointed or Cracked Concrete Pavements. Transportation Research Record No. 671, Transportation Research Board, National Research Council, Washington, D.C., pp. 11-19. 
101. Tang, T., D.G. Zollinger, and S. Senadheera (1993). Analysis of Concave Curling in Concrete Slabs. Journal of Transportation Engineering, ASCE, Vol. 119, No. 4, pp. 618633.

102. Tayabji, S.D. and Colley, B.T. (1986). Analysis of Jointed Concrete Pavements. Technical Report FHWA-RD-86-041, Federal Highway Adminstration, McLean, Virginia.

103. Teller, L.W., and E.C. Sutherland (1935). The Structural Design of Concrete Pavements, Part 2: Observed Effects of Variations in Temperature and Moisture on the Size, Shape, and Stress Resistance of Concrete Pavement Slabs. Public Roads, Vol. 16, No. 9, pp.169197.

104. Tia, M., J.M. Armaghani, C. Wu, S. Lei, and K.L. Toye (1987). FEACONS III Computer Program for Analysis of Jointed Concrete Pavements. Transportation Research Record No. 1136, Transportation Research Board, Washington, D.C., pp.

105. Timoshenko, S., and J.M. Lessels (1925). Applied Elasticity. Westinghouse Technology, Night School Press, East Pittsburgh, Pennsylvania.

106. Timoshenko, S.P., and J.N. Goodier (1959). Theory of Elasticity, Third Edition, McGrawHill.

107. Thomlinson, J. (1940). Temperature Variations and Consequent Product by Daily and Seasonal Temperature Cycles in Concrete Slabs. Concrete Constructional Engineering, Vol. 36 No. 6, pp. 298-307, and No. 7, pp. 352-360.

108. Thompson, M.R., B.J. Dempsey, H. Hill, and J. Vogel (1987). Characterizing Temperature Effects for Pavement Analysis and Design. Transportation Research Record No. 1121, Transportation Research Board, National Research Council, Washington, D.C., pp. $14-22$. 
109. Uddin, W., D. Zhang, and F. Fernandez (1994). Finite Element Simulation of Pavement Discontinuities and Dynamic Load Response. Transportation Research Record No. 1148, Transportation Research Board, National Research Council, Washington, D.C., pp. 69-74.

110. Uddin, W., P. Noppakunwijai, and T. Chung (1997). Performance Evaluation of Jointed Concrete Pavement Using Three-Dimensional Finite-Element Dynamic Analysis. Presented at the $76^{\text {th }}$ Annual Meeting of Transportation Research Board, National Research Council, Washington, D.C., Paper No. 1414.

111. Underwood, P. (1992). Dynamic Relaxation. Computational Methods for Transient Analysis, Mechanics and Mathematical Methods, a Series of Handbooks Third Edition, Vol. (1), Edited by T. Belytschko and T.J.R. Hughes, pp. 245-263.

112. Van Breeman, W. (1955). Experimental Dowel Installation in New Jersey. Bulletin of Highway Research Board No. 34, National Research Council, Washington, D.C., pp. 8-33.

113. Westergaard, H.M. (1926). Stresses in Concrete Pavements Computed by Theoretical Analysis. Public Roads, Vol. 7, No. 2, pp. 25-35.

114. Westergaard, H.M. (1927). Analysis of Stresses in Concrete Pavements Due to Variations of Temperature. Proceedings of the. $6^{\text {th }}$ Annual. Meeting Highway Research Board, National Research Council, Vol. 6, pp. 201-215, Washington, D.C.

115. Westergaard (1929). Spacing of Dowels. Proceedings of Highway Research Board No. 8, National Research Council, Washington, D.C., pp. 154-158.

116. Whirly, R.G. and Hallquist, J.O. (1991). LLNL-DYNA3D Manual. Lawrence Livermore National Laboratory, Livermore, California. 
117. William, G.W., and S.N. Shoukry (2000). Mechanistic Evaluation of the Depth to Bedrock and its Effect on the Response of 3D Finite Element Model. Pavement Subgrade, Unbound materials, and Nondestructive Testing, Geotechnical Special Publication No. 98, ASCE, pp. 73-86.

118. Wu, C., T.J. Larsen (1993). Analysis of Structural Response of Concrete Pavements under Critical Thermal-Loading Conditions. Proceedings of the Fifth International Conference on Concrete Pavement Design and Rehabilitation, Purdue University, West Lafayette, Indiana.

119. Yoder, E.J. and M.W. Witczak (1975). Principles of Pavement Design, Second Edition. John Wiley \& Sons, Inc., New York, N.Y.

120. Yu, H.T., K.D. Smith, M.I. Darter, and L. Khazanovitch (1998). Performance of Concrete Pavements Volume III: Improving Pavement Performance. Report No. FHWA-RD-95111, Federal Highway Administration, McLean, Virginia.

121. Zaghloul, S.M., T.D. White, A.J. Ramirez, and N.B.R. Prasad (1994). Computerized Overload Permitting Procedure for Indiana. Transportation Research Record No. 1148, Transportation Research Board, National Research Council, Washington, D.C., pp. 40-52.

122. Zaghloul, S.M., T.D. White, and T. Kuczek (1994). Evaluation of Heavy Load Damage Effect on Concrete Pavements Using Three-Dimensional Dynamic Nonlinear Analysis. Transportation Research Record No. 1149, Transportation Research Board, National Research Council, Washington, D.C., pp. 123-133.

123. Zaman, M., Alvappillai, A. (1995). Contact-Element Model for Dynamic Analysis of Jointed Concrete Pavements. Journal of Transportation Engineering, ASCE, Vol. 121, No. 5, pp. 425-433. 
124. Zienkiewicz, O.C., and Y.K. Cheung (1967). The Finite Element Method of Structural and Continuum Mechanics. McGraw-Hill Publishing Company Limited, London. 